Portland State University

PDXScholar

$1-1-2012$

\title{
Feasible Models of Universal Health Insurance in Oregon According to Stakeholder Views
}

Terry Richard Hammond

Portland State University

Follow this and additional works at: https://pdxscholar.library.pdx.edu/open_access_etds Let us know how access to this document benefits you.

\section{Recommended Citation}

Hammond, Terry Richard, "Feasible Models of Universal Health Insurance in Oregon According to Stakeholder Views" (2012). Dissertations and Theses. Paper 500.

https://doi.org/10.15760/etd.500

This Dissertation is brought to you for free and open access. It has been accepted for inclusion in Dissertations and Theses by an authorized administrator of PDXScholar. Please contact us if we can make this document more accessible: pdxscholar@pdx.edu. 
Feasible Models of Universal Health Insurance in Oregon According to Stakeholder Views

by

Terry Richard Hammond

A dissertation submitted in partial fulfillment of the requirements for the degree of

\author{
Doctor of Philosophy \\ in \\ Urban Studies
}
Dissertation Committee:
Margaret Neal, Chair
Neal Wallace
Chad Cheriel
Anthony Rufolo
Barbara J. Friesen

Portland State University

(C)2012 


\begin{abstract}
This study collects the views of 38 health policy leaders, answering one open-ended question in a 1-hour interview: What state-level reforms do you believe are necessary to implement a feasible model of universal health insurance in Oregon?

Interviewees represented seven groups: state officials, insurers, purchasers, hospitals, physicians, public interest, and experts. About 370 coded arguments in the interview transcripts were condensed into 95 categorical topics. A code outline was constructed to present a dialogue among stakeholders in one comprehensive narrative. Topical sections include the cost imperative, politics, model systems, insurance, purchasing, delivery system, practice management, and finance. Summary results show the prevalence of group attention to each topic, group affinities, and proximity correlations of different arguments mentioned by individuals.

The most common arguments related to problems of low-value care and delivery system reform. There was a generally felt imperative to control costs. Regarding universal health insurance, stakeholders were split between two main alternatives. One model, favored mostly by insurer and purchaser groups, supported the state-sponsored individual mandate. This plan, embodied in the current Oregon Action Plan to implement universal health insurance, involved managed competition for insurers and clinical governance over professional practice. A separate set of arguments, favored mostly by expert and physician groups, emphasized the need for a unified public system, or utility model, possibly with centralized funds and regional global budgets.
\end{abstract}


The ability of the individual mandate plan to control costs or manage quality appears doubtful, which strengthens opposition. The utility model is more likely to work at cost control and governance, but it disrupts the status quo and its details are vague, which strengthens opposition. Neither model is endorsed by a majority of the stakeholders, and political success for either one alone is not promising. Possibly, a close analysis of the two models could find a way to combine them and generate unified support. 


\section{Acknowledgments}

I am grateful to my committee members for helping me through this long process, and for their enduring patience. I especially want to acknowledge the long mentor role delivered to me so graciously by Dr. Margaret Neal; the propelling forces applied by the late Dr. Elizabeth Kutza and Dr. Craig Wollner, who both helped shape and deepen my understanding of important issues related to the policy context in Oregon; and to Dr. Neal Wallace and Dr. Chad Cheriel for knowing best what in the world I am talking about; and foremost to the disputed passage presented to me as a challenge and inspiration by my past committee chairs, Dr. Sherril Gelmon and Dr. Anthony Rufolo. 


\section{Table of Contents}

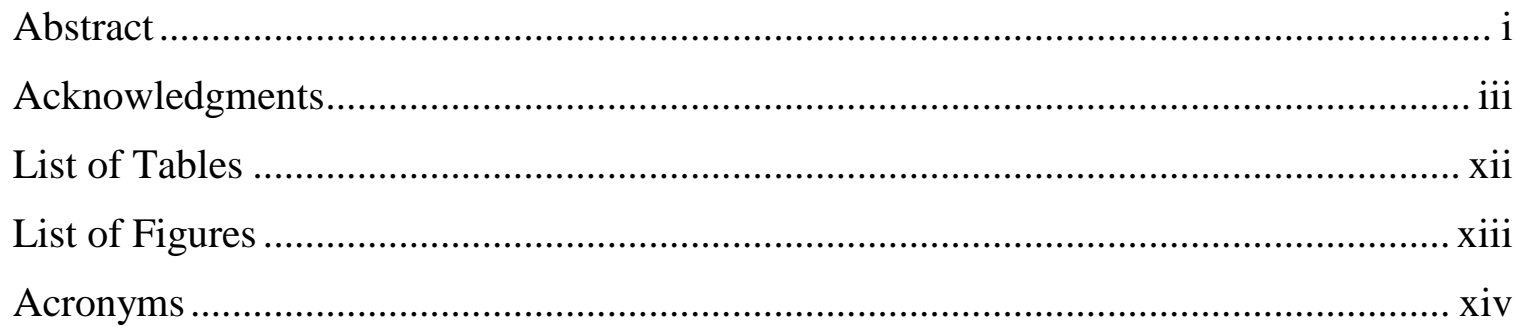

\section{Chapters}

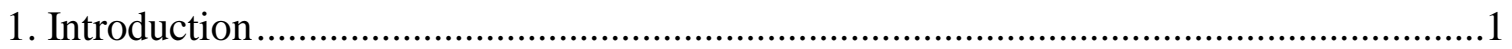

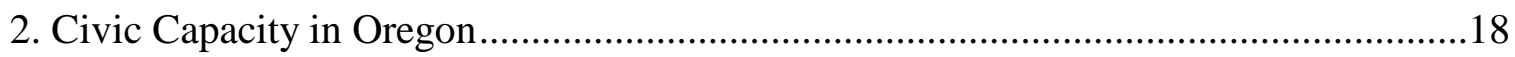

3. Principal Models of Universal Health Insurance ...................................................49

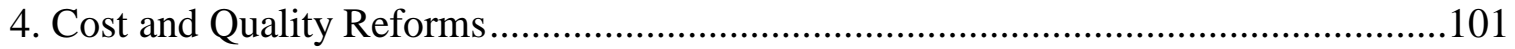

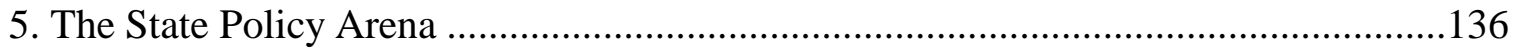

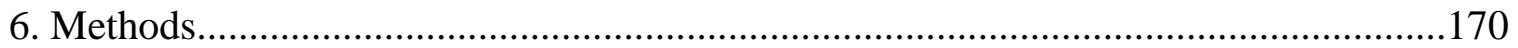

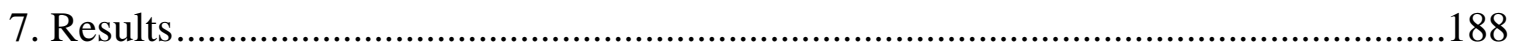

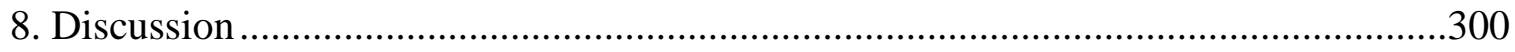

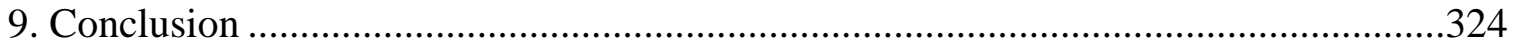

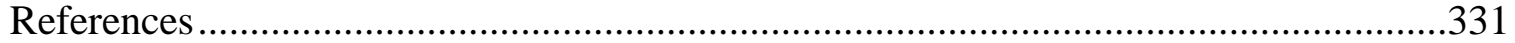

\section{Chapter Sections}

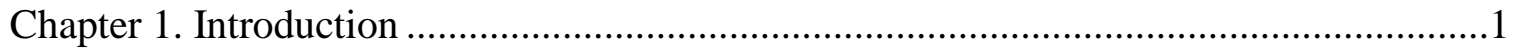

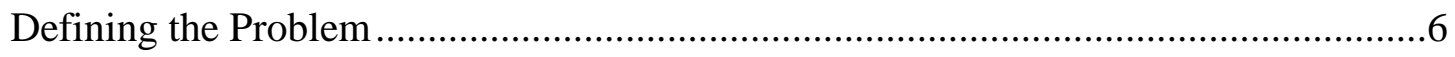

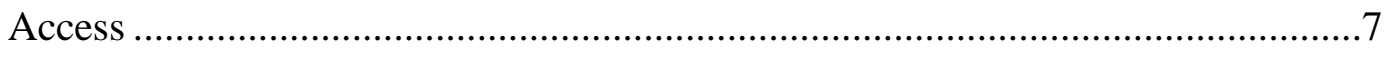

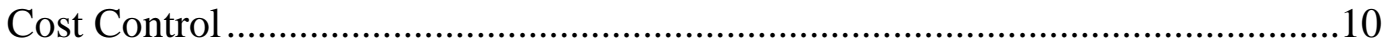

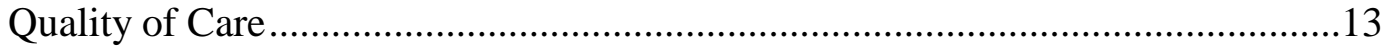

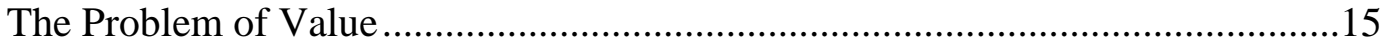

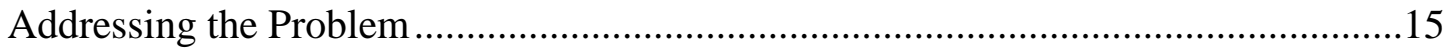

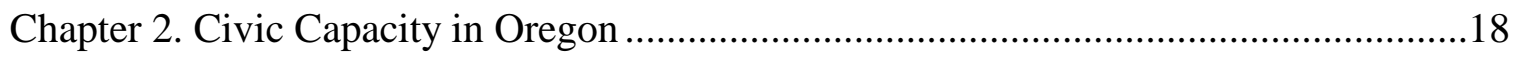




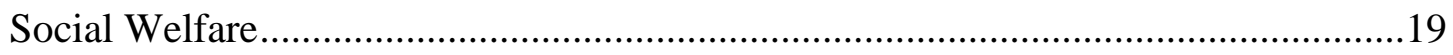

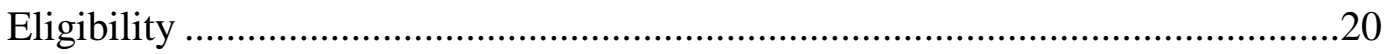

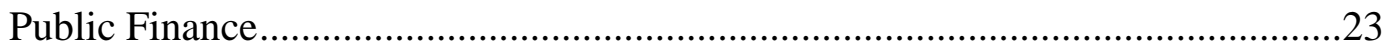

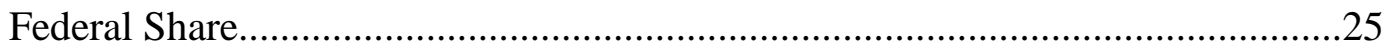

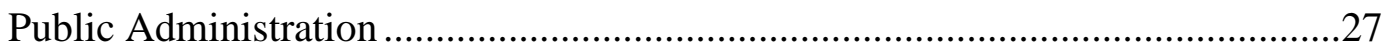

Patronage

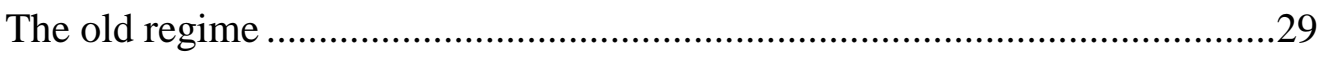

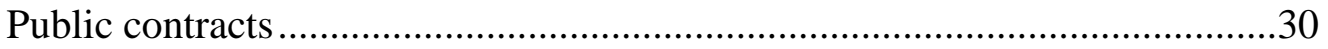

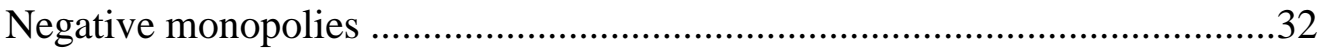

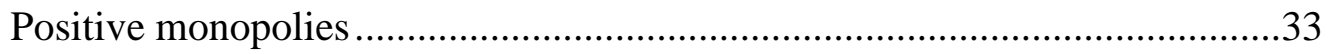

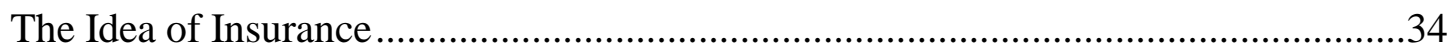

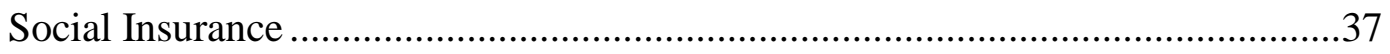

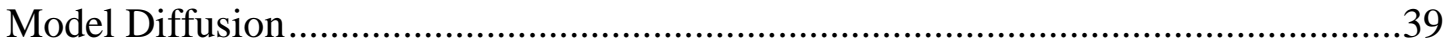

The Oregon Plan …………………….......................................................4

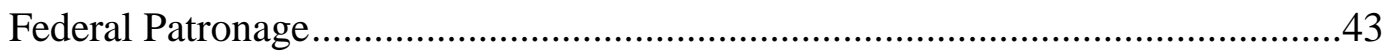

Public Education as a Model Social Contract.........................................................45

Chapter 3. Models of Universal Health Insurance .......................................................49

Voluntary Incrementalism......................................................................................49

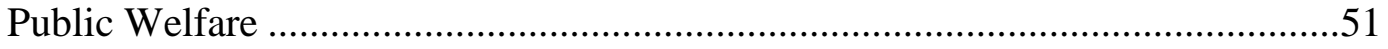

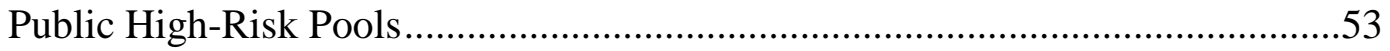

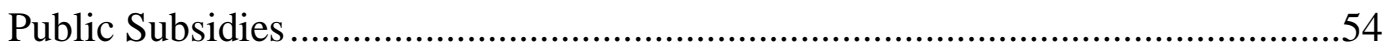

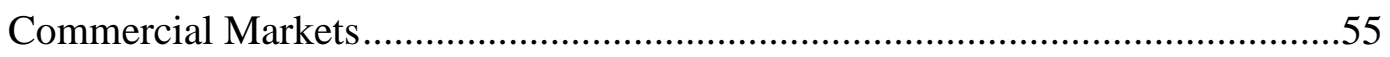

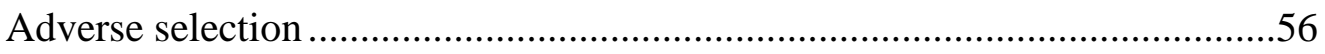

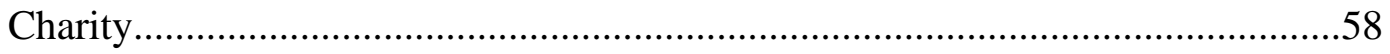

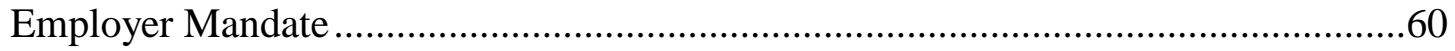

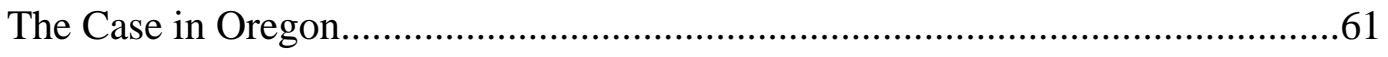

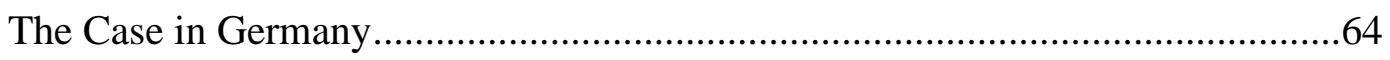

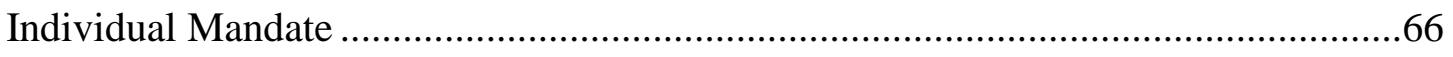

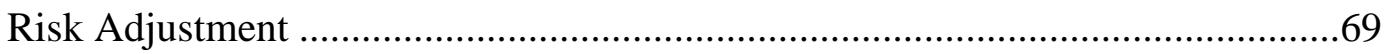

Managed Competition in Employment-Based Insurance Pools.............................72 


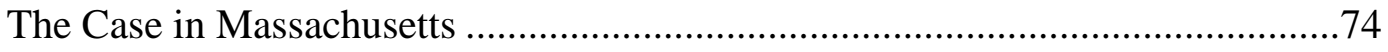

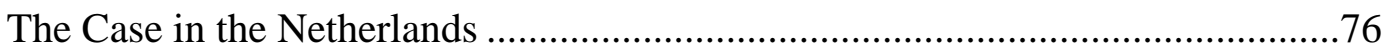

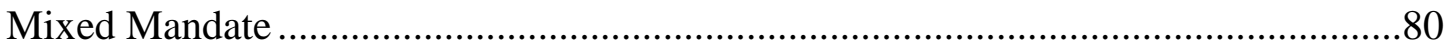

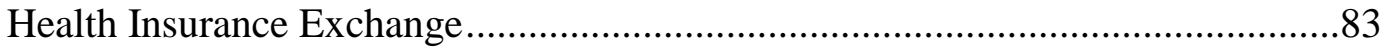

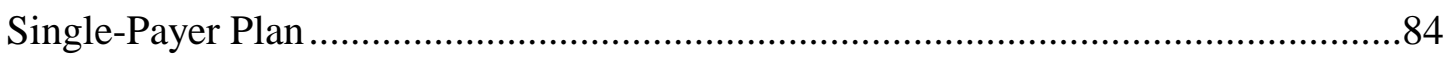

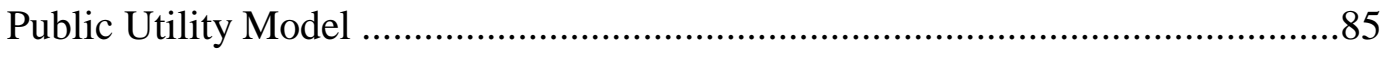

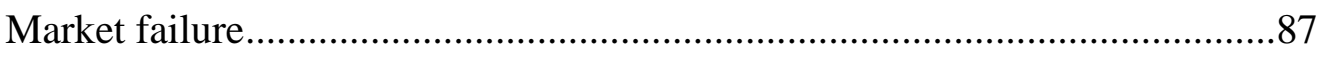

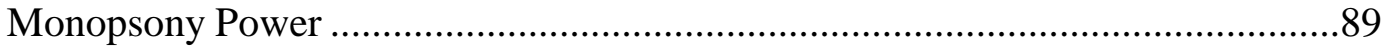

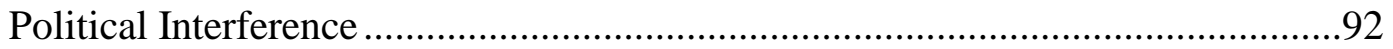

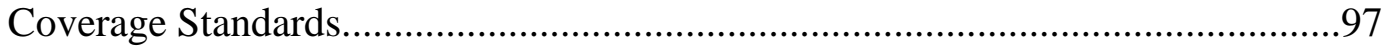

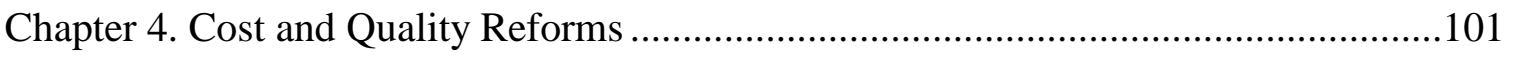

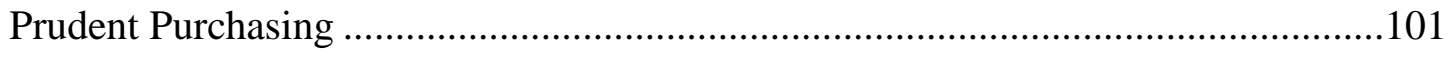

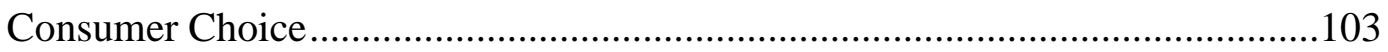

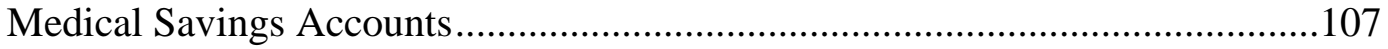

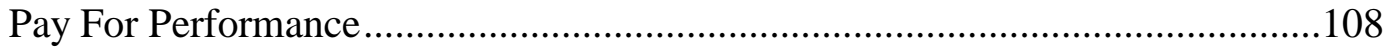

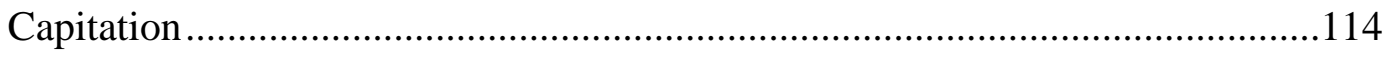

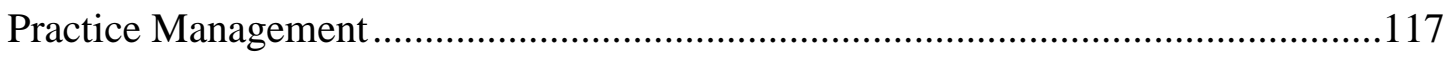

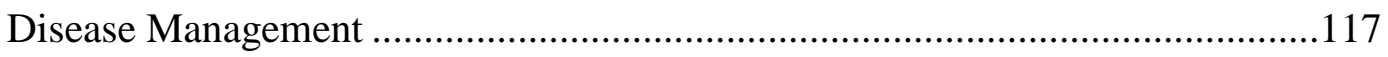

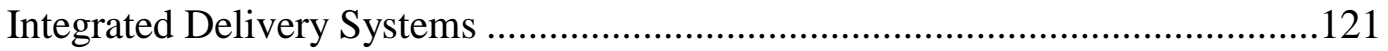

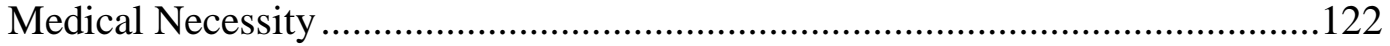

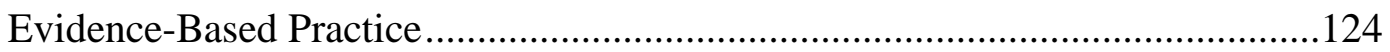

The Case in the United Kingdom............................................................. 127

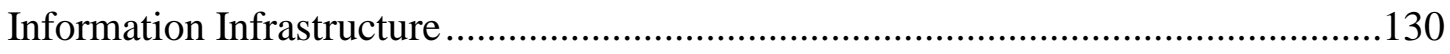

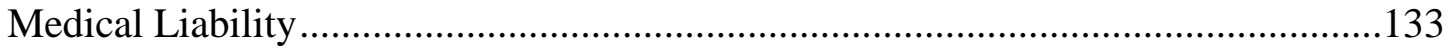

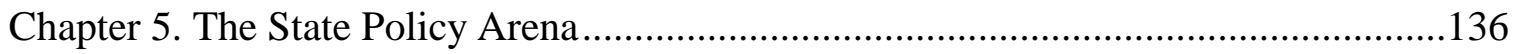

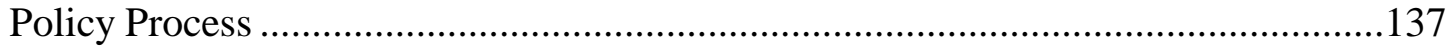

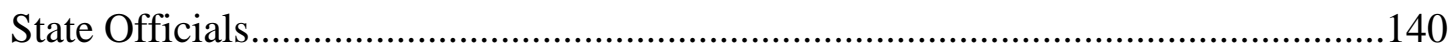

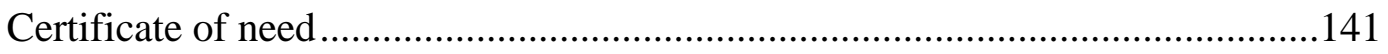

Oregon Health Authority ........................................................................ 143 


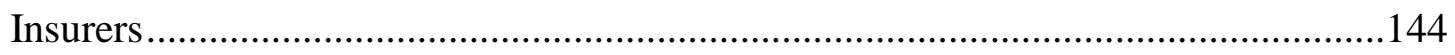

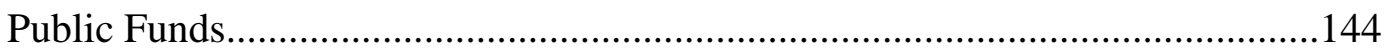

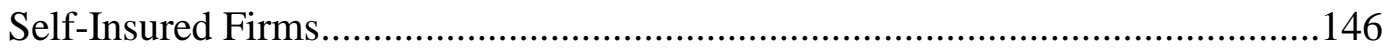

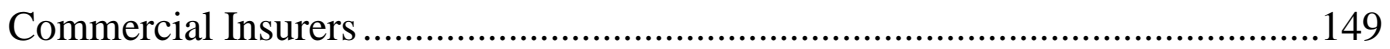

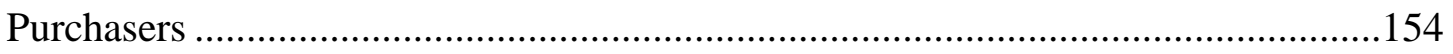

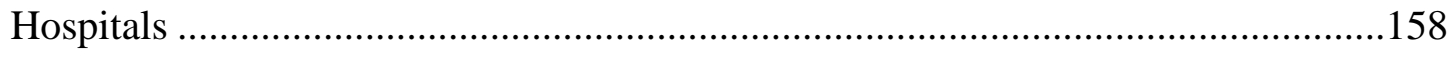

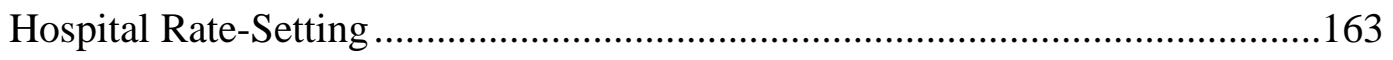

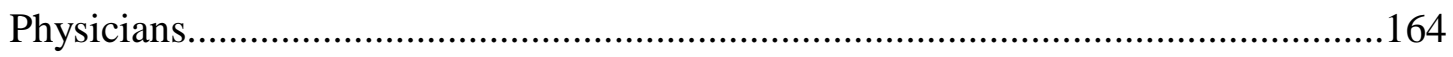

Public Interest Groups.......................................................................................167

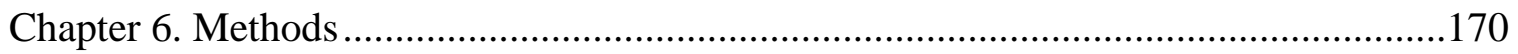

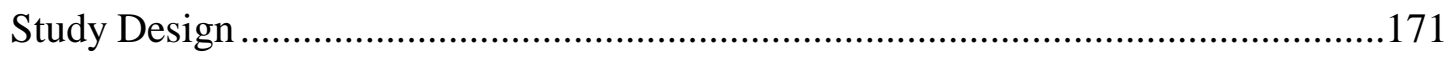

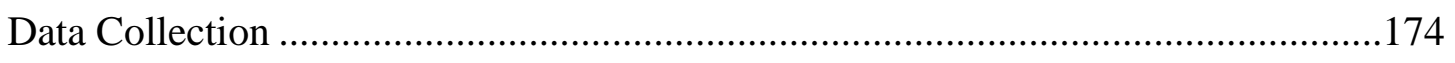

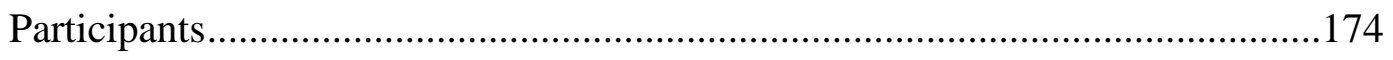

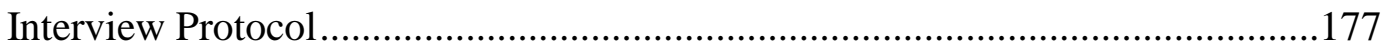

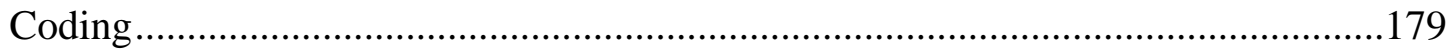

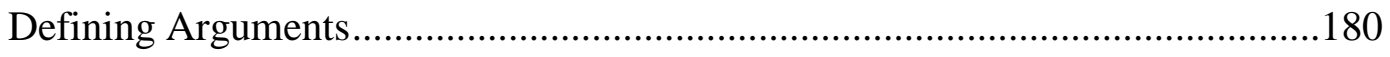

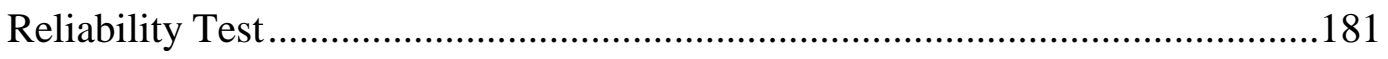

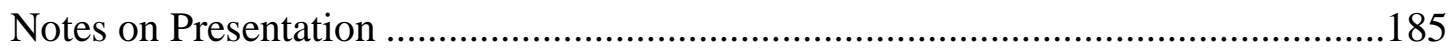

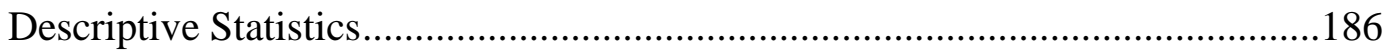

Chapter 7. Results ..............................................................................................188

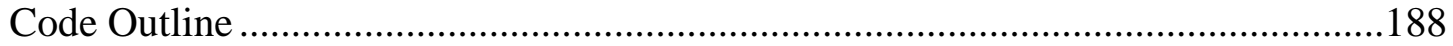

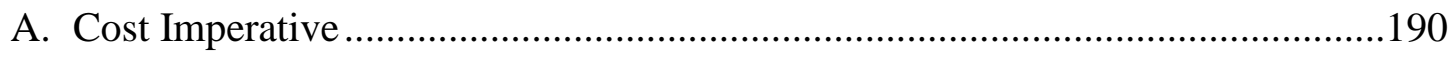

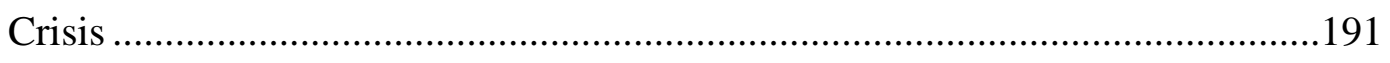

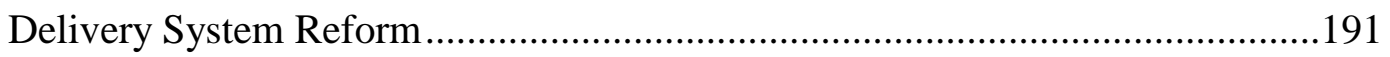

Medical Errors and Liability ........................................................................192

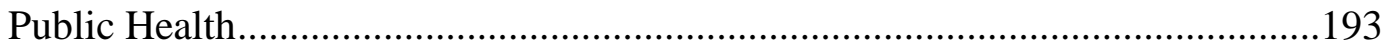

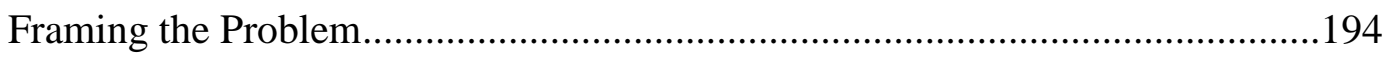

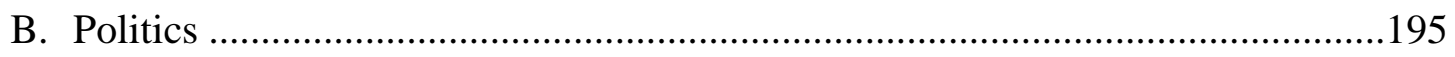

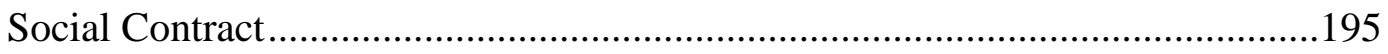




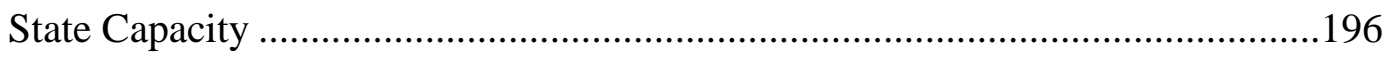

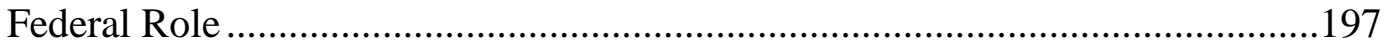

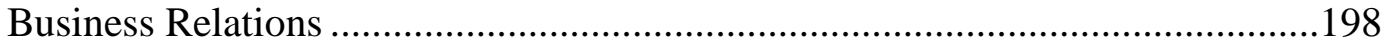

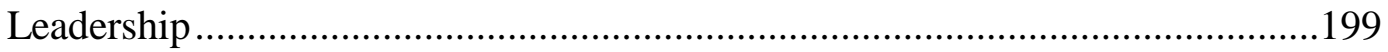

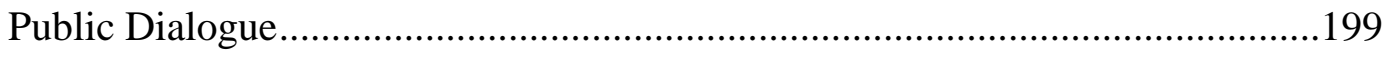

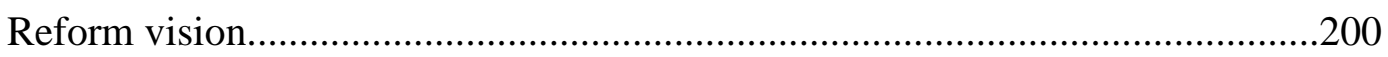

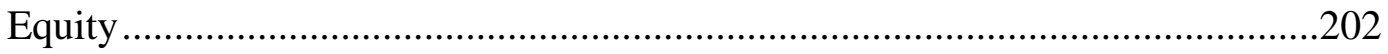

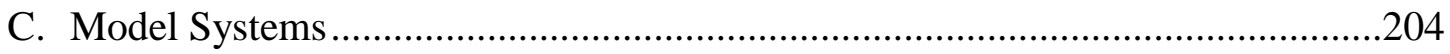

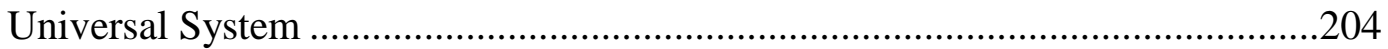

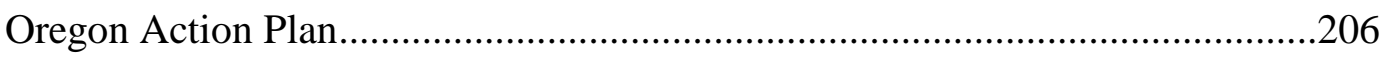

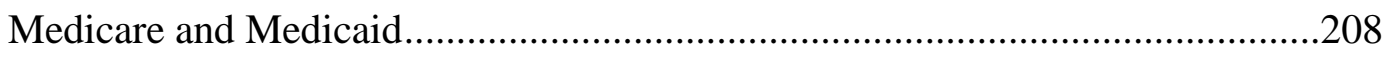

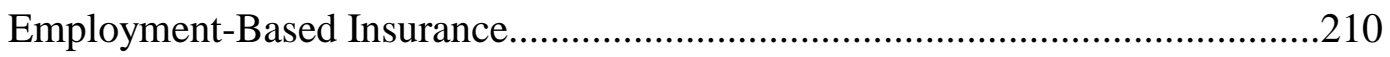

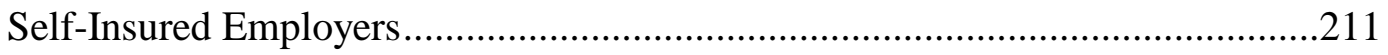

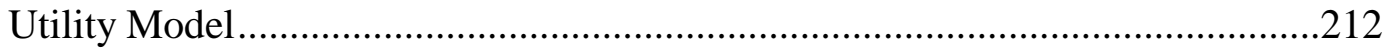

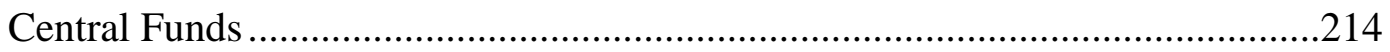

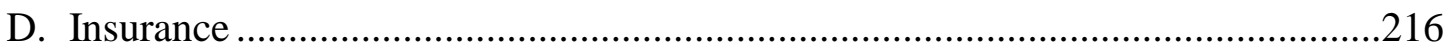

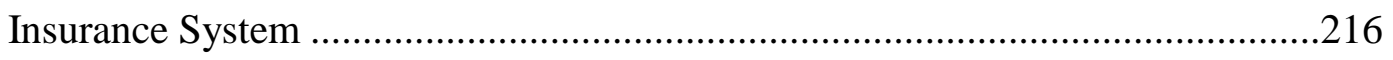

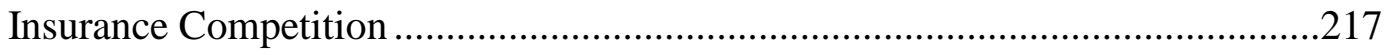

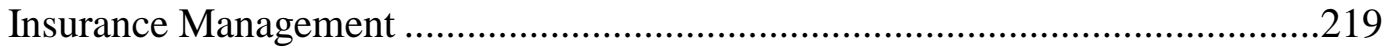

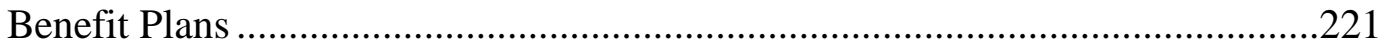

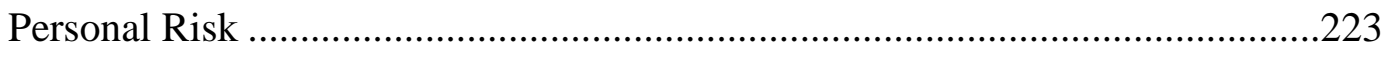

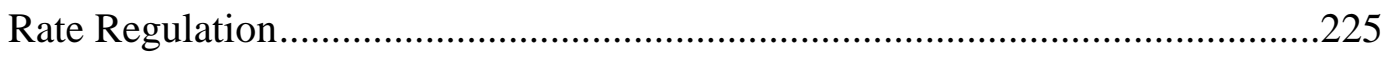

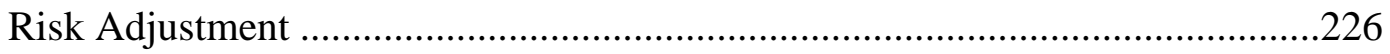

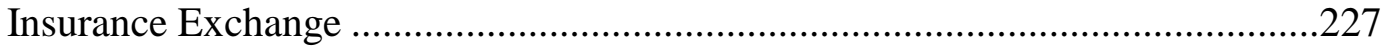

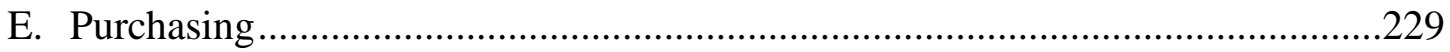

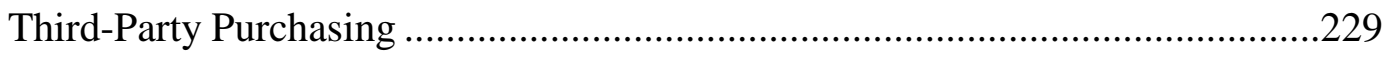

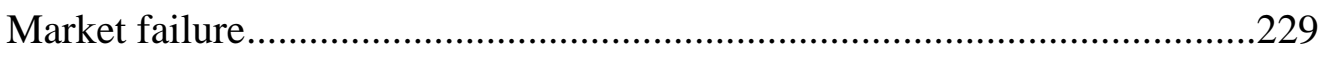

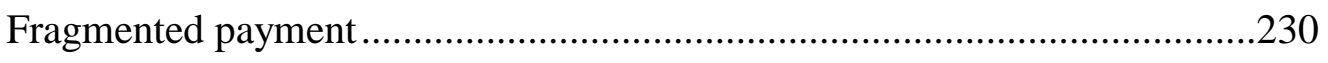

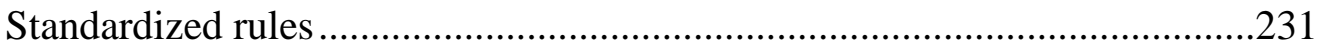

Administrative simplification .................................................................232

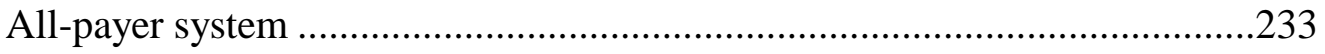




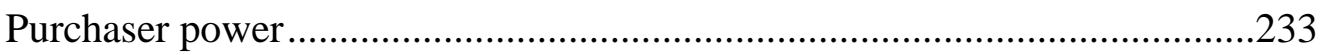

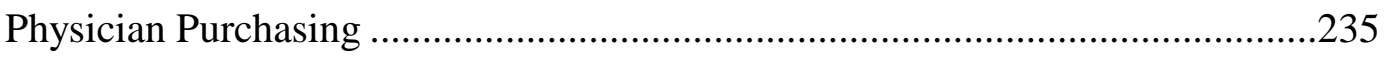

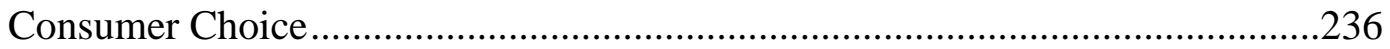

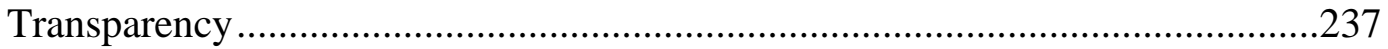

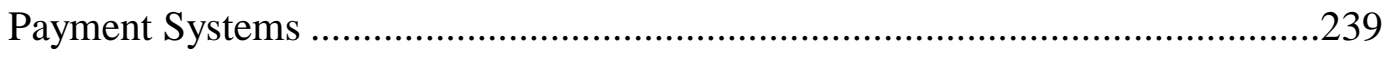

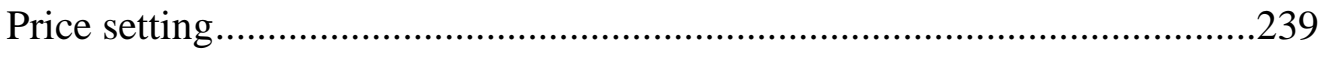

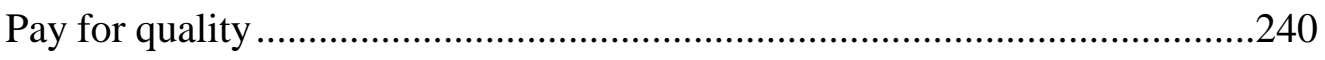

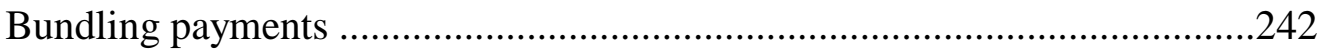

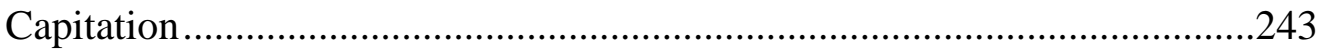

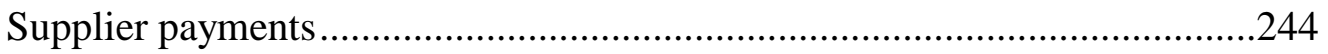

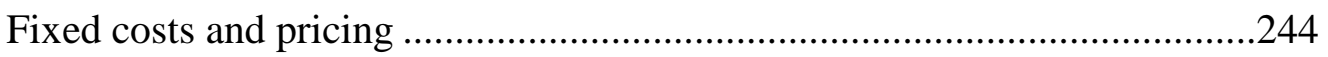

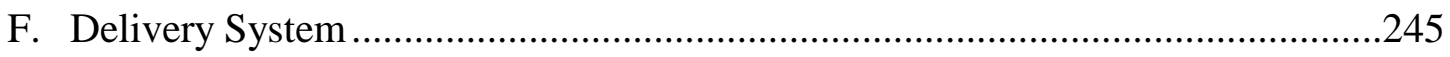

Coordinated Care and Teamwork ……………………….............................245

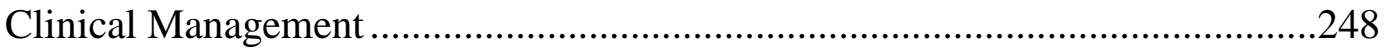

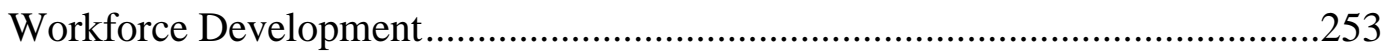

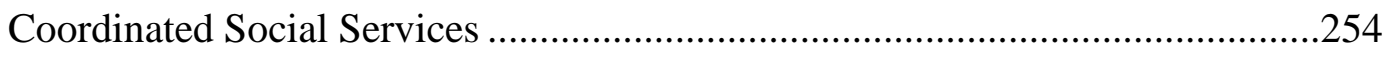

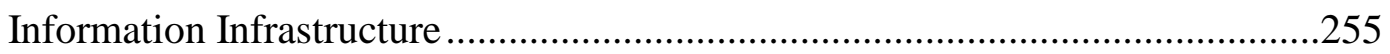

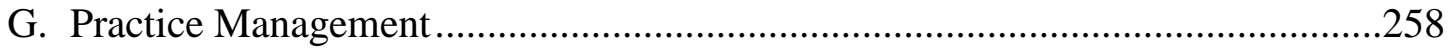

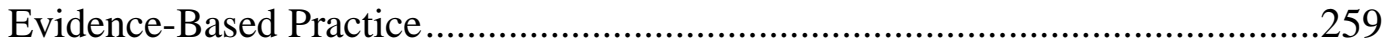

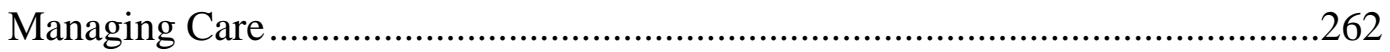

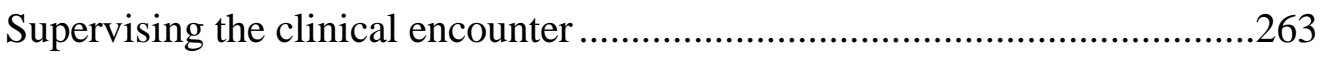

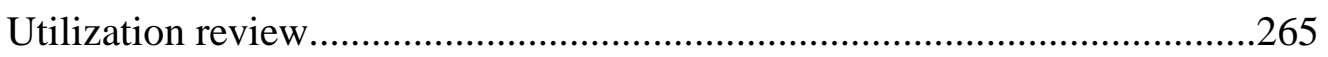

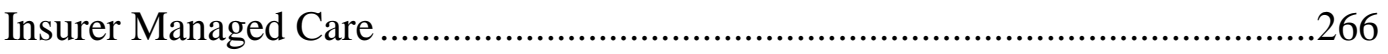

Accountable Care Organizations ………….................................................269

Provider Practice Management ………………………...............................22

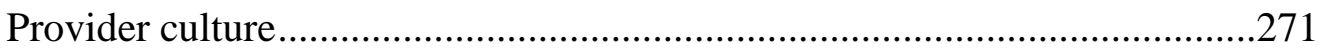

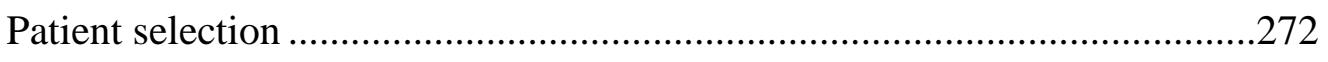

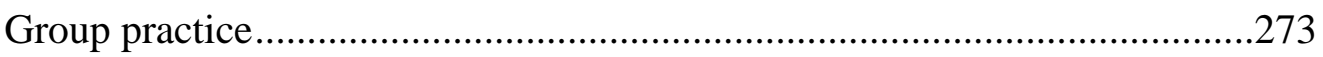

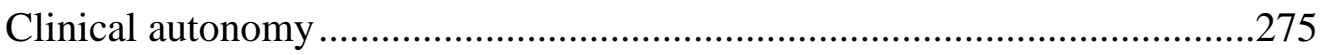

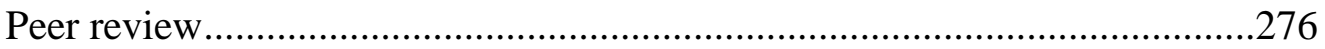

Community Practice Management ...................................................................22 


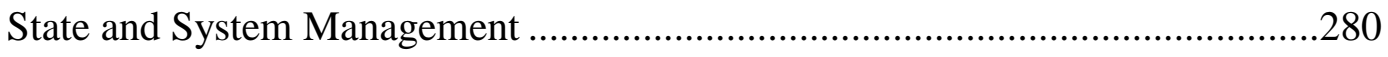

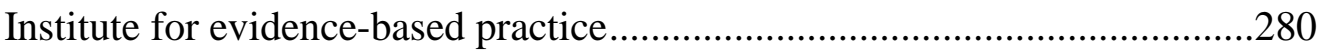

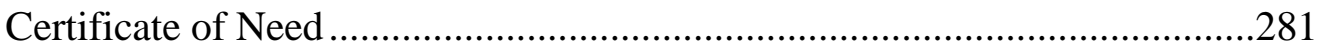

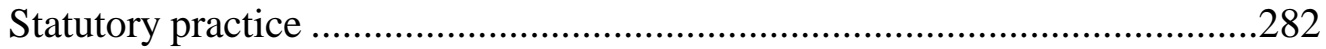

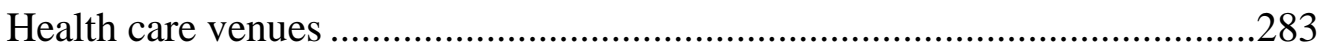

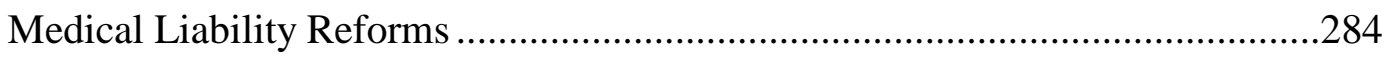

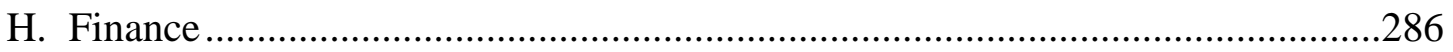

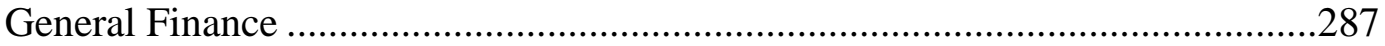

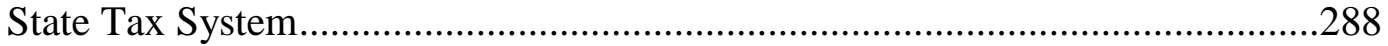

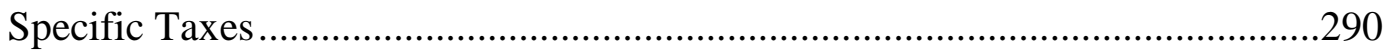

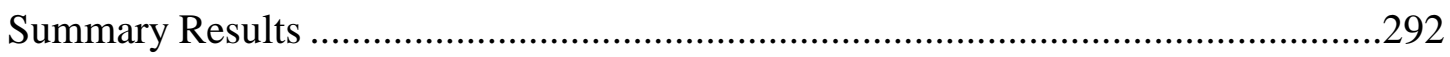

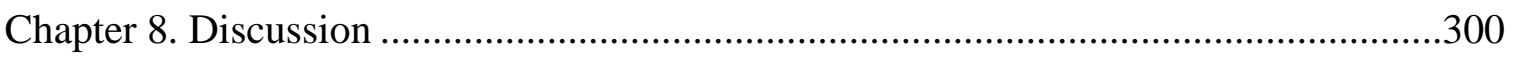

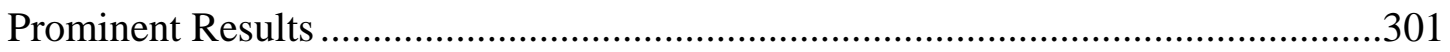

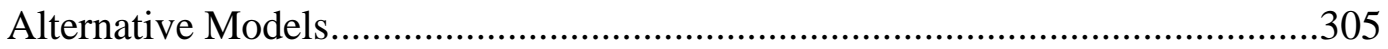

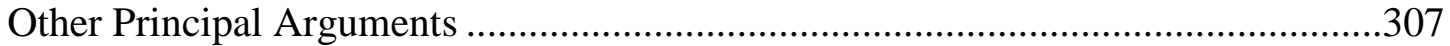

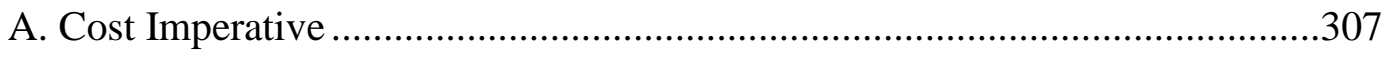

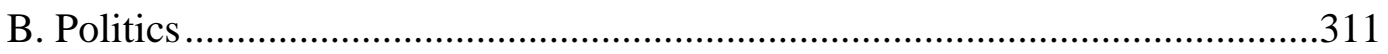

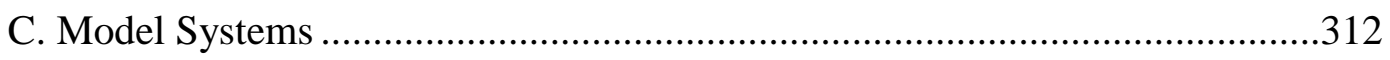

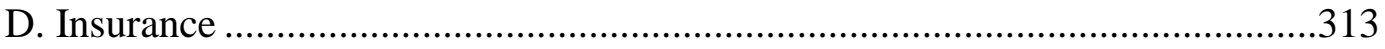

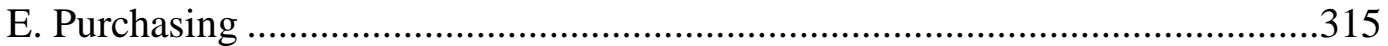

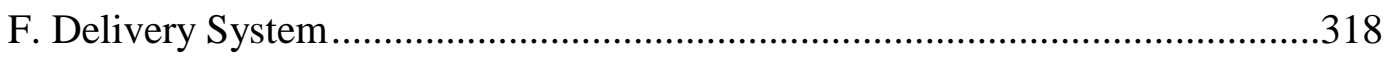

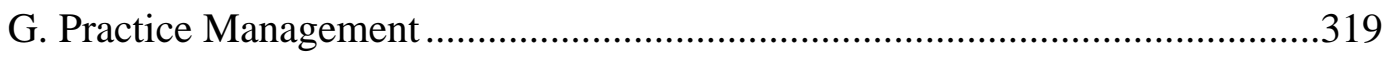

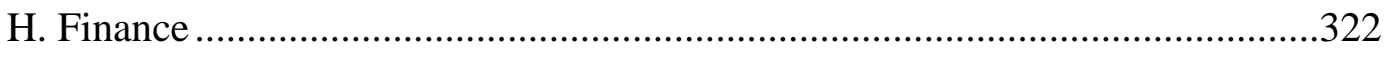

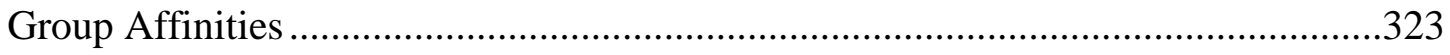

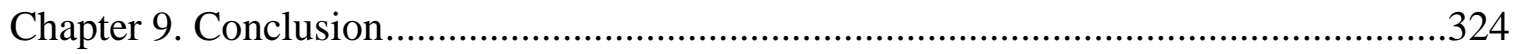

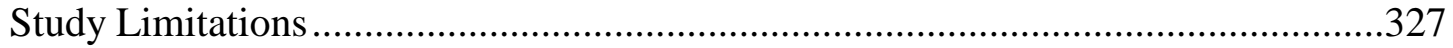

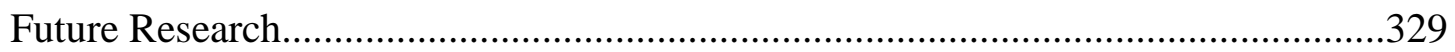




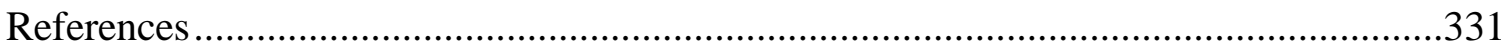

\section{Appendices}

Appendix A. Initial Contact Letter to Interview Subjects...........................................394

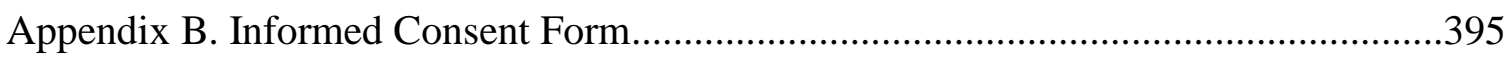

Appendix C. Health Policy Leader Interviews ..........................................................397 


\section{List of Tables}

Table 1. Distribution of Personal Healthcare Expenditures by Source of Funds, USA 2000-2001

Table 2. Commercial Health Insurance in Oregon by Covered Lives

Table 3. Health Insurance Carriers in Oregon by Premium Revenue

Table 4. Oregon Hospitals and Services Grouped by Workforce Regions, 2010 ........160

Table 5a. Intrarater Reliability: Code Comparison of Coder 1A to Coder 1

Table 5b. Interrater Reliability: Code Comparison of Coder 2 to Coder 1

Table 6. Percentage Support for Coded Arguments by Group and Topic

Table 7. Comparison of Stakeholder Groups: Prevalence of Attention and Proximity Correlation of Groups on Main Items Within Topical Sections ...299 


\section{List of Figures}

Figure 1. Distribution of Personal Healthcare Expenditures, 1996.............................50

Figure 2. Oregon Counties and 15 Workforce Regions .........................................159

Figure 3. Jaccard Diagram of Commonly Associated Arguments by Individuals ........295 


\section{Acronyms}

$\begin{array}{ll}\text { AHRQ } & \text { Agency for Healthcare Research and Quality } \\ \text { AMA } & \text { American Medical Association } \\ \text { BBA } & \text { Balance Budget Act 1997 } \\ \text { BCBS } & \text { Blue Cross Blue Shield } \\ \text { CAHI } & \text { Council for Affordable Health Insurance } \\ \text { CMS } & \text { Center for Medicare and Medicaid Services } \\ \text { DCBS } & \text { Oregon Department of Consumer \& Business Services } \\ \text { DHS } & \text { Oregon Department of Human Services } \\ \text { DRG } & \text { Diagnosis-related groups } \\ \text { ERISA } & \text { Employee Retirement Income Security Act 1974 } \\ \text { FPL } & \text { Federal poverty level } \\ \text { GAO } & \text { U.S. General Accounting Office } \\ \text { HEDIS } & \text { Health Plan Employer Data and Information Set } \\ \text { HIAA } & \text { Health Insurance Association of America } \\ \text { HCFA } & \text { Health Care Financing Administration } \\ \text { IOM } & \text { Institute of Medicine } \\ \text { IPA } & \text { Independent practice association } \\ \text { JAMA } & \text { Journal of the American Medical Association } \\ \text { JCAHO } & \text { Joint Commission on Accreditation of Health Care Organizations } \\ \text { KFF } & \text { Kaiser Family Foundation } \\ \text { MCO } & \text { Managed care organization } \\ \text { NAIC } & \text { National Association of Insurance Commissioners } \\ \text { NCSL } & \text { National Conference of State Legislators } \\ \text { NCQA } & \text { National Committee for Quality Assurance } \\ \text { OHP } & \text { Oregon Health Plan } \\ \text { OHPR } & \text { Oregon Health Policy and Research } \\ \text { OHSU } & \text { Oregon Health \& Science University } \\ \text { OMIP } & \text { Oregon Medical Insurance Pool } \\ \text { ORS } & \text { Oregon Revised Statutes } \\ \text { OTA } & \text { U.S. Congress, Office of Technology Assessment } \\ \text { PPO } & \text { Preferred-provider organization } \\ \text { RBRVS } & \text { Resource-based Relative Value Scale } \\ \text { RUGs } & \text { Resource Utilization Groups } \\ \text { UK } & \text { United Kingdom } \\ & \end{array}$


Give me health and a day

and I will make the pomp of

emperor's ridiculous

- EMERSON 


\section{Chapter 1}

Introduction

The first determined campaign in the USA to legislate "compulsory social insurance" for healthcare costs began in the early 1910s, supported by an example passed in the United Kingdom in 1911, which in turn was based on the original model passed in Germany in 1883 (Foerster, 1912; Orloff \& Skocpol, 1984). These early models of social health insurance were not yet "universal," but applied only to workers and later their dependents. In the USA, the idea was included as a plank in the unsuccessful presidential campaign of Theodore Roosevelt and his Progressive Party in 1912. Later, it was drafted in a model bill by the American Association for Labor Legislation and was debated in at least a dozen state legislatures (Ross, 2002). None succeeded. Thereafter, compulsory health insurance, with an expanded scope to include the whole U.S. population, became prominent in political discourse and proposed bills at regular intervals: in the 1930s, 1950s, 1970s, and 1990s (Quadagno, 2005; Starr, 1982). Repeatedly, none succeeded.

In the most recent period of reform efforts, 1987-1994, the national government and a majority of the states considered ambitious policies—not always universal in scope - aiming to ensure affordable health insurance to a larger proportion of the population. States took the lead. Various motives have been ascribed to the remarkable surge of activity by the states in health insurance reforms during this period (Leichter, 1997a). Federal policies over the preceding decades had increasingly deferred 
responsibility for domestic policies to the states, and state regulatory capacity was more developed, but a cost imperative appears to have been the most important motivation; state budgets for Medicaid were being pressured by new federal mandates for coverage, additional expenditures were dedicated to the elderly and long-term care, and cost increases were mounting by 10\%-20\% per year (Office of Technology Assessment, 1992). More people were poor and uninsured, and those eligible for Medicaid were using more services.

Through the 1980s states had tried restricting eligibility, coverage, and fees to balance budgets as public obligations escalated. Finally, insurance reforms of various types were attempted, aiming to increase coverage in the commercial market and spread the costs of health insurance more broadly across the covered population. Most states focused on market reforms; four states (California, New Jersey, New York, and Iowa) undertook major demonstration projects to expand coverage; and eight states (Hawaii, Massachusetts, Oregon, Florida, Minnesota, Vermont, Maryland, and Washington) adopted comprehensive measures that aimed to provide universal health insurance (Frank, Sullivan \& DeLeon, 1994).

In Oregon and several other states, universal health insurance was believed to be a way to control runaway costs and improve social and economic conditions. As Senate president in the Oregon Legislative Assembly, John Kitzhaber (1989) introduced the concept of the Oregon Health Plan by outlining the case of Oregon children suffering and people dying due to the lack of timely medical care. He rejected the "insidious" state practice of simply redefining poverty to make the problem go away. An early description 
of the Oregon Health Plan (Oregon Medical Assistance Programs, 1993) defined the problem more broadly, opening with the declaration: "The rising costs of medical care and the growing number of people unable to afford it threaten the social and economic health of this country" (p. 1). A broad-based group of stakeholders reportedly agreed on a common objective to "keep Oregonians healthy." State initiative was supposed to help motivate and shape more fundamental national reforms.

When a national proposal for comprehensive health insurance took precedence after 1992, state momentum was deflected. In the 1993 Oregon legislative session, hesitation was evident among legislators implementing the Medicaid expansions in the Oregon Health Plan (Senate Special Committee on the Oregon Health Plan, 1993). Then, with the eclipse of the national Health Security Act (1994), a widely observed chill fell over state reform activities and enthusiasm for reform generally. Universal health insurance was removed from the agenda and incremental policy reform became accepted practice (Aaron, 1998; Blumenthal, 1999; Marmor \& Hamburger, 1994). Many states established innovative programs to expand coverage for Medicaid populations; some formed purchasing cooperatives, over half instituted high-risk pools, but no state succeeded in establishing a universal model of health insurance that covered the entire population (Achman \& Chollet, 2001; Leichter, 1997c; Peterson, 2004). A review of state reform activities in this period, including Oregon (Leichter, 2004), drew two contrary conclusions on the appropriate forum for reform efforts-one view saying the states are clearly failures and have shown they lack the requisite ambition for successful 
systemwide reforms, the other saying the federal government is clearly a failure and the only possibility for successful reform rests with renewed effort by the states.

Attention for universal health insurance eventually resurfaced in a wide arena in August 2003, when 8,000 physicians (Physicians' Working Group for Single-Payer National Health Insurance, 2003) advocated a universal healthcare system for the nation in the Journal of the American Medical Association. They were supported by a report from the Institute of Medicine (2002), Fostering Rapid Advances in Health Care, that named affordable state-level health insurance coverage for all as one of five critical areas needing a system demonstration. According to the report, state health insurance for all "should rank among the highest of health care priorities, even though it will not be easy to find solutions to achieve this goal" (p. 71).

Renewed interest in universal health insurance emerged from social and economic pressures similar to the earlier period of reform. Following a period of incremental improvements through the mid-1990s, by the early years of 2000 the number of uninsured, the rate of cost increases, and persistent obstacles to quality improvement reflected a set of circumstances similar or worse than a decade earlier. A special issue of the Journal of Health Politics, Policy and Law (Peterson, 2000) reviewed the insurance systems that had developed in the states: the failed politics, the dynamics of markets and regulations, the inability of insurance market reforms to significantly expand coverage, the unsustainability of public programs, and the debate about who, national or state governments, should lead further reform efforts. 
In Oregon, the early successes of the Oregon Health Plan at reducing the number of the uninsured crumbled under financial pressures in 2002 (Carlson \& Wright, 2005; Mann \& Artiga, 2004; Oberlander, 2006; OHPR, 2003, 2005a, 2005b; Wright, Carlson, Allen, Holmgren \& Rustvold, 2010). Cutbacks the following year drastically reduced enrollment. At the end of 2004, the Oregon Business Council Healthcare Task Force produced a white paper outlining the multiple cost pressures in the healthcare system, and concluded with recommendations that included a system of coverage for all. In response, a Senate Special Committee on Health Care Reform began deliberations in 2005. By then, at least 18 states were considering legislation for universal health insurance (National Conference of State Legislatures, 2005). In 2006, the state of Massachusetts passed an ambitious mandate to achieve universal health insurance, which served as a model for other states and the national government in reform efforts.

Public advocacy for universal health insurance in Oregon took shape in 2006, with the formation of the influential Archimedes Movement, an interest group founded by former Governor John Kitzhaber (re-elected as governor in 2011). The following year, the Oregon Health Policy Commission produced a Road Map for Health Care Reform (2007) that included healthcare access for all as a key component. State legislators established the Oregon Health Fund Board (OHFB) to study the issue and present a report to the next biennial session. The board held statewide community meetings and formed a number of study groups on core topics, involving a large number of stakeholders and policy experts. The OHFB report (2008) elaborated a model that legislators followed in 2009 to establish the Oregon Health Authority and Oregon Health Policy Board, intending to implement 
coverage expansion and steps toward a system of universal health insurance. ${ }^{1}$ In 2010 , Congress enacted a national system of universal health insurance (Greaney, 2011; Patient Protection and Affordable Care Act, 2010) that reflected the general form and basic elements of the plan already underway in Oregon. At the end of 2010, the Oregon Health Authority published an action plan, following the state initiative and the requirements of the federal mandate, which the legislature took up in 2011.

\section{Defining the Problem}

The present study began in 2002, when the current cost pressures in the healthcare system were becoming acute. The principal aim was to achieve a comprehensive view of healthcare system reform and understand what a feasible model of universal health insurance in Oregon might look like as a possible solution for the most endemic problems. The study was concluded in 2011 , as the Oregon legislature grappled with the same challenging questions. Hopefully, the results here can contribute to the ongoing policy discussions.

The following introduction, here and in the next several chapters, addresses the basic elements of health insurance and the healthcare delivery system. The review concentrates on the period from 2002 to 2007, when a perception of crisis was prompting

\footnotetext{
1 The 2009 Oregon Legislative Assembly passed House Bill 2009 (HB2009), with the following features.

- Established the Oregon Health Policy Board, an uncompensated body of nine persons, charged to develop an action plan to achieve universal health insurance in Oregon, and continually review key state healthcare reforms to produce recommendations.

- Established the Oregon Health Authority to manage state health and health insurance functions, and develop a plan for an Oregon Health Insurance Exchange according to specified provisions.
} 
renewed attention and action by local stakeholders and policymakers. Conditions during this period form the backdrop for the views of the stakeholders interviewed for this study between June 2008 and June 2010.

The basic conditions that motivated stakeholder attention to health insurance reform, and in particular, a movement toward universal health insurance, need to be understood first. The perceived problems remain the same as in the earlier period of reform activity, typically grouped in three categories of access, cost control, and quality of care.

Access

Studies of insurance coverage after 2002 indicated about one-sixth of the U.S. population was uninsured, about one-third was underinsured, and existing coverage was eroding under pressure from rising costs (Kaiser Family Foundation/Health Research and Educational Trust, 2003; Schoen, Doty, Collins \& Holmgren, 2005; Simmons \& Goldberg, 2003). Public coverage under Medicaid was reduced, and hospitals were being pressured to deny access due to an increasing burden of uncompensated care (Bazzoli, Kang, Hasnain-Wynia \& Lindrooth, 2005; Mann \& Artiga, 2004; OHPR, 2004a). The number of full-year uninsured in Oregon in 2004 was about 480,000, or 14\% of the population, a number slightly higher and a percentage slightly lower than in 1993 (Oregon Progress Board, 2005).

Price is an obvious reason why individuals remain uninsured, preferring to accept risk than incur a definite loss by paying a premium. Yet, individuals notoriously 
underestimate risk when associated with unimaginable illness or injury in the future (Liebman \& Zeckhauser, 2008; Newhouse et al., 1993). Once medical care is judged to be necessary, without insurance, the price for services can readily exceed individual means. In 1999, of 1.29 million personal bankruptcies in the USA, medical reasons accounted for over $40 \%$ of them (Warren, Sullivan \& Jacoby, 2000). These figures were corroborated by another study (Himmelstein, Warren, Thorne \& Woolhandler, 2005), where medical reasons accounted for about half of all personal bankruptcies in the USA. Medicare beneficiaries are also vulnerable. Nearly half of the bankruptcies among those aged 65 and over were due to a medical reason. One half to three-quarters of the bankruptcies due to medical expenses involved persons who started out with health insurance, indicating inadequate coverage. These figures indicate an evident inability of individuals to judge risks, prepare for contingencies, or do without when personal health care is necessary. They also indicate the present system of health insurance does a poor job of managing affordable access to health care for those who need it.

About one-fourth of those without health insurance in the USA are aged 19-34 (Holahan \& Cook, 2009), suggesting that many are likely to be in good health. Yet, evidence has consistently confirmed that the uninsured (as those without health insurance came to be known in the 1990s) in general are "sicker and poorer," less likely to obtain timely care, and subject to less intensive intervention and worse outcomes (Hadley, 2003). On average, the full-year uninsured may spend one-fourth or one-fifth of the amount spent on health care by the full-year insured (Merlis, 2002). This lower overall 
spending by the uninsured may be explained by reduced access and lower use of health services, foregoing needed care (Cunningham, 2010).

The risk of financial ruin has always been the primary motive for insurance. Since the later 1990s, publicity campaigns, such as projects by the Robert Wood Johnson Foundation, began to characterize the misfortunes of uninsured individuals and families in selected stories designed to illustrate the meaning behind the statistics. The human element was elevated as a critical aspect of the access issue. This tactic was supported by earlier examples: used with success by Dorothea Dix (2006) in her dramatic testimonials to raise state and federal government support for humane treatment of the insane in the 1840s; and in the graphic illustrations of the "specter of insecurity" (Epstein, 1933) that preceded federal legislation for unemployment insurance and Social Security in the 1930s.

In the campaign for the uninsured, two notable summaries of information eventually appeared: a major project in six volumes by IOM (2004), and a systematic review of the evidence by Jack Hadley (2003) of The Urban Institute. In his review, showing lower income, health status, and treatment outcomes for the uninsured, Hadley suggested if any more evidence is needed to spur political action, then a randomized trial may be in order as recommended by IOM. Hadley argued further, however, that information on the widespread human cost of being uninsured for health care was already abundant, yet no decisive action had been taken to address the problem.

Various stakeholder groups and opponents of state-sponsored social insurance in the USA have steadily resisted moral arguments for welfare reforms (Noble, 1997; 
Quadagno, 2005, 2010; Trattner, 1999). Opposition to publicly sponsored health insurance has revolved around other issues, related to public distrust of government, clash of interests, and fear of rationing (Morone, 1992). A recent perspective (Mechanic \& McAlpine, 2010) pointed out that stakeholders must often be "paid off" to obtain needed reforms, indicating purely financial motives can redirect reforms to benefit a few.

In a more theoretical view, substantiated by the content of numerous welfare reform debates, University of Oregon sociologists Kenneth Hudson and Andrea Coukos (2005) claimed that evidence of highly emotional responses among the opponents of welfare reforms may be due to the cultural influence of Calvinist Puritanism, or "the dark side of the Protestant Ethic.” Framing their views on the work of Max Weber, Hudson and Coukos argued that commonly observed objections in exclusion debates-directed against the so-called "undeserving poor" (Katz, 1989) or against groups identified by race, class, sex, or citizenship_-might be exacerbated by the symbolic sanctification of work and wealth in America's religious heritage.

\section{Cost Control}

In the early 1990s, Oregonians heard of the uninsured and the need for access to health care in terms of cost control (Mapes, 1994). A cost shift was claimed to be occurring-increasing the medical bills for those covered by commercial insurance to pay for the uncompensated care received by the uninsured. At the time, health insurance premiums were rising faster than general inflation in the economy, and cost shifting was 
viewed as a main cause. This concept was advanced as a reason to support universal health insurance.

In the campaign for the Oregon Health Plan (OHP), then Senate President John Kitzhaber also emphasized another cost factor due to the lack of access. As a former emergency room physician, Kitzhaber raised an alarm about the unnecessary use of emergency care by the uninsured, often due to preventable conditions and the lack of primary care. With cutbacks in 2003 in OHP and social services, Oregon saw Kitzhaber's point confirmed in news and research reports, showing that cuts in public health insurance led to worsening health conditions and more intensive care that mostly offset cost savings (see further discussion in Chapter 3, Public Welfare).

Cost increases in health care declined through the early 1990s, and flattened in 1995, but afterward began to rise again at a rapid rate. In Oregon, a large increase in insurance premiums appeared in 2002, when rates for some carriers jumped by $30 \%$ to 40\% (Oregon Insurance Division, 2003). Costs for hospital care, professional services, prescription drugs, and for insurance itself (premium minus benefits) all continued to increase at rates several points above the rate of inflation, accelerating toward an annual rate of increase of 14\% in 2003 (Heffler et al., 2003). The percentage of the Gross Domestic Product (GDP) devoted to healthcare expenditures was projected to reach $17.7 \%$ by 2012 . The increase was already within reach by 2010 , when national healthcare expenditures were reported at $17.3 \%$ of GDP (Truffer et al., 2010).

Increasing volume and value account for a large share of increased spending on health care. In many areas, medicine is expanding its capacity for helpful intervention and 
is proving its worth in absolute terms of human benefit (Cassel, 2005). Nevertheless, healthcare costs in the USA are highest by far among the 30 countries in the Organization for Economic Cooperation and Development (OECD) and benefits are often lower (Anderson, Reinhardt, Hussey \& Petrosyan, 2003; Anderson \& Squires, 2010). In 2003, the median per capita cost in OECD countries was $\$ 1,983$, compared to $\$ 4,631$ in the USA: 2.3 times higher. Even when considering only the most developed countries, the difference from the USA remains about the same.

For this considerable extra spending, measures of value on a variety of indicators were about the same or worse in the USA. In an in-depth study of four diseases in the USA and Germany (cited by Anderson et al., 2003), researchers concluded that per capita expenses were $40 \%$ higher in the USA, yet the healthcare resources received were $15 \%$ lower than in Germany. A comparison of the USA to seven other top OECD countries (Germany, France, United Kingdom, Canada, Japan, Australia, and New Zealand) showed the following rankings (Anderson, Petrosyan \& Hussey, 2002).

1. Health conditions and the burden of disease. Obesity prevalence, and incidence rates for breast cancer, colon cancer, and lung cancer were highest (even though smoking prevalence was lowest)

2. Mortality rates. Longevity was slightly worse, infant mortality decidedly worse, mortality due to diabetes mellitus and lung cancer highest, mortality due to acute myocardial infarction and breast cancer in the middle range, and mortality due to colon cancer among the lowest.

3. Healthcare capacity. Acute-care hospital beds in the population were lowest, hospital admissions second lowest, length of hospital stay third lowest, and the number of practicing physicians and nurses in the population in the middle.

These comparatively poor results can be partly attributed to a notably higher burden of disease, but the U.S. population clearly received less value by many healthcare 
indicators, and in only a few instances demonstrated about the same or better care than other countries that spent considerably less. Perception of value was also lower in the USA than in other countries. In a survey conducted about the same time (Blendon, Schoen, DesRoches, Osborn \& Zapert, 2003), U.S. citizens were found to be generally less satisfied with their health care than citizens in other countries. A study of OECD countries that compared demographic factors (such as age, income, education) in health system costs found such factors influenced cost growth significantly, but were "swamped in importance by benefit growth" (Kotlikoff \& Hagist, 2005, p.2). Controlling for demographic factors, the USA was found to be the least able to control costs.

\section{Quality of Care}

In terms of quality of care, a number of agencies concentrated on generating improvements through the 1990s. The U.S. Preventive Services Task Force published its influential Guide to Clinical Preventive Services (1989), followed in 1990 by Congressional funding for what has become the Agency for Healthcare Research and Quality (Gray, Gusmano \& Collins, 2003). The National Committee for Quality Assurance (NCQA) began in 1991 as a promotional organization for health maintenance organizations (HMOs), but the association quickly achieved independence and a remarkable authority over accreditation of healthcare facilities and certified practices (Anders, 1996), particularly with its well-known and growing body of Health Plan Employer Data and Information Set (HEDIS) measures. Efforts to monitor and report healthcare quality since the early 1990s have supported a variety of quality indicators and 
performance measures, combined with contract and legal obligations to report them (cf., ORS 743.814).

Attention to quality of care rose considerably following a landmark Institute of Medicine report (2000) that publicized an estimate of 44,000-98,000 deaths each year from medical errors. The number is probably too low. Adverse drug reactions may kill at least that many and seriously injure millions more, particularly the elderly (Beijer \& de Blaey, 2002; Lazarou, Pomeranz \& Corey, 1998; Phillips \& Bredder, 2002). Another 57,000 preventable deaths may occur each year due to neglected conditions and poor follow-up (NCQA, 2003). In general practice, a broad survey showed one-fourth of adult respondents and nearly one-fifth of physicians have experienced a medical error with serious health consequences (KFF/Harvard School of Public Health, 2002).

Actual performance and positive health outcomes in quality improvement have proven surprisingly obdurate (Boyne \& Walker, 2002). While moving enthusiastically toward a theoretical ideal of evidence-based practice and reporting of outcomes for a decade, accumulating evidence by the 2000s showed more information is (a) often burdensome and expensive to produce, with few coordinated systems to make it truly useful (McGlynn, 2003); (b) a source of conflict for those who disagree with the quality indicators or scores (e.g., Dranove, Kessler, McClellan \& Satterthwaite, 2002); (c) often ineffective in changing clinical practice (Grimshaw et al., 2001); and (d) often applied inconsistently (NCQA, 2003). 


\section{The Problem of Value}

Arguments for universal health insurance usually apply to the problem of inadequate access to care. Cost control and quality improvement are more difficult to comprehend and resolve. Cost and quality together define value, which is necessary to achieve a sustainable system of universal health insurance (Fuchs, 2004; Lawrence, 2002). In turn, the idea that a universal health system will be more successful at controlling costs arises naturally from the example of other countries, as outlined above. The first Office of the Oregon Health Plan Administrator reflected upon this circular problem of value in its first report to the legislature on reform alternatives, in response to the question, "Are Reforms Necessary?" (1995a, p.9).

Cost control and universal coverage are closely linked. On one hand, we cannot sustain the financing for universal coverage if we do not control costs. On the other hand, it is unlikely that we can control costs effectively if we do not reach universal coverage. It is very difficult to control costs in a system where providers and payers can react to spending constraints by shifting unpaid expenses to other payment sources or by restricting charity care.

In this line of thinking, access to health insurance is only the first goal for a system of universal health insurance. The statement by the OHP Administrator indicates such a system may also be necessary to solve the problem of value. Of course, the results in testing this assertion will depend a great deal on the details of the established model.

\section{Addressing the Problem}

The following chapters review a number of the details in reforms related to universal health insurance, concentrating on those areas raised in the discourse of health 
policy leaders presented subsequently. Chapter 2 begins with an orientation to civic capacity in Oregon, including an account of the early history of social welfare and health insurance in the state. This look backward provides a context for current reform discussions and raises a number of relevant themes and principles.

In Chapter 3, various aspects of health insurance are reviewed, while updating the examination of alternative models of universal health insurance identified by the OHP Administrator in 1995. Although no favorable option was selected at the time, all of the model systems are still active in current policy discussions. In Chapter 4, critical cost and quality reforms are reviewed to address the problem of value. In Chapter 5, principal health policy stakeholders in Oregon are identified, involving six institutional categories: state officials, insurers, purchasers, hospitals, physicians, and public interest groups. Chapter 6 outlines the methods that were used to conduct, code, and summarize the results of 38 interviews with individual stakeholders. In Chapter 7, the results of the interviews are presented in a detailed narrative. Independent quotations have been organized to produce an analytical dialogue that covers a wide array of critical issues for a system of universal health insurance, related to funding, insuring, purchasing, delivering, and managing healthcare services. The final two chapters discuss the results and draw conclusions from the study.

For useful policy, any analysis of abstract models needs to be grounded in the current discourse of policy agents, content experts, and stakeholders actually present, who define the immediate situation and tangible interests. The importance of current discourse among leaders in the policy process was demonstrated in a seminal study by John 
Kingdon (1995), which established the term policy window to refer to a propitious moment when stakeholders agree on the salient problems and solutions surrounding a particular topic. Political conflict is commonly observed to be the most significant obstacle to health insurance reform (e.g., Barlett \& Steele, 2004; OHP Administrator, 1995a).

By itself, however, political agreement is also an abstraction. Policy alternatives need to be grounded further in real objective possibilities. The practical problems of the employer mandate in Oregon in the early 1990s, for example, eventually led to the withdrawal of support by the business community and legislators who previously supported it. The present study combines the political perspective suggested by Kingdon with a practical analysis that observes objective interests, evidence, and problems to suggest what might be expected from different model reform proposals. This kind of comparison of political and practical perspectives, or subjective and objective rationality, follows the interpretive method established by German sociologist Max Weber (1968).

This study of feasible models of universal health insurance in Oregon according to stakeholder views may help Oregon policymakers evaluate currently proposed healthcare system reforms and understand critical topics. The inclusion of local, authoritative discourse by stakeholders on issues of immediate importance offers unique value. 


\section{Chapter 2}

\section{Civic Capacity in Oregon}

Current views of universal health insurance reforms are likely to depend on more than the specific issue of healthcare delivery and health policy. Several aspects of a successful health insurance regime depend on general characteristics of social organization and public administration (Kornai \& Eggleston, 2001 ${ }^{2}$ ). How a society defines possession and right, and controls finance, exchange, contract, and crime-and for whom—-produces the fundamental basis of civil society (Hegel, 1942). These factors in civil society cannot be taken for granted. Variations occur in both senses one might make of the term civic: as a city, where strangers are welcome, within limits; and as a courtesy, a civility that makes another person feel welcome. Public utility, public good, solidarity, social right, and welfare are all terms, among others, that describe the basic ideas of welcome and rights among strangers. How these concepts have been developed and instituted in Oregon is fundamental to understanding the willingness and capacity of the state to achieve a system of social health insurance.

The idea for health insurance emerged from the idea for insurance, which in turn emerged from practices related to social welfare. Reviewing the origins of social welfare in Oregon offers simple examples of fundamental issues that appear later in this study.

\footnotetext{
${ }^{2}$ Interesting developments in the study of civil society are emerging from Eastern Europe, partly in relation to the organization of social insurance and the healthcare system, following the collapse of Soviet institutions in 1989 (e.g., Iatridis, 2000; Kornai, Haggard \& Kaufman, 2001; Kornai \& Rose-Ackerman, 2004). This literature raises most of the key topics found in this chapter.
} 
Salient themes that emerge include eligibility, public finance, the federal share, and public administration.

\section{Social Welfare}

Early Oregon settlers eagerly sought government, primarily to secure property rights and promote commerce (Heider \& Dietz, 1995). In this respect, Oregon argonauts founded a new state with interests similar to early medieval cities in Flemish Europe, where civil society in modern terms originated (Pirenne, 1914, 1915). The main functions of municipal government in Oregon, as in medieval cities, focused on commercial transportation development and social control (Throckmorton, 1961; Unruh, 1979). In both places, the population consisted of large numbers of strangers and vagrants, freed of communal ties. Civil institutions were uninterested and incapable of supporting the general welfare of all individuals. Among residents, however, clannish private associations, guilds, and church congregations provided generous relief to members, according to need, as a system of patronage.

Yet, Oregon's original manifestations of civil society also differed from the medieval baseline, showing signs of community solidarity and mercy not only in private or religious associations, but also as a function of government. The priority of public education is one sign of development. Notably, too, local governments in Oregon considered "relief of paupers" a natural function from the beginning, consistent with a long tradition of English and American local peoples and governments (Riesenfeld, 1955). Although early county government "was at best frugal in its provision of public 
welfare" (Bourke \& DeBats, 1995, p. 101), individual subscribers and local governments in Oregon did provide relief to destitute residents and emigrants, partly out of compassion, but also for practical reasons: desperation bred danger and defeated the hope for industrious neighbors to promote prosperity for everyone (Unruh, 1979).

Motivations for control or compassion in early public welfare activities are difficult to separate. Both are present, for example, in care for insane persons, which was accepted as a duty by early county governments and later the state. The state responded rapidly to relieve counties of part of the burden, seeking federal funds in 1853 for an insane asylum, and in 1861 contracted for inmate treatment at a private asylum located in Portland, directed by Dr. J.C. Hawthorne (Larsell, 1945). State-sponsored insane asylums were widely diffused in the states following the lobbying efforts of Dorothea Dix in the 1840s and 1850s (Trattner, 1999). The asylum in Oregon was justified to protect the insane person and also avoid annoyance and harm to others-not unlike the justification for holding inmates at other early state institutions, such as the penitentiary, juvenile reform schools, tuberculosis hospital, and homes for the blind, deaf, and "defective"-all of which came together administratively under the Board of Control in Oregon in 1913 (Bates, 1914). The name underscores the intent.

\section{Eligibility}

As small units, local governments in general are unable to spread risk very far, which makes them vulnerable to excessive demands, depending on the local degree of poverty, illness, and ignorance. Communities from earliest America have been sensitive 
to vagrancy and the potential costs of extending social welfare (Trattner, 1999).

Townships commonly excluded "idle and disorderly persons" (Burns, 1994, p. 45).

Undesirable persons were not allowed to remain in town, or were removed from

respectable society to a county poor farm, asylum, hospital, or jail. Police protection did not necessarily apply to strangers in Oregon, and was originally denied to nontaxpayers.

Early Oregon law did stipulate, however, that vagrants in need of medical care must be treated before they could be removed. Also, Oregon dropped its harsh vagrancy laws in 1889 , before many other states, presumably due to the heavy influx of migrating laborers working on the transcontinental railroad, which reached Portland in 1883, followed by others who arrived on the much easier rail route (MacColl, 1988; Millis, 1898b). Exclusionary practices of all sorts for certain persons nevertheless remained in the application of the police power and in a variety of widespread social norms in Oregon related to race, religion, gender, class, and so on-indicating a fundamental sense of eligibility to gain access to public grace (Harring, 1977; Yale Law Journal, 1950).

The depth of social divisions in western states has been at times frankly ugly and vicious. Accounts of violent discrimination against labor activists, blacks, Japanese, or Chinese are common (e.g., Schwantes, 1982). ${ }^{3}$ Although possibly less so in Oregon

\footnotetext{
${ }^{3}$ The long shadow of social attitudes is illustrated in the ruthlessness directed against indigenous peoples in Oregon, which continued a pattern of shock and awe begun in the early American colonies (Churchill, 1997; Gallay, 2002). This, in turn, mimicked the scorched-earth policy of the British in Ireland, in full swing by 1600 (Lecky, 1892). Centuries of civil development did not dampen this sanguinary spirit. The campaign of General Crook against the Snake and Paiutes in eastern Oregon in 1867-68 employed a strategy practiced throughout the West to "attack them in their winter homes, kill the bucks, capture their women, and destroy their supply of provisions, and thus so cripple them that they would be glad to surrender and beg for peace" (Cozzens, 2002, p. 19).
} 
compared to other states (cf., Stearns, 1937), exclusion has helped mold civil society and may remain as a source of divisiveness today. The Public Accommodations Act that allowed blacks to patronize any business establishment passed in Oregon only in 1953 . Realtor contracts to redline neighborhoods and exclude certain groups was notorious during the same period and later (Burns, 1994; MacColl 1979; McLagan, 1980). In spite of historic movements and many lesser advances in civil rights and social justice, fundamental divisions in the population persist, leading at times to exclusion in the delivery of private charity or state welfare. As one example, welfare benefits and eligibility may be reduced as the percentage of a minority racial group in the population increases (Gooden \& Douglas, 2006).

Apart from such civil boundaries associated with strangers and suspect classes of persons, the provision of relief among the resident population in early Oregon hinged on means. The first settlers and their local churches, associations, and governments defined eligibility for welfare in the classic sense of charity: if you can pay now, or your family can pay soon, then you pay; if you are impoverished, then you may be eligible for relief. The system was based on patronage. Relief could be given or refused, or given in exchange for work. One of the first acts of county governments in Oregon involved defining the family duty of support to avoid or recoup public costs for relief efforts (Millis, 1898a).Public welfare was considered an option of last resort. ${ }^{4}$

\footnotetext{
${ }^{4}$ Social welfare in Oregon currently follows this same charitable model. Assistance is provided to persons "on the basis of need, taking into account the income, resources and maintenance available to the individual from whatever source derived and the necessary expenditures of the individual and the conditions existing in each case" (ORS 411.710). Related provisions refer to required responsibilites of parents and spouses, and instances when the state can recover funds.
} 


\section{Public Finance}

According to public records, about half of the early Oregon state budgets were devoted to charges of the insane asylum. The financial burden of managing social welfare was keenly felt, along with the increasing burden of paying for an active state government. Protests against government spending, beginning in the late $19^{\text {th }}$ century, were encouraged to a significant degree by visible corruption in the election of public officials and racketeering in the use of public funds in salaries, contracts, and subsidies (illustrated nationally by Steffens, 1904, 1906; and in Oregon by Ferguson \& Ferguson, 1983; Messing, 1966). Providing for social welfare and public utilities was also plainly expensive, as for the insane asylum or the expanding development of sanitation and public health measures that proved so remarkably effective after 1900; or caring for bridges, parks, hospitals, and fire departments that were originally started by private capital and later donated to state or local governments.

In addition, Oregon followed and sometimes led the familiar pattern of policy development through the Progressive era, learning to regulate business, finance, and civil service; and to protect labor, women, children, and the environment, which required new supervisory roles and public salaries for an expanded class of civil servants with a universal view (Nash, 1971). Supported by a very ugly reality in the prevalent misery of the working population, the unemployed, the poor, the aged, and others, arguments such as those by Professor Charles Henderson (1908, p.12)—calling the "laissez faire philosophy, a theory made to excuse, justify and glorify neglect"—gradually prompted 
increases in government activity. By the 1970s, Oregon state budgets show that government management became accepted practice in a number of areas of concern to assure prosperity and social justice.

Paying for state services at first relied mostly on property taxes, which financed up to $80 \%$ of general state budgets, falling largely on real estate (Millis, 1908; Seligman, 1890). The Oregon State Hospital, built in Salem in 1881 to replace private contracting for care of the insane, was funded with a 1 mil (one-tenth of one percent, or onethousandth of a currency unit) addition to the property tax.

At Dr. Hawthorne's asylum in Portland, like other private asylums in the country, the low reimbursement for public charges was subsidized by private charges (Larsell, 1945; Dowbiggin, 1997). Public funding provided a broad base to make the institution possible, and wealthy donors and private patients kept it solvent. Adding to the asylum's purpose of mental health treatment, private demand also called for purely custodial care. Oregon recognized the need in 1908 by creating an independent home for the "incurably deficient" (insane and feeble-minded).

Managing the limits of public commitment was difficult in a social environment where need abounded. State investigators of the public hospital in 1928, for example, reported that counties were sending "senile dotards, paralytics, and other helpless cripples, who should be cared for by the county," while others were voluntarily committing themselves to obtain free medical care (Larsell, 1945). The state faced an institutional hazard, where people shaped public services to fit their needs, regardless of the explicit purpose of an institution. A similar situation occurs in current healthcare 
practice when the uninsured use emergency hospital treatment for primary care, and when prisons provide cells for mental-health patients who have nowhere else to go (e.g., Alakeson, Pande \& Ludwig, 2010). Cutting costs in one area obtrudes upon other areas, with potentially greater expense.

\section{Federal Share}

The imprint of national patronage has been evident from Oregon's earliest days. Westward pioneers were among the first public beneficiaries of free medical care sponsored by the national government, delivered at army forts, along with information and maps, service and supplies, rescue in distress, and road building (Unruh, 1979).

The first territorial government in Oregon also relied upon the national government when it organized local militias (Throckmorton, 1961; Winterbotham, 1994). Regular infusions of federal cash continued to pay and supply armies in Oregon, pay federal officials (such as judges, postmasters, surveyors, and Indian agents), fund transportation projects, and later, supplied pensions to the large number of Civil War veterans among the population (Skocpol, 1993) — all adding a significant spur to economic development and the money supply. These examples show that Oregon has depended on federal financial support from the beginning.

The presence of the national army and forts was welcomed by local residents as a source of income: living on the "government teat," as Oregon Indian war correspondent Joseph Wasson expressed it in 1867 (Cozzens, 2002, p. 55). Among many examples, the Rogue River War was reputedly fomented to bring army business to a depressed and 
isolated region in southern Oregon. Early settlers in Umatilla and Klamath also depended on feeding the army (Farnham, 1956; Josephy, 1965). These are examples of common rent-seeking behavior, as conceptualized in economics: seeking a padded market profit through government contract or rule (Gunning, 2003). The practice was endemic in Oregon as elsewhere.

For the early Rogue River military expenses, the national government eventually paid about half the charge (Winterbotham, 1994), setting a precedent that persists today: underfunding programs, partly for lack of adequate national funds, and also to draw local contributions and responsibility. The national government was unable to pay for all the road and water improvements and other solicitations for funds from across the country. Federal patronage always flowed steadily into Oregon, but local initiative was primarily responsible for funding public works.

Demand for public welfare became acute during the 1930s. In the 1937-38 biennial Oregon budget, the state relief effort took $50 \%$ of the general fund, involving assistance for poverty, old age, the blind, dependent children, child welfare, crippled children, special work projects, and nonresident care. Relief activities consumed triple the amount of the previous biennial budget, amounting to over $\$ 10$ million, including county contributions; the charge for nonresident care was 10 times greater. Attention to children was new in some areas, prompted by federal grants, but overall, in spite of active intervention by the national government, the federal share was only $30 \%$ of the total state relief budget, while the state covered $44 \%$, and counties $26 \%$ (in addition to local transportation and distribution responsibilities). 
As in earlier relief efforts, both social control and charity were factors in these welfare provisions. Oregon politicians, like those in other western states, generally opposed federal assistance programs (Patterson, 1969) as well as labor unions, public housing, and anything resembling socialism; but the extent of joblessness and misery in the 1930s demanded action and help from the federal government, not only to "avert suffering," according to Governor Julius Meier in a letter to President Herbert Hoover in 1932, but also to avoid "possible uprisings" (Robbins, 2002). Once again, desperation bred danger, and in this period a real threat of insurgency.

Two points are clear in these monumental relief efforts enacted at all levels of government during the depression years in the 1930s. First, the state responded with energy to the challenge, just as Oregon's earliest residents subscribed to relieve destitute emigrants and neighbors. Second, the system of state patronage was strained to the breaking point when private institutions in society failed. This experience could be viewed as a strong argument for better forethought through insurance, which is designed to diffuse heavy loss in crisis events.

\section{Public Administration}

Patronage. Early state relief activities operated as a system of patronage. An early example is observed in Washington County in 1857, when commissioners responded to a petition of concerned citizens to pay for the care of a resident "in a destitute condition on account of blindness, and another established resident with an insane wife and small children, along with seven others" (Bourke \& DeBats, 1995, p. 101). Local government 
devoted what resources it could and would to relief as charity, serving a minimal control function beneficial for certain affected individuals and society generally.

Personal patronage at all levels of government was a common expectation in $19^{\text {th }}$ century America, much as persons in England or elsewhere applied to parliament or a monarch for personal favor. The matter-of-fact nature of patronage is observed in the career of early Oregon booster Hall Kelley, who perpetually petitioned the national Congress in later life attempting to get a pension for his influential pamphlets that helped to spur settlement and secure Oregon for the United States (Powell, 1917). In another case, Congress in 1846 approved a special exemption for prosperous black settler George Washington Bush to own an otherwise forbidden land claim in Washington territory, following a petition by white friends (McLagan, 1980). In 1938, the Oregon state budget contained the same characteristic special provisions, including a pension "to compensate the parents of Floyd B. McMullen for his death April 25, 1935 while fighting the fire that destroyed the capitol."

Abuse of such special acts by local governments prompted many states to prohibit special legislation, which did not necessarily solve the problem or relieve the tendency toward patronage, as witnessed in the flourishing American tradition of city bosses and political machines that persist to the present (Binney, 1894; Johnston, 1982). Party machines that ruled notoriously in cities such as New York or Chicago were also prevalent in Oregon, stamping government with the familiar virtues and vices of personal patronage, spoils, and cronyism (MacColl, 1979, 1988). 
The old regime. Civil service and other reforms have improved administration and reduced fraud and corruption, but have done little to change the essential character of autocracy, involving patriarchy and patronage in the administration of bureaucracies, business organizations, associations, and families. Remarkably clear in the American social experiment is the solid persistence of ancient aristocratic ideas and forms nearly everywhere, apparently derived from the traditional old regime well-known in Europe (Hamerow, 1969; Levine, 1992; Mayer, 1981).

Although Americans opposed aristocracy and identified with the new liberal ideals of free enterprise, free markets, free labor-in short, liberty as John Stuart Mill finally put it — the old regime never disappeared. The revolutions of 1848 in Europe played out in America as fiercely, or worse if the Civil War is counted as a characteristic conflagration between the old regime and the new liberal state. Neither revolutions nor war resolved the conflict between the two political ideas, dichotomized in various labels, such as power vs. pluralism, hierarchy vs. liberty, or monopoly vs. free enterprise. The contradiction is embedded in American history, often associated with religious themes and factions (Smith, 1984). The autocratic ideal flourished in America both before and after the Civil War. Beside the notorious example of slavery, a patrician class of various propertied and commercial origins took root through the earliest Colonies and blossomed into the so-called mushroom aristocracy of the Jackson era, albeit without royal titles (Wilentz, 1990). These dignities were followed by captains of industry, princes of finance, and by the 1920s, Lords of Creation (Allen, 1935)—alongside a preponderance of petty local officials, bosses, grand dragons, and pervasive male hegemony dotted 
throughout society. Securing democratic institutions was a constant struggle, in many instances with doubtful results.

These patterns are evident in Oregon as well. Ancient forms of autocratic governance for private benefit persisted in America and trailed westward, and did not magically disappear with the founding constitution of the country. Monopoly, rent-seeking, and racketeering were common dynamics in the Oregon economy, along with free markets. (No short list of sources can adequately portray these large-scale phenomena; see references in this section and above, particularly under Eligibility and Public Finance, plus other examples in the West and Oregon in Billington \& Hardaway, 1998; Cohen, 2004; Prescott, 2007; Toy, 1986; Tyack, 1967.)

For Americans, however, autocracy was generally tempered by a widespread belief in free contracts, which was the essentially new element of social organization antithetical to the old regime. By the turn of the $20^{\text {th }}$ century, along with pervasive patriarchal authority and bossism, the development of voting and deliberative decisionmaking in a variety of assemblies, courts, corporate boards, unions, and committees put a definite liberal stamp on American government, business, and society that was distinct from Europe or anywhere else. The U.S. Constitution provided the model. In Oregon, efforts to avoid one-man rule were evident in the way county governments were established (e.g., Bourke \& DeBats, 1995), and are illustrated in the commission form of government that still operates in the city of Portland.

Public contracts. Manipulation of public contracts for particular private interests (rent-seeking) was exceedingly common in American and Oregon local governments 
(e.g., Lau, 2004). In the 1880s, the example of exorbitant charges in corrupt private contracts for New York City's insane asylum influenced Oregon to adopt a model of bureaucratic administration for its asylum (Larsell, 1945). Whereas Dr. Hawthorne's private asylum in Portland was commendable and favorably reviewed by Dorothea Dix when she visited in 1869 (Cutler, 2002), later public institutions for inmates tended, through underfunding, to degenerate into miserable dens (Katz, 1995; Opdycke, 1999). Gradually, the bureaucratic administration of asylums gave way to alternative types of location and services.

This example of reviving the use of public contracting, or planned markets, in spite of corruption and other problems of supervision, reflects the advantages: providing ready access to diverse facilities where no public capacity exists, and avenues for patronage from private donors to support public charges (Hasenfeld, 1985). The cycle from contract to bureaucracy and back again also illustrates the uncertain advantage of the one type of administration over the other. Private contracts may be more efficient in certain instances, or less efficient, depending on the service and contract terms, transaction costs, and enforcement (Hansen, 2003; Saltman \& Otter, 1995; Smith, 1993; Snyder, 1999). A meta-analysis of public contracts from several countries confirmed the point that no systematic advantage favors contracted services over bureaucracy (Hodge, 1999).

Negative monopolies. In both Europe and America, from about 1880-1920, efforts to curb the despotism and exploitation of private business, and to control monopoly and fraud, led local governments to actively regulate markets in business, finance, labor, and 
natural resource conservation (Columbia Law Review, 1961; Dykstra, 1913; Hansen \& Law, 2006; Keller, 1990; Pinchot, 1932; Urofsky, 1985). States in the USA began to regulate corporate charters in the 1850s: setting maximum capital stock, limits on debt, composition of boards of directors, and open books for shareholders; but failed to implement administrative supervision to be sure the laws were effective (Nash, 1964). Characteristic corporation laws were enacted in Oregon in 1862.

Pressure for more effective public administration of securities regulation and protection from monopoly arose from farmers, aroused over transportation rates (Nash, 1964). Progressive-era reforms concentrated on establishing public administration to enforce state business regulations. Monopoly and fraud in public contracts were ameliorated, if not eliminated, by administrative rules for open bidding, arms-length dealing, disclosure of conflicts of interest, constitution of boards, and so on (Alexander, Weiner \& Bogue, 2001; Coglianese \& Lazer, 2003).

In California, after 1900, officials at the State Mining Bureau, primarily a research agency, used information as a regulatory tool (Nash, 1964). The bureau attempted to curb fraudulent corporations by disseminating accurate information, publicizing swindles in the press, and keeping a file of complaints_-similar to practices in the Oregon Insurance Division today. Enforcement currently involves licensing, revocation of permits, publicity, investigation, fines, and criminal indictment (Oregon Insurance Division, 2010b).

Large firms such as Oregon Steam Navigation Company, the early transportation giant on the Columbia River that enriched Oregon's first bankers, could enforce 
monopoly business by rate wars without rent protection from the state, and particularly, without interference from the state (MacColl, 1988; Miller, 1958); but other smaller firms in early Oregon, typically in transportation, did rely on government to protect monopoly interests. The attitude of firms toward government intervention to protect monopoly, or protect against monopoly, might change according to the situation. The story of tram monopolists strenuously urging regulation of jitney taxis when they appeared in Portland in the 1910s is representative (Johnston, 1998). Vernon Parrington (1930) distinguished two alternating positions in the politics of the Progressive Era: government was deemed good or bad, depending on whom it helped.

Positive monopolies. The evident public willingness to protect monopolies for certain firms in early Oregon indicates not just signs of corruption, which abound, but also a public will to master transportation problems. Rent protection related to ferries was one of the first acts of local Oregon governments, as observed in 1851 in Umpqua County (now defunct; Winterbotham, 1994). Similar ferry regulations were adopted in California in 1850, and are regarded there as the beginning of public utility regulation (Cassidy, 1956).

Licensing ferry operators and setting rates served to protect a monopoly for a lucrative business, but also served a genuine public interest. Westward pioneers had witnessed the pervasive violence and sabotage among ferry operators along the trek, and were well prepared to accept that monopoly power was a better alternative than a free market (Unruh, 1979). Physicians favored licensing later, beginning in Oregon in 1889, for similar reasons: to control harmful medical practice as well as ensure their own 
monopoly on medical authority (Atwood, 1985; Starr, 1982). Various other established businesses and professionals favored regulation and certification to protect their services.

Apart from mere rent seeking, such publicly authorized monopolies remain defensible as a way to assure the provision of a good in areas where failure is not an acceptable option. An early example of an expensive, but high-quality public utility is observed in the pilot and towing monopoly enjoyed by Capt. George Flavel at the mouth of the Columbia River in the 1850s, licensed and subsidized by the state (Miller, 1958).

\section{The Idea of Insurance}

Mobility, money, and advancing urbanization, all characteristic of frontier America, helped to detach individuals from the traditional, territorial social networks of the old regime. Voluntary association was the central principle of the new liberal state, and Americans embraced it. Along with churches, business contracts, and political parties, voluntary fraternal associations flourished as mass organizations from about 1850, and more so following the Civil War (Crowley \& Skocpol, 2001; Meyer, 1901). Associations were established for a variety of reasons, but assuring self-reliance by reducing the risks of poverty, unemployment, illness, or death was a central function.

The earliest fraternal associations found mentioned in Oregon were the Masons and the International Order of Odd Fellows, both well established elsewhere and widespread. Blacks and other ethnic groups established associations dedicated to their own communities soon after arrival in Oregon, as illustrated by the Finnish Brotherhood Lodge established in Astoria in 1886, where "many young men joined it because they had 
no or few relatives here, and the lodge helped them in case of illness and gave them a feeling of security" (Miller, 1958; Palmer, 1944).

By 1900, membership in fraternal associations comprised about 5 million Americans, or 1 in 3 persons (Meyer, 1901). Half of the associations provided relief to members, often on a very ambitious scale. Originally, the system of relief followed the ancient tradition of patronage, with a fund set aside or subscriptions solicited from members as the need arose. A growing number of failures and substantial increases in dues, however, eventually drew fraternal associations to adopt actuarial principles pioneered by life insurance companies.

By 1910, although the prevalence of commercial insurance finally overtook association benefits, an estimated 8 million Americans were still explicitly covered for death benefits through associations. Such insurance contracts in associations became a separate category from relief efforts. Although initially reluctant to interfere with association affairs, states gradually began to regulate association financial solvency in the same way as regular insurance companies. Fraternal associations are still recognized in Oregon insurance codes as a type of risk-bearing organization.

As commercial life insurance became reliable and began to grow rapidly from about 1870, a corollary market for burial insurance spread among industrial workers (Whaples \& Buffum, 1991). High mortality rates made burial and life insurance understandable priorities. An effort in the 1840 s to provide commercial sickness insurance failed, and was only revived on a small scale in the 1890s (Henderson, 1907). 
Chapter 2. Civic Capacity in Oregon. The Idea of Insurance 36

The system of Workers' Compensation, established in Oregon in 1914, was originally designed primarily as a system of voluntary insurance for employers against tort cases (Weinstein, 1968), but it helped promote the idea of insurance for workers' medical costs. Yet, no state or national proposals for publicly funded sickness insurance succeeded; employers, insurers, and associations alike found sickness insurance difficult to successfully implement. Whereas insurers wished to control the triggers and terms of coverage to specific conditions for set periods, physicians wished to provide whatever was medically necessary by their own judgment (Henderson, 1907; Starr, 1982; Wollner \& Dodds, 2000). Supported by the American Medical Association, physicians resisted prepaid medical practice, which typically included fee schedules and utilization review by a corporate insurer.

Nevertheless, in the early $20^{\text {th }}$ century, once the idea of insurance was firmly established in life insurance, fraternal associations, and workers' accident insurance-and medical care was improving in quality — a type of medical insurance proliferated in Oregon under the name of hospital associations. The associations sold a type of indemnity medical insurance, mostly to logging companies, for a flat fee per worker (Williams, 1932; Wollner \& Dodds, 2000). Workers could rely on the insurance for core services, but remained responsible for extra services and charges. Only a small number of the population was covered, and antagonistic relations with physicians remained unresolved.

In 1942, an alternative solution was implemented in Oregon Physician Services, a physician-run insurer that later joined Blue Shield when it organized nationally in 1946 
(Wollner \& Dodds, 2000). California provided the model in 1939 as one of the first plans of this type in the nation. Insurance in this case was administered without fee schedules, utilization review, or balance billing of patients. Risk was passed downstream to providers by compressing prices for services as funds were depleted.

During the same period, and particularly after 1945, Kaiser Permanente established another model of health insurance on the West Coast, involving a combination of insurance and group-practice medical services under one organization (Hendricks, 1991). Powerful Henry Kaiser managed to overcome the opposition of the AMA to the "corporate practice of medicine" in the new organization, but physicians generally continued to oppose it. Organized labor, however, supported the Kaiser plan and assured its survival.

Notable in this development is the transformation of welfare from a system of patronage to a system of contracted rights and obligations. This development is observed most clearly in the evolution of benefits offered by fraternal associations, where the idea of insurance replaced the traditional ties of social dependence. None of this was yet social insurance, involving a "compulsory" social contract; legislators and courts began to regulate insurance, but showed a marked reluctance to intrude on the private welfare activities of individuals and organizations (Keller, 1963).

\section{Social Iinsurance}

All of the original health benefit plans were marketed to employers, following the model of industrial insurance (or burial insurance) successfully marketed earlier by life 
insurers. Once the idea of health insurance appeared practical, government-sponsored social insurance emerged to expand health coverage to vulnerable segments of the population that remained unprotected. Many of the earliest examples of social insurance, from about 1880 to 1940 , occurred to calm social unrest, particularly in response to workers and organized labor unions—as observed in Germany (Stone, 1980) and in the USA (Klein, 2000; Weinstein, 1968). A social sense for solidarity, as developed in European countries, may be a precondition (Horstman, 2001; Ullrich, 2002). Public motives appear to involve a complex mixture of constitutional obligation to promote the general welfare, compassion for those in need, practical concerns for social control, avoiding the cost of providing welfare services for those unable to support themselves, and efforts to build human capital to promote general prosperity.

In the USA, following the passage of Social Security in 1935 (Ikenberry \& Skocpol, 1987), the idea of security became a prominent theme for labor unions, commercial insurers, and large employers, all endeavoring to take the initiative to satisfy and control the workplace (Klein, 2000). Among the primary motives attributed to large employers, benefits were provided to increase order and avoid revolution (anti-socialism), to better manage labor relations (anti-unionism), and preempt a government system of benefits and taxation (anti-statism). This development in the USA and worldwide has been called welfare capitalism (Brandes, 1976). By a succession of supportive measures in the 1940s and 1950s, the U.S. federal government encouraged employment-based health insurance (Dobbin, 1992). Commercial insurance carriers responded with types of indemnity insurance, designed according to methods in other insurance domains, and 
dominated the market, gradually replacing most of the earlier types of prepaid benefit plans.

A preference for private solutions to public welfare did give way in a few instances to repeated public demands for security, and state-sponsored insurance systems established worker injury benefits, unemployment insurance, and civil service pensions (Beveridge, 1943; Conover, 1921). In response to national legislation, Oregon instituted state unemployment insurance in 1935 (Oregon Employment Department, 2009). In 1965, the Oregon legislature broadened the Workers' Compensation law to function more like social insurance (Oregon DCBS, n.d.). Also in 1965, at the national level, Medicare and Medicaid began to cover the nonworking population and made a substantial contribution to the welfare of older adults (Myles, 1989; Stevens, 1996). The sum of these social welfare policies placed the USA not so far behind policy developments in other developed countries. Many of them occurred only after bitter conflicts, but the general trend was the same as elsewhere. In view of this cumulative result, the idea of American exceptionalism, arguing that socialism “didn't happen here” (Lipset \& Marks, 2000) appears to be overstated.

\section{Model Diffusion}

The power of prior models is especially relevant to state policies related to health insurance. Clear and explicit evaluative reports and model legislation contribute significantly to the policy process in general (Brown \& Stewart, 1993; Shulock, 1999; Wilensky, 1997; Weiss, 1977), as observed in several examples in the previous sections. 
For health insurance reforms, models might figure as an essential feature. In one notable example, in 1964, a Canadian royal commission studying health policy reforms made a surprising recommendation for universal health insurance in the country-and it was adopted (Neuschler, 1990).

Features of the Oregon Health Plan also originated in models; a Governor's Commission on Health Care (1988) submitted a report, Improving access to health care for all Oregonians, that recommended the very system Oregon achieved by 1995: (a) expanded Medicaid coverage to $100 \%$ of the federal poverty level (FPL), (b) two public insurance pools for high-risk groups (established 1987, funded 1989), and (c) an incremental policy for expanding "equitable access without excessive burdens." This plan, too, evolved from a prior model, called Health Access America, developed by the American Medical Association (AMA) in 1982-87 (Todd, Seekins, Keichbaum, \& Harvey, 1991). Local medical associations carried the agenda to the states and became central players in forming coalitions, clearly so in Oregon and California (Senate Special Committee on OHP, 1993; Oliver \& Dowell, 1994).

The AMA model also included components that later failed, notably the proposed employer mandate. Once the employer mandate was definitely abandoned in Oregon in 1995, the package of health insurance reforms adopted in the same session was also the result of a model plan, drafted in 1991 by public regulators in the National Association of Insurance Commissioners (NAIC) together with private insurers in the Health Insurance Association of America (HIAA; Hall, 1992). NAIC traditionally employs model 
legislation to guide policy enactment in all the independent state legislatures where insurance is regulated (Cheit, 1993; Pomeroy \& Gates, 2000).

Nearly every state adopted a similar package of reforms by 1995, including features of portability, guaranteed issue, and underwriting restrictions and rate bands to limit price variation and promote community rating ${ }^{5}$ (Oliver \& Fiedler, 1997). In 1996, the national Health Insurance Portability and Accountability Act (HIPAA) extended the same insurance reforms to all carriers, including self-insured employee benefit plans exempt from state regulation under the Employee Retirement Income Security Act (ERISA) of 1974. HIPAA also carried significant provisions for electronic billing and protection of privacy, but basically reflected an agenda already confirmed in the model implemented in the states. Throughout this period of healthcare reform, state and national governments as well as a number of private interest groups developed models that overlapped, built on each other, and sometimes competed for attention.

${ }^{5}$ Definitions for these terms may be helpful.

- Portability: the option for an individual to retain insurance or pension benefits after a change in employment or other status.

- Guaranteed issue: requirement for an insurance carrier to accept all who apply for coverage in a designated market.

- Underwriting restrictions: typically, defines the information a carrier may use to determine price and eligibility for insurance coverage.

- Rate bands: restrictions on premium variation for persons in different risk categories, usually due to health status or group size, expressed as a percentage, plus or minus, from an index rate.

- Community rating: all individuals or defined groups in a market pay the same premium for equivalent benefits, regardless of health status or other risk factors; partial community rating, as in Oregon, may allow limited variation according to a small, defined set of risk factors. 


\section{The Oregon Plan}

In 1989, then Oregon Senate President John Kitzhaber became a vocal advocate for a "menu" of healthcare services to help control costs while expanding access to low-income health insurance through the Oregon Health Plan (Mahar, 1993). The resulting Prioritized List of Health Services was built on the model used by Medicare since 1983, using diagnostic groups to administer set fees for services. Ranking the list in a transparent public process was the unique aspect of the Oregon plan, which sparked the imagination of policy analysts around the world, considering the impact the list might have on managing and possibly rationing health care (Garland, 1992; Holm, 1998; Jennings, 1992). Kitzhaber emphasized the intention to use the ranked services to exclude lines of coverage if the budget proved inadequate, rather than cutting eligibility for individuals.

Oregon is recognized as a world leader in prioritizing health services to establish coverage limits according to cost effectiveness. An early commentary on Oregon's priority list (Hadorn, 1996), however, observed that the development process for the ranked condition-treatment pairs involved politics as well as science; difficult evaluations of efficiency according to surveys of public values were finally decided by decisions of face validity by Health Services Commission board members, with no explicit reference to economic formulas for cost effectiveness. The Oregon Plan was often criticized for this lapse of scientific rigor, but this characteristic turned out to be a defining factor elsewhere, too. Oregon's priority list has been adapted as a model in other countries, and a similar combination of scientific and political values has been a consistent feature in 
evaluating health treatments (Ettelt, Nolte, Thomson \& Mays, 2007). In these benefit plans, economic assessment is distinguished from policy appraisals. Benefits related to medical procedures were more sensitive to politics, whereas pharmacy benefits were determined more directly from the scientific results of comparison and cost assessments.

Since 1993, the original Prioritized List of Health Services has been regularly updated, and HSC continues to refine its methods and the shape of the list to help define OHP benefit plans (Oregon HSC, 2011). In a 2003 law, the Oregon legislature revitalized the HSC mission to apply comparative and cost-effectiveness analyses in ranking the condition-treatment pairs. Yet, for all the attention, the list was only used as intended in an isolated instance, when deep cuts to OHP passed by the 2003 legislature dropped 30 lines of coverage. The implemented change in following years was revised upward in negotiation with the federal government, which must approve coverage changes (Office of Medical Assistance Programs, 2006). The most substantial OHP cuts occurred by reducing eligibility. Lack of financing was too severe to honor the original plan to insure all individuals with incomes up to $100 \%$ of the federal poverty level regardless of shifts in the level of coverage. Consequently, in practice, Oregon's priority list has operated chiefly as a classification system, like Medicare's DRGs or other fee schedules, to define coverage and assign prices to expected categories of service (DiPrete \& Coffman, 2007). The ambitious Oregon plan to ration coverage, not people, failed to materialize (Jacobs, Marmor, Oberlander, 1999; Leichter, 1999). 


\section{Federal Patronage}

In the mid-1980s, state Medicaid programs covered the population at an average $50 \%$ of the federal poverty level (FPL); Oregon Medicaid coverage reached 52\% FPL, including about one-third of the population below the poverty line (U.S. General Accounting Office, 1987). No state covered all of the eligible population up to $100 \%$ FPL, but several states, more so than Oregon, covered people in additional medically needy categories above the poverty line (such as pregnant women and children). In this context, Oregon's commitment to cover persons with incomes up to $100 \%$ FPL with the launch of the Oregon Health Plan in 1989 was ambitious.

The plan was heavily dependent on federal funds and makeshift resources. OHP revenue sources in 1999 characterize the situation as it was established from the beginning (Becky Frederick, personal communication, Aug. 30, 2000).

$\begin{array}{lrr}\text { Federal funds }= & \$ 1,336.9 \mathrm{mil} & (61 \%) \\ \text { Oregon General Fund }= & 563.4 \mathrm{mil} & (25 \%) \\ \text { Tobacco tax }(+ \text { settlement })= & 191.8 \mathrm{mil} & (9 \%) \\ \text { Other revenues }= & 115.8 \mathrm{mil} & (5 \%)\end{array}$

Total $=\quad \$ 2,207.9$ mil $\quad(100 \%)$

These figures, at the height of OHP's prosperity, raise the question to what degree Oregonians were ever really committed to the Oregon Health Plan or further reforms to expand social health insurance. The federal share in the Oregon Health Plan was $61 \%$ of total revenues, while the Oregon General Fund provided 25\%. Currently, the proportion is much reduced, with $13 \%$ of Medicaid spending in Oregon paid from the General Fund (KFF, 2011). This proportion places Oregon in a cluster of states at the low end of 
broad-based General Fund spending on Medicaid, along with Idaho and Californiaclearly separate from the states with the highest contributions (Ohio, 36\%; New Hampshire, 31\%; Massachusetts, 28\%), but above the lowest cluster (Alabama, 3\%; Utah, 6\%; Mississippi, 7\%).

Similarly, the general Oregon Human Resources budget over three bienniums (1997-2001), including OHP, shows the average federal share of total revenues was 58\%, and near $85 \%$ in major health and senior divisions. The budget indicates Oregon's commitment to human resources has been essentially taken over by federal assistance.

In the American federal system, state welfare financing often relies on higher levels of government for local needs (Trattner, 1999). Population mobility, vagrancy, and unequal distribution of resources have sometimes imposed unsustainable burdens on local jurisdictions. Although issues of safety and security have traditionally been left to the states, the dominance of national funding in current Oregon social welfare activities raises the question if Oregon is capable of conceiving or implementing a state-sponsored social contract for universal health insurance or general welfare at all. Richard Musgrave (1999) provides a concise statement on this issue:

In practice, decentralized redistribution policy can only operate within narrow limits. Any jurisdiction which unilaterally imposes higher taxes at the upper end of the scale invites the loss of mobile resources, including both capital and high-income residents. Conversely, jurisdictions which unilaterally offer greater benefits to the poor will attract outsiders to share in the benefits. Movement between jurisdictions now assumes a perverse function. For this reason, distribution policy must be a matter of national concern (p 67). 
Chapter 2. Civic Capacity in Oregon. Model Diffusion 46

\section{Public Education as a Model Social Contract}

In 2004, as the first recipient of the eponymous Kitzhaber Chair on Health Care Policy created by the Foundation for Medical Excellence, John Kitzhaber raised the original vision of the Oregon Health Plan in a lecture tour through the state, titled On the Road to Revolution (Hammond, 2004). The message reiterated his longstanding view that we are paying for everyone's health care anyway, and we could do it much more effectively by assuring coverage with an explicit, basic package of benefits for all. In this renewed charge at the issue of universal health insurance, Kitzhaber used public education as a model for reform, applying the principle that everyone pays for everyone's kids, and no one is excluded.

This ideal model of public education illustrates two critical factors in social commitment—known in Europe as social solidarity (Maarse \& Paulus, 2003)—that can be applied to universal health insurance: (a) risk solidarity, pooling the whole population for both finance and delivery of a good, regardless of different levels of need, and (b) income solidarity, where financial contributions are based on ability to pay. The model elements only approximate actual practice related to public schools in Oregon.

Subsidizing and supervising public schools was among the earliest acts of the Oregon territorial legislature, funded mostly by sales of federal land (Heider \& Dietz, 1995; Tyack \& James, 1986). Primary support, however, derived from local communities, which organized and funded public schools with a property tax as elsewhere in America. A percentage contribution rate naturally increased the share contributed by those with 
more resources. To confirm accountability for the social contract, county governments were known to protect the school tax in an "irreducible" trust fund, which could not be redirected by government officials (Winterbotham, 1994).

Solidarity was opposed by those who favored using individual resources or disagreed with standardized materials and procedures thrust on local jurisdictions by state or federal officials (Lau, 2004). A system of mandatory public education was strongly contested, until the idea was validated by a Supreme Court decision that encouraged the model to diffuse through the states between 1870 and 1918 (Richardson, 1980; Tyack \& James, 1986). Oregon established its minimum-attendance law in 1889, based on a model from Iowa, adopted from Michigan, in turn adopted from northeastern states.

In the early 1920s, solidarity collided with individual choice in a famous case in Oregon that went to the Supreme Court. Oregon voters had approved an initiative to make public education universal, expressing a desire to turn out a uniform stock of good English-speaking, and basically Christian Protestant Americans (Dumenil, 1990; Holsinger, 1968; O'Brien, 1961; Tyack, 1968). Well-established parochial schools would have been closed down. The Supreme Court ruled the state law unconstitutional for preempting the original right of the family to make its own choices in how to achieve childhood education.

Income solidarity at a local level was also insecure. In finance, a variety of sources funded schools in Oregon beside taxation, including religious sponsors, private benefactors, federal land grants, and state subsidies. As wealth accumulated in capital by the end of the $19^{\text {th }}$ century, the property tax itself was contested as an inequitable method 
of finance. The first property tax revolt in Oregon in 1906 installed a 6\% cap to limit a "burden on real estate entirely disproportionate to its value or income" (City Club of Portland, 2002, p. 19). Yet, the state approved an alternative income tax regime only in 1929 , over 20 years later, after voters rejected it four times through the 1920 s.

Subsequently, the state share of school finance increased to about $30 \%$ of operating expenditures, until 1990, when another property tax limit was passed (Measure 5) and state revenues replaced local resources. The state currently pays about $70 \%$ of school operating expenditures (Legislative Revenue Office, 2004). The remainder is covered mostly by property taxes, and includes smaller shares from the state lottery, federal funds, and other sources.

In this development, it appears that the original features of social solidarity in public education have diminished, and even in the earliest phases, displayed diversity, disparities, and opposition. As with public welfare, a higher level of government gradually took precedence, though local interests continued to operate. The case serves as an example for a social contract, and illustrates characteristic issues that may operate as well in a model of universal health insurance. 


\section{Chapter 3}

Models of Universal Health Insurance

At the conclusion of the period of energetic state healthcare reform, 1987-1994, the newly formed Oregon Health Plan Administrator (now evolved into Oregon Health Policy and Research), reported to the legislature on alternatives to a measure proposed for an employer mandate, and declared at the outset: "Maintaining the status quo is not an option" (OHP Administrator, 1995a, p.9). Yet, no solution emerged.

Currently, as then, many state leaders are advocating universal health insurance. Disagreement persists, however, over what a feasible model of universal health insurance should look like. Alternatives appear about the same as those identified earlier (OHP Administrator, 1995a, 1995b, 1994): (a) voluntary incrementalism, (b) employer mandate, (c) individual mandate, (d) mixed mandate, and (e) single-payer plan. Discussing the models introduces critical language in insurance reform that policy actors are presently using and developing.

\section{Voluntary Incrementalism}

Voluntary incremental reform was rejected in the OHP Administrator report (1995a) as inadequate for reaching universal health insurance, or managing to control costs or quality of care. Observations by Thomas Oliver (2000, 1999), among many 
Chapter 3. Models of Universal Health Insurance. Voluntary Incrementalism 50

others, and experiences in Oregon and other states since support the same conclusion: incremental reforms have done virtually nothing toward the problem of uninsurance.

A voluntary "income approach is simpler to administer and easier to abandon" (Wildavsky, 1977, p. 117), but subsequent analysis indicates a mandate is necessary to achieve a sustainable system of universal health insurance. The necessity of including everyone is quickly illustrated in the distribution of personal healthcare expenditures (Figure 1). Supplying coverage for the lowest-spending $90 \%$ of the population, or even $98 \%$, leave out the greatest costs (Krueger \& Reinhardt, 1994). A similar pattern is found in subgroups, such as Medicare (MedPAC, 2003).

- The top-spending $1 \%$ of the population use $27 \%$ of healthcare resources.

- The top-spending $5 \%$ use $45 \%$ of healthcare resources.

- The lowest-spending $90 \%$ use less than or equal to their share of healthcare resources.

- The lowest-spending $50 \%$ use $3 \%$ of healthcare resources.

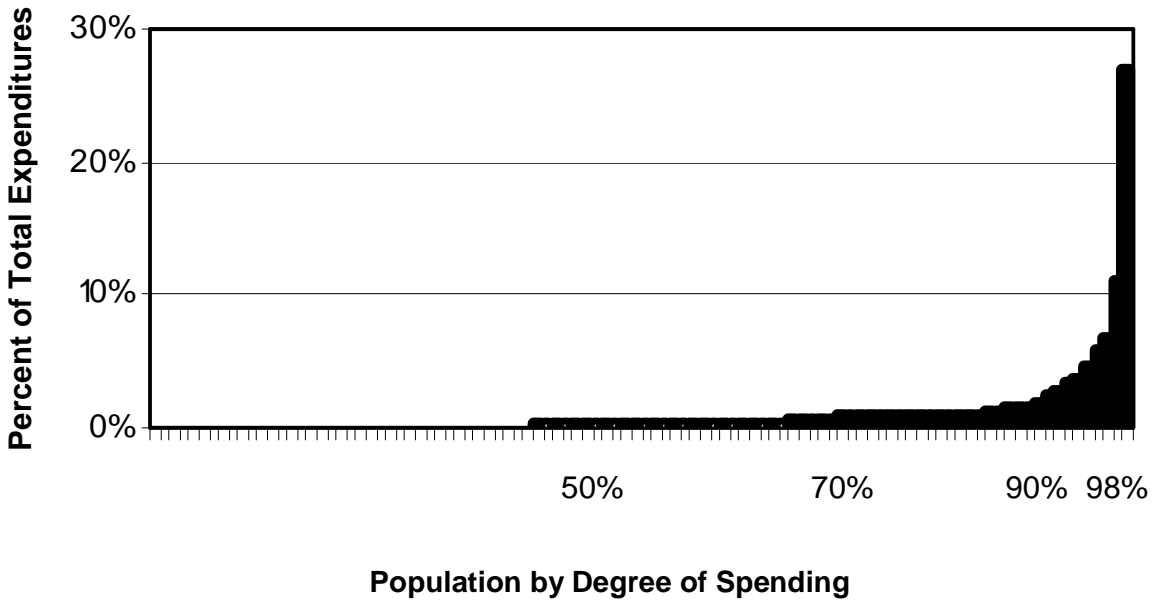

Source: Berk \& Monheit, 2001

Figure 1. Distribution of Personal Healthcare Expenditures, 1996 
The sections below describe voluntary approaches to expand access to health insurance, involving (a) public welfare, (b) public high-risk pools, (c) public subsidies, (d) commercial markets, and (e) charity.

Public Welfare

The basic plank in the Oregon Health Plan to raise Medicaid eligibility to $100 \%$ of the federal poverty level was a considerable ambition compared to past performance in Oregon and most other states. State coverage typically reached 50\% FPL or less (Bovbjerg \& Holahan, 1982), though a few states covered about 90\% of their eligible populations for Medicaid.

An impetus to expand Medicaid eligibility affected nearly all states through the 1990s. Oregon's federally shared Family Health Insurance Assistance Program (FHIAP) offered subsidies to children and pregnant women up to $170 \%$ FPL. Even as the economy weakened by 2002, and the rate of healthcare cost increases multiplied 2-3 times over the rate of inflation (Bruen \& Holahan, 2002; Smith, Ramesh, Gifford \& Ellis, 2003), states continued to enact legislation to expand eligibility (Johnson, 2003). The expansive, upbeat tone in OHP quarterly reports in the midst of cutbacks reflected the trend, until early 2003, when drastic cuts were announced (Oberlander, 2006; OHPR, 2003, 2005a, 2005b). Subsequent studies of OHP revealed the following conditions (Carlson \& Wright, 2005; Mann \& Artiga, 2004; Wright, Carlson, Allen, Holmgren \& Rustvold, 2010).

- About three-fourths of OHP beneficiaries ( 80,000 people) disenrolled by 2005 , due to higher premiums and copays. 
- Cuts took effect, while most proposed coverage expansions were not implemented.

- Eligibility for OHP Plus - a category not subject to premiums and only nominal copayments - covered up to $185 \%$ FPL for children and pregnant women, 74\% FPL for the elderly and disabled, 52\% FPL for parents, and $43 \%$ FPL for other adults.

- Uninsurance in Oregon declined from $14 \%$ of the population in the early 1990 s, to a low of about $11 \%$ through OHP expansions, before rebounding to about $17 \%$ of the population in 2004 .

Several studies in Oregon have since documented the effects of disenrollment, including worsening health conditions (Carlson, Devoe \& Wright, 2006) and increased uncompensated care in hospital emergency departments (Lowe, Fu \& Gallia, 2010; Lowe et al., 2006); increased costs, due to more intensive care, which offset all or nearly all of the observed savings obtained through the cuts (McConnell, Wallace, Gallia \& Smith, 2008; Wallace, McConnell, Gallia \& Smith, 2008); and increased enrollment burden (Allen, Balcker, Finkelstein, Taubman \& Wright, 2010) and confusion among those still eligible for coverage, which resulted in under-enrollment, particularly for children (DeVoe, Ray \& Graham, 2011).

Among the more successful states to increase insurance access, Minnesota registered up to $95 \%$ coverage, achieved by high employer-based coverage, public reinsurance pools, and Medicaid programs running up to 300\% FPL (Chollet \& Achman, 2003). Nevertheless, shifting eligibility requirements left gap groups, and a low, but significant measure of uncompensated care borne by hospitals (Minnesota Department of Health, 1999). As a welfare program subject to the exigencies of federal sharing and 
fluctuating state budgets, Medicaid does not provide individuals, or providers, a secure insurance contract.

\section{Public High-Risk Pools}

The Oregon Health Plan began in 1989 with the implementation of a public high-risk pool (administered by the Oregon Medical Insurance Pool) to subsidize insurance for individuals rejected in the commercial market; and a small-business pool, administered by the Insurance Pool Governing Board, to provide lower large-group premiums to small businesses. Effects on the problem of uninsurance have been modest. Market penetration is notoriously low for voluntary pools (Long \& Marquis, 1993).

Oregon's high-risk pool in 2011 covered nearly 14,000 enrollees (OMIP, 2011), apparently reaching a maximum capacity that has remained fairly constant since 2006. Individuals in the high-risk pool pay $60 \%$ of premium costs; an assessment on commercial insurers, based on each carrier's number of private covered lives, pays the remaining $40 \%$. By this arrangement, an incentive is generated for employers to selfinsure and avoid the assessment (Kenkel, 1991). As the number of lives in the pool rises in proportion to the commercially insured population, the limited capacity of the premium assessment eventually pressures the state to redefine terms or reduce eligibility.

In theory, high-risk pools are a fine corollary to failures in the individual market, but in practice the pools turn out to be underfunded and restrictive (Achman \& Chollet, 2001; Chollet, 2002). Public funds tend to accumulate a growing share of the worst risks among the whole population. In 2003, Oregon legislation added flexibility to accepting 
applicants in the commercial market in an attempt to improve the acceptance rate and reduce stress on the state's high-risk pool.

\section{Public Subsidies}

All but one of the seven coverage proposals by early 2004 presidential candidates involved tax credits (Collins, Davis \& Lambrew, 2003). The administration's proposal for a maximum $\$ 1,000$ refundable tax credit to invest in a personal health savings account was estimated to add coverage for 1.8 million people, or less than $10 \%$ of the uninsured (Gruber, 2004).

Separately, an analysis of proposals to subsidize small employers to enhance offer rates to employees showed similar results (Hadley \& Reschovsky, 2002). Facing a very low elasticity of demand, subsidies must be increasingly large to produce even small marginal effects. This analysis concluded that "targeting subsidies at small establishments appears to be a blunt and inefficient policy instrument" (p. 134).

A similar conclusion is drawn from an analysis of voluntary participation in a publicly sponsored health insurance program, even with a minimum monthly premium as low as $\$ 10$ (Long \& Marquis, 2002). Another analysis found that tax credits benefit the young and healthy, leaving others with substantial and unaffordable costs (Gabel, Dhont \& Pickreign, 2002). In spite of continuing popularity among policymakers, and some instances of positive results, subsidies have generally not proven to be effective as a policy tool to increase health insurance coverage. 


\section{Commercial Markets}

In a free market, pricing of insurance favors those who have lower risks. Risk selection by insurers is a longstanding, traditional practice, originally instituted in health insurance to assure the public of financial solvency (Horstman, 2001). Medical testing and underwriting have been common to improve the insurer's knowledge of the health condition of the insured. The insurer then applies an actuarially fair premium to each individual according to the level of risk. This kind of system tends to insure those with low risks, who can afford the premiums, and excludes those with high risks, whose premiums are largely unaffordable.

As noted in the previous section, state options to provide coverage for high-risk individuals, segmented from the remainder of the insurance market, are expensive and difficult to sustain. This produces an incentive to expand the commercial insurance market to relieve the pressure on the state budget. Private-market expansion involves regulation to require inclusive policies and pooling over broader segments of the population, applying concepts of guaranteed issue and community rating. ${ }^{6}$ A package of insurance reforms passed in Oregon and most other states in 1995 (see Chapter 2. Model Diffusion) established underwriting and premium restrictions, portability, and elements of guaranteed issue and community rating that helped add value in health security for

\footnotetext{
${ }^{6}$ See definitions for these terms in note \#5 (p. 41). The concepts of guaranteed issue and community rating are common in health policy. The discussion here follows accounts in Nichols (2000) and Oliver \& Fiedler (1997), and information from commercial health insurance contracts. For this study, insurance contracts were examined from CareOregon as publicly available documents, and from Providence Health Plan and Regence Blue Cross Blue Shield, all from 2002, available through the Washington State Insurance Division. The latter two firms are Oregon insurers that also do business in Washington state. Private contracts are not publicly available in Oregon.
} 
individuals. More directly, the reforms added a level of support for established insurers to stabilize the market and reduce fraud and rogue competition (Hall, 1992).

In Oregon, the regulations (ORS 743) helped higher-risk individuals in groups obtain and retain employment-based coverage in pools with a community rate applied equally to all, regardless of individual health status. Underwriting for groups is not allowed to examine individual health characteristics, but may examine the claims history of the group, which allows a close approximation of potential costs (Wrightson, 2002). Extra flexibility is allowed in the case of small groups of 2-50 persons, where carriers may evaluate applicants by location, age, and family composition, and segment workers into different plans as long as individual health status is not a consideration. As a check, carriers must post average premium rates for each area served, keep premium offers within rate bands, and offer coverage equally to all small businesses in the region. Under these conditions, insurance contracts may themselves require a level of guaranteed issue in group markets to ensure participation by low-risk individuals who might otherwise drop out and skew the risk pool unfavorably.

Adverse selection. Regulated underwriting and rate bands provide sufficient flexibility for insurers to continue to select risks and maintain viability, involving a variety of subtle mechanisms in advertising, selective market entry, coverage options attractive to those in good health, and so on (Hall, 2000a). Adverse selection—being left with high risks in an insurance pool after lower risks have been drawn away by competitors-is an enduring concern for insurers. Even small differences in rates or coverage can cause an insurer to either reduce coverage to match a competitor, or retreat. A clear example of this 
phenomenon was observed in the changes in the market for Medicare managed care contracts after 1997. When certain carriers in a market reduced coverage for prescription drugs, the threat of adverse selection forced all carriers to restabilize benefits at the new reduced level, or simply exit the market (Biles, Dallek \& Dennington, 2002). The example illustrates how insurers tend to be uncomfortable standing out as a payer for expensive treatments that attract high risks. Market forces in health insurance do not necessarily reward quality, innovation, and better value as is commonly understood to operate in other markets (Cutler, 2002; Cutler \& Reber, 1998; Cutler \& Zeckhauser, 1999; also see further discussion and references on this issue in the section on managed competition later in this chapter).

Large cross-subsidies are a natural feature of community-rated insurance (applying the same premium to all, regardless of health status), but this transfer of funds from those in good health to those in poor health only works in a market setting if one firm controls all the choices (Halvorson \& Isham, 2003; Hester, 2001). Otherwise, a competitor can reduce coverage and prices to attract only low-risk individuals, and leave the high risks with the original insurance carrier. Such adverse selection becomes increasingly unsustainable as a long tail of obligations are processed. If the original insurer attempts to raise premiums to account for the higher costs of the risk pool, more of the lower risks will drop out, increasing the cost pressure even more. This phenomenon is called a death spiral.

The principal that medical underwriting, experience rating, and risk selection drive out community rating is well understood, because it was so clearly observed in the 
demise of community rating in the original Blue Cross Blue Shield (BCBS) plans. Commercial competition succeeded against early BCBS plans through the development of health-related actuarial science in the 1940s (Thomasson, 2002). By the 1950s, BCBS avoided adverse selection in its group plans by behaving like a commercial insurer, selecting lower-risk groups and eventually adopting experience rating for group insurance plans. This development illustrates how commercial markets expand, covering the healthy population first. In a system of incremental reforms to expand the commercial market, insurance carriers are likely to discover methods to continue excluding high-risk individuals to avoid adverse selection. The most expensive segments of the populationamong the highest-spending 5\% that use about half of all healthcare resources (see Figure 1) — would be the ones to remain uninsured.

\section{Charity}

A patient in crisis may view a $1 \%$ chance of survival as a compelling opportunity, regardless of price (Groopman, 1997, 2000). Similarly, physicians are led by professional ethics to provide critical services as needed, also regardless of price. Perhaps unexpectedly, the attitude to provide all needed care is also found among insurers (Chernew, Jacobson, Hofer, Aaronson \& Fendrick, 2004). The gravity of health care needs commonly defy market constraints.

Indeed, the inability to say "no," the very nonmarket quality of health decisions, is the reason insurance is desirable. Insurance establishes a cushion against financial ruin for 
both the patient and the provider when decisions for health exceed the rules of price. Without it, charity may be required to provide resources.

In 1988, the Oregon Medical Association observed that free care accounted for more than $\$ 88$ million in uncollected revenue among Oregon physicians, amounting to nearly 20\% of total practice revenues (OHP Administrator, 1995a). Physicians have long provided charity care by sliding-scale fees, voluntary service, and in medical education, using charity services to gain access to hospital patients (Starr, 1982). Now, sliding-scale fees are prohibited by Medicaid policy, which also formalizes access to care, and offers such low reimbursement that physicians may feel they are already providing charity care (Kronick, 2001). Further, medical education is now subsidized by Medicare, which diminishes the need for charity care to gain access to patients. Physicians do still contribute to charity care, with one study showing $76 \%$ of patient-care physicians provided an average of about 11 hours per month (Reed, Cunningham \& Stoddard, 2001). With insurance coverage declining since about 2001, the alleged failure of hospital charity care has been highlighted in lawsuits, government investigations, and headlines (Kaiser Network, 2005). The expectation that hospital charity can supply care for the uninsured population is struggling under the burden of uncompensated care. From the hospital's perspective, individual bills to people with low incomes go almost entirely unpaid (Beck \& Paul, 1998; Weiner \& Andes, 2010). Patients may be dunned by aggressive bill collectors (Kaiser Network 2004). Nonprofit status does not necessarily indicate that a hospital will provide unrestricted public access to health care, and the expectation to do so threatens its existence (Opdycke, 1999; Wall, 2002). 
Charity has never been adequate to satisfy the health needs of the population. This is why insurance was invented. Early arguments for life insurance, for example, applauded the protection given to individuals to avoid charity and maintain their dignity and civic status in the face of crisis (Epstein, 1936; Horstman, 2001).

Although insurance is a remedy for charity, achieving a system of social health insurance will probably not eliminate the need for charity. Philanthropy already contributes a great deal to medical research in particular diseases and conditions, like cancer, or lung and heart disease, and charity plays a key role in supporting community clinics to reduce barriers for those with special needs (Opdycke, 1999), and particularly in mental health funding (Brousseau, Langill \& Pechura, 2003). The services of unpaid, informal home caregivers have been estimated to be worth nearly $\$ 200$ billion per year in the USA (Arno, Levine \& Memmott, 1999). In these and other areas, charity and supplemental commercial insurance is likely to wrap around the perimeter of social health insurance coverage, wherever it happens to be set, as occurred in response to both Social Security and Medicare (Atherly, 2001; Dobbin, 1992; Moon, 1996).

\section{Employer Mandate}

In the early 1970 s, the idea of national health insurance was encouraged by the expanded share of public funding established in 1965 through Medicare and Medicaid, which had grown to encompass $42 \%$ of all U.S. healthcare spending (Klarman, 1977). In the surge of bills for health insurance reform debated in Congress in the early 1970s, the employer mandate emerged as a favored option (Marmor \& Goldberg, 1994). 
Chapter 3. Models of Universal Health Insurance. Employer Mandate 61

Anticipating what it thought was an imminent national reform movement, Hawaii enacted an employer mandate in 1974, requiring that all employers offer insurance to their full-time employees, and that all employees accept it (Lewin \& Sybinsky, 1993; Neubauer, 1997). Hawaii's plan was passed just prior to the federal enactment of ERISA, which ever after obstructed state mandates from affecting, in any way, employer-based insurance policies (Chirba-Martin, 1994; Fox, 1997). Hawaii’s employer mandate was allowed an exemption from federal authority only in 1983, after numerous court and congressional battles (Fox \& Schaffer, 1989). No other state has succeeded in obtaining an ERISA waiver since.

\section{The Case in Oregon}

Oregon's failure to obtain an ERISA waiver by a deadline in 1995 marked the end of OHP ambitions toward achieving universal health insurance. Given that state leaders by then had visibly lost confidence in the proposal for an employer mandate, the federal government had a reasonable political basis for inaction (Senate Special Committee on the Oregon Health Plan, 1993; Thorne, 1997).

A divided legislature was probably not the decisive factor in the failure of the employer mandate in Oregon after 1993. The employer mandate in the national Health Security Act failed, too, when Congress was not divided (Ayres, 1996; Johnson \& Broder, 1996). Nationally, the employer mandate aroused presidential opposition through the 1980s, and Republicans voted against it consistently along party lines in both houses of Congress (Monheit \& Short, 1989; Zedlewski, Acs \& Winterbottom, 1992). Later, a 
boost for the employer mandate emerged in a report by the 1990 President's commission on health care_-dubbed the Pepper Commission_advising incremental reforms accompanied by an employer mandate (Rockefeller, 1991).

Inherent flaws in the employer mandate emerged first in the opposition of restaurant and homebuilder associations, and small business coalitions, which gradually organized to oppose it (Ascuaga, 1992; Phelps, 1980). In Oregon, the opposition of Associated Oregon Industries, among the largest of Oregon lobby organizations, reflected the discontent of small businesses, corresponding to national resistance by the National Federation of Independent Businesses (Leichter, 1997b; Skocpol, 1996).

Forced costs imposed on small businesses to cover their employees were supposed to be ameliorated by tax deductions, subsidies, state pools, and purchasing cooperatives (Helms, Gautier \& Campion, 1992). Regardless, small businesses were unwilling to endure the hassle of administering insurance for a shifting sea of employees (Cooper \& Schone, 1997; Zedlewski, Acs \& Winterbottom, 1992). Many said they would not insure employees at any cost.

A research report on the employer mandate, contracted by the Oregon legislature, was delivered in 1995 with unfavorable conclusions (NERA, 1995). Genuinely unappealing prospects, and not mere politics, appear to have given the final word in the failure of the employer mandate. Apart from opposition by small-business interests, the Oregon plan appeared increasingly disconnected from the original mission to achieve universal access, cost control, and quality of care. With the employer mandate in Hawaii, for example, a "gap group" of as much as $17 \%$ of the population was uninsured 
(Neubauer, 1997). Oregon's employer mandate hoped to increase the number of insured residents, but huge gap groups were recognized to exist (OHP Administrator, 1995b).

- $20 \%$ of the workforce in Oregon was part-time, and thus outside the mandate.

- The plan was voluntary for employees to accept or reject, creating a prospect of adverse selection and rising premiums to accommodate higher risks.

- Even with proposed rate bands, several hundred thousand healthier workers were expected to drop out of the system as already expensive health insurance became unaffordable.

Following this anticipated slow start, the Oregon Health Plan offered no suggestions how the employer mandate would develop further toward the goal of universal health insurance. Realizing insurance coverage might not increase at all under the employer mandate, since most large businesses were insured anyway, the OHP Administrator (1995b) recommended various "triggers" in the system to make the mandate more compulsory if it were underutilized.

An original supporter of the employer mandate, the Oregon AFLCIO (n.d.), continues to maintain a website endorsing a pay-or-play version of health insurance reform. At the spring 2004 conference of the Northwest region union members (in Eugene), the old conflict between the employer mandate and single-payer, over a decade old, erupted in full form. At the opening plenary session on healthcare reform, a labor researcher argued well for the employer mandate, a labor manager acknowledged the union's interest in continuing to administer benefit funds, while many of the audience asked why labor could not support a system for everyone. Other examples show labor authorities are wedded by interest to employer-based health benefits (Gottschalk, 1999). 
Chapter 3. Models of Universal Health Insurance. Employer Mandate 64

\section{The Case in Germany}

The strongest argument for a system of universal health insurance beginning from a foundation of employer-based coverage derives from Germany, the country with the earliest example of social health insurance. The evolution of the system over the past century, however, highlights problems rather than strengths once the model is applied to the whole population.

The Bismarck model of social health insurance originated in the 1880s with a plan to insure workers first, targeting the productive segment of the population who could pay the premiums. The concept of publicly sponsored health insurance was only incrementally expanded to include other segments of the population (Bärnighausen $\&$ Sauerborn, 2002). As coverage in Germany expanded to the whole population, employment-based financing became inadequate for funding the system. The original contribution-based financing of the Bismarck system, in Germany as well as other countries that adopted the employment-based plan, gradually converged with revenue-financed and state-controlled public financing as in the UK (Parliamentary Assembly, Council of Europe, 2003).

Employers in Germany have responded in the same manner as small-business owners threatened to do in Oregon: traditional long-term employment relationships are being replaced by temporary and part-time labor, partly in response to the high costs imposed by mandatory employer contributions to social insurance (Amelung, Glied \& Topan, 2003). The example in Germany shows (a) a distortion in labor relations, 
(b) reduced income solidarity, due to contributions from payroll rather than all wealth, and (c) a shrinking tax base as the share of assessable wages declined (Wagstaff et al. 1999).

Price variation between health insurance policies in Germany is substantial, resulting in adverse selection for carriers (Schut, Gress \& Wasem, 2003). Consequently, risk selection among carriers, rather than competitive behavior to improve quality and value, remains a primary strategy for profit maximization (Kronick \& de Beyer, 1999; Pfaff \& Wassener, 2000). In a study of five countries with Bismarck-style social health insurance, adverse selection in Germany was observed to be the worst, with consequent turbulence and inefficiency in the market (van de Ven et al., 2003). Data from the Organization for Economic Cooperation and Development (OECD) showed Germany had the highest healthcare expenditures among all countries with universal systems, though costs were only about three-fourths of expenditures in the USA (Anderson, Petrosyan \& Hussey, 2002).

Although the case in Germany was correctly anticipated in Oregon, and the employer mandate appeared discredited for good following its definitive failure by 1995 , a resurgence of reform activity in the states revived the employer mandate in California in 2004. The measure did not pass, but the case renews interest in the original story, and failure, of the employer mandate in state reform efforts. In all, the success of an employer mandate is impeded by the following problems.

- Produces instability and high potential for adverse selection among competing insurers.

- Tends toward inequitable public financing. 
- Imposes excessive administrative burdens on small businesses.

- Distorts the job market due to expensive employee benefits.

- Fails to significantly improve access to health insurance.

- Disrupts the continuity of an individual's healthcare relationships when coverage changes with a change in employment or unemployment.

- Encourages job lock, particularly for the chronically ill or those with family members who are chronically ill (Gruber \& Madrian, 2001; Stroupe, Kinney, Kniesner, 2001).

\section{Individual Mandate}

The individual mandate originated as a foil to the national proposal for an employer mandate (Pauly, 1980). The plan arrived in Oregon with freshman State Senator Gordon Smith in 1993, sponsoring SB861 at the request of the Small Business Coalition. Curiously, the bill was identical to the language of the already drafted bill for the employer mandate, only substituting individual for employer. The edge of political opportunism in the individual mandate makes it difficult to take the proposal seriously, yet the idea continued to appear regularly in state reform agendas and is the basis for social health insurance in Switzerland (Reinhardt, 2004). Additional support for the idea appeared in the Netherlands, when the individual mandate became the basis for the country's new health insurance regime, implemented in January 2006. Massachusetts adopted the same plan, later in 2006, in its reforms to establish universal health insurance.

Presently, private individual health insurance in Oregon covers a little over 5\% of the population (Oregon Insurance Division, 2010a), about the same as the proportion nationwide (KFF/eHealth Insurance, 2004). The potential reach is much larger. A national 
survey (Duchon et al., 2001) found $27 \%$ of the adult population, aged 19-64, had attempted to purchase or had already purchased individual health insurance in the past year. Nearly three-quarters of the respondents found it unaffordable or impossible to obtain. Another study tested access to individual policies by sending seven hypothetical applicants in less-than-perfect health to 60 carriers in eight locations across the country (Pollitz, Sorian \& Thomas, 2001). Together, the applicants were rejected $37 \%$ of the time, offered coverage with premium markups or coverage restrictions $53 \%$ of the time, and given "clean" offers $10 \%$ of the time. Even the subject whose only fault was hay fever was rejected five times and given a clean offer only three times. These results indicate the acute sensitivity of the individual market to health status, which makes coverage unaffordable for most individuals who seek to purchase it. Heterogeneous risks, limited pooling, and information asymmetries make the individual market a risky business for insurers.

Adverse selection is not a great concern in the individual market presently, because individuals represent a very small part of any carrier's total business. Expanding the individual market, however, would make risk selection more prominent. The adult population with individual health insurance is characterized as older, concentrated in ages 55-64, with a lower average income, and one-third changing insurance each year-about 10 times more transient than the population with employer-based coverage (Chollet 2000; Simantov, Schoen \& Bruegman, 2001). Carriers regularly implement a strategy called churning to encourage disenrollment and re-enrollment to shed and reassess high risks (Families USA, 2004; Hall, 2002; Short, Graefe \& Schoen, 2003). These conditions 
indicate the individual market is more costly, both in medical expenses and administrative costs.

The 1995 package of health insurance reforms in Oregon standardized a health statement for the individual market, involving a checklist of personal medical information. The form protects carriers by standardizing the available information, and protects the applicant by limiting what can be asked. If an individual mandate allows this kind of underwriting, the state would need to maintain a high-risk pool to accept those who are rejected; or if a system of guaranteed issue is adopted to avoid rejection, the state would need to perform the underwriting itself and subsidize carriers for higher riskscalled risk adjustment (discussed in the next section)— to avoid problems of risk selection in a competitive market. Either of these options involve a substantial element of public finance, plus closely supervised regulation to manage competition by insurance carriers. Achieving a stable balance between public and private financing does not solve the further issue of higher costs in the individual insurance market. Consensus by health economists with different viewpoints has emerged regarding individual health insurance (Pauly \& Nichols, 2002), concluding: (a) the nongroup market has administrative costs three to four times higher than the group market, and (b) the threat of adverse selection is magnified. Earlier, another pair of economists concluded: "If people are increasingly charged on the basis of their individual risk characteristics, the efficiency losses could be severe" (Cutler \& Zeckhauser, 1999, p. 65f).

Earlier, Pauly and Percy (2000) discounted the objection of higher administrative costs in the individual market, even though their own data from HIAA and NAIC showed 
loading charges for individual insurance averaging $37 \%$, compared to $15 \%$ for group insurance. The difference can hardly be ignored. Insurers spend more time on individual contracts, and also carry an extra burden of risk (Hall, 2000c).

An individual mandate in a commercial health insurance market produces the following problems.

- Requires a public system of finance to support either a subsidized public pool or a system of risk-adjusted payments to carriers to cover high-risk persons.

- Encourages churning by carriers to cycle out poor individual risks.

- Increases the potential for adverse selection in a market that includes groups, and especially discretionary groups.

- Raises transaction costs for individuals, and increases administrative costs and risk for insurers.

\section{Risk Adjustment}

Risk adjustment is a fairly recent product of public policy, intended to stabilize prepayment for healthcare services in managed care contracts, and avoid risk selection by insurers competing in the same market (Ingber, 2000; Keenan, Buntin, McGuire \& Newhouse, 2001). Risk adjustment boosts payment to cover the costs of higher-risk beneficiaries. Under an individual mandate, where all citizens are required to purchase insurance in a competitive market, risk adjustment becomes a central concern to assure community rating for those in poor health, and also protect carriers from adverse selection.

Employers operating competitive insurance pools sometimes subsidize higher-priced plans to account for higher-risk employees choosing those plans, thus 
offsetting adverse selection (Peele, Lave, Black, et al., 2000). The concept of risk adjustment is more complex. The technique was designed for government entitlement programs when funds are contracted out to the private market. It was first developed as a tool for managed competition in the 1990s in the Netherlands (van de Ven, van Vliet, van Barneveld \& Lamers, 1994), along with other forms of risk sharing (van Barneveld, Lamers, van Vliet, van de Ven, 2001). About the same time, health policy analysts in the USA and other countries were also becoming aware of the necessity to risk adjust payments to publicly contracted carriers to avoid risk selection (Newhouse, 1994).

Risk adjustment was mandated for Medicare managed care contracts in 1997, but full implementation was delayed until 2004 (Weissman, Wachterman \& Blumenthal, 2005). Medicare's state-of-the-art Principal Inpatient Diagnostic Cost Group (PIP-DCG), applies risk-adjusted premiums to individuals, giving weight to prior-year inpatient costs, age, location, and other factors. This level of detail only became possible once data were available through the Medicare DRG payment system. In other situations, as in rating a larger group as a whole, or when employees are the only individuals in a small group, then simple personal characteristics like age and sex may be adequate factors to adjust risk payments. This corresponds to underwriting practices in the Oregon small-group market. Adding nonemployed persons of variable health status and class conditions-as individuals_complicates the matter considerably.

Although considered to be state-of-the-art, Medicare's risk adjustment remains imperfect and still allows risk selection (Kan, 2002). Insurers know more than state analysts about actual risks in the market. Current carriers of Medicare managed care 
contracts have been awarded with a favorable selection of clients at favorable prices, topped by favorable risk adjustment that makes the system inviting for contractors (GAO, 2008).

For Medicaid, Oregon has had difficulty anticipating heterogeneous risks in its capitated managed care contracts (according to a CMS online summary). Contrary to underwriting restrictions for commercial insurance for small groups, which disallow carriers from assessing actual or anticipated individual health status, the capitation ${ }^{7}$ formula for the special Medicaid population expanded to include 14 different risk classes, adjusting for geography, maternity, newborns, methadone dependency, and categories of chronic illness and disability (Oregon Department of Human Services, 2003). Evidently, public capitation rates are still too low and risky to encourage commercial contracts; direct fully-capitated provider groups in Oregon with Medicaid contracts are bringing complaints of inadequate payment and unacceptable financial risk (Mercer, 2003; Spitz, 2007).

Conflict is endemic with insurers and providers subject to risk-adjusted payments (Weissman, Wachterman \& Blumenthal, 2005). Even the best systems of risk adjustment fail to prevent the ability and incentive for insurers to select favorable risks, and may also produce perverse incentives to encourage overtreatment to raise future payment.

\footnotetext{
${ }^{7}$ Capitation: a periodic payment to a physician, hospital, or health plan to cover all healthcare services for an enrolled user, often as a payment per participant per month (pppm); certain services may be carved out and provided only with extra payment The concept of capitation is different, but sometimes confused with bundling, which involves a set payment for defined services anticipated for a diagnosed condition, whether or not the services are actually provided.
} 
Healthcare systems in other countries find adequate risk adjustment a continual challenge (van de Ven et al., 2003).

What needs to be recognized here is that risk adjustment is equivalent to underwriting (Wrightson, 2002); the state denies insurers the right to underwrite risks in favor of community rating, and then takes over the function itself. In the same way that

good experience-rated contracts take the appearance of prepayment for expected costs, a good system of risk adjustment simply pays actual costs in advance. One observer of risk adjustment concluded: "Like so much else about the U.S. health system, it seems an astonishingly complex way to achieve some straightforward policy goals" (Kuttner, 1998, p. 1956).

\section{Managed Competition in Employment-Based Insurance Pools}

The individual mandate plan, operating with a health insurance exchange to facilitate individual enrollment, as exists in Massachusetts, is based on a model of managed competition promoted for 30 years by Alain Enthoven. The model is currently endorsed by several national groups (Fronstin, 2009) and is represented in the operation of the Federal Employees Health Benefits Program and other employer insurance pools (Feldman, Thorpe \& Gray, 2002). In employer pools, one strategy involves defined benefits, where the employer pays a set premium contribution and employees must pay extra for any insurance choice over that amount. Cost-awareness by employees is supposed to help reduce costs, or at least improve efficiency through market competition, which will then trickle down to manage and improve costs in the delivery system. 
Current summaries of managed competition in employer health insurance purchasing pools (Buchmueller, 2009; RAND, n.d. Analysis of purchasing pools) confirm there is no clear evidence of cost control or quality improvement in the delivery system. Reports occasionally observe small advantages, and just as often disadvantages. In a strategic plan outlined in 2002, CalPERS (Freezor, 2002) admitted that its former efforts at managing competition, though apparently successful, were doing nothing to control the underlying costs in the delivery system.

The idea of managed competition begins with a fundamental logical problem in supposing that insurance competition can produce quality in health care. In group purchasing pools, when employees are offered choices for insurance products, competition can put high-value carriers in a vulnerable position, due to adverse selection: healthy individuals tend to be more sensitive to price, while unhealthy individuals are more sensitive to benefits (Berry \& White, 2000; Cutler \& Zeckhauser, 1997; Marquis \& Long 1999). Pool managers tend to be most concerned to control high premiums, but low premiums are the threat from the perspective of the insurance carriers. Predatory pricing to attract good risks can be most easily introduced by low-value plans, dominant carriers, naïve or fraudulent carriers incapable of managing the risk, or carriers operating under different state regulations or an advantageous risk-adjustment formula. Even in the ideal model of the Federal Employees Health Benefits Plan, carriers can be threatened with a death spiral (Newhouse, 1994). If a pool manager aggressively negotiates for lower rates, the added risk to carriers can result in truly catastrophic failures as occurred in California at the end of the 1990s. 
Commercial insurers have long favored rate regulation to avoid destructive competition (Harrington, 2000). States occasionally implement a marketing assistance plan to combine insurers into a rate-regulated regional risk pool to promote insurance coverage in a critical economic domain (Meier, 1988)—as Oregon did a few years ago to solve high rates of uninsurance in the construction industry (Oregon Insurance Division, 2004a). Insurers apparently do not trust community rating in a difficult market without a fixed, agreed-upon price among competitors.

\section{The Case in Massachusetts}

Managed competition was the primary model for the failed national healthcare reform effort in 1993 (Iglehart, 1993). Similar market-based reforms were promoted through the 1990s (as reviewed earlier), but were increasingly rejected, even by former supporters. The individual mandate was recognized as the most expensive type of mandate for reform. This all changed dramatically when a version of managed competition with an individual mandate and a health insurance exchange was implemented in 2006 in the Netherlands, where Alain Enthoven's (1980) ideas have been followed most closely. Later in 2006, a version of the same model appeared in Massachusetts in reforms aiming to achieve universal health insurance.

A recent evaluation of the universal health insurance reform in Massachusetts (Holahan \& Blumberg, 2009) showed coverage was successfully expanded to nearly the entire population. However, costs were increasing faster than before, and (as was anticipated in the earlier discussion of the commercial market in a universal system) one 
insurance carrier dominated the market. Funding remains heavily dependent on federal assistance.

A principal architect of the Massachusetts reform, Jonathan Gruber (2011a, $2011 b$ ), continues to defend the success of the reform, but the positive points for cost control for insurance premiums and hospital charges appear unconvincing in the face of other accounts. Reductions in premiums may have been mostly associated with the introduction of plans with substantially reduced coverage. Overall healthcare expenditures per person in Massachusetts have risen to $30 \%$ above the national average (Holtz-Eakin, 2011), which might be expected with a segment of the previously uninsured population now covered by health insurance, but rising costs and increased demand for health services are straining the state budget and the capacity of the delivery system. The online health insurance exchange, or Connector (www.mahealthconnector.org), has apparently managed to operate with a very low operating budget, but signs of adverse selection in the competitive insurance market, with options for catastrophic coverage and the federally approved tiers of "bronze" and higher benefit plans, appear to be threatening its viability.

In general, the evaluation reports from inside Massachusetts put a positive appearance on reforms, focusing on coverage results (Doonan \& Tull, 2010; Gruber, 2008; Massachusetts Taxpayers Foundation, 2009; Pande, Ross-Degnan, Zaslavsky \& Salomon, 2011), but other, broader accounts raise concerns (Holahan \& Blumberg, 2009; Holtz-Eakin, 2011). Certainly, no significant results have occurred in terms of cost 
control. Nevertheless, accounts appear so far incomplete and more time may be necessary to adequately judge the experiment and resolve conflicting views.

\section{The Case in the Netherlands}

The privatization of public health insurance in the Netherlands was apparently developed by insurers and state officials, over the complaints of physicians, who were excluded from the process (http://devrijehuisarts.org). Prior to the reform, the Dutch healthcare system had one of the best primary care delivery systems in the world, with highly effective clinical management (Hardy, Mur-Veemanu, Steenbergen \& Wistow, 1999), and declining costs in the previous years (Rosenau \& Lako, 2008). There was no mandate for universal health insurance for those with higher incomes, yet only $1 \%$ of the population remained uninsured.

These initial conditions make the radical reform puzzling on the surface. The plan for an individual mandate with a health insurance exchange to promote consumer choice in an expanded system of managed competition might be viewed as a shift to promote yet more improvement through a market-based system—and this is how the reform was framed—but such an abstract purpose is hard to fathom in a system that was working so well.

The true reason appears to be much more practical: rent-seeking behavior by insurers. Prior to the reform, the public sickness funds covered and controlled finances for nearly $70 \%$ of the population; private insurers covered the rest. The individual 
mandate and insurance exchange proved to be a simple method to transfer all the funds to private firms (Naderi \& Meier, 2010).

The insurance market in the Netherlands grew more concentrated as insurers spent large amounts on advertising, until major conglomerate firms dominated. Since the reform, the remaining commercial insurers have reported large losses on their premium income, but "do not appear to be worried," due to their high reserves (Rosenau \& Lako, 2008). As financial institutions, insurers can bring in as much as one-third of total profits from reserve investments (Meier, 1988). ${ }^{8}$

The transfer of wealth from public to private funds, and the resulting oligopoly power did not perform according to the claims of managed competition to reduce costs and improve quality. Insurer response was much like earlier results experienced in a model of managed competition instituted in Israel. There, a few quality indicators eventually displayed small but significant improvements (Rosen et al., 2011), but insurers originally displayed more concern for market share and managerial control of coverage costs than for genuine value in the delivery of health care (Gross, 2003; Gross \& Harrison, 2001).

According to one evaluation of the Dutch reform (Okma, 2008), regulation and complexity increased, the tax department hired over 500 new employees ${ }^{9}$ to process the

\footnotetext{
${ }^{8}$ The Oregon Insurance Division (2011) notes that health insurers obtain less profits from investment income than other insurers, because claims occur more rapidly. Over the past 5 years, the average net investment income by Regence Blue Cross Blue Shield, the dominant carrier in Oregon, averaged a little over $2 \%$ of premium income, or about $\$ 50$ million per year.

9 According to relative population size in the Netherlands and Oregon, the 500 new subsidy administrators could translate to over 100 new positions in Oregon under a similar system. Population in the Netherlands in 2010 was about 16,783,000 (index mundi: www.indexmundi.com/netherlands); that is 4.4 times the
} 
premium subsidies for low-income families through the exchange (comprising $40 \%$ of the population); and disadvantaged segments of the population failed to enroll and pay premiums, so their coverage status was in jeopardy—which had never been a problem before- until the Health Ministry shouldered the cost of sending out local agents to collect the premiums, if the insurers would consent to keep the delinquents insured.

Within the Dutch health insurance exchange, market forces were negligible. After substantial movement in the first year, less than $1 \%$ of the population thereafter tended to change health plans by choice, and only up to $5 \%$ when costs increased, leading to the conclusion that expectations for insurance competition in the exchange may have to be “tempered" (Hendriks, de Jong, Brink-Mulnen \& Groenewegen, 2009). Analysts of managed competition in Israel were more blunt, saying the theory contains "unrealistic assumptions" about the kind of competitive behavior that is supposed to occur and the capacity to monitor quality. This is the same kind of criticism leveled at managed competition earlier from practical experience in the United Kingdom (Light, 1997). The conclusion then was that "managed cooperation" rather than "managed competition" is the appropriate goal in health care. This issue will be discussed in more detail in the next chapter on quality reforms.

The analysis of the new Dutch insurance system by Rosenau and Lako (2008) concluded with a series of lessons for the United States (paraphrased):

1. It is a mistake to expect dramatic health care cost reductions with the introduction of regulated competition, at least in the short term. 
2. Regulated competition is unlikely to make voters/citizens happy. Dutch consumers, for the most part, are not highly satisfied with the change.

3. Consumers cannot be expected to act as economic models predict.

4. If insurance companies focus more on market share than on making a profit, financial losses are likely for a considerable period of time.

5. Dutch policy makers thoroughly underestimated the opposition from health care providers. A large percentage of doctors in the Netherlands are primary care physicians in family practice who define their profession as more than simply a job.

6. Consumer premiums will have to increase considerably in the future if insurers are to make a profit on the basic policies. In the USA, will popular support for the Health Insurance Act erode if this happens and translate into a political backlash?

7. The experience in the Netherlands has had little impact on policy makers. The experiment goes forward with a new energy and with a confidence that relatively incremental changes will be needed to fine-tune the model and improve performance. In the face of initial failure to control costs, the reaction of the Dutch government has been to reiterate its faith in the free market for health insurance and argue that cost containment was not an important rationale for the Health Insurance Act in any case.

8. Is it realistic to expect market-oriented, regulated competition for universal health care to succeed in the United States when the challenge is substantially greater than in the Netherlands, due to the need to reduce the number of uninsured simultaneously, and when reform starts off with a far higher costbase and lower public satisfaction with the present health system?

The authors followed these points with a warning: "Few have questioned the appropriateness of regulated competition for the health services sector, but the experience of the Netherlands should give pause" (p. 1050). 


\section{Mixed Mandate}

The first question for defining groups in a universal system of health insurance is how to maintain, strengthen, or replace the clearly strong basis of coverage through employment. A little over one-half of the U.S. population is insured through employment, with about one-fourth covered directly as employees and one-fourth covered as family members (Monheit \& Vistnes, 2005). Despite the flaws in the employer mandate, employment-based insurance is the backbone of most universal healthcare systems and of insurance systems generally around the world (Krueger \& Reinhardt, 1994). The idea of combining an employer and an individual mandate to cover the whole population looks, at first glance, like a natural way to reach universal health insurance.

In the OHP Administrator's report on reform alternatives, the idea of a mixed mandate was rejected as the most costly, due to complexity (OHP Administrator, 1995a). Moreover, there was no clear plan how to apply the mandates together and no model available to copy. Since that time, Massachusetts now provides a limited model, with a cautious pay-or-play employer mandate (not yet tested in court against ERISA), welded to an individual mandate.

As the only state with full authority to implement an employer mandate, Hawaii has come closest to a mixed regime that incorporates an individual mandate (Lewin \& Sybinsky, 1993; Neubauer, 1997). The state exhibited typical features of avoidance by employers as described earlier for the employer mandate: encouraging more part-time and contract employment to reduce benefit obligations. Policy proposals in Hawaii continue looking toward single-payer plans as an alternative (NCSL, 2005). States in general have 
shown a definite reluctance to pair the employer mandate with an individual mandate to guarantee universal coverage.

The public role in a mixed mandate is a neglected topic. Presently, private insurers rely on public risk pools to remove extraordinary risks from the market. A mixed mandate, just like an employer or individual mandate alone, will necessarily involve a share of public finance to accommodate high risks and those with low incomes. Acknowledging this third element in the mix of funds could obviate the need for any mandates. The Netherlands before 2005, for example, covered about $60 \%$ of its population in a public risk-pool that reached $430 \%$ FPL, while the rest of the population was covered through employment-based or individual insurance without any mandate to compel them, leaving only $1.5 \%$ of the population uninsured (Okma, 2001). Once the public share is acknowledged and appropriately funded, a universal mandate may be superfluous.

A central problem with the mixed mandate involves the threat of adverse selection for insurers. In an insurance market with both group and individual plans, discretionary groups formed by "mom and pop" small businesses could form to avoid a health rating in the individual market; or individuals could join an association with group benefits. These and like practices expose insurers to unanticipated risks (Hall, 2000b). The threat to carriers of high risks congregating in discrete groups, and low risks ping-ponging from group to group toward lower prices, is the reasoning behind the current provision in Oregon law to restrict insurance purchasing by discretionary associations to legitimate 
and stable groups (ORS 743.522). Under a mixed mandate, the sectors would need to be equalized, or efficient group underwriting simply eliminated (Berry \& White, 2000). Various efforts to create discretionary groups to purchase insurance-in private purchasing cooperatives, multiple employer welfare arrangements, or limited public pools

of various sorts - have proven mostly disappointing and sometimes alarming (Achman \& Chollet, 2001; Hall, Wicks \& Lawlor, 2001; Kofman, Bangit \& Lucia, 2004; Myers, 1995; Wicks \& Hall, 2000). Allowing free enterprise to operate in forming group risk pools makes caution urgent, as many examples present serious cases of insolvency and fraud.

\section{Health Insurance Exchange}

The idea of a health insurance exchange is based on the model of the Massachusetts "Commonwealth Health Insurance Connector Authority," or Connector (www.mahealthconnector.org), a public website that advertises benefit plans offered by private insurers that pass certain qualification standards to participate. The exchange offers a convenient way for individuals to compare plans and obtain insurance coverage when they are not part of an employment-based health plan. The exchange also operates as a conduit to distribute premium subsidies to those eligible for assistance due to low income (Lischko, Bachman \& Vangeli, 2009).

Organizing a health insurance exchange to facilitate the purchase of individual health insurance under the individual mandate presents a number of critical issues for sustainability—mostly related to the problem of mixing individual and 
employment-based insurance in the overall market for health insurance. An outline of the issues produced prior to the federal reform law (Jost, 2009) supplies a good summary (paraphrased):

1. Adverse selection is a common problem for an exchange as it tends to contain or attract sicker and more costly enrollees. One solution is to prohibit those eligible for insurance through the exchange to buy insurance anywhere else. If insurance is freely available both inside and outside the exchange, plans should have to play by the same rules and charge the same premiums. Risk adjustment should apply to insurers both inside and outside the exchange. Finally, employers and insurers can be regulated to discourage them from steering bad risks into exchange plans.

2. The exchange can only save on administrative costs if it replicates insurance functions so well that insurers do not have to repeat the procedures for groups of enrollees. Otherwise, the exchange basically duplicates existing functions.

3. Previous experience with exchanges has on the whole been discouraging. The most successful public exchanges have been the Federal Employee Health Benefits Program; state pension programs, like CalPERS, or state employee benefit programs; and the Massachusetts Connector. These exchanges, however, have not been able to keep cost growth significantly below that experienced generally in the private market.

4. Insurers prefer to control group relationships with employers rather than individual employees, who can change insurers easily at open enrollment periods.

5. When exchanges have tried to limit the commissions of agents, who largely duplicate the functions of the exchange, agents have simply steered applicants elsewhere. A separate analysis of purchasing pools by RAND (n.d.) concludes that good relations with agents is an essential feature of success.

In addition, extra costs for infrastructure need to be taken into account.

Individualized risk adjustment will require significant new data sources and numerous staff. Also, applying a means test to determine income status for subsidies will be costly for both administrators and applicants without a system of automatic enrollment. Ensuring compliance for disadvantaged persons will require a network of personalized local services. Experience with other programs indicates the cost of administering 
individual subsidies, simply to pay them, could equal one-fourth of the total amount disbursed (Dorn, 2008).

\section{Single-Payer Plan}

Single-payer bills appear regularly in various states and several times in Oregon: in $1987,1991,1993,2001$, and 2011. In the most successful year of 1993, the Human Resources Subcommittee allowed the bill to emerge with a "Do Pass," but the bill was forced back into committee and died. That strong show of public and legislative support has not been repeated.

A group that encompasses the entire population is an understandably attractive solution for reform, because it immediately solves problems of group size. The universal group, by definition (a) solves the problems of adverse selection in a competitive insurance market (as long as migration of poor risks from outside the "universe" is controlled), (b) unifies funding streams for purchasing power and better coordination of care, (c) reduces administrative expense and billing, and (d) installs a lifetime population perspective on health that favors public health, prospective care, and prevention in order to control costs (Maciosek, Coffield, Flottemesch, Edwards \& Solberg, 2010).

The OHP Administrator (1995a) reviewed the single-payer plan favorably among the list of reform alternatives. An updated analysis of reform options to achieve universal health insurance by the Institute of Medicine (2004) compared the same basic options as the OHP Administrator and came to a similar conclusion; without making a recommendation, IOM's side-by-side comparison noticeably favored a single-payer plan 
to achieve the essential principles of reform. Such listed advantages make little difference, however, if stakeholders are opposed to a single state-run system for other reasons. The OHP Administrator concluded, like many others, that it was simply not politically feasible. The main reason at the time was the threat of eliminating 11,000 jobs in the insurance industry, which has a vital interest in managing the flow of funds into the healthcare system.

\section{Public Utility Model}

The single-payer model has characteristics of a public utility. As a model example, public utility districts for water, water power, and electric energy were established in the Oregon Constitution in 1930 (Art. XI, Sec. 12). The plan involved years of debate, with charges of socialism being the chief objection (Schmidt, 1931). The movement for public utility legislation was common in the states during that period, which brought attention by the Supreme Court to define the nature of a legitimate public business. A clarification by Chief Justice Taft, which became a guiding standard, made subsequent connections to health care apparent: "[In this category] ... the thing which gave the public interest was the indispensable nature of the service and the exorbitant charges and arbitrary control to which the public might be subjected without regulation" (E.A.M., 1932, p.770). Later case law restricted the definition from including widely available goods or services that might be necessary to public welfare, but were amenable to competition and could be regulated if necessary to assure reasonable access in commercial markets. 
Although health care appears to fit the definition of a public businessindispensable, exorbitantly expensive, and characterized more by market failure than effective competition-health insurance and major areas of the delivery system involve substantial productive capacity in a variety of private organizations that might be more easily managed by regulation and contract to promote the public interest. When the American Hospital Association proposed a public utility model for hospitals in the 1970s, this same observation of the diverse private capacity of the healthcare system was raised as an objection (Somers, 1972). Establishing hospital health systems through organizational integration and contracting, or "franchising," was viewed as a preferable model.

In subsequent decades, integrated delivery systems of various forms developed, but not always easily or with optimal results (Gaynor \& Haas-Wilson, 1998; Goddeeris \& Weisbrod, 1998; Lutz \& Gee, 1995; Tennyson \& Fottler, 2000; Weil, 2001). Vertical integration by hospitals with physicians and other provider groups has exhibited the most difficulties. The result has not demonstrated that a private network approach actually achieves the goals of a public utility, and the partial nature of a network in a region may actually obstruct coordinated care (see discussion in Chapter 4. Practice Management). Also, in a competitive market, hospitals are commonly associated with monopoly power and overdevelopment (Devers, Casalino et al, 2003; Devers, Brewster \& Casalino, 2003).

The utility model was associated with a single-payer system of universal health insurance, related to national reform (Bodenheimer, 1993), and has also been associated with state reform efforts, including Arizona and California (Flanagan \& Smith, 2003; 
Hughes \& Rissi, 2004). An analysis that related a utility model to health care (Colton, Frisof \& King, 1997) reviewed the earlier history of public utilities and presented "a triangle of public interests": universal access, public accountability, and quality of service. The review indicated notable parallels in utility systems and the problems that would need to be resolved in a system of universal health insurance, such as redistribution of premium funds to subsidize costs for those with low incomes, administering local facilities through more cost-effective centralized administration, and combining elements of market principles (e.g., fees for services) with regulation (e.g., set standards and prices).

Market failure. In any of these perspectives on the utility model, the earlier objection of diverse private capacity remains unresolved. What part of the healthcare system would be designated as a public utility? How would it relate to insurers, various providers, and community partners? In these questions, an analysis of markets and market failure may be necessary to determine those areas where a public utility could improve value. The issues of market failure are different for insurance and the delivery system, and may be different again for different kinds of providers or provider relations.

Third-party payment is a commonly recognized aspect of market failure in the use of healthcare services, because both provider and the insured individual may be susceptible to moral hazard ${ }^{10}$ (Cutler \& Zeckhauser, 1999). Information deficits and the general incapacity of individuals to assess health risks and potential expenses before they

\footnotetext{
${ }^{10}$ Moral hazard: a situation where an individual is more likely to engage in a transaction, due to being insulated from the risk or cost.
} 
occur are other factors in market failure (Liebman \& Zeckhauser, 2008), particularly for insurance, but also in health care, where physicians are commonly regarded as responsible agents for choosing appropriate services under conditions of uncertainty (Arrow, 1963). Also, health as a vital good distinguishes health care from any other product. Thomas Rice (2003) evaluated a number of other market models and their problems in relation to the healthcare system (such as revealed preference, utility maximization, cost sharing, incentives, profit maximization, and so on).

The main point here is that both functioning markets and market failure may be present in different parts of the healthcare system, and the idea of a public utility in relation to the entire system is difficult to conceive, or justify, in those places where market forces work well enough or better at promoting value. Some sections in these opening review chapters focus on areas where competition does not work, and regulation appears necessary. In other sections, problems appear with regulations, and more flexibility appears necessary. In the choice between markets and regulation (if those are the only two choices available), neither appears entirely satisfactory. No inherent preference for one or the other should be inferred in the presentation here. It appears quite clear that no theory should elevate markets or regulation in health policy without looking first at the evidence in various applications.

A connection between market principles (competition, consumer interest, choice) and regulation is found in transaction cost economics (Williamson, 1996). In this perspective, a firm can optimize operations by deciding what functions will be kept within the organization under bureaucratic control, and what functions will be separated from the 
organization and obtained in a competitive market outside the firm. The obvious difficulty here is that the healthcare system is not a firm, and the interpenetration of bureaucracy and markets appears fragmented, with no clear authority to sort and optimize transactions.

Even if a public utility model could be applied to an overall public system, answers would need to be found for at least three primary objections to the restrictive "socialist" implications of public governance, related to (a) public monopsony, (b) political interference, and (c) coverage standards. These issues, discussed in the sections below, may apply to any mandated system of universal health insurance, not just single-payer. They are also points of concern that may be applicable to certain trends in commercial insurance and managed care, which were originally viewed as socialist, too, when they first emerged (Starr, 1982).

\section{Monopsony Power}

Monopsony power (the ability of a single purchaser to dictate prices) receives less attention in the U.S. economy than monopoly power (the ability of a single supplier to dictate prices), but the concept is particularly relevant to healthcare markets (Gaynor \& Vogt, 2000). As a single government payer for a set population, Medicare represents a clear example of monopsony power over healthcare providers. Medicare is a single-payer, top-down system for healthcare providers, shaped by Congress, with set prices, elaborate regulations, and performance incentives, giving it a strong resemblance to a socialist economy with its trademark inefficiencies (Kornai, 1992). Medicare is notorious for 
rulemaking, creating a constant churning that amounts, by one estimate, to a "new instruction from the CMS every five hours of every day of the year" (Lovern, 2001).

The prospect of rising costs in the 1970s brought Medicare to install prospective payment systems with specific terms of eligibility, coding of services, and set fees (Cassel, 2005), first for hospitals (DRGs in 1983), then for physicians (RBRVS in 1989), and then skilled-nursing facilities (RUGs in 1997) ${ }^{11}$. With these fee schedules installed, definitions of medical necessity that were originally evaluated by local custom have been gradually drawn into an orbit of financial policy from the center. Healthcare providers have been put under pressure from underpayment in certain areas, sometimes causing crisis. Home health providers were hardest hit following the implementation of RUGs (Demel \& Baker III, 2000; GAO, 2000; National Association for Home Care, 2000; Office of Inspector General, 2001). Many service providers went out of business, and the number of persons served and the number of visits per person swiftly deteriorated, falling in many areas to half of former levels. Primary care has been gradually retarded under RBRVS payments (Goroll, Berenson, Schioenbaum \& Gardner, 2007).

There is some doubt if any of this price-fixing really restrained cost growth overall, or merely shifted costs to other venues and denied care to high-risk service users (Vogel, 1999; Meltzer, Chung \& Basu, 2002). Further, the threat of direct government enforcement in an audit may inhibit certain practices, which can affect the quality of care offered (Sloan, 1998).

\footnotetext{
${ }^{11}$ DRGs = Diagnosis Related Groups RBRVS = Resource-Based Relative Value Scale $\mathrm{RUG}=$ Resource Utilization Groups
} 
The development of Medicare managed care contracting represents an effort to add market forces, using contracts with local carriers to operate as care managers. Meanwhile, use of Medicare fee schedules has become prevalent among commercial insurers (Nichols, 2009), so private carriers may themselves wield monopsony power over providers, particularly physicians (Dafny, Duggan, Ramanarayanan, 2010).

The physician perspective has always been generally opposed to the corporate management of medicine through economic imperatives (Starr, 1982). Current views remain testy on the subject (Samuel, Dirsmith, McElroy, 2005). The pharmaceutical industry and medical-device manufacturers also fiercely resist any centralized authority as a purchaser of health care (Foote, 2002), with the convincing argument that the buyer's position is too strong and too final.

Managing prices by bureaucratic authority is reminiscent of the successes and absurdities of the New Deal's National Recovery Administration trying to set matchstick prices (Schlesinger, 1959). Confusion in Medicare billing is documented in a GAO (2002) report that observes the stress involved in conforming to a complex regime of rules, magnified by fears of unintentional fraud and criminal prosecution. Price setting in Medicare is tying the system in knots by making the very act of billing a stressful, expensive transaction. In Medicare's RBRVS system of physician reimbursement, a sustainable growth rate is specified (presently causing so much controversy among physicians in relation to federal reforms). Many observers find the RBRVS prices as well as the growth rate deeply flawed. Fee schedules may support a comfortable predictability 
in practice, or alternatively, operate like a bevy of screws on the capacity of providers to deliver quality care.

\section{Political Interference}

Passage of the Medicare prescription drug benefit in 2003 highlights a fundamental problem in Medicare as a single-payer system, demonstrating how it often takes, literally, an act of Congress to make business decisions for social health insurance. This problem is partly due to powerful lobbying interests that do not want a strong central administrative authority making national coverage determinations (Foote, 2002). By keeping decisionmaking in the political body of Congress, special interests may hope to obstruct unfavorable policies. Currently, health interests spend more on lobbying Congress than any other economic sector (Center for Responsive Politics, 2010). The pharmaceutical industry spends more than any other industry overall, and exerts major influence (Public Citizen, 2001).

Across the 50 states, politically mandated benefit laws affecting the commercial insurance market ballooned from 158 in 1974 to over 1,000 by 1995, when mandated coverage reportedly accounted for 7\%-21\% of all insurance claims (Jensen, 1995). Oregon's list of mandated benefits in 2010 consisted of 30 treatments and 13 qualified providers; federal preventive care requirements in the Affordable Care Act have since added another 49 treatments (Oregon Insurance Division, 2011, 2010). Oregon, in 1985, was one of the first of 26 states to establish a review process to track the effects of mandated benefits (Bellows, Halpin \& McMenamin, 2006). 
Mandated benefits tend to be unpopular for both insurers and small employers, because the cost of insurance increases and becomes less affordable (Jensen \& Morrisey, 1999). State mandates for private health or pension benefits are sometimes justified as a form of protection, for both individuals and the public, to relieve future burdens on social welfare. An association of insurance carriers that monitors state-mandated benefits proposed a different view, involving rent-seeking behavior (Bunce \& Wieske, 2010, p.1).

For almost every health care product or service, there is someone who wants insurance to cover it so that those who sell the products and services get more business and those who use the products and services don't have to pay out of pocket for them.

Another review of benefit laws in the states (Laugesen, Paul, Luft et al., 2006) concluded that political consensus, due to the symbolic force of an issue or for other reasons, was more important than science. Some benefit laws that spread widely across the states were later shown to have no value. Standard benefit packages with explicit coverage rules in some areas and gaps in others, as commonly observed in Medicare, can distort medical practice, encourage more expensive options such as hospitalization, and pose serious consequences for patients (Cassel, 2005).

Medicare criteria for hospice care provide one example of adverse consequences from what appear at a distance to be reasonable rules. The three simple criteria-(a) certified life expectancy of less than 6 months, (b) must accept only palliative care, and (c) have a full-time primary caregiver - often cannot be determined exactly or cannot be met; and the threat of federal enforcement prevents physicians from appearing to violate them. The result is serious underuse of hospice (Larson \& Larson 2002; MedPAC, 2002). 
Subsequently expanded payments to encourage hospice did not eliminate the rules, but may have encouraged overextended stays, for which a current advisory report recommended more rules, investigations, and pay adjustments (MedPAC, 2010). Without normal market incentives to guide behavior and prices, the purchasing system begets rules upon rules in efforts to right itself.

In another example, a growing array of mandated preventive tests, immunizations, and disease monitoring may produce disputable results. In some instances, what is apparently good practice for a select group, when spread over a wide population can actually increase harm-for example, in relation to hypertensive thyroid tests, osteoporosis screening, mammography, and many other cases (Gollust, Dempsey, Lantz, Ubel \& Fowler, 2010; Halvorson \& Isham, 2003; Helfand, 1992; Masson, 2010; Nelson, Helfand, Woolf \& Allan, 2002).

In addition to directing treatment options, standard benefit packages —in both public and commercial insurance plans - can also encourage providers to give ready access to questionable treatments, simply because they are specifically covered. Insurers, for their part, need to have some form of control over the definition of medical necessity and the limits of coverage to control costs, but these concerns do not necessarily require specific prescriptions or proscriptions on medical practice. Centralized coverage authority can sweep whole categories of people, providers, or care alternatives in or out of the domain of care. In this respect, even commercial insurance plans can be considered as a case of bureaucratic (if not exactly political) interference in the conduct of health care. 
New value-based benefit designs, promoted by the business-led Oregon Health Leadership Council and the Public Employees' Benefit Board (PEBB), appear to adopt a middle ground by applying tiers with gradually diminishing coverage for certain "less valuable" treatments (Fendrick, Smith \& Chernew, 2010; Kapowich, 2010). The design corresponds to a plan recommended by Joseph Newhouse (2004) for the thoughtful application of cost sharing. Like others, though, Newhouse was skeptical that costsharing will make an appreciable impact on cost control. The value-based plan is at least more thoughtful than other consumer-driven plans with standard copayments, coinsurance, or deductibles, which tend to cause confusion and financial or medical crises for patients (Cunningham, 2010; Lieu et al., 2009; Reed, Benedetti, Brand, Newhouse \& Hsu, 2009). Although value-based plans have become popular among large employers and purchaser groups, there exists as yet little direct evidence that the plans will work to improve health outcomes or help control costs (Choudhry, Rosenthal \& Milstein, 2010). Implementing any benefit plan determined by purchasers, supported by science or not, is open to criticism by physicians, who "often question the relevance of study results ... and are concerned about their applicability to real settings" (Brousselle \& Lessard, 2011, p. 835). A concern of this kind recently appeared in a news story in the Bend Bulletin (Hawryluk, 2010) in connection to benefit restrictions in OHP coverage. One physician complained that the OHP priority list fails to take into account the severity of a patient's condition. Another physician, telling the story of a particular patient, concluded that his job to provide appropriate care was being obstructed by a "cookie-cutter approach" in the priority list that placed all individual cases into a single category. This 
same criticism was raised in the assessment of Oregon's original prioritized list of services when it was submitted to the federal government for approval (Office of Technology Assessment, 1992).

The development of the formulary ${ }^{12}$ represents another popular application of centralized decisionmaking. Formularies organize a complex array of pharmaceuticals to direct physicians and consumers toward the most efficient options. Formularies became a standard for managed care in the mid-1990s, and have now been widely adopted by government and private healthcare purchasers (KFF/HRET, 2010; GAO, 2009). The comparative cost-effectiveness of formularies to alternative cost-control strategies has not been well studied (Lu, Ross-Degnan, Soumerai \& Pearson, 2008), but one study has shown that formularies can significantly reduce pharmacy costs (Huskamp, Epstein \& Blumenthal, 2003).

Even a useful practice guideline like a formulary can interfere with medical practice when applied haphazardly. Formulary strategies vary and may cause confusion when a physician faces multiple sets of rules from different purchasers, each with more or less aggressive enforcement, education, and authorization policies (Wallack, Weinberg \& Thomas, 2004). Efforts to standardize formularies may produce conflict with pharmaceutical companies and pharmacy benefit managers who profit from the details of the design (Meador, 2011).

\footnotetext{
${ }^{12}$ Formulary: a list of drugs and a set of rules regarding their use and how a health plan will cover and pay for dispensing of specific drugs (Frank, 2004, p.24).
} 


\section{Coverage Standards}

Recent single-payer proposals in Oregon have basically suggested a single fund for everyone to cover everything (see HB3801[2001] and HB3510[2011]). The goal for full coverage is often ridiculed as unobtainable; but then the question arises: What level of coverage is acceptable?

Social contracts in the USA, such as Medicare and Social Security, are typically designed to be inadequate (Moon, 1996; Dobbin, 1992). Medicare covers only $56 \%$ of the total personal healthcare expenditures of its beneficiaries (Gluck \& Hanson 2001). This safety-net standard of coverage raises the question if social health insurance is really protecting the welfare of the whole population as intended. The problem here is that many people get left out (Hadley, 2003).

A study of Medicare coverage showed most beneficiaries use a variety of options to reach full coverage: about $33 \%$ relied upon employer-sponsored policies, $24 \%$ on Medigap policies, $11 \%$ on Medicaid, and 17\% on managed care (Laschober, Kitchman, Neuman \& Strabic, 2002). The remaining $13 \%$ that relied only on Medicare used fewer services than anyone else (Medicare Current Beneficiary Survey, 1999). Interestingly, this category of Medicare "uninsured" was about the same size as the percentage of uninsured in the general population.

An actuarial comparison of health plans in Oregon (OHPR, 2001) showed Medicare was poorest, significantly less rich in benefits than coverage for federal employees, small employers, or Medicaid. For one thing, Medicare has no stop-loss feature to cap individual losses. In 2002, the typical senior on Medicare spent $22 \%$ of 
income on out-of-pocket health costs, for an average of \$3,757 (Maxwell, Storeygard \& Moon, 2002). The top $10 \%$ of out-of-pocket costs were $\$ 6,523$ or more. Those in poor health among the top $10 \%$ paid $\$ 9,174$ or more. When facing direct costs like this, lower-income households experience a greater proportional burden.

Some studies conclude that none of the insurance options available to the older adults in the private market, neither Medigap nor managed care, protect those in need from high out-of-pocket costs (Gold \& Achman, 2002). A more detailed study, however, showed the choice made among managed care plans or the 10 standard options for Medigap insurance can make a considerable difference (Snyder, Rice \& Kitchman, 2003). Unfortunately, there is no easy way to anticipate what will be the right choice. On a low, fixed income with uncertain health status, choosing an appropriate benefit package can be a treacherous decision.

The conclusion here is that an inadequate system of healthcare coverage is full of peril and inequities. Left to themselves in the private market, many individuals face exclusion, unbearable risks, and prices that quickly outstrip means, particularly if they are in poor health. A recent survey of 11 English-speaking and European countries showed U.S. adults faced the highest out-of-pocket costs, access barriers, and disputes, even when insured (Schoen et al., 2010). An earlier study of underinsurance in the USA (Waters, Anderson \& Mays, 2004) found widespread vulnerability to catastrophic spending shocks (reaching $40 \%$ of income), particularly for families with one member with two or more chronic conditions, and for poor families below 200\% FPL. 
These examples suggest a model of universal health insurance will need to reach toward some reasonable concept of full coverage to successfully protect vulnerable individuals in the population. An additional need for long-term-care insurance as a corollary to medical care for the elderly and disabled is also evident. Medicare presently offers coverage only for rehabilitation, both in skilled-nursing facilities or home care, and does not cover chronic assistance without improvement (Cassel, 2005). Medicaid, however, is required to cover long-term care for eligible program participants, and in 2009 paid 33\% of the nation's long-term care expenses (CMS, 2009). The elderly sometimes spend down their life savings until they become eligible for Medicaid, which has been shown to discourage household savings (Lee, Kim \& Tanenbaum, 2006; Liu, Doty, \& Manton, 1990). The burden on state Medicaid budgets for long-term care is a pressing concern.

The issue is related to healthcare coverage, but is also different-complicated by the extended commitment and generational inequities (Brown \& Finkelstein, 2011; Wiener, Illson \& Hanley, 1994). Also, the intersection of long-term care with informal family caregiving and support may cause policymakers to fear crowding out personal and charitable resources with a broad social insurance program. Evidence indicates this does not necessarily occur (Penning, 2002).

A recent survey of long-term care experts showed strong favor for a system of mandatory social insurance for long-term care, possibly added to Medicare benefits (Miller, Mor \& Clark, 2010). The private market is unlikely to provide a solution in this area of coverage. Low uptake for privately purchased long-term care insurance has 
persisted for decades and presently covers a small part of the population, mostly those with higher incomes (Zhou-Richter, Brown \& Grundl, 2010). This result is observed worldwide. Subsidies or tax credits to help expand the private market in the USA have not produced much effect (Goda, 2011). The subsidies proposed in current federal reforms in the Community Living Assistance Services and Supports (CLASS) Act are unlikely to work any better. Moreover, the voluntary character of the plan is expected to produce an unsustainable market, prone to adverse selection (Miller, 2011). 


\section{Chapter 4}

\section{Cost and Quality Reforms}

Universal health insurance may be a poor bargain if safety and quality of care are not also improved (Fuchs, 2004; Lawrence, 2002). Many current developments in healthcare reform focus on quality improvements. Although quality reforms are not directly related to insurance coverage, several models for quality improvement have been developed since the OHP reports on reform alternatives in 1995, and they are often raised as critical corollaries to reform. A landmark report by the Institute of Medicine in 2001, Crossing the Quality Chasm, identified six general principles, stating that health care must be safe, effective, patient-centered, timely, efficient, and equitable. These principles have become a foundation for current developments in quality improvement efforts.

The following sections discuss areas of activity that appear to be critical, or are believed to be critical, in shaping the system of finance and delivery in health care: (a) prudent purchasing, (b) practice management, (c) information infrastructure, and (d) medical liability. All contain multiple parts.

\section{Prudent Purchasing}

Current strategies for prudent purchasing in health care developed first in the 1980s, when Medicare designed a prospective payment system, or fee schedule, to replace the original cost-plus purchasing arrangement that boosted prices uncontrollably through 
the 1970s (Moon, 1996). Further controls through managed care and capitated contracts in the 1990s unsettled consumers, resulting in legislation for patient protection (Yount, 2001). Capitation suffered an additional, severe loss of credibility at the end of the decade, when major risk-bearing service providers went bankrupt (Robinson \& Casalino, 2001). Nevertheless, capitation remains a popular proposal for prudent purchasing. The strategies outlined in the subsections below—consumer choice, medical savings accounts, pay-for-performance, and capitation-represent the most recent generation of ideas to control costs through a purchasing regime. The related topic of managed care or value-based management—called here practice management—is discussed separately in the next section.

\section{Consumer Choice}

Patient decisionmaking in purchasing health care is a default option in the USA, due to lack of insurance coverage. In addition to the one-sixth of the population that is uninsured, employers that provide benefits have been responding to double-digit inflation in healthcare costs by steadily shifting a larger share of direct costs to their employees (Claxton et al., 2010; KFF/HRET, 2003, 2010).

Transferring costs to service users reduces costs for corporate purchasers, but the addition of consumer choice through out-of-pocket costs is unlikely to improve value. Testimony from the beginning of medical practice in the USA, and more recent empirical studies, attest that consumers are largely incapable of reasonably assessing value in health care at the point of purchase (Newhouse et al., 1993; Schlesinger, 2002b; Starr, 1982). 
Consequently, medical practice is regulated by ethics, professional standards, and certification to assure a level of quality and assure confidence in a market that is otherwise too full of unfathomable risks.

Mandating choice can actually cause harm, raise costs, or otherwise reduce patient welfare (Frank, 2004). In matters of health, individuals are often vulnerable, and disinclined or incapable of acting as prudent purchasers. Deborah Stone (2004) illustrated in a personal account of her failing mother, how shopping for care when faced with ill health or disability is not something anyone wants to think about. Stone reasserted the value of paternalism in care relationships, calling the expectation that a dependent person should shop for health services a "cruel hoax," and an evasion of our moral responsibility as family members and citizens. Many others have echoed this concern (e.g., Appleby, 1998; Brown, 1999). A current analysis of clinical decisionmaking (Lenert, 2010) highlighted an array of inputs from patient, physician, family, third-party coverage, disease state, test outcomes, and so on, and pointed out that placing expectations of individual choice on patients through financial responsibility may actually reduce rather than enhance patient empowerment.

A 1996 IOM report, Primary Care: America's Health in a New Era, restated common doubts about relying upon consumer sovereignty to select appropriate care, and made a distinction between patient-centered care and consumer choice. Integrating personal responsibility and shared decisionmaking as much as possible in clinical practice remains a top priority, according to IOM, but the patient is not expected to mold the system through purchasing authority. A long-time advocate of consumer choice, Paul 
Ellwood (2003) reversed his position to match the IOM view. Ellwood declared:

"Exaggerated assumptions about the power of consumer financial choices to permanently change provider behavior or the health system's structure have undermined everyone's including our attempts at health system reform."

Empowering consumer choice in healthcare decisions has two basic thrusts, one through a financial motive with out-of-pocket costs, and a second through supplying information. Regarding out-of-pocket costs, the RAND Health Insurance Experiment (Newhouse et al., 1993) showed that patients are poor judges of healthcare value. Costs above zero significantly reduce utilization in most instances, and patients drop high-value as well as low-value care indiscriminately. In recognition of these results, managed care generally makes certain core services free to encourage access to appropriate health care, and out-of-pocket costs are applied in varying degrees to out-of-area care, certain classes of care, and specific products-a system known as tiered networks (Fronstin, 2003; Iglehart, 2002). Current plans for value-based benefit designs follow this system, segmenting out-of-pocket costs in tiers according to the insurer's judgment of the value of care. In hard-to-decide cases with significant consequences, however, professional judgment and patient views are supposedly the principal components of a decision, while costs and consumer choice are irrelevant (Brody, 1997).

In health care, common expectations about market behavior, supply and demand, utility and efficiency, appear to operate differently than might be expected from other familiar domains. For example, eliminating cost barriers all together is unlikely to cause overutilization in dental care, mental health (Newhouse et al., 1993; Ringel, Hosek, 
Vollaard \& Mahnovski, 2002), or in primary care for the elderly and disabled (van de Voorde, van Doorslaer \& Schokkaert, 2001). Some analysts are now arguing that moral hazard due to insurance coverage, rather than reducing welfare, might actually promote value (Cutler, 2004; Nyman, 2004). In mental health, generous benefits may reduce medical costs (Goldman, McCulloch, Cuffel \& Kozma, 1999; Sturm, 1997), though mental health drugs may be subject to overuse (Angell, 2011; Meyerhoefer \& Zuvekas, 2010; Shern, Beronio, Minniear \& Steverman, 2010). The many coverage gaps in Medicare may actually raise rather than lower costs (Asch, Sloss, Hogan, Brook \& Kravitz, 2000).

In regard to information, the intent to improve value by facilitating competition and choice does not seem to work in health care. A report by the Congressional Research Service (Austin \& Gravelle, 2007) found positive effects from price transparency in other markets, but not in health care. A recent review of the literature (Kolstad \& Chernew, 2009) confirmed that only a few subgroups of the population, or agents such as employers, were likely to respond to information to make choices for health plans or providers; when individuals chose a physician, proximity and personal characteristics were the most important factors. Consumers may appreciate choice, but have demonstrated they are not likely to use quality indicators to make decisions (Greene \& Peters, 2009).

Another problem with information involves friction in transmission, mostly due to limits in the receptive capacity of those expected to use it. Problems of interpretation and overload are common (van Zandt, 2004). Keeping information current is another 
challenge (Felt-Lisk, Barrett \& Nyman, 2007). Initiatives in Medicare to enhance choice through information have had a modest effect in helping beneficiaries select options, along with massive and costly confusion. CMS Administrator Thomas Scully (2002, p. 109) complained : "There is definitely a problem when 65,000 seniors a day are calling for information about Medicare.” Rather than simplify the system to absolve beneficiaries from so many important choices, his proposed solution was to pepper the media, bulletin boards, and mailboxes with yet more information. Beneficiaries have reported being overwhelmed (Hibbard \& Peters, 2003).

The level of illiteracy in the USA is a also defining factor. According to a study reported in JAMA, and discussed in the IOM (2003b) national priority areas, nearly half of the U.S. adult population is barely literate: $21 \%$ (40-44 million people) are functionally illiterate, and another 25\% (50 million people) are marginally literate, unable to synthesize information from complex or lengthy texts; in terms of dealing with the healthcare system, the combined $46 \%$ are considered functionally illiterate, relying upon spoken instructions and faulty recall. Literacy constraints are a common barrier in a variety of settings (e.g., Magasi, Durkin, Wolf Deutsch, 2009).

Regardless, over the past 10 years, state advocates for consumer choice as a market principle continued building information systems to promote informed decisionmaking, unconvinced of skeptical appraisals (Dahl, 1999; Hess, Schwartz, Rosenthal, Snyder \& Weil, 2008). The idea of transparency has been pursued as an end in itself, and is now faced with challenges of accuracy, timeliness, fairness, simplicity, transmission, and relevance (Suchy, 2010). 
Although consumer choice is not likely to produce market efficiency, other avenues for patient-centered choice exist in the healthcare system that could improve value in other ways (Ebeler, 1999).

1. Choice to modify treatment or referral, or choose a different physician.

2. Choice of insurance carrier and coverage plan (within socially responsible limits).

3. Choice to find information on quality, if desired, to enhance decisionmaking.

4. Choice for a fair process, with options for appeal and external review.

\section{Medical Savings Accounts}

A consumer-choice regime is best exemplified in medical savings accounts (now renamed health savings accounts) and other high-deductible plans. A medical savings account is an individual savings account dedicated to healthcare expenses, usually established by a contributing employer. Accounts are designed with a large deductible, a doughnut hole of no coverage, and a cap of catastrophic coverage. The plan design was promoted by the federal government in the Balanced Budget Act (BBA) of 1997, and by many other organizations and states (Rosenthal, 2004). Increased attention to such defined-contribution plans has emerged since 2000, with several local examples (e.g., Foundation for Medical Excellence, 2003).

Analysis of medical savings accounts as a reform alternative by the OHP Administrator (1994) concluded the proposal would be inadequate as a system of universal insurance, partly because those in most need would suffer repeated shocks of high deductible payments, and would finally depend upon catastrophic coverage, which 
offers no improvement toward the stated purpose of cost control; and meanwhile, those in good health would build up independent funds inaccessible to insure others. An abundance of more recent analysis confirms the assessment. Medical savings accounts are essentially the antithesis of insurance, segmenting risks by removing funds from insurance risk pools and directing increased resources to higher-wage, younger, and healthier individuals attracted to personal accounts (Forget, Deber \& Roos, 2002; Olsen, VanDerhei, Salisbury \& Holmer, 1999). Other insurers in group markets are thus exposed to adverse selection (McNeill, 2004), and increased complexity and overall costs (Christianson, Parente \& Taylor, 2002; Moon, Nichols \& Wall, 1996).

Moreover, in practical terms, establishing individual accounts for everyone would be extremely difficult if not impossible, due to administrative and information burdens on employers and individuals, lack of existing capacity, inevitable delays in making cash payments for individual investments, increased costs that would require subsidies from high-wage earners to low-wage earners to avoid exclusion, and heightened vulnerability to error and fraud, which would require a comprehensive regime of strict regulation and supervision, among myriad other problems (EBRI, 2001; Salisbury, 1999; Whitman, 2006).

\section{Pay For Performance}

Acquiring access to data, and a capacity to use the data, are the first challenges in prudent purchasing. Case studies show a variety of healthcare purchasers are managing to make quality standards into a working language of performance with providers, but 
generally there is a manifest demand for better, quicker, and more comprehensible information (Fossett et al., 2000; Milbank, 2000, 2001). Purchasers also complain of getting too much information, possibly standardized by a few basic HEDIS measures, but often contradictory or incomparable.

A now commonly held view, long in coming, recognizes that measuring and producing comparative information by itself is not enough (Avorn \& Fischer, 2010; Maio, Goldfarb, Carter \& Nash, 2003). To be effective, information must be targeted with a definite purpose to a definite audience with the organizational capacity for making improvements (Berwick, James \& Coye, 2003; Mannion \& Davies, 2002; Sage, 2000). Data and information translation to reach this active audience is a new frontier in quality information. $^{13}$

A study of enforcement of Medicare fees showed that providers bill more modestly when they know the purchaser cares and is paying attention (Becker, Kessler \& McClellan, 2004). Likewise, the federal Agency for Healthcare Research and Quality found "timely feedback from reporting systems is a critical incentive to continue to report medical errors" (AHRQ, 2003, Ch. 2). Medicare notably fails to supervise to an effective degree to reduce the "error rate" in billing, or more importantly, to give providers a sense that an active intelligence resides behind the machinery of the purchasing authority (Clemmitt, 2000; National Academy of Social Insurance, 2002; Reinhardt, 2003a).

\footnotetext{
${ }^{13}$ One sign of the growing attention to the distinct issue of implementing knowledge in practice is seen in the appearance of an open-source journal, Implementation Science, available online since 2006 at www.implementationscience.com
} 
Occasional studies have shown statistical improvement of performance indicators through the use of payment incentives (e.g., Rodriguez, von Glahn, Elliott, Rogers \& Safran, 2009), but in most cases paying for performance by itself has failed to produce the desired results (McClellan, 2011; Mullen, Frank \& Rosenthal, 2009; Werner, Kolstad, Stuart \& Polsky, 2011). Promoters believe provider profiling using claims data could succeed (Wennberg, Fisher, Stukel \& Sharp, 2004), but many physicians and others are apprehensive, believing the results will be negative rather than positive (JAMA 2000; MacKinnon \& Lipowski, 2000).

One problem is that many quality indicators fail to account for risk factors. Standard online performance reporting for nursing homes by CMS, for example, or current reports in Oregon from Quality Corp are virtually impossible to interpret, because case mix is not taken into account. Hospital-based infections and certain other isolable conditions might be amenable to absolute quantification, but for most healthcare indicators case mix is essential in quality reporting (Carey \& Burgess, 1999; Cowper et al., 2001; Yegian, 2003). More accurate assessments are possible, and easier to obtain, with a larger population: in hospitals or other organized delivery systems, or in geographical areas (Thomas, Grazier \& Ward, 2004).

Other problems reported by physicians relate to the reporting burden, conflicting expectations from different purchasers, errors, inappropriate applications of evidence that could harm patients or waste resources, and intrusion on clinical autonomy by nonprofessionals (Beckman, Mahoney \& Greene, 2007). Numerous examples show provider report cards tend to create a negative environment that may lead to providers 
refusing difficult patients, and appear to always produce conflict over the legitimacy of the quality measures (Dranove et al., 2002; Hibbard, Stockard \& Tusler, 2003; Mehrotra, Bodenheimer \& Dudley, 2002; Weissman et al., 2005; Werner \& Asch, 2005). An elegant study of inpatient practice patterns in Oregon and Florida (Welch, Miller \& Welch, 1994) demonstrated the feasibility of physician profiling within a system, but participants in the ensuing (and continuing) debate appeared to agree that such information should be used only for physician feedback, which often shows positive results in quality improvement (JAMA 2000; MacKinnon \& Lipowski, 2000; Shortell et al., 2005).

Systematic performance monitoring is represented in various reporting regimes, notably in the National Nosocomial Infections Surveillance program, instituted in 1970 to monitor hospital-based infections (Anon., 2000); also in a reporting standard developed by the National Quality Forum for use by the states as healthcare purchasers (Rosenthal \& Booth, 2003); and many other areas (UCSF Evidence-based Practice Center, 2001). Such systems are typically used for quality management and purchasing decisions—not direct performance incentives. When reporting is voluntary, and public disclosure is involved, low performers tend to drop out, indicating one difficulty with voluntary reporting in a punitive environment (McCormick, Himmelstein, Woolhandler, Wolfe \& Bor, 2002). Emphasis on individual financial incentives can actually reduce performance by focusing on a narrow indicator or a narrow elite class of providers (Alexander, Waters et al., 2001; Anderson et al., 2003; Behn, 2002). Measured indicators may improve at the expense of other aspects of quality that are not measured. In other workplace settings, the use of financial incentives to improve safety has been shown to produce positive results 
in some cases, but may also lead to distortions, such as underreporting errors, or produce no effect (Elsler et al., 2010; Goodrum \& Gangwar, 2004; Haines, Merrheim \& Roy, 2001). Best results were observed to occur when incentives were combined with other management and team initiatives.

In 2003, a stellar cast of healthcare analysts published a petition in Health Affairs endorsing the principle of paying for performance (Berwick, DeParle et al., 2003).

Although "available measures are less than perfect," the group said, adequate tools exist to begin, and Medicare should lead as the nation's major single purchaser. In addition to negative responses from physician associations, which might be expected, former HCFA administrator Bruce Vladeck (2004) posted a highly skeptical response, with the following objections.

- Quality is already improving without explicit financial incentives, and adding incentives could retard rather than accelerate improvement.

- Lack of appropriate data, though evolving rapidly, makes reimbursement-related incentives presently impracticable.

- The record of explicit reimbursement incentives is decidedly mixed, often producing contrary results to what is intended.

- $\quad$ Payment incentives promote rules-based management that does not necessarily comprehend the complexity of medical decisionmaking - and human lives are at stake.

- If performance could be truly measured reliably, then a public program like Medicare should stop paying for unacceptable performance rather than pay more for high performance.

- Performance-based purchasing is yet another effort by payers to exert control over providers, and undermines professional autonomy through the exercise of economic muscle. 
- Developing quality-related technology, by itself, offers a much better prospect for quality improvement.

An interesting feature of the literature on performance indicators and pay incentives is the completely different viewpoints from those observing from the top down, embracing the perspective of purchasers, health plans, and scholars using aggregate data versus the perspective that emerges from physicians and caregivers. Imposing a framework of performance language and metrics on clinical practice, combined with financial incentives, may confuse priorities and judgment, erode moral relationships with patients, and result in low morale (e.g., Doran \& Roland, 2010).

The most haunting messages appear in personal stories of physicians who decide to leave general practice, due to the burgeoning rules-based environment. In one example (Reisman, 2010), a physician for the Veterans Health Administration, a model delivery system, found her time increasingly rushed as the paperwork on her desk stacked up with coding and documentation requirements, and lists of phone calls to make; and finally realized it was time to go one day when she was horrified to find she had only been half listening to her patients with serious problems, because she was thinking about these other tasks. In breaking off her connections with longtime patients, she had to explain, "I love the VA. But this job isn't working for me anymore" (p. 1071). A very similar goodbye message appeared in the literature from the United Kingdom, under its system of clinical governance (Elliot-Smith, 2009; see further discussion in the section below on clinical governance in the UK). 


\section{Capitation}

Capitation remains a favored option to limit the supply of health care, and is used in other countries in the form of global budgets to contain the supply of hospital or health care for a population. In the USA, since the retrenchment of managed care organizations in the late 1990s, balancing the conflicting incentives for too much care under fee-forservice payment and too little care under capitation has been an enduring conundrum.

Capitation has disappeared from most of the United States (Zuvekas \& Cohen, 2010), but remains prevalent in Oregon and Washington state in Medicaid contracts. Public contracts that offer a capitated payment usually pass risk directly to service providers or an intermediate health plan, which may be organized in various ways and is rarely an actual insurance carrier. Growing in importance since the mid-1990s, riskbearing provider-sponsored organizations (PSOs) have become a separate category of insurer. As of November 2003, about two-thirds of the 389,154 eligible Oregonians covered by Medicaid were in medical, dental, or mental health managed care (Oregon DHS, n.d.); only $7 \%$ were covered by commercial managed care insurers; $19 \%$ were covered by CareOregon, a Medicaid-only MCO; while $72 \%$ were in prepaid health plans, involving direct contracts with risk-bearing provider organizations (CMS, 2002).

To acquire these capitated contracts and survive, providers gradually developed the capacity to assess risk themselves. Solo physicians joined independent practice associations (IPAs) or hospital organizations, first to gain market access, but also for bargaining power, and for services in risk assessment and contract negotiation (Gold, Hurley \& Lake, 2001). Group practice grew, though most physicians continued to be 
reimbursed by fee-for-service, with an umbrella organization managing the capitated contracts (Starfield \& Oliver, 1999).

Once provider groups learned to handle risk, there appeared to be no reason to include insurance carriers as a third (or fourth) party. PSOs began direct contracting for group insurance under capitated contracts, accepting a set payment per person per month. The number of PSOs nationwide grew strongly through the 1990s (Lewin Group, 1997). Direct contracting looked like the wave of the future when Congress, in 1997, determined it would award Medicare managed care contracts to PSOs, even if they did not meet state insurance requirements for reserve funds to carry the risk.

This decision by Medicare was rash. The once-prevailing goal for providers to acquire as much risk as possible_-even demanding capitation in order to manage budgets and definitions of medical necessity by their own standards—-suffered a severe blow in 1999-2000 with the bankruptcies of two giant, globally capitated PSOs in California (Robinson \& Casalino, 2001). The event induced increased regulatory supervision by the state and aroused the fear of an epidemic of failures (Robinson, 2001b; Casalino, 2001).

Current reform plans in Oregon expect to use capitated payments for medical homes or accountable care organizations (Oregon Coalition of Health Care Purchasers, 2009). In response, James Robinson and Emma Dolan (2010) recently stepped forward to remind policymakers of the failures and disruption in California when 147 providersponsored organizations that accepted risk contracts failed, stranding 4 million people without coverage or care. 
Although certain provider systems operate comfortably under capitated contracts, capitation in general was in retreat in the last years of the 1990s (Hurley, Grossman, Lake \& Casalino, 2002). PSOs began to limit the degree of shared risk in the contracts (Gold et al., 2001).

One primary reason for the failure of capitation was the significant deterioration of access and quality of care when implemented in small-group settings, such as independent practice associations, which contributed to public dissatisfaction (Christie, 2004; Hornbrook, 2000; Schauffler, McMenamin, Cubanski \& Hanley, 2001). State-of-the-art prospective payment systems designed by Medicare, though more sophisticated, face the same objection (Frymark \& Mullen, 2005).

By the latter half of the 1990s, patient protection laws in the states began to demand more accountability and more data from HMOs undertaking capitated contracts with providers (Yount, 2001). The major components of patient protection, or quality assurance, were legislated in Oregon in 1997 and 2001 (ORS Ch. 743). This trend produced an incentive for insurers to manage claims and medical necessity internally, rather than pass risk and accountability downstream to providers (Robinson \& Casalino, 2001). Although legislation and court decisions waffle on the exact terms of accountability for insurers, the risk is sufficient to encourage fee schedules for designated services, which allows spot contracting with individual physicians, centralization of data, and flexibility in networking (Robinson, 2001a). 


\section{Practice Management}

Practice management refers to many different types of organization and oversight. Often it relates to the concept of coordinated care, working for an efficient provision of health care throughout an episode with different providers and settings. Insurers are most concerned about clinical management of persons with high-cost chronic conditions.

\section{Disease Management}

Disease management programs have grown rapidly since about 1997, focusing on conditions with potential for serious complications, like asthma, diabetes, or heart disease (Harvard Managed Care Industry Center Group, 2002; Villagra \& Ahmed, 2004). The programs are sometimes operated directly by insurers, or contracted out to private companies, or through in-house hospital or clinical programs. Not all disease management programs have been successful, but examples show positive results in managing disabilities and chronic care (NASI, 2003), in geriatric medicine (Johri, Beland \& Bergman, 2003), occupational disability management (Tompa, Dolinschi1, de Oliveira1 \& Irvin, 2007), and for individuals with low literacy (Lee, Arozullah \& Cho, 2004). In a recent pilot project implemented by Boeing in Washington state (Milstein, 2009), targeting high-risk groups and paying for additional case management by a dedicated care team appeared successful.

Other systematic reviews of disease management in medical interventions are ambiguous. A current review of disease management program for costs, quality of care, health outcomes, and implementation (RAND, n.d. Analysis of disease management) 
indicates quality of care is the most likely to show improvement, while other factors are less certain; costs may increase, depending on the intervention strategy. These conclusions match the results of a systematic review of home nursing care for the elderly (Lupari, Coates, Adamson \& Crealey, 2011). Educational interventions for kidney disease have shown additional evidence of improved health outcomes (Mason, Khunti, Stone, Farooqi, \& Carr, 2008).

The main issue of concern here, for practice management, is how a prudent purchaser can apply a form of payment to encourage effective clinical management. Simply paying an additional fee is probably not enough. Most disappointing in this respect were the results from a Medicare Coordinated Care Demonstration, 2002-2006, which showed only one significant reduction in costs for chronic conditions among a diverse set of 15 participating organizations; and the savings did not recoup the extra payment (Peikes, Chen, Schore \& Brown, 2009). Each organization—including commercial disease management vendors, hospitals, academic medical centers, an integrated delivery system, a hospice, a long-term care facility, and a retirement community—was allowed to design its own intervention. In spite of limited measurable effects, physicians were generally happy with the project, believing their patients were getting better care, though they recognized patient self-management had not improved.

Differences in performance observed in the Medicare demonstration highlighted characteristic elements for success that also appeared in a separate analysis of Primary Care Case Management fees. The Medicaid fees have been used since the 1980s in about 30 states, including Oregon (Verdier, Byrd \& Stone, 2009). Important factors in both 
accounts were: (a) target high-risk patients, (b) in-person patient contact, (c) in-person caregiver contacts, (d) timely information from hospital and ER admissions, (e) focus on patient self-management, and (f) team-based nurse staffing. This list reflects findings from other studies as well.

- Successful intervention between a practitioner and a patient often requires a sustained, multifaceted approach (Davis \& Taylor-Vaisey, 1997; Ferlie \& Shortell, 2001; Gawande, 2004; Mehta \& Eagle, and Holmboe, 2003).

- Organizational culture is a primary consideration, with the most effective settings involving a personal relationship or active presence (contact learning) with peers, an opinion leader, researchers, or a nurse consultant responsible for specific conditions (Bedregal \& Ferlie, 2001; Berta \& Baker, 2004; Heslop, Elsom \& Parker, 2000; Miles, Bentley, Polychronis, Grey \& Melchiorri, 2001; Timmermans \& Mauck, 2005).

The critical feature here is management capacity, not simply better policy or pay (Bohmer, 2010). Following up on this perspective, physician self-governance is being gradually eroded in favor of health-system governance. Locally, CareOregon has developed a multidisciplinary case management team, operated from its central office (Klein \& McCarthy, 2010). Contracts from Providence Health Plans and Regence BCBS show similar provisions. Patients with repeated hospitalizations or unusually high costs are typically turned over to the insurer's case management team. Kaiser Permanente and other integrated health plans are already expert at managing asthma, diabetes, and a number of other chronic conditions, with proven value in health, though cost savings are more elusive (Fireman, Bartlett \& Selby, 2004; Kemper, Applebaum \& Harrigan, 1987). Care management is resource-intensive and expensive.

One problem with the trend toward disease management programs is the carving out of discrete conditions, which obscures a holistic view of the patient as advocated in 
gerontology to deal with multiple interacting conditions (Bodenheimer, 1999; Cassel, Johnston-Fleece \& Reddy, 2010). One strategy to improve patient-centered care is observed in the PACE program, supported by a combined, capitated fee from Medicare and Medicaid. PACE programs, including contractors in Oregon, coordinate care for the frail elderly in a community-based support system to avoid placement in a nursing home; and the intervention appears to work. Program evaluations have shown PACE cost a little more, but values in healthy outcomes were significantly better, including reduced nurse visits, hospital admissions, and hospital and nursing-home days, as well as improvement in functional status, quality of life, satisfaction with care, and socialization (Abt Associates, 1998, 2000). Medicare reform in BBA 1997 changed PACE from a demonstration project to a permanent program, but diffusion has been slow. Profits are apparently difficult to achieve.

All of these examples indicate that payment reform in itself is not effective. In a book on finance and quality management in value-based care (Dlugacz, 2010), among all the reported indicators and data arrays, the supplied examples of improvement derived from active agents inside the delivery system. In another account (Smoldt, 2010), pay for performance was distinguished from pay for value, emphasizing an intention to align incentives for the delivery system to manage itself, often using limited shared-risk payments and dynamic learning strategies. 
Integrated Delivery Systems

Currently, healthcare purchasing strategies are a major problem in care coordination. The variety of purchasers and short-duration relationships with any one patient contribute to gaps in care and different applications of care management (Cebul, Rebitzer, Taylor \& Votruba, 2008). In a report on mental health services under the Oregon Health Plan, care coordination was obstructed by carved-out contracting that encouraged a confusing multilayered system with diverse locations, procedures and billing, complicated by fluctuating coverage for individuals and a high patient turnover rate; plus, one-third of the plans dropped out over a few years, and plan features changed (Laws, Gabriel \& McFarland, 2002). Similar problems bedeviled the marketing of early Medicare managed care plans, resulting in confusion and uncertainty that caused many beneficiaries to drop out (Biles et al., 2002).

Purchasers and providers largely agree on the importance of integrating and coordinating care with patient-centered interests (cf., Hardy et al., 1999; IOM, 2003a). The challenges of integration are directly relevant to current debates about how to define and organize accountable care organizations (McClellan, McKethan, Lewis, Roski \& Fisher, 2010). Hospitals are a natural locus for this kind of purchasing authority, due to institutional control over facilities and a perspective that incorporates both finance and delivery. Like insurers, hospitals are data warehouses, with an added advantage in being able to directly apply accumulating information on resource use, practice patterns, and outcomes to improve the quality of care (Joyce, Cioffi, Petriwsky \& Robinson, 2011). 
In terms of governance, according to one physician survey (Budetti et al., 2002), group culture in rapidly growing systems has been difficult to achieve and leadership problems widespread. Physicians were alienated from the administrative system when individual productivity measures were applied. In another study of physician attitudes (Greener, 2003), care management by administrators produced a negative effect and confusion. Physicians were skeptical of accountability standards and micromanagement, and preferred to be treated as independent professionals, provided with better support for clinical services and useful information systems.

Purchasers exert authority over clinical autonomy even in individual practice through two specific mechanisms: the definition of medical necessity, and evidence-based practice standards. These core elements of practice management are discussed in the following sections.

\section{Medical Necessity}

In his classic social history of American medicine, Paul Starr (1982) gave considerable attention to the resistance of physicians to corporate intrusion in medical practice through third-party contracts. This longstanding perspective of professional independence continues to characterize physicians today. The very recent failure of capitation to effectively localize medical decisionmaking on a broad basis has reinstated the old conflict between purchasers and providers.

Most state laws apply definitions of "appropriate and necessary medical care" in relation to insurance carriers by naming a committee, a firm, a primary care physician, or 
a managed care organization's medical director as an ultimate authority (American Association of Health Plans, 2002). Only a few states give the individual physician in charge the top authority, saying: medical necessity "means the standard for health care services as determined by physicians and health care providers"; all add the provision— "in accordance with prevailing practices and standards of the medical profession and community." Similar phrases are found in private insurance contracts.

One of the odder aspects of Medicare is the disagreement between its stated mission in the law to provide all care that is "reasonable and necessary," and its accompanying extensive text setting limits to what that means [SSA1862(a)(1)(A)]. This dual posture combines the idea of benefit as needed, open to professional interpretation, alongside a predetermined catalogue of services typical of a liability insurer. Although expressly forbidden to define medical necessity, and expected to rely instead on standards of appropriate care, and "usual and customary" prices in the community, Medicare's prospective payment systems classify and bundle diagnoses with standard treatments, with specific terms of eligibility and coding. Defining medical necessity through codes is a major function in claims processing by Medicare intermediaries and carriers (Gottlich, 2003).

The incursions of managed care taking over definitions of medical necessity from physicians are well popularized (e.g., Anders, 1996; Makover, 1998). Less publicized, preferred provider organizations (PPOs) have become prominent intermediaries between contracted providers and over half of employment-based health plans (KFF/HRET, 2010). PPOs develop discounted fee schedules for a range of services attractive to clients, who 
are usually self-insured firms (Hamer \& Anderson, 2000). The fee schedules define medical necessity by determining coverage for sets of activities associated with a price.

In both public systems and private enterprise, medical necessity is commonly predefined. Oregon's priority list of diagnosis-treatment pairs-Governor Kitzhaber's "menu" at the feast of health care (Mahar, 1993)—represents the most ambitious state effort to define the terms of coverage (DiPrete \& Coffman, 2007).

\section{Evidence-Based Practice}

The paradigm of evidence-based medicine, inaugurated in the early 1990s (Evidence-based Medicine Working Group, 1992; Guyatt, 1991), accompanied a growing recognition for the need of quality improvement, both in hospitals and in clinical practice. By the end of the 1990s, hospitals and physician organizations were beginning a new generation of clinical management (Bovbjerg \& Miller, 1999), exemplified in a move by OHSU to form EBM Solutions in 1999 (now HealthGate Evidence-Based Medicine Clinical Guidelines, available online at the U.S. National Library of Medicine website), joining with five other academic medical centers to produce marketable evidence-based practice guidelines and treatment options. The example shows the strategic position of hospitals, and particularly academic medical centers, in the production and use of effective information and protocols to promote value in health care (e.g., Stoller, 2004).

Enthusiasm for evidence-based practice is tempered by physicians arguing they should remain free to judge the source and substance of the evidence, distinguish "fact from fervor," and rely on professional experience to avoid "paralytic indecisiveness" 
when solid information is not available (Naylor, 1995). Such arguments for professional autonomy lost force as evidence accumulated by the late 1990s that voluntary systems of applying evidence-based medicine rarely work (e.g., Cukor, Fairbrother, Tassi, Butts \& Friedman, 2002; Gilbart, 2003; Grimshaw et al., 2001). In the United Kingdom, a 2001 government report documented failures in clinical performance that "sent out a clear signal that self-regulation of clinical governance was no longer seen as sufficient to safeguard standards and patients" (Ham, 2004, p. 179).

Creating binding rules from evidence in statistics or randomized-clinical trials or any other information source is resisted by physicians, because such rules are often enough wrong and may cause harm. The evidence base itself may be incalculably contrived from biased sources, making providers correct to resist or modify the guidelines by their own judgment (Bodenheimer, 2005; Groopman, 2010; Groopman \& Hartzband, 2009). Practitioner disagreement with guidelines can reach as high as $90 \%$ (Cabana et al., 1999; Christianson, Wholey, Warrick \& Henning, 2003). Physicians themselves are careful to take account of the uncertainty of rules and allow professional disagreement, as in an intensive-care unit, for example, where dissent of one physician on a team can block a treatment decision (Zussman, 1992). Patients, too, have shown a preference for voluntary guidelines rather than mandatory rules for clinical practice (Gerber, Ptashnik, Doherty \& Dowling, 2010).

Two conflicting trends are apparent in this debate over the locus of authority in practice management. A study of purchasing by major insurers (Robinson \& Yegian, 2004) observed an increase in cooperative supervision. Insurers were relaxing 
prohibitions on medical practice and relying more on supplying information resources toward medical management and patient education. UnitedHealth Group, the nation's largest health insurer, "led the health insurance industry in dropping prior authorization and precertification requirements in 1999, arguing that the cost of administering barrier methods to utilization management exceeded the financial benefits" (p. 273). Earlier, life insurers had arrived at a similar conclusion, determining that it was more profitable to simply accept secondary risks rather than invest in barriers to detect and exclude them (Horstman, 2001). If informed in a timely fashion, studies show physicians do respond to reducing costs, not only for themselves (Shortell et al., 2001), but also for their group or system (Alexander, Waters et al., 2001; Roth, Plastaras, Mullin, Fillmore \& Moses, 2001) and for patients (Korn, Reichert, Simon \& Halm, 2003; Narine, Senathirajah \& Smith, 1999; Reichert, Simon \& Halm, 2000; Wynia, Cummins, VanGeest \& Wilson, 2000).

Meanwhile, the U.S. healthcare system is moving steadfastly toward a resurgence of direct utilization management, with clinical rules imposed through purchasing power, and increasing demands for quality reporting and performance benchmarks devised from academic evidence, with financial consequences for providers (Endsley, Kirkegaard, Baker \& Murcko, 2004; Jacobson, 2001; Kapur, Gresenz \& Studdert, 2003; Mays, Claxton \& White, 2004). The theories of new public management are clear in this trend. The principal model is found in the managerial regime of clinical governance that existed in the United Kingdom until last year (Timmins, 2010), when a new wave of reform proposed to overturn everything and start over. 


\section{The Case in the United Kingdom}

The National Health Service (NHS) in the United Kingdom (UK), with 50 years of experience operating with clinical autonomy, moved in the 1990s toward a system of clinical governance, similar in appearance to organizational developments in the USA that intervene in clinical autonomy with external practice guidelines (Bindman, Weiner \& Majeed, 2001). Contrary to a common misperception in the USA that the UK healthcare system represents socialized medicine (Beier, 2000), actually both primary-care gatekeepers and hospital-based physicians employed directly by NHS, possess, or possessed until recently, complete clinical autonomy (Ham, 2004). Historically, cost control in the UK was maintained by allocation formulas, which stopped short of intervening in specific coverage decisions, and allowed a flexible and responsive system of care.

Reforms in the NHS aimed to add flexibility in service delivery by making hospital budgets rely in part on contracts with physician primary-care groups, similar to IPAs in the USA (Koen, 2000). The contracting groups were originally voluntary, but became mandatory in 1997. Flexible contracting was supposed to encourage community-based alternatives to hospitalization and better care coordination, according to the principles of managed competition (Allen, 2000; Enthoven, 2000). The explicit details of contracts, however, "laid the groundwork for the further development of accountability mechanisms in the form of performance measures" (Tuohy, 2003, p. 207), which undermined the culture of clinical autonomy and professional discretion. The 
primary-care groups became essentially a "subcommittee of the health authority" (Huntington, Gillam, Rosen, 2000).

Although the theory of new public management intends to "banish bureaucracy" (Osborne \& Plastrik, 1997) and infuse market principles in areas where markets have traditionally not functioned, the exact opposite has occurred, in both health and education, producing more bureaucracy and rules-based management in a command-andcontrol environment over professional practice (Charlton, 2000; Waring, Dixon-Woods, Yeung, 2010). In both the UK and the Netherlands, physician discontent has been escalating-visible in letters and blogs, editorials, surveys, journal articles, and books. A few titles from the UK provide a shorthand entry into this boiling controversy: "Medical regulation, spectacular transparency and the blame business" (McGivern \& Fischer, 2010); and under the same specter, "The grim threat to British universities" (Head, 2011). Similar titles with the same themes, though less angst, are appearing in the USA (e.g., Kurtzman et al., 2011).

Part of the discontent among physicians refers to financial inequities, including problems with small-group risk contracts and "persistent variation from fair budgets" (inflated payment or crisis), patient selection to avoid high risks and other denial of services, and the burden of unfunded mandates for quality monitoring and improvement (Jones et al., 2010; Smith, 1999). Other complaints involve conflicts in physician culture, produced by the attempt to combine roles as care agent and fiscal agent (Marmor, 2001).

The rhetoric becomes scathing in regard to the imposition of evidence-based practice rules by bureaucratic decisionmakers (Fitzpatrick, 2009). One eloquent manifesto 
protested the "takeover of the clinical consultation by an alliance of managers and their statistical technocrats who are empowered to define 'best practice."' (Charlton \& Miles, 1998, p.372). Others remarked in grim jest that if they followed the guidelines they would kill people. Radical protest eventually became too widespread to discount as a fringe element. British physicians and caregivers (e.g., Rose \& Gidman, 2010) have been obligated to draw together arguments and patiently explain the nature of evidence-based practice as an inherently uncertain enterprise that requires independent judgment and care in its application.

The new public management implemented in NHS is also being applied in health systems around the world, imposed in Latin America and Africa, for example, by requirements from the World Bank and the International Monetary Fund—known as decentralization, or more ironically, (de)centralization (Homedes \& Ugalde, 2006; Saltman, Bankauskaite \& Vrangbaek, 2007). The model was applied in Canada in the early 1990s, where it developed a reputation for rigid, bureaucratic control and hierarchical power (Trottier, Champagne, Contandriopoulos \& Denis, 1999). In Europe, the model is labeled as managerialism or managerial regimes (Kuhlmann \& Burau, 2009).

Various applications of the managerial regime show different results, some unexpected and unwanted, such as hospital domination and reduction of primary care in local budgeted regions. Hierarchical supervision can work, as in the RAND Health Insurance Experiment showing improved quality and cost control under managed care (Newhouse et al., 1993), and in other successful applications of clinical guidelines (e.g., 
Wigder, Ballis Urgo \& Dunn, 1998). Results in the UK, however, showed an increase in administrative and transaction costs, diversion of attention from quality improvement, and "few tangible benefits" (Ham, 2004, p. 178).

\section{Information Infrastructure}

Information capacity is a primary theme in healthcare finance and delivery. The following list draws together a number of separate elements, each critical to system performance.

- Evidence-based practice (systematic review)

- Evidence-based medicine (decision tools)

- Computerized physician order entry (pharmacy control)

- Electronic medical record

- Claims data

- Quality reporting (encounter data)

- $\quad$ Safety reporting (sentinel events)

- Data collection, analysis, and evaluation

- Data and information translation

- Interoperability (health information network)

- Organizational culture (contact learning)

Rather than examine these constituent parts of the healthcare information infrastructure in detail, it may be enough to merely note the many different aspects and the complexity of the overall system in terms of hardware, software, coordination, administration, and organizational capacity. Once widely installed, an electronic 
information infrastructure is expected to promote value, producing a net savings, according to one estimate, of $\$ 77.8$ billion per year through reduced transaction and material costs, coordinated care with other providers, lab work, record exchange, billing, and so on (Walker et al., 2005). The most advanced information systems are developing in integrated organizations where the positive externalities of the large investment in the delivery system accrue to the purchaser in the same organization (GAO, 2003a). Kaiser Northwest was a pioneer in the ambitious Kaiser information system (Kaiser Permanente NW, 1999).

According to a recent survey of U.S. hospitals (Jha, DesRoches, Kralovec \& Joshi, 2010), only about $12 \%$ reported having a comprehensive system of electronic health records - a central feature of information capacity and coordinated care. Only $2 \%$ of the hospitals reported having the capacity to meet the current federal definition for “meaningful use." An earlier study showed health information networks within organized delivery systems showed numerous signs of development (Coddington \& Moore, 2002), but proprietary systems also faced staggering challenges in terms of finance and long-term sustainability. Further, interoperability outside the organization for clinical information was virtually nonexistent. In Oregon, several large hospital systems have developed impressive internal information systems, but presently none of these systems will speak to one another except on special terminals like those between OHSU and the VA hospital. Developments have been slow, and the USA has been shown to be already behind other developed countries in health system information technology (Goldsmith, Blumenthal \& Rishel, 2003). 
Apart from the hardware concerns, recent reviews of information technology (IT) in health care have not been entirely positive. One systematic review (Buntin, Burke, Hoaglin \& Blumenthal, 2011) showed "predominantly positive results," which left room for a number of negative findings: lack of leadership to plan teamwork around the IT system; impaired practitioner relations and work flows; machine errors that affected patient safety and medical decisions, and disrupted practice; and lack of capacity to include comprehensive records or two-way interactions. These results have only gradually become a significant feature of the health policy literature. Another recent study (Metzger, Welebob, Bates, Lipsitz \& Classen, 2010), related to computerized physician order entry (CPOE) for prescription medications at 62 hospitals, presented another set of discouraging results. A simulation showed the system only detected about half of the medication orders that would have resulted in fatalities, and did not detect a great number of potential adverse drug events, with a wide degree of variation. This result contradicts the earliest reports and high hopes for CPOE demonstrations, and confirms subsequent doubts.

Such results provide reason for caution. Tales of practices returning to paper indicate a purpose and security that is not always capable of being replaced. IT systems may not be universally applicable or beneficial. This observation presents a quite different conclusion from the vast promise of IT systems suggested by the evidence even 5 years ago . That earlier confidence is now engraved in national policy in the Affordable Care Act. 


\section{Medical Liability}

A major barrier to the effectiveness of any reporting system, voluntary or mandatory, is the secretive and fearful environment that currently exists in medical practice due to the threat of litigation. Survey results confirm a common observation that the adversarial, litigious climate in health care is a serious obstacle to disclosure of medical errors (Lamb, Studdert, Bohmer, Berwick \& Brennan, 2003; Ofri, 2010), and also increases costs through defensive medicine, which were recently estimated to be $\$ 55.6$ billion or $2.4 \%$ of total U.S. healthcare expenditures (Kessler \& McClellan, 1996; Mello, Chandra, Gawande \& Studdert, 2010).

The "malpractice barrier" obstructs the effectiveness of hospital decisionmaking in clinical management by driving relevant data underground. Meanwhile, the current tort system fails to compensate even a small portion of those actually harmed, and in most cases also fails to provide any incentive to providers to improve quality (Sage, 2003). In this environment, "issues of medical liability, patient safety, and just compensation for the medically injured seem to be caught in a vicious cycle" (Bovbjerg \& Raymond, 2003, p. 23; Thorpe, 2004).

Traditional types of tort reform applied in the states focus on moderating costs for physicians and insurers (like award caps), but none have managed to correct the system to promote safety, accountability, and just patient compensation, nor assuaged the anxiety of physicians for the "dread risk" of malpractice liability (Carrier, Reschovsky, Mello, Mayrell \& Katz, 2010). According to this perspective, a culture of safety in medical care requires a nonpunitive system for providers that encourages transparency. Mandatory 
disclosure of medical errors, currently popular in state reform efforts, is not enough (Mastrolanni, Mello, Sommer, Hardy \& Gallagher, 2010). Fundamental tort reform is required to achieve the most effective hospital and physician decisionmaking.

In 2003, Oregon embarked on its own hospital safety reporting system by creating a Patient Safety Commission to establish a reporting standard and feedback mechanism for voluntary participants, including hospitals, healthcare facilities, and associations. Like the Joint Commission on Accreditation of Health Care Organizations (JCAHO), the program demands that notification of serious adverse events also be reported to the patient involved. The new law attempted to soften this ethical consideration by protecting reported incidents from further disclosure or subpoena, but this promise is legally questionable, and also difficult to combine with the purpose of quality improvement (Liang, 2000; Marchev, Rosenthal \& Booth, 2003). Consequently, the program is likely to face the same reticence for full reporting as observed in relation to JCAHO and other reporting systems (AHRQ, 2003; IOM, 2000; Kaiser Permanente Institute for Health Policy, 2000).

Clinical management has shown noteworthy success in a patient safety program in the Veterans Health Administration, with both IT decisionmaking support and a nonpunitive culture (Atkins, Kupersmith \& Eisen, 2010). A reporting system installed in 1999-2000 resulted in a 900-fold increase in reporting of close calls in high-priority events (Heget, Bagian, Lee \& Gosbee, 2002).

To promote a culture of safety, Studdert and Brennan (2001) recommended a system of no-fault compensation for medical injuries, modeled on the system in Sweden, 
and partially implemented in Utah and Colorado. This is also the system favored in IOM's (2000) To Err is Human. No-fault regimes in the USA have performed equivocally, partly because they have been only partially and voluntarily implemented as so-called "choice no-fault" (Cole, Eastman, Maroney \& McCullough, 2004; Meier, 1988). Studdert and Brennan argued that the no-fault system can be readily combined, if desirable, with additional options for enterprise liability, possibly directed toward hospitals or health systems (Sage, Hastings \& Berenson, 1994); or with experience rating, to provide an incentive for improved performance (Sloan, 1990). The details of such systems are complex (O’Connell, 1975).

Jeffrey O'Connell (2007) is now advocating an "early offer" approach as a specific application of the no-fault idea, with an analogy to Workers' Compensation. The ultimate goal is to achieve a system that communicates promptly and sympathetically with affected patients (Liebman \& Hyman, 2004), and further, to produce an environment that encourages providers to participate in a reporting system that can target and reduce errors (Claremont, 2000). General progress is impeded by the current tort system. Leading academics have called for a new paradigm (Brennan \& Mello, 2003, p. 271):

The conflicts between the tort system and error reduction programs are fundamental and severe, and physicians' concerns about being sued and losing their liability insurance have reached a fever pitch. Appeals to professionalism may ring hollow with physicians operating under a siege mentality. Unavoidably, a system to improve safety and quality in health care must accompany any reform that intends to increase access to health insurance to the whole population. Medical liability reform, favoring a type of no-fault insurance, is a top priority. 


\title{
Chapter 5
}

\author{
The State Policy Arena
}

Prior to the 1970s, the policy process in state legislatures was clearly dominated by specific corporate and private interests (Hrebenar \& Thomas, 1987). Although this circumstance has not disappeared, descriptions of the policy process since recognize a diverse array of interests in shifting combinations (Hamm, 1983; Heclo, 1978).

One thorough study of insurance regulation (Meier, 1988) showed state bureaucrats and business leaders were the most effective policy agents. Political officeholders tend to affect insurance legislation as champions of consumer interests; while public interest groups influence the direction of reform toward increased access, but exert the least influence over actual policy.

A study of provider-sponsored organizations that offer health insurance (Lewin Group, 1997) collected information from (a) state insurance commissioners, (b) provider organizations, and (c) insurance carriers-pointing to a selection of bureaucrats and business leaders as the most significant policy leaders in health insurance. A more recent study of national health policy networks found associations of business providers, suppliers, and purchasers to be the most influential leaders (Heaney, 2006).

Gathering together these cues from previous studies, the sections below introduce six categories of influential health policy agents in Oregon: state officials, insurers, 
purchasers, hospitals, physicians, and public interest groups. The immediate section below first reviews basic influences in the legislative policy process.

\section{Policy Process}

The package of health insurance reforms that succeeded in Oregon in 1995 appears to have been the result of an iron triangle, a recognized strategy for successful policy influence that combines bureaucrats, interest groups, and a legislative committee (Hamm, 1986, 1983). Various updates redefine the triangle as a diverse issue network or coalition (Browne, 1990). The current influence of public opinion and public interest groups on legislators is clear (Nownes \& Freeman, 1998; Rosenthal, 1993), and the increased use of grassroots direct lobbying, surveys, and public opinion polls makes a convincing extra point of influence in state policymaking; however, allying such an interest with a key legislator, government agency, or private interest remains a primary strategy. The many permutations for the iron triangle do not overcome the simple designation of three priority points of power: chief legislator, chief bureaucrat, and chief private interest. For health insurance regulation, the principal influence of private interests, particularly insurers, and bureaucratic experts looks like the classic power structure (Meier, 1988).

Legislators are often heavily influenced by information and models developed by lobbyists, and they may even produce a bill in partnership with lobbyists. Oregon's ambitious land-use planning law of 1973, for example, was saved from a committee deadlocked in "acrimonious debate" through substantial revisions made by a work group 
composed mostly of lobbyists (Heider \& Dietz, 1995). In 1986, Governor Neil

Goldschmidt brought together business and labor lobbyists to write Workers'

Compensation legislation, which passed in a one-day session. In a similar move,

ambitious health insurance legislation in Massachusetts passed in 2006, through input by a task force of "power brokers," led by major insurers, convened to overcome legislative deadlock (Kaiser Network, 2006).

Personal relationships with legislators over time has been observed to be a primary factor in lobbyist influence (Rosenthal, 1993). Bureaucrats in relevant public agencies possess an additional insider status as representatives of the public interest, which tends to add credibility and influence with legislators (Abney, 1988). Experiences in Oregon indicate the following key participants in state policymaking: (a) an inside champion, such as senate president, house speaker, governor, or committee chair; (b) leaders of relevant state agencies; and (c) lobbyist access.

Expenditure records of lobbyist organizations from the Oregon Department of Standards and Practices Commission offer a view into legislative influence. ${ }^{14}$ The Oregon Medical Association was the top lobbyist in the period 1987-1997. In more recent legislative sessions, 2007-2009, the Oregon Medical Association was ranked sixteenth in the list of expenditures, and the top healthcare stakeholder was Regence BCBS, ranked fifth, followed closely by the Oregon Association of Hospitals and Health Systems.

\footnotetext{
${ }^{14}$ A note of caution is in order, because money and influence correspond only vaguely - a classic example being the Hawaii Government Employees Association, reported to be one of the most powerful lobby organizations in the state, but reporting zero expenditures (Lee, 1987). Active lobbyist organizations in the Oregon Legislative Assembly are listed in expenditure reports compiled by the Government Standards and Practices Commission, available online since 2000 at www.oregon.gov/GSPC/public_records.shtml
} 
During both periods, eight organizations related to health care appeared among the fifty top-spending organizations. In those listings, it appears insurers and hospitals have taken over the political initiative from physicians and caregivers in current legislative sessions.

Policy entrepreneurs are well recognized as an important factor in policy success, and appear in surprising victories (Conlan, Beam \& Wrightson, 1995; Kingdon, 1995/1984). The role of state policy entrepreneurs in health policy reform was revisited by Thomas Oliver (2004), following an earlier, more extensive review (Oliver \& PaulShaheen, 1997). Oregon was included among the case studies, recognizing the key role of John Kitzhaber as senate president in the progress of the Oregon Health Plan.

In spite of legislative successes, however, few if any of the reforms Oliver highlighted were actually implemented or managed to survive through the changing political climate of the 1990s. Actual results indicate a policy entrepreneur may be viewed as a necessary but not sufficient condition for success. Legislative composition and processes, and the objective characteristics of a policy and the interests it involves, are important corollaries.

In the period 1987-1993, when the Oregon Health Plan was being shaped, the legislature lost its strong Democratic leadership, Republicans gained control of the House, and the Senate became more competitive, with a narrower Democratic majority. The number of bills introduced related to health insurance access steadily increased (possibly as a result of gridlock and political strategies for obfuscation), the number of successful bills declined from 10 in 1989, to 8 in 1991, to 4 in 1993. Then, when strong 
Republican leadership took control of both the Senate and the House in 1995, a model package of health insurance reforms was passed.

The course of this history seems to plainly support the idea that a divided legislature increases gridlock. Yet divided legislatures are also capable of significant accomplishments (Meier, 1988; Prince, 2000). In this case, success in passing the early OHP reforms in 1987 and 1989, and the package of health insurance reforms in 1995, both derived from existing models developed earlier by policy experts.

Throughout the period, as the legislature divided, no increase occurred in the number of bills locked in a committee in the opposite chamber. Most bills simply languished in committee upon adjournment in the chamber where they originated. Bills that did emerge from committee typically passed unanimously or nearly unanimously. In four sessions, only one bill among some 200 introduced actually failed on the floor. A few were re-referred to committee by the Senate president or House speaker, without being passed to the opposite chamber. The authority of committees and the Senate president or House speaker appear clearly in these results as the most decisive structural elements in the policy process (Hamm, 1986). What happens in those committees, involving the influences and objective interests of the iron triangle, are key factors in policy success.

\section{State Officials}

State administrative departments, boards, and commissions provide a number of services related to health insurance and the healthcare system. The oldest involve 
licensing of physicians and other professionals, and certification of hospitals and other facilities to protect the public. Similarly, the Insurance Division supervises legal standards for the insurance industry. Public health and safety form a large component of state activity. As described in Chapter 2, direct provision of services, except for the state mental hospital, was traditionally organized at county and local levels. The state has an interest in supporting these activities, but central information and supervision may be disorganized (OHPR, 2004b). Senior and community services of various kinds are now coordinated directly at the state level, with substantial service contracting and private partnerships.

Core state functions directly related to health care relate to administering the Medicaid program, including the key features installed with the Oregon Health Plan: the high-risk pool (for individuals denied coverage in the commercial insurance market), the Health Resources Commission (technology assessment), and the Health Services Commission (maintains the priority list). The commissions are operated by volunteers appointed by the governor. In addition, Oregon Health Policy and Research was established with OHP to provide research and policy analysis.

\section{Certificate-of-Need}

Another older department activity, somewhat set apart, is the certificate-of-need (CON) program, established in 1971, near the time when federal legislation mandated the program for all states. The intent was to curb excess technical capacity in local markets. CON programs were generally unpopular and showed only moderate or no effects in 
restraining hospital investments or the diffusion of medical technology (Conover \& Sloan, 1998; Hackey, 1998). Excessive friction with private commercial interests was common, and many states merely rubberstamped applications. Many states dropped CON once the federal law expired in the 1980s.

CON requirements in Oregon continue to operate (OAR 333-575), applied only to new hospital and long-term care facilities. An updated appraisal of CON by the National Conference of State Legislatures (2011), for the 36 states where it remains, shows other states apply the regulations to many additional aspects of technology, including imaging equipment, open-heart surgery, neonatal intensive care, and other high-cost treatments and facilities. Similar arrangements to control capital investments exist in both the UK and the Netherlands, alongside other forms of technology assessment, which appear to exist everywhere.

Limiting technology can promote value when safety or questionable benefits are an issue (Baker, Birnbaum, Geppert, Mishol \& Moyneur, 2003); but CON regulates markets, and conflict with private investment and competitive interests continues to raise serious objections. Arguments on benefits and costs swing wildly in opposite directions. The Federal Trade Commission and U.S. Department of Justice (2004), following 27 days of joint hearings on various market issues in health care and hearing testimony from 250 panelists and over 60 written submissions, made the recommendation to abolish CON programs. 


\section{Oregon Health Authority}

A broad array of state workgroups related to health care evolved during the current reform initiatives, beginning with the creation of the temporary Oregon Health Fund Board in 2007, and the permanent Oregon Health Authority in 2009. The OHFB (2008) report to the legislature provided arguments for model reforms. Listing the division of committees and work groups for the project may be the quickest way to perceive its scope. Topics included coverage benefits, delivery systems, quality institute, eligibility and enrollment, federal laws, finance, exchange, health equities, and health information infrastructure.

Current or recently completed committees and work groups under the Oregon Health Authority drop a few of the earlier topics, divide others into finer categories, and add several, including administrative simplification, cost sharing, healthcare-acquired infections, workforce, incentives and outcomes, information infrastructure, technology and privacy, liability, research and evaluation, data, all-payer claims database, safety net, Medicaid, prescriber and consumer education, physician credentialing, physicians-ordersfor-life-sustaining-treatment (POLST) registry, patient-centered primary care home, health improvement, and public employers health purchasing.

Most of the persons involved in these workgroups are active stakeholders in other sectors of health care, outside the state bureaucracy. Their perspectives and knowledge have contributed to the state enterprise and been influenced in turn by the forward momentum on so many topics at once since 2007. All of these topics and several of the persons involved in these groups appear in the present study of stakeholder views. 


\section{Insurers}

Health insurance in the states is divided into three sectors of roughly equal proportions: commercial insurance, self-insured employers, and public insurance (Iglehart, 1997). Presently, state control only fully applies to commercial insurance, or one-third of the whole.

\section{Table 1. Distribution of Personal Healthcare Expenditures by Source of Funds, USA 2000-2001}

\begin{tabular}{cccccc} 
& $\begin{array}{c}\text { Covered } \\
\text { lives (mil) }\end{array}$ & $\begin{array}{c}\text { Percent of } \\
\text { population }\end{array}$ & $\begin{array}{c}\text { Expenditures } \\
\text { (billions) }\end{array}$ & $\begin{array}{c}\text { Percent of } \\
\text { expenditures }\end{array}$ & $\begin{array}{c}\text { Payments } \\
\text { per capita }\end{array}$ \\
\hline $\begin{array}{c}\text { Public Health } \\
\text { Insurance }\end{array}$ & 62.6 & $22.3 \%$ & $\$ 537.2$ & $43.4 \%$ & $\$ 8,587.71$ \\
$\begin{array}{c}\text { Private Health } \\
\text { Insurance }\end{array}$ & 178.7 & $63.8 \%$ & $\$ 437.0$ & $35.3 \%$ & $\$ 2,445.04$ \\
$\begin{array}{c}\text { Individual } \\
\text { Out-Of-Pocket } \\
\text { Payments }\end{array}$ & -- & -- & $\$ 205.5$ & $16.6 \%$ & -- \\
$\begin{array}{c}\text { Other Private } \\
\text { Payments }\end{array}$ & -- & -- & $\$ 56.8$ & $4.6 \%$ & -- \\
Uninsured & 38.7 & $13.8 \%$ & -- & -- & -- \\
Totals & 280.0 & $100.0 \%$ & $\$ 1,236.5$ & $100.0 \%$ & $\$ 5,124.68^{*}$ \\
\hline
\end{tabular}

* Includes private over-the-counter health supplies.

Source: Author calculations from CMS Office of the Actuary. Available online (Aug. 9, 2003): cms.hhs.gov/statistics/nhe/historical/tables.pdf; Holahan, J. Pohl, M.B. (2002); U.S. Census 2000

\section{Public Funds}

Public health insurance allows private insurance to operate in a select environment. Both self-insured firms and commercial insurers covering employed groups are spared the expense of covering the aged and the indigent covered under public programs, and are also unlikely to extend coverage to those with disabilities, chronic conditions, or serious illnesses that prevent employment. According to national data for 
fiscal year 2000-2001, just prior to state cutbacks in Medicaid after 2002, public-sponsored health insurance paid about 3.5 times more of the population's total healthcare expenditures per person than private health insurance, covering about one-third as many people at greater total expense (Table 1).

A cost shift is often announced as a principal reason for the rising costs of private health insurance (Families USA, 2009), but a more careful study has estimated that most uncompensated care from the uninsured is covered through special reimbursement formulas in Medicare and Medicaid designed for that purpose (Hadley \& Holahan, 2003). Cost shifting does exist, and complicates timely and appropriate reimbursement that threatens the solvency of hospitals and safety-net clinics (OHPR, 1999; Sigmond, 2004), but it appears to be only a small factor in rising premiums in the private market.

The principal public funds, Medicare and Medicaid, together cover about one-fourth of the Oregon population, in relatively equal shares. Commercial insurers intersect with the public domain by contracting to cover the entitlement populations. Increased funding for Medicare managed care increased enrollment among eligible Medicare beneficiaries, following the Medicare Prescription Drug, Improvement, and Modernization Act of 2003 (also, the name changed to Advantage from the previous, faltering Medicare+Choice plans). CMS data for Medicare managed care in 2003 and 2011, available online, shows enrollment in Oregon increased by over 50\%, partly due to growth in the population; managed care penetration increased 20\% and now covers 54\% of the eligible population. Large enrollment increases occurred in several rural counties, where managed care was previously nearly unknown. Many small and even large 
commercial insurers thrive on Medicare contracts. Kaiser has a proven record of expansion in Medicare managed care, even in difficult markets (Achman \& Gold, 2002; Draper, Gold \& McCoy, 2002).

In Medicaid, low payment levels have caused private carriers to exit. During the mid-1990s, commercial insurers expanded operations into rural counties to accommodate new Medicaid managed care contracts under the Oregon Health Plan, and by 1999, Kaiser, ODS, Providence, and Regence took about $48 \%$ of the Medicaid medical contracts. By late 2003, only Providence remained in the list, with a 3\% share of covered lives, one-fifth its former size. Contracts are now concentrated in CareOregon and a variety of smaller health plans.

\section{Self-Insured Firms}

The exclusion of self-insured employers from state regulation was established in 1974 in the federal Employee Retirement Income Security Act (ERISA). Lobbyists for heavy industry and labor combined to make ERISA supersede the patchwork of state regulations and mandates with a uniform federal standard. The law simplifies administration for large interstate businesses and guarantees the independence of negotiated benefit plans agreed upon by business and labor under the Taft-Hartley Act (Gottschalk, 1999). Preemption of state authority avoids common state taxes on premiums (Fox \& Schaffer, 1989).

ERISA recognizes the authority of states to regulate the business of insurance, but forbids states from deeming a self-insured employee benefit plan as an insurance business 
(Chirba-Martin \& Brennan, 1994). Barring state interference has succeeded in making knowledge about self-insured plans very limited. Although self-insured firms file Form 5500 with the Pension and Welfare Benefits Administration of the U.S. Department of Labor, and state lists are available for a fee, no definite numbers are published. In its latest annual report, the Oregon Insurance Division (2011) states that self-insured firms cover about $9 \%$ of the population. Although this is probably a guess-ERISA plans are not required to report to the Insurance Division - the figure may be accurate. A now dated estimate from a survey study (Park, 2000) suggested ERISA plans are available in firms covering about $36 \%$ of the employed workforce in Oregon, which would put the total, with dependents, close to $18 \%$ of the population; but these firms usually offer a number of options, and not all employees will choose the self-insured plan. Commercial carriers intersect with most self-insured firms by offering private plans, and in many cases act as a third-party administrator.

The total population covered by ERISA plans in Oregon appears to be far less than in most other states, possibly due to lower average firm size in Oregon. Analysis of survey data show self-insured employee benefit plans are concentrated in larger firms (Acs, Long, Marquis \& Short, 1996; Park, 2000).

- $1,000+$ employees: $85 \%$ offer self-insured plans

- 250-999 employees: 50\% offer self-insured plans

- 50-249 employees: $25 \%$ offer self-insured plans

- $\quad<50$ employees: $5 \%$ offer self-insured plans 
Removing self-insured firms from the purview of state regulators has contributed to a "criminogenic" environment, especially vulnerable to fraud (GAO, 2004; Kofman et al., 2003; Tillman, 1998). The U.S. Department of Labor reviews less than 1\% of ERISA plans. Consequently, employee pension funds are highly vulnerable to fraud and abuse, and many have been looted with impunity since the 1980s (Barlett \& Steele, 1992; Victor, 1989). In addition, fraudulent health insurance firms may operate under the guise of ERISA protection for years before state regulators discover they possess the authority to move in and stop them. Congress amended ERISA in 1983 to grant states the right to regulate multiple employer trusts, which are especially prone to fraud and abuse. A later proposal by the Department of Labor in 1991 to improve federal enforcement for ERISA plans was withdrawn in response to business opposition (Stein, 1993).

An updated analysis of ERISA court decisions (Jacobson, 2009) indicated one small inroad for local jurisdictions in a San Francisco law, which applied a levy on employers of a certain size, mandating they offer some form of support for healthcare expenditures to employees or pay into a city fund for that purpose. In 2010, after 2 years of litigation through the U.S. Court of Appeals, the law was finally upheld after 2 more years, when the Supreme Court refused to hear the case. This kind of victory may be more than a state wants to endure, particularly because it still has no authority to inspect an ERISA firm's benefit accounts to enforce the law. A law of the same kind failed to pass the courts in Maryland. In Massachusetts, the pay-or-play employer mandate is a sole survivor, because no litigation has yet been raised against it. ERISA has also prevented 
attempts to mandate utilization review or include workers in self-insured firms in any system of coordinated recordkeeping or managed care requirements.

\section{Commercial Insurers}

The state licenses and monitors commercial insurance. Carriers are registered with the Oregon Insurance Division, which publishes summary information. Contracts and other information are not available in Oregon, but are available in Washington state. Premium and enrollment information for commercial insurers is also available from the assessment list of the Oregon Medical Insurance Pool (OMIP), which assesses a premium tax to support the high-risk pool.

The 2002 OMIP assessment list showed 162 primary insurers. Most cover very few people (Table 2). The small number of covered lives may be explained by affiliation with larger pools outside the state. A significant portion of the carriers is likely to be fraudulent (Oregon Insurance Division, 2004b).

\section{Table 2. Commercial Health Insurance Carriers in Oregon by Covered Lives}

\begin{tabular}{rrr} 
Covered lives & Number of carriers & Total covered lives \\
\hline $1-10$ & 46 & 174 \\
$11-100$ & 32 & 1,508 \\
$101-1,000$ & 25 & 7,230 \\
$1,001-10,000$ & 39 & 124,544 \\
$10,001-40,000$ & 11 & 216,775 \\
$85,000+$ & 9 & $1,516,247$ \\
Totals & 162 & $1,866,478$ \\
\hline
\end{tabular}

Source: Oregon Medical Insurance Pool Assessment 22 by Company_January 2002. Note: The number of covered lives includes duplication, making the actual number of persons closer to one-third of Oregon's total population. 


\section{Table 3. Commercial Health Insurance Carriers in Oregon by Premium Revenue}

Health Insurer Company

Regence BlueCross BlueShield of Oregon

${ }^{*}$ Regence Life and Health Insurance Co.

Kaiser Foundation Health Plan of the Northwest

Providence Health Plan

Health Net Health Plan of Oregon, Inc.

* Health Net Life Insurance Co.

PacificSource Health Plans

* Clear One Health Plans

ODS Health Plan, Inc.

* Oregon Dental Service

United Healthcare Ins. Co.

PacifiCare of Oregon, Inc. (United Healthcare affiliate)

Lifewise Health Plan of Oregon Inc.

Aetna Life Ins. Co.

Health Plan of CareOregon, Inc.

Standard Ins. Co.

American Family Life Assurance Co. of Columbus

Mid Rogue Health Plan, Inc.

Samaritan Health Plans, Inc.

Marion Polk Community Health Plan Advantage, Inc.

Atrio Health Plans, Inc.

Trillium Community Health Plan, Inc.

Familycare Health Plans, Inc.

Willamette Dental Ins., Inc.

Mega Life and Health Ins. Co.

Pioneer Educators Health Trust

Mid-Valley IPA Employee Benefit Trust

Western Grocers Employee Benefits Trust

Preferred Health Plan, Inc.

Advantage Dental Plan, Inc.

American Medical and Life Insurance Co.
Premiums 2009

$\$ 2,382,758,458$

$1,924,625,852$

$939,442,490$

$626,406,363$

$622,108,406$

$283,597,945$

$283,100,353$

$254,063,516$

$217,666,677$

$113,706,029$

$71,591,381$

$70,361,892$

$65,067,145$

$56,352,137$

$55,416,311$

$49,312,959$

$45,000,093$

$37,265,278$

$27,197,929$

$26,358,672$

$16,789,918$

$16,675,991$

$8,450,984$

$6,625,403$

$6,378,827$

$5,872,952$

$1,108,754$

Source: Oregon Insurance Division. (2010b). Report for Oregon insurance complaints from calendar year 2009. Oregon Department of Consumer and Business Services. 
Recent Oregon Insurance Division annual reports provide detailed information on the top seven insurance carriers by premium revenues. According to the most recent report, with data from 2009 , these insurers earned $92 \%$ of the total $\$ 4.8$ billion in “comprehensive health insurance premiums" (Oregon Insurance Division, 2011, p. 26). The report also documented two basic facts that define the healthcare system.

- National health expenditures amounted to 17.6 percent of GDP.

- The number of uninsured in Oregon was 647,000 , or $17.3 \%$ of the population.

The division's most recent, separate report on insurance complaints provides a broader picture of Oregon insurers and premium revenues (Oregon Insurance Division, 2010b); it provides a list of 31 firms and subsidiaries with their associated premium revenues for 2009. Examining the list more closely provides several useful insights on the character of health insurance in Oregon, beyond the seven industry giants (Table 3).

1. Firms on the list met at least one of three inclusion criteria: (a) Have at least $1 \%$ market share in Oregon, (b) Have at least 10 confirmed complaints, or (c) Have its headquarters in Oregon. This indicates that none of the 100-200 insurers with a small number of covered lives, discovered on the OMIP assessment list, are domiciled in Oregon. A separate listing of these insurers available on the Oregon Insurance Division website shows a wide variety of investment firms and funds, life insurance, large-business funds, labor unions, a handful of fraternal organizations, and others, all evidently providing a source for group rates or cheaper individual rates for individuals without a local option.

2. The sum of the premiums on this list is over $\$ 8.2$ billion, indicating a total market for health insurance nearly twice the size of the $\$ 4.8$ billion market for comprehensive health plans. This market contains a vast array of indemnity and other security arrangements, representing a large market for insurers to capture either with comprehensive plans once the state implements universal health insurance, or some permutation interacting with state-mandated plans. The "top seven carriers" on this list (excluding the United Healthcare firms) comprise $85 \%$ of the displayed total. 
3. The designation of plans as domestic or foreign in this list is not always clear in terms of corporate structure. Nearly all are licensed in Oregon, but the parent may be elsewhere. Providence was initiated by local medical providers, but the ultimate parent is in Canada. Health Net is licensed in Oregon, but is largely administered by its national parent out of state. This is true, too, for PacifiCare, now licensed in Indiana, with a parent home office in Minnesota.

4. It is not easy to determine, for many of the firms, if they are for-profit or nonprofit. Many of the larger firms are apparently for-profit firms carefully structured under nonprofit umbrella organizations or holding companies, sometimes domiciled in other states.

5. Many of the smaller firms were created by associated providers organized to accept Medicare or Medicaid contracts. A couple are multiple-employer trusts. The initiative of providers to organize health insurance to secure payment is also evident in several of the larger firms. PacificSource, interestingly, is even older than Kaiser in Oregon, beginning in 1933 through physician associates, and later becoming one of the original hospital associations.

The first points above illustrate the difficulties a small body of state regulators face in supervising the complex products, operations, markets, ownership, and locations of funds relative to health insurance corporate finance. Domiciled carriers are subject to Oregon insurance laws and examinations, and the predominance of domestic firms in Oregon makes control easier. To better protect the public interest, state regulators have emphasized the need to unify authority over provider-sponsored and managed care organizations that accept risk contracts (Lewin Group, 1997). Theoretically, a larger bureaucratic organization can support more specialization to deal with a complex industry. Small and large insurance firms have distinct interests and issues, and a diverse market requires more stringent and capable regulation (Meier, 1988). In addition, some solution appears to be necessary to overcome the confusion and obstruction of state 
regulation of risk-bearing contracts connected to federal ERISA and Medicare plans, which often involve smaller health plans.

The issue of nonprofit insurers raises another area of concern. Following the extensive innovation in health system organization and integration since the mid-1980s, Congress and the Internal Revenue Service applied increased scrutiny to vertically organized health systems under a nonprofit umbrella to test for integral part, community benefit, and private inurement to insiders (Furrow, Greaney, Johnson, Jost \& Schwartz., 2000, Chapter 2). The test is especially difficult for finance-oriented health plans (Dewees, 1997). For-profit firms often complain of unfair competition from nonprofit firms, and claim they are actually the better citizen and community partner due to large tax contributions. Nonprofit health plans may be exempted from regulations that remain binding on others. In a market environment with competitive contracts, nonprofit systems must increasingly defend their charitable missions.

Finally, the prominent role of physicians and hospitals in the erection of insurance organizations raises questions about antitrust and conflict-of-interest laws that endeavor to prevent cartels, closed networks, and self-referral (Greaney, 2007; Rodwin, 1993). On the one hand, negative consequences are recognized (Hillman \& Goldsmith, 2010), yet innovative providers have also developed the organizational and financial capacities that make the current healthcare system work. Simply banning ownership or professional combination appears to conflict with the enterprise physicians and hospitals have demonstrated in the past, and is still expected from them to organize funding for 
healthcare services, particularly in underserved rural areas. Rethinking these issues appears to be necessary to help support the future health system.

A general perspective on insurance will assist in understanding the discussion of specific issues by stakeholders regarding health insurance, purchasing, and the delivery system. Four general principles of insurable risk—recognized initially in relation to fire insurance (Greene, 1985) — apply to any insurance, and provide a fundamental frame of reference.

- Group size. The objects to be insured must be (a) numerous enough, and (b) homogeneous enough to allow a reasonably close calculation of the probable frequency and severity of losses.

- Shared Risks. The insured objects must not be subject to simultaneous destruction.

- Moral hazard. The possible loss must be accidental in nature, and beyond the control of the insured.

- Triggers and terms. There must be some way to determine whether (a) a loss has occurred, and (b) how great that loss has been.

The demonstrated relationship of these principles to profit and loss has given them a solidity resembling axioms. They might be overruled by bringing forward other actuarial elements or product management, but they remain as sentinels calling for extra caution whenever any one of them is violated (Stein, 1998). In various ways, they permeate the language of health insurance practices.

\section{Purchasers}

Purchasing healthcare services is the primary function of health insurance. Corporate purchasers of health care are a diverse group, including risk-bearing 
organizations such as commercial insurers and self-insured firms, as well as hospitals and physician organizations that subcontract or carve out services; or associations such as employer purchasing alliances, or public funds; or third-party administrators, or preferred provider organizations (PPOs), which contract for services for purchasing by others. Employers or business groups may also purchase healthcare services directly, or take an active interest in the terms for purchasing in contracts with insurers or PPOs.

In the years since the earlier peak of healthcare reform in 1994, a proliferation of organizations has occurred-HMOs, MCOs, PPOs, IPAs, PHOs, PSOs—all involved in different degrees with claims processing, mapping network adequacy, negotiating contracts with providers, accumulating data for state and quality reporting, and more. Nationally, PPOs enroll 52\% of employees in large firms in developed regional provider networks with contracted fees (Hurley, Strunk \& White, 2004). PPOs developed capacity to examine claims electronically and supervise purchasing (Hamer \& Anderson, 2000), and since the implementation of federal HIPAA rules in 2003, took advantage of electronic claims processing as standard practice for billing public health insurers. Quality reporting is a corollary to claims processing, increasingly important as a measure for accountability since the advent of managed care and contracted services (Brach et al., 2000). Ancillary organizations support this attention to value purchasing. Quality standards are packaged and evaluated by the National Committee for Quality Assurance, U.S. Preventive Services Task Force, Agency for Healthcare Research and Quality, Joint Commission on Accreditation of Health Care Organizations, and Medicare quality assessment organizations, such as Acumentra Health in Oregon, which also 
evaluates Medicaid contractors for the state. The Health Services Commission, with the Oregon priority list, made notable progress by classifying medical diagnosis and procedure codes for both medical practice and purchasing. The Oregon Evidence-based Practice Center provides systematic reviews for drugs and other treatments, which add to the global enterprise for evidence-based practice led by the Cochrane Collaboration and the National Institute for Health and Clinical Excellence in the United Kingdom.

All together, providers, purchasers, and researchers are remarkably advanced in speaking the same language through codes for medical diagnosis, treatment, and billing. Today, though not universal, electronic monitoring of basic claims data allows rudimentary supervision of cost and quality profiling (Romano et al., 2003; Wennberg et al., 2004). Standardization has been complicated by resistance of insurers to state efforts to regulate the composition and use of claims data (Cole \& McCullough, 2004).

Business purchasing alliances, such as the nationally recognized Leapfrog group (Galvin, Delblanco, Milstein \& Belden, 2005), are joining and sometimes leading the effort to exert control over medical practice and value in provider contracts. Locally, the Oregon Coalition of Health Care Purchasers formed in 2000, following a feasibility study based on the Buyers Health Care Action Group in Minnesota. The white paper issued by the Oregon Business Council in 2004, enunciating A New Vision for Health Care, helped focus attention on the problem of rising costs and the need for employers to take a leadership role to drive change. In 2008, these Oregon business organizations commissioned the Oregon Health Leadership Council (originally called a "Task Force") to devise solutions and strategies (www.orhealthleadershipcouncil.org). The activities of 
the state-directed Oregon Health Fund Board over the previous year, organizing various stakeholders into work groups, created a dynamic environment where business purchasers could hope to be influential with a concentrated agenda for reform. The council has become an active partner with the Oregon Health Authority in implementing policy objectives.

Using market-based strategies, supported by organized connections to numerous business employers and healthcare executives, the Oregon Health Leadership Council (2010) has launched a number of purchasing initiatives, including the following.

- Administrative simplification

- Standardization and automation of key insurance processes

- Value-based benefit design (tiered copayments)

- Chronic disease management programs

- Pre-authorization of high-cost imaging

- Utilization management

- Development of evidence-based practice guidelines and clinical pathways

- Common credentialing repository to streamline provider contracting

As with the state initiatives listed earlier, all of these topics and several of the persons involved in this primary segment of activity by purchasers in Oregon appear in the present study of stakeholder views. 


\section{Hospitals}

Hospitals, more than any other element of the healthcare system, are anchored in the communities they serve, both physically and in the sentiments of the population. Market consolidation or failure occasionally eliminates a hospital, but several examples in Oregon have shown communities will rally to maintain a hospital in trouble. Medicare pays a higher fee to designated critical access hospitals in rural areas to help keep them solvent. Currently, all but 2 of Oregon's 58 acute-care hospitals are nonprofit, most as voluntary organizations, a portion with a religious affiliation, and another portion publicly supported by local governments or a health service district (the total does not include Veterans Affairs hospitals in Portland and Medford, and Shriners in Portland).

By their nature, hospitals also present a ready source of data. The map of Oregon below (Figure 2) is provided as a reference for hospital placement, showing counties grouped by standard Oregon workforce regions; the size of these regions appears appropriate to assess the relative distribution of hospitals in terms of population, distance, and access. The subsequent table ranks Oregon hospitals within the workforce regions and presents key hospital data. The effort here aims to illustrate how collections of hospitals are serving their communities, and how the communities are using them. No current research report organizes all hospitals geographically in this manner (though the Office of Rural Health produces excellent maps of rural hospitals). ${ }^{15}$

\footnotetext{
${ }^{15}$ The Oregon Department of Business Development and the Oregon Department of Transportation group counties into regions differently. Regarding hospitals, Dartmouth Atlas researchers divide the nation into hospital referral regions, with five in Oregon, centered in Portland, Salem, Eugene, Medford, and Bend. Residents in Eastern Oregon may be drawn out-of-state to Spokane or Boise.
} 


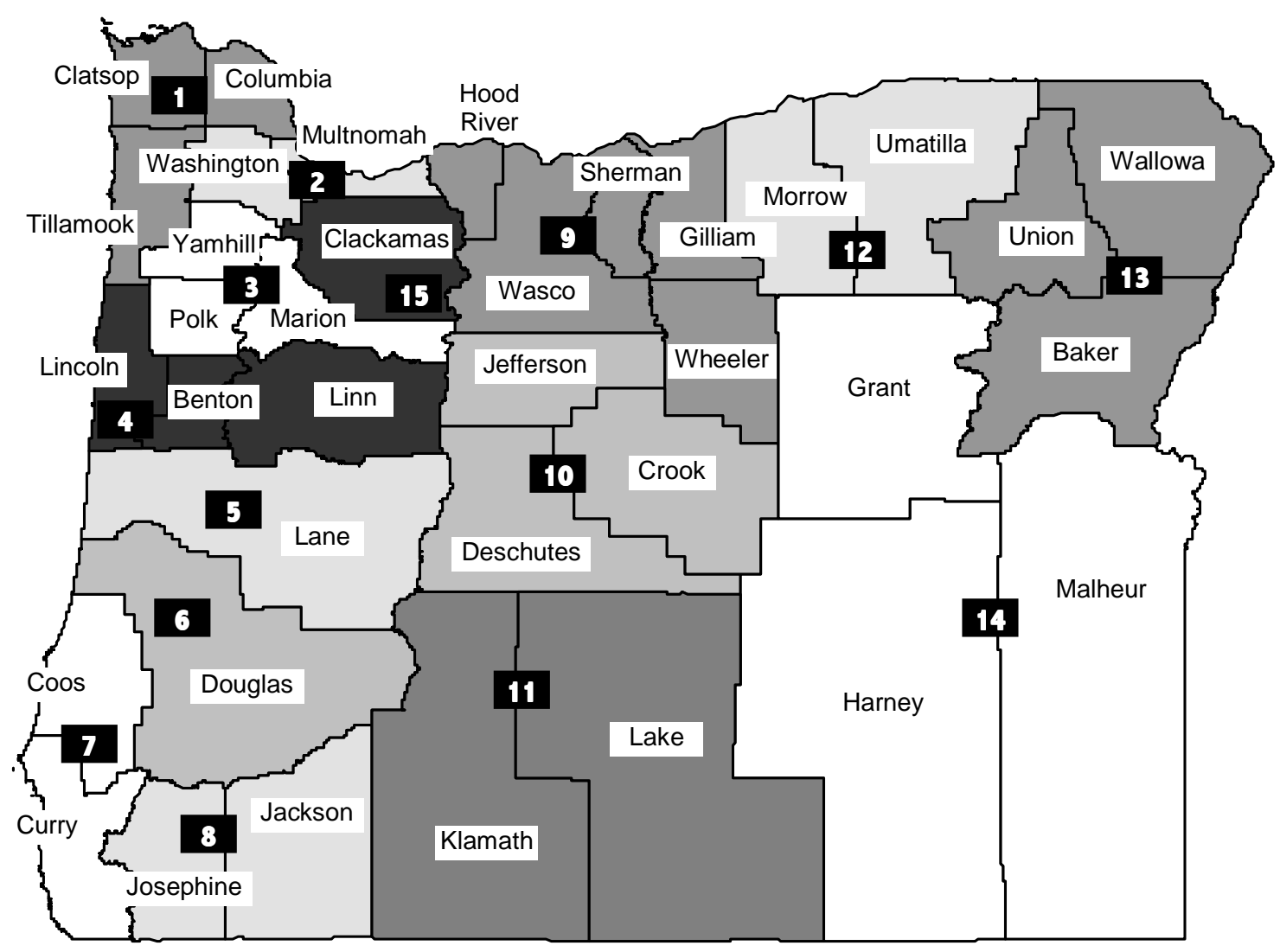

Figure 2. Oregon Counties and 15 Workforce Regions

The table on the following page ranks Oregon's 58 hospitals by size within regions, along with key data elements: number of beds, discharges, length of stay, outpatient visits, emergency department (ED) visits, percent of ED visits resulting in inpatient admission, total operating revenue (patient charges actually paid), and operating margin (percentage of profit or loss on total patient care). OHPR (2009) provides additional summary information about Oregon hospitals. The data here represents only a single year and does not account for underlying characteristics related to the health of the population, safety of the environment, and specific capacity and conditions at the hospitals; however, several useful insights may be observed. 
Table 4. Oregon Hospitals and Services Grouped by Workforce Regions, 2010

Hospital Facility

\begin{tabular}{|c|c|c|c|c|c|c|c|c|}
\hline Hospital Facility & 号 & 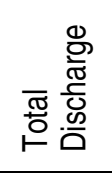 & 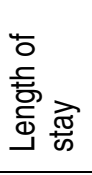 & 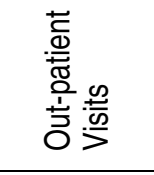 & 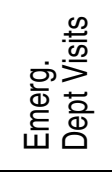 & 崖章 & 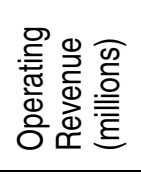 & 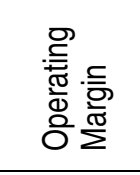 \\
\hline $\begin{array}{l}\text { REGION } 1 \text { (pop.=111,760) } \\
\text { Clatsop, Columbia, Tillamook }\end{array}$ & 0.7 & 33 & 4.1 & 2,381 & 282 & & $\$ 1.3$ & $\begin{array}{l}\text { Per } 1,000 \\
<<\text { pop. }\end{array}$ \\
\hline Columbia & 25 & 1,771 & 3.0 & 110,314 & 13,402 & $3 \%$ & $\$ 54.0$ & $2.5 \%$ \\
\hline Tillamook County & 25 & 1,115 & 3.6 & 44,935 & 9,644 & $3 \%$ & $\$ 44.7$ & $3.3 \%$ \\
\hline Providence Seaside & 25 & 847 & 7.2 & 110,835 & 8,495 & $4 \%$ & $\$ 41.4$ & $0.2 \%$ \\
\hline REGION 2 (pop.=1,267,855) & & & & & & & & Per 1,000 \\
\hline Multnomah, Washington & 2.0 & 104 & 4.8 & 3,096 & 288 & & $\$ 2.8$ & $\ll$ pop. \\
\hline OHSU & 534 & 28,805 & 5.4 & 755,654 & 35,636 & $25 \%$ & $\$ 954.9$ & $5.9 \%$ \\
\hline Providence St. Vincent & 440 & 27,701 & 4.7 & 809,634 & 72,603 & $17 \%$ & $\$ 706.3$ & $8.4 \%$ \\
\hline Legacy Emanuel & 405 & 18,293 & 5.5 & 242,818 & 46,302 & $20 \%$ & $\$ 521.7$ & $-0.4 \%$ \\
\hline Providence Portland & 383 & 23,551 & 4.4 & $1,235,453$ & 54,727 & $20 \%$ & $\$ 590.3$ & $2.3 \%$ \\
\hline Legacy Good Samaritan & 249 & 11,276 & 4.8 & 166,157 & 25,576 & $18 \%$ & $\$ 277.5$ & $3.2 \%$ \\
\hline Adventist & 248 & 11,404 & 3.8 & 396,996 & 45,846 & $16 \%$ & $\$ 254.7$ & $2.9 \%$ \\
\hline Tuality & 149 & 5,320 & 4.4 & 242,312 & 43,006 & $6 \%$ & $\$ 170.4$ & $-1.0 \%$ \\
\hline Legacy Mt. Hood & 80 & 4,958 & 3.4 & 76,588 & 41,833 & $8 \%$ & $\$ 88.1$ & $1.4 \%$ \\
\hline REGION 3 (pop. $=490,800$ ) & & & & & & & & Per 1,000 \\
\hline Marion, Polk, Yamhill & 1.4 & 71 & 4.0 & 2,138 & 338 & & $\$ 1.7$ & $<$ pop. \\
\hline Salem & 454 & 23,585 & 4.4 & 502,552 & 80,945 & $15 \%$ & $\$ 483.1$ & $1.5 \%$ \\
\hline Willamette Valley & 88 & 4,177 & 3.7 & 110,379 & 20,327 & $13 \%$ & $\$ 106.9$ & $23.9 \%$ \\
\hline Silverton & 48 & 3,650 & 2.6 & 130,412 & 23,732 & $8 \%$ & $\$ 89.7$ & $3.3 \%$ \\
\hline Providence Newberg & 40 & 2,245 & 3.1 & 196,377 & 16,956 & $8 \%$ & $\$ 83.5$ & $8.2 \%$ \\
\hline Santiam & 38 & 971 & 2.9 & 34,181 & 11,171 & $6 \%$ & $\$ 28.5$ & $6.3 \%$ \\
\hline West Valley & 6 & 130 & 2.3 & 75,607 & 12,601 & $1 \%$ & $\$ 19.7$ & $4.9 \%$ \\
\hline REGION 4 (pop.=248,710) & & & & & & & & Per 1,000 \\
\hline Benton, Lincoln, Linn & 1.2 & 72 & 3.6 & 1,823 & 288 & & $\$ 2.2$ & $<$ pop. \\
\hline Good Samaritan & 165 & 9,478 & 4.3 & 148,430 & 17,217 & $27 \%$ & $\$ 262.7$ & $2.4 \%$ \\
\hline Samaritan Albany & 65 & 3,672 & 2.9 & 94,898 & 20,869 & $12 \%$ & $\$ 105.9$ & $5.8 \%$ \\
\hline Samaritan Lebanon & 25 & 1,906 & 2.9 & 79,477 & 12,741 & $14 \%$ & $\$ 72.8$ & $3.1 \%$ \\
\hline Samaritan Pacific & 25 & 1,479 & 2.8 & 74,520 & 11,529 & $9 \%$ & $\$ 60.2$ & $-0.2 \%$ \\
\hline Samaritan North Lincoln & 25 & 1,255 & 2.4 & 56,124 & 9,303 & $8 \%$ & $\$ 46.3$ & $2.4 \%$ \\
\hline REGION 5 (pop.=352,010) & & & & & & & & Per 1,000 \\
\hline Lane & 1.6 & 99 & 4.1 & 1,167 & 296 & & $\$ 1.9$ & $<$ pop. \\
\hline Sacred Heart Riverbend & 334 & 24,256 & 4.1 & 162,220 & 40,008 & $24 \%$ & $\$ 401.7$ & $-1.1 \%$ \\
\hline McKenzie-Willamette & 113 & 6,308 & 3.2 & 52,273 & 22,463 & $15 \%$ & $\$ 115.3$ & $10.5 \%$ \\
\hline Sacred Heart Eugene & 96 & 2,680 & 7.1 & 33,013 & 23,454 & $7 \%$ & $\$ 101.1$ & $-10.6 \%$ \\
\hline Peace Harbor & 21 & 1,156 & 3.3 & 87,285 & 7,379 & $11 \%$ & $\$ 52.8$ & $2.0 \%$ \\
\hline Cottage Grove & 14 & 483 & 2.6 & 76,136 & 10,774 & $3 \%$ & $\$ 15.3$ & $-4.3 \%$ \\
\hline REGION 6 (pop. $=107,690)$ & & & & & & & & Per 1,000 \\
\hline Douglas & 1.5 & 74 & 4.1 & 2,678 & 415 & & $\$ 1.7$ & $\ll$ pop. \\
\hline Mercy & 141 & 7,377 & 3.8 & 269,917 & 41,377 & $13 \%$ & $\$ 162.6$ & $3.5 \%$ \\
\hline Lower Umpqua & 16 & 637 & 8.1 & 18,448 & 3,321 & $6 \%$ & $\$ 18.1$ & $-9.1 \%$ \\
\hline REGION 7 (pop.=85,390) & & & & & & & & Per 1,000 \\
\hline Coos, Curry & 2.3 & 106 & 3.3 & 1,810 & 400 & & $\$ 2.0$ & $<$ pop. \\
\hline Bay Area & 129 & 7,272 & 3.2 & 73,085 & 21,377 & $18 \%$ & $\$ 118.7$ & $-1.4 \%$ \\
\hline Coquille Valley & 25 & 571 & 3.5 & 20,602 & 4,402 & $8 \%$ & $\$ 14.3$ & $7.2 \%$ \\
\hline
\end{tabular}




\begin{tabular}{|c|c|c|c|c|c|c|c|c|}
\hline Hospital Facility & 禺 & 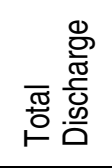 & 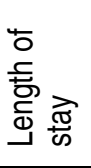 & 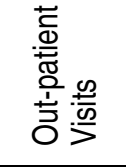 & 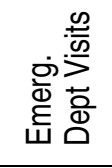 & 崖 & 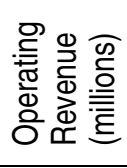 & 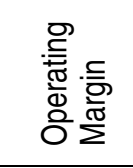 \\
\hline Curry & 24 & 728 & 3.6 & 47,999 & 4,084 & $13 \%$ & $\$ 20.2$ & $2.3 \%$ \\
\hline Southern Coos & 19 & 471 & 4.5 & 12,912 & 4,327 & $7 \%$ & $\$ 13.9$ & $-4.4 \%$ \\
\hline $\begin{array}{l}\text { REGION } 8 \text { (pop. }=286,115 \text { ) } \\
\text { Jackson, Josephine }\end{array}$ & 2.0 & 101 & 4.1 & 3,138 & 335 & & $\$ 2.3$ & $\begin{array}{l}\text { Per } 1,000 \\
\ll<\text { pop. }\end{array}$ \\
\hline Rogue Valley & 307 & 14,790 & 4.5 & 318,379 & 30,234 & $28 \%$ & $\$ 338.8$ & $7.9 \%$ \\
\hline Providence Medford & 134 & 5,604 & 4.2 & 321,250 & 24,808 & $13 \%$ & $\$ 150.1$ & $7.0 \%$ \\
\hline Three Rivers & 107 & 7,155 & 3.2 & 195,014 & 32,094 & $19 \%$ & $\$ 125.4$ & $4.6 \%$ \\
\hline Ashland & 37 & 1,489 & 3.4 & 63,044 & 8,842 & $11 \%$ & $\$ 50.3$ & $-6.1 \%$ \\
\hline $\begin{array}{l}\text { REGION } 9 \text { (pop. }=52,695 \text { ) } \\
\text { Hood River, Gilliam, Sherman, } \\
\text { Wasco, Wheeler }\end{array}$ & 1.4 & 71 & 3.0 & 5,061 & 471 & & $\$ 2.8$ & $\begin{array}{l}\text { Per } 1,000 \\
<<\text { pop. }\end{array}$ \\
\hline Mid-Columbia & 49 & 2,201 & 3.2 & 129,621 & 16,775 & $6 \%$ & $\$ 82.9$ & $4.8 \%$ \\
\hline Providence Hood River & 25 & 1,540 & 2.6 & 137,081 & 8,041 & $6 \%$ & $\$ 63.8$ & $10.3 \%$ \\
\hline $\begin{array}{l}\text { REGION } 10 \text { (pop.=200,675) } \\
\text { Crook, Deschutes, Jefferson }\end{array}$ & 1.8 & 97 & 3.8 & 2,165 & 320 & & $\$ 2.4$ & $\begin{array}{l}\text { Per } 1,000 \\
\ll<\text { pop. }\end{array}$ \\
\hline St. Charles Bend & 261 & 15,066 & 3.9 & 282,817 & 29,311 & $22 \%$ & $\$ 376.4$ & $7.1 \%$ \\
\hline Pioneer & 25 & 754 & 3.8 & 47,189 & 8,537 & $2 \%$ & $\$ 23.5$ & $4.8 \%$ \\
\hline St. Charles Redmond & 48 & 2,380 & 2.7 & 76,840 & 16,241 & $6 \%$ & $\$ 55.2$ & $6.9 \%$ \\
\hline Mountain View & 25 & 1,192 & 3.9 & 27,556 & 10,211 & $6 \%$ & $\$ 24.0$ & $1.6 \%$ \\
\hline $\begin{array}{l}\text { REGION } 11 \text { (pop. }=74,395 \text { ) } \\
\text { Klamath, Lake }\end{array}$ & 1.5 & 90 & 4.4 & 3,192 & 300 & & $\$ 2.2$ & $\begin{array}{l}\text { Per } 1,000 \\
<<\text { pop. }\end{array}$ \\
\hline Sky Lakes & 100 & 6,045 & 3.4 & 210,222 & 19,335 & $21 \%$ & $\$ 148.6$ & $1.3 \%$ \\
\hline Lake District & 15 & 618 & 14.2 & 27,213 & 3,004 & $11 \%$ & $\$ 12.4$ & $-8.8 \%$ \\
\hline REGION 12 (рор.=87,175) & & & & & & & & Per 1,000 \\
\hline Morrow, Umatilla & 0.8 & 46 & 3.3 & 1,387 & 317 & & $\$ 1.4$ & $\ll$ pop. \\
\hline Good Shepherd & 25 & 2,145 & 2.7 & 43,001 & 15,483 & $7 \%$ & $\$ 72.6$ & $13.3 \%$ \\
\hline St. Anthony & 25 & 1,766 & 3.1 & 62,369 & 11,448 & $9 \%$ & $\$ 47.1$ & $10.3 \%$ \\
\hline Pioneer & 21 & 105 & 20.1 & 15,517 & 734 & $5 \%$ & $\$ 5.7$ & $-19.3 \%$ \\
\hline REGION 13 (рор. $=49,000)$ & & & & & & & & Per 1,000 \\
\hline Baker, Union, U & 1.5 & 69 & 9.4 & 3,558 & 439 & & $\$ 1.8$ & $\ll$ pop. \\
\hline Grande Ronde & 25 & 1,560 & 3.3 & 131,781 & 11,364 & $14 \%$ & $\$ 48.7$ & $0.4 \%$ \\
\hline St Alphonsus & 25 & 1,088 & 13.5 & 26,244 & 7,242 & $6 \%$ & $\$ 27.3$ & $1.1 \%$ \\
\hline Wallowa & 25 & 719 & 16.4 & 16,295 & 2,902 & $10 \%$ & $\$ 13.8$ & $-7.2 \%$ \\
\hline REGION 14 (pop.= & & & & & & & & Per 1,000 \\
\hline Grant, Harney, N & 1.9 & 84 & 5.8 & 2,514 & 537 & & $\$ 1.9$ & $\ll$ pop. \\
\hline St Alphonsus & 49 & 2,962 & 2.9 & 75,117 & 18,919 & $8 \%$ & $\$ 58.6$ & $2.8 \%$ \\
\hline Harney District & 25 & 539 & 3.6 & 18,725 & 2,700 & $6 \%$ & $\$ 13.4$ & $-11.9 \%$ \\
\hline Blue Mountain & 16 & 399 & 30.0 & 22,408 & 3,217 & $8 \%$ & $\$ 13.9$ & $-10.9 \%$ \\
\hline$=376,780)$ & & & & & & & & Per 1,000 \\
\hline Clackama & 1.4 & 96 & 3.4 & 1,306 & 366 & & * & $<$ pop. \\
\hline Kaiser Sunnyside & 251 & 19,986 & 3.6 & 54,460 & 44,948 & $22 \%$ & * & * \\
\hline Legacy Meridian Park & 130 & 7,485 & 3.4 & 98,266 & 29,428 & $15 \%$ & $\$ 147.3$ & $11.9 \%$ \\
\hline Providence Milwaukie & 66 & 3,186 & 3.1 & 219,890 & 33,091 & $6 \%$ & $\$ 88.2$ & $8.2 \%$ \\
\hline Providence Willamette Falls & 91 & 5,344 & 2.5 & 119,564 & 30,442 & $10 \%$ & $\$ 99.2$ & $1.6 \%$ \\
\hline
\end{tabular}

Source: Oregon Health Policy and Research. Databank 2010 and other hospital data files, available online (May 22, 2011): www.oregon.gov/OHA/OHPR/RSCH/databank.shtml 
1. Hospitals are engines of capital. Patient revenues from the largest hospitals surpass the premium revenues of all but the largest of the state's insurers. In terms of local coverage, even smaller hospitals are likely to be the dominant partner in market relations.

2. The example of Kaiser proves the feasibility of an exception in financing patient care. With a membership system, Kaiser does not produce financial data as the other hospitals.

3. Emergency departments are heavily used. Average use shows about 1 ED visit per 1,000 persons each day across the state. Most hospitals show high use for nonthreatening conditions. In a few rural regions, the numbers suggest the community is using the ED as a source of primary care. This point corresponds to a national study that showed $28 \%$ of all acute-care treatment was provided at hospital emergency departments (Pitts, Carrier, Rich \& Kellerman, 2010).

4. Smaller hospitals have a harder time remaining solvent. Regions 1 and 12 (northwest and northeast parts of the state) appear to be inadequate for the population. Tillamook County General Hospital is one of the examples where the community has made extraordinary efforts to keep its hospital.

5. Hospitals are evidently used by the community for outpatient services far more frequently than for inpatient care.

Consolidation of hospital delivery systems as financial giants in health care is a notable phenomenon of the past three decades, partly resulting from the entry of private capital investment in the 1980s (Lutz \& Gee, 1995). Many Oregon hospitals, though nonprofit, have adopted the strategy of forming systems that incorporate multiple hospitals, including rural areas (notably Providence and Samaritan). Developments in business accounting and system thinking in hospital administration have been particularly valuable in comparing and improving performance in rural hospitals, often by contract management (Carey \& Dor, 2004).

Hospital systems have some difficulty integrating with physician groups, but such vertical integration is proceeding in the current system along with horizontal expansion 
(Lake, Devers, Brewster \& Casalino, 2003; Weil, 2001). Federal fraud and abuse laws may be encouraging combinations, since the laws "permit concerted action when the hospitals and physicians combine into a single entity or at least share substantial financial risk" (Budetti et al., 2002, p. 204). The rapid consolidation of delivery systems to face managed care contracting and bear risk has made a strong and vigilant cadre of administrators leading powerful organizations (Devers, Casalino et al., 2003).

\section{Hospital Rate-Setting}

Several states have experimented with hospital rate-setting as a way to budget the system, beginning in New York in 1969 and reaching over 30 states by 1980, before retreating to only two states by 1997: Maryland and West Virginia (McDonough, 1997). Overall, the experience with rate-setting was acrimonious, exacerbated by the shifting volume of uncompensated care a hospital must accommodate. Rate-setting also resulted in bodies of regulation of Byzantine complexity, which experts could interpret without resistance, especially in an environment of busy medical professionals. The same acrimonious atmosphere was evident in Canada, where strict hospital budgets reduced costs for a period before springing back sharply to the expected trend level once restraints were relaxed (Tuohy, 2002).

An updated review of hospital rate-setting (Atkinson, 2009) glossed over evidence earlier problems. A review of hospital rate-setting as it exists in Maryland (Murray, 2009) showed the state has succeeded at controlling costs per admission, assuring fair prices to maintain solvency, and keeping stakeholders satisfied with 
government coordination of a regulatory regime. The volume of hospital admissions has increased, however, and reduced the cost-saving effect of price regulation. Current efforts are attempting to expand the rate-setting regime to include outpatient as well as inpatient care (Atkinson \& Murray, 2008).

\section{Physicians}

Physician organizations were central in developing the reform agenda that grew through the 1980s, maturing in several state versions of the Oregon Health Plan, and nationally in the Clinton Health Security Act. Although a decline has been observed in the influence of physician lobbies (Morone, 1995; Schlesinger, 2002a), the Oregon Medical Association remains among Oregon's top handful of consistently high-spending lobby organizations.

The Oregon Medical Board supervises licenses for a growing list of over 11,500 licensees of various types. The most current Oregon Physician Workforce Survey (Division of Medical Assistance Programs, 2010) targeted every eligible physician on the medical board's lists and sent out 9,629 questionnaires in May 2009. Descriptive statistics from the survey provide the following results.

- About $30 \%$ of physicians are in the primary-care specialties of family practice or general internal medicine.

- Nearly one-third are female; $20 \%$ are aged 60 and over, and another $32 \%$ aged 50-59.

- In terms of primary practice settings, $57 \%$ of physicians operate a private office or clinic; $18 \%$ work in hospitals as a hospitalist, inpatient care, or emergency and urgent care; $10 \%$ work in a community-based clinic; $8 \%$ in hospital-based ambulatory care; and $7 \%$ other. 
- In terms of practice size, $19 \%$ work in a solo practice (most common in Eastern Oregon, at 39\%); $43 \%$ work in small groups of 2-10; $20 \%$ in groups of 11-50; and $18 \%$ in groups over 50 . Over two-thirds of physicians work in single-specialty practices.

These points indicate an aging workforce and a significant proportion of female physicians, which suggests diverse work-family obligations. Also, in spite of a growing concentration of physicians in group practice, single and small-group practitioners remain the norm; a significant portion works in hospital settings. Regarding equitable distribution of physicians across the state, Oregon operates a subsidy program to encourage new physicians to locate in underserved areas (Oregon Office of Rural Health, 2006), and the legislature regularly passes new bills to relax rules or add incentives for nonphysician providers of health services in underserved areas.

Other recent physician surveys used consulting firm databases to enroll participants from across the country. Two different surveys produced a similar, cautionary result. In one (Santiago, 2010), three-fourths of the physicians expected negative consequences from current national reforms, and $46 \%$ expected to quit practice once reforms were implemented. In the second (Ledue, 2010), conducted some 10 months later through a different firm, $60 \%$ of the physicians expected healthcare reforms would cause them to quit or significantly restrict their practices, and $40 \%$ said they would drop out of patient care in the next 3 years. The Oregon physician survey did not directly address these issues (a question about "retirement" is not the same as quitting patient care), though it did show over three-fourths of Oregon physicians rated Medicare reimbursement reforms and the cost of doing business as very important. 
Physician interest and influence in health insurance reform is frequently subordinated to the financial interests of insurers. In the previous chapter, a number of points were introduced in the section related to prudent purchasing that exhibited physician disaffection. Physician decisionmaking in the USA is more restricted than in any other English-speaking country. In the USA, 37\% of physicians in 2000 reported problems with "external review of clinical decisions to control costs," compared to Australia 21\%, UK 19\%, New Zealand 16\%, and Canada 13\% (Blendon et al., 2001).

Prior to fee schedules, however, the original cost-plus reimbursement system in Medicare, by common consent, resulted in extraordinary price inflation, intensified services, and practice patterns favoring covered services (Moon, 1996). During the same period, and earlier, commercial liability insurance produced similar distortions, favoring hospitalization and intensive interventions (Robinson, 1999).

The currently evolved system of fee schedules and contract rules revive the old war by physicians against the corporate practice of medicine. Physicians remain acutely aware of this issue, often complaining they are not compensated for activities outside the clinical setting, and often within the clinical setting when coverage rules fail to include needed care (Wynia et al., 2000). Consultation services are typically neglected or undervalued, resulting in a mounting deficit of geriatricians and general practitioners (Cassel, 2005; Warshaw, Bragg \& Shaull, 2002). Often, the present system is poorly equipped to handle person-centered care, due to fragmented contract networks and coverage gaps (Bodenheimer, 2000; Kapur et al., 2003). 
Physician discontent is a well-documented phenomenon nationally, concentrating mostly on loss of control: facing pressure from fee schedules, reduced time, fragmented coverage that frustrates care coordination, and a host of recommendations from various sources on how to practice, which cumulatively result in a heated environment of unrealistic demands (Bodenheimer, 2000; Luft, 1999; Mechanic, 2003).

The environment in Oregon bears the same signs. At the end of an interview with John Kitzhaber MD (in between terms as governor), a news writer remarked (Goldsmith, 2003, p. 123): "Your colleagues in medicine are a bunch of really unhappy people right now"- to which Kitzhaber, a former emergency-room physician, replied tersely: "They are."

\section{Public Interest Groups}

The array of public interest groups involved in policy debates about universal health insurance is well illustrated by the groups that participated in the earlier period of health insurance reform in Oregon and the nation. In the Oregon legislature in 1993, Senator Frank Roberts sponsored SB707, at the request of 100 organizations, in support of a single-payer system of universal health insurance in Oregon. The same bill was introduced in the house. The composition of the Oregon interest groups supporting the single-payer plan in 1993 was notably similar to coalitions nationally and in other states (Center for Public Integrity, 1996; Leichter, 1997c; Marmor \& Hamburger, 1994). The group of 100 supporters identified with SB707 fall into the following categories. 
- Labor $=26$

- Health interest $=23$

- Political \& civic $\quad=25$

- Seniors $=9$

- Education $=8$

- Church =6

- Business \& professional $=3$

This list indicates labor unions as a leading type of group with an interest in the outcome of health insurance reform. Many labor unions favor a single-payer plan, as shown here, but others favor an employer mandate, where the union maintains authority over administering benefits (Gottschalk, 1999). Labor unions have been active in the past and in the current wave of reforms to expand health insurance coverage (Ball, 1995; Stern, 2003).

Health interest groups also exert a definite voice in reform activity. In the earlier period of reform, Oregon Health Action Campaign, the spearhead for the single-payer campaign, actively lobbied the legislature, spoke at hearings, and produced published materials for the public record. The same group and others are active today. Another prominent group, Health Care for All Oregon, sponsored an initiative for universal health insurance that appeared on the ballot in 2002 (and failed).

Political parties are prominent in the category of political and civic groups. Other groups, related to senior issues, education, church, and others, may help to illustrate health insurance issues as consumers of health care. Apart from a few unions, however, such groups in state lobbying efforts are small and fairly inconsequential. As shown in the list of supporters for SB707, public interest may be represented by a combination of 
forces that fit no easy category. In this sense, the definition of a public interest group dedicated to health insurance reform is best left open to include those who are immediately present with an active agenda.

The category of public interest groups is not completely fluid, however. Organizations representing consumer interests need to be distinguished here from lobbyist organizations with positive stakeholder interests as insurers, providers, or purchasers. For example, the least represented category in the list above-business and professional groups-is less likely to be concerned about universal health insurance and more involved in the parochial interests of purchasers. Likewise, subgovernments such as county or city governments are among the top-spending lobbyist organizations in the state, but their interest in health insurance is primarily related to purchasing within a given budget, either providing healthcare services for indigent citizens, or maintaining a specially designated health service district, or as a purchaser of health insurance for public employees. Very few lobbyist organizations qualify as a public interest group with the primary purpose of promoting social welfare.

Other groups focusing on health policy, such as the now-defunct Oregon Health Forum, do not lobby directly, but publish news and organize events. This kind of grassroots activism raises public awareness and operates as a key support for public interest lobbyists and state officials (OHPR, 2004b). 


\section{Chapter 6}

\section{Methods}

The previous chapters reviewed (a) civic capacity in Oregon for social welfare, (b) principal models of universal health insurance reform currently available, (c) critical quality reforms in health care, and (d) characteristics of the principal health policy agents in Oregon. The review established a foundation for understanding policy options for universal health insurance. Understanding the prospects of particular models of reform now requires attention to current patterns of discourse in the views of local health policy leaders. Open-ended interviews are used to collect the information.

Interview-based research is common in health-policy studies. In health insurance, the works of James Robinson and Mark Hall, referenced in earlier chapters, are largely based on field interviews that provide key insights into the policy process. Another significant contribution, also referenced earlier, is a Lewin Group (1997) study of provider-sponsored organizations, conducted for the U.S. Department of Health and Human Services. Interview-based research is common in government investigative reports.

The following sections describe the study design, and methods for collecting, coding, and analyzing arguments from health policy leaders. In basic outline, this study follows the format John Kingdon (1995) used in his classic public policy study that defined a policy window. Kingdon interviewed policymakers in various domains, 
including health insurance reform, and measured agreement on particular problems and solutions.

\section{Study Design}

This study was designed as qualitative research, using interviews to collect, combine, and compare samples of discourse from Oregon health policy leaders. Guided by John Kingdon's interview-based study of health insurance reform, critical arguments and models were not suggested to the respondents beforehand or during the interviews, in order to preserve spontaneity. An open format with general prompts, commonly used in interview research, helps to avoid the imposition of observer bias (Seidman, 1991). Open questions, without a structured list of topics, allow spontaneous response on issues of primary concern to the participants and establish a degree of prominence for the arguments. In Kingdon's study, only spontaneous responses were included in the final, coded arguments. This procedure was followed here. Prompts during the interviews referred only to topics already raised by the interviewee. Any topic introduced by the interviewer, as occasionally occurred, was excluded from the results.

Interviews were sought with a minimum of five respondents from each of seven categories, including the six categories introduced in the previous chapter on the state health policy arena, plus an additional category for independent experts. This seventh category included individuals who met criteria for inclusion, but did not fit squarely in any of the preconceived categories. The seven groups represented were state officials, 
insurers, purchasers, hospitals, physicians, public interest groups, and experts. For the state group, bureaucratic officeholders were selected as sources of expert information.

The collection of recorded interviews was transcribed, coded, and organized into an analytical framework. This process involved iterative steps, collecting arguments into topical categories and a logical order. The arrangement followed the flow of the policy process and the flow of money, and moved overall and within sections from general to specific ideas. This process and the resulting outline are described below in more detail.

The discourse provided by stakeholders is reported in a narrative presentation of results. Prominence for particular arguments is identified by summary measures for the entire sample and within each group. Degrees of emphasis for certain points by interviewees are included in the narrative.

In Kingdon's study, a trend was considered favorable for successful policy action when agreement on a particular topic reached $60 \%-80 \%$ of the sample. In addition to subjective agreement, however, policy success also depends on objective practicality. In Kingdon's results, for example, remarkably similar language among policy leaders in health care in the 1970s did not result in successful reform. The case suggests that subjective agreement, indicating a policy window, may be weakened if not supported by persuasive evidence that a policy will really achieve what is intended. The failure of the employer mandate as a part of the Oregon Health Plan in 1993-1995 (see Chapter 3) offers an example where original approval disintegrated when details emerged that showed it to be impractical. 
Consequently, along with measures of agreement reported in the chapter of results below, the subsequent discussion and conclusion chapters add objective evidence from the introductory review chapters to frame the specific points raised by stakeholders. Topics introduced in previous chapters indicate particular areas of concern to help evaluate the recorded discourse, including observation of those topics that are absent or underrepresented. The attention of stakeholders to additional topics expand the previous review to other areas.

Comparing the subjective ideas of policy leaders to rational objectives corresponds to the interpretive method developed by Max Weber (1968/1920; 1949/1904). Weber observed that subjective rationality in social action may not conform to what appears to be objectively rational, nor fit the intended purpose, but instead follow alternate goals, values, feelings, or traditions, which themselves remain unexpressed.

Following Weber's method, no definite scientific conclusions are expected from the results of this study and its analysis of critical issues in relation to a system of universal health insurance. The goal is to better understand the issues and those who represent them in the policy process. The organization of topics and related discourse accomplished here highlights levels of agreement, anomalies, contradictions, and neglected areas of concern that help to define and understand the situation. The results and analysis may help to confirm or revise what appears to be rational in the current, local context, and guide attention to those models of reform most likely to succeed in Oregon, both politically and practically. 


\section{Data Collection}

\section{Participants}

Participants were chosen by the following two eligibility criteria:

(a) knowledgeable on health policy issues, and (b) holds or has held a position of authority in an organization with influence in state policy decisions, with an intrinsic interest in the outcomes of healthcare reform. Eligible participants were identified through a snowball sampling technique, initiated by a selection of notable individuals in key organizations who were active in state-level health policy discourse.

Researchers using the snowball sampling method generally agree that the sample ought to grow until saturation is reached — to the point where the variety of different arguments is exhausted — but they disagree on whether a definite number of respondents can be determined beforehand (Seidman, 1991). Seidman mentions a point of saturation at 25 participants. Use of snowball sampling in the delphi technique indicates that "few new ideas are generated within a homogenous group once the size exceeds thirty well-chosen participants" (Delbecq, van de Ven \& Gustafson, 1975, p.89). In a similar range, a national study of health insurance experts conducted "more than thirty" structured telephone interviews (Christianson et al., 2002). By these observations, a total target of 35 respondents was set as an appropriate goal, or 5 participants in each of the seven identified groups. Notably diverse viewpoints led to additional interviews in some of the groups, resulting in a total of 38 interviews. Specifically, an additional interview was conducted for the insurer, public interest, and expert groups. 
First contacts led to others. Each participant was asked at the end of the interview to supply three names of people who met the criteria and might be willing to participate in the study. A list of all participants is included in Appendix C. All interviewees are listed with their titles, the organization they represented, and the location of the office where they were reached. The list provides important information on the coverage of the sample, in terms of the organizations represented. Efforts were made to include participants from around the state, which was fairly successful; interviewees were included from Central Oregon, Eastern Oregon, the South Coast, and different locations in the Willamette Valley, as well as the Portland metropolitan area.

Selected first contacts included Oregon's leading insurer (Regence BCBS), physician and hospital associations, a major physician organization (Oregon Clinic), the state's executive director of the Oregon Health Fund Board, a purchaser association that was influential in the Oregon Health Plan reforms in the early 1990s (Associated Oregon Industries), and two long-time participants in public-interest organizations (Oregon Health Action Campaign and Oregon Health Forum/The Lund Report). All other participants were recommended by others as the interviews proceeded, and were selected according to the prominence of the organizations or perspectives they represented.

Nearly all interviewees worked in health policy in other capacities, representing a variety of other organizations or working groups, currently or in the past. Several have now moved to other positions. These other associations are too numerous to mention. In a few cases, an interviewee was selected for a recent association or a long history of associations that was reflected in their current position. The active arena of discourse 
surrounding the work of the Oregon Health Fund Board during the early period of the interviews probably influenced the paths of the snowball sample; interviewees were likely to mention the names of people they had worked with or seen in action.

Each interviewee confirmed being in the group they were selected to represent, but the distinctions are sometimes blurred. Individual physicians, for example, appear in the insurer, state, and expert groups. Regarding titles, medical directors appear in both the physician and insurer groups, due to the kind of group they represented. The representative from Kaiser (an integrated health system) presented a choice, and was assigned to the hospital group as a closer match, though the insurer group might have been appropriate as well. Two consultants who could be considered independent experts were assigned to the purchaser group, due to the organizations they worked with most closely.

Contact was attempted for all eligible stakeholders recommended more than once by interviewees in the snowball sample. Contact was unsuccessful with thirteen potential interviewees after multiple efforts. One intended target for interviews failed: two contacts with large self-insured employers, intended to represent the purchaser group, indicated their organizations would have nothing to say on health insurance reform in Oregon. For these firms, state-level concerns were not relevant, because they generally operate in several states and are exempt from state health insurance regulations.

This study was approved by the Human Subjects Research Review Committee at Portland State University, and all participants signed a consent form (sample appended) or recorded verbal consent in telephone interviews. Sources remain confidential in the 
results; where quotations are used, names and identifying information are suppressed. All participants agreed to have their names listed separately.

\section{Interview Protocol}

First contact with prospective interviewees was originally made through a letter on PSU stationery sent through the mail, followed by telephone contact. Response from those contacted made it quickly apparent that this once standard method of approach was out of date. E-mail contact was preferred. Consequently, a shorter contact message was designed for e-mail (sample appended).

Interviews were conducted at a place and time most convenient for each participant. All interviews were recorded on a small digital recorder, except for one interviewee, who chose not to be recorded, making handwritten notes necessary. A few interviews were recorded over the telephone. Consent was obtained at the outset, along with a business card to identify the participant correctly in the preferred format. For telephone interviews, consent and appropriate identification were recorded at the beginning of the audio file.

Only two questions defined the interview, one long and one short.

Q1. What state-level reforms do you believe are necessary to implement a feasible model of universal health insurance in Oregon?

Q2. Do you believe a system of universal health insurance is a desirable goal in Oregon? (suggested Yes/No)

The main first question often required repetition. The second question was typically reserved for the end of the interview to clarify the single point it addressed, but if too 
much hesitation occurred in the beginning, the second question was brought forward and worked effectively as an ice-breaker. Prompts throughout the interviews requested more detail on mentioned topics.

Interviewees were also encouraged to provide any written materials or references they thought represented their point of view. The original intention was to include these sources in the coded arguments, but early probes indicated such sources did not necessarily represent the interviewee's views in all respects; the relevant parts, most prominent for the interviewee, were those actually mentioned. The sources helped frame the nature of the arguments. Mentioned sources are presented in the results and the subsequent discussion. In a few cases, interviewees referred to Powerpoint presentations they had developed and reviewed specific slides to make points. These arguments and the clarifications in the slides are included in the main results.

All interviews were conducted between June 2008 and June 2010. A delay occurred following the first three interviews to conduct a reliability test for the coding procedure (described in the next section). Several important developments occurred in health policy during the 2-year period when the interviews were conducted, including national legislation to establish universal health insurance, but the work of the Oregon Health Fund Board in 2008, which defined the health-policy environment in the early interviews, was never superseded. The remarkably thorough model of reform developed by OHFB reflected the principal topics in national health policy debates, shaped state 
legislation, and continues to define the Oregon Action Plan. For the most part, national reform merely imposed a schedule of deadlines and offered new sources of funding for state initiatives.

The total time for all 38 interviews was nearly 36 hours. The average length was 56 minutes per interview, with a minimum of 16 minutes and a maximum of 86 minutes. The total time in each interview is a poor measure for the number of arguments, considering different characteristics of storytelling and repetition. Only one interview clearly ended short of the requested 1 hour due to a time constraint. The shortest interview, like others that were less than 1 hour, simply completed answering the questions in that time. Interview time for the state group was the shortest, averaging 48 minutes per interview. The physician group gave the most time, averaging 69 minutes per interview.

\section{Coding}

All recorded interviews were transcribed using Transana qualitative analysis software (University of Wisconsin-Madison Center for Education Research: Www.transana.org); the transcripts were then imported into Atlas.ti for the extensive coding procedure. The sections below describe the basic coding method and the reliability test that was conducted following the first three interviews. 


\section{Defining Arguments}

In preparation for this study, a test was performed with 12 health policy books, published over 30 years, to determine if arguments could be extracted page by page to produce a meaningful analysis. The test proved arguments could be identified and provided experience in handling large quantities of complex information as data bits. The arguments were categorized as problems or solutions, and this feature became the essential definition of an argument - that it represents either a problem or a solution, an idea with direction. This definition corresponds to the dictionary definition of an argument as "a course of reasoning aimed at demonstrating the truth or falsehood of something" (American Heritage). In the sense here, the "aim" is toward a positive or negative appraisal of an idea for health reform. Anything that is not an argument by this standard is excluded. This definition of an argument differs from Kingdon's (1995) measurement of positive arguments only. Focusing only on agreement fails to account for controversy.

During the analysis of results here, it became clear that simple quantification of support or opposition to an argument was inadequate for describing controversy. Percentages are reported for the number of interviewees that agreed or disagreed with a particular argument, but the results are also presented with the characteristic details of the arguments to observe the relations. This feature of the presentation allows conflicting views to argue with each other in their own language and preserves the original emphasis. 


\section{Reliability Test}

Following the first three interviews, a test for interrater and intrarater reliability was performed to confirm the accuracy of the coding system. The first coder (the researcher, Coder 1) completed a first pass and established a list of codes organized into family divisions and topical categories to collect related codes together. The code outline helped in finding an appropriate code in a topical area and avoid duplication. Blank transcripts were then supplied to a competent second coder (Coder 2), who was familiar with qualitative analysis, but not familiar with concepts in health policy. The second coder was trained on one of the transcripts to identify quotations that represented a problem or a solution in healthcare reform, making it a relevant argument. The second coder then independently coded the remaining two transcripts. The code outline established by the first coder was available to the second coder during this process.

The second coder returned the independently coded transcripts in Atlas.ti, including a number of new codes. The first coder then recoded the same two transcripts from blank copies (Coder 1A) to test intrarater reliability. The codes created by the second coder were available to the first coder on this second pass through the transcripts.

For the two tested transcripts, the total number of codes by all coders (Coder 1, Coder 1A, and Coder 2) was 56 for the first (IV\#1), and 56 for the second (IV\#2). Using the total number of codes for each transcript as the denominator, the level of agreement in coding for interrater reliability (Coder 1 to Coder 2) was $80 \%$ for both transcripts. The 
level of agreement in coding for intrarater reliability (Coder 1 to Coder 1A) was $93 \%$ for IV\#1, and $91 \%$ for IV\# $2^{16}$. Details of the results are displayed in the tables below.

The raw list of codes in each case was reduced to a valid set of codes by removing (a) invalid codes produced by Coder 2, involving responses prompted by the interviewer on independent topics, which violated the criterion for spontaneity; (b) duplicate codes, involving codes that were combined during the analysis, plus codes created by Coder 2 in language extracted from the transcript that corresponded to existing codes; and (c) duplicate related codes, involving details related to a more general code, which could be combined without losing significant information.

Agreement between coders was charted first by locating exact matches, then content matches, including codes with the same idea but different words. A third category of match related codes was more difficult to reconcile, involving codes that drew out somewhat different interpretations, but were included in the same part of the code outline. Disagreement between coders divided into two categories. Code pairs identified as disagree related involved different codes applied to the same quotation that were each valid, but missed an interpretation applied by the other coder and placed the code in a different category in the code outline. Disagree definite applied to codes by one coder that were completely missed by the other coder (see Table 5a, 5b).

1.

\footnotetext{
16 The level of agreement between two coders may be interpreted from ICC test values according to the following scale below (Shrout, 1998): 0 to $.1=$ virtually none; .1 to $.4=$ slight; .41 to $.6=$ fair; .61 to $.8=$ moderate; .81 to $1=$ substantial. Shrout argued that even a substantial level of agreement, according to the number produced, should be closely inspected for sources of error.
} 
Table 5a. Intrarater Reliability: Code Comparison of Coder 1 A to Coder 1

\begin{tabular}{|c|c|c|c|c|c|c|}
\hline \multirow[b]{2}{*}{ CODES } & \multicolumn{3}{|l|}{ IV\#1 } & \multicolumn{3}{|l|}{ IV\#2 } \\
\hline & Coder 1 & \multicolumn{2}{|c|}{ Coder 1A } & Coder 1 & \multicolumn{2}{|c|}{ Coder 1A } \\
\hline Raw Codes & 53 & & 54 & 52 & & 51 \\
\hline Invalid Codes & 0 & & 0 & 0 & & 0 \\
\hline Duplicate Codes & 0 & & 0 & 1 & & 1 \\
\hline Duplicate Related Codes & 0 & & 2 & 1 & & 0 \\
\hline Total Valid Codes & 53 & & 52 & 50 & & 50 \\
\hline \multicolumn{2}{|l|}{ CODER $1 \mathrm{~A}$ to CODER 1} & Sum & Percent & \multicolumn{3}{|c|}{ Sum Percent } \\
\hline Match Exact & Code & 51 & $91 \%$ & Code & 45 & $80 \%$ \\
\hline Match Content & list $=$ & 0 & $0 \%$ & list= & 0 & $0 \%$ \\
\hline Match Related & 56 items & 1 & $2 \%$ & 56 items & 6 & $11 \%$ \\
\hline Match Total & & 52 & $93 \%$ & & 51 & $91 \%$ \\
\hline Disagree Related & & 2 & $3.5 \%$ & & 0 & $0 \%$ \\
\hline Disagree Definite & & 2 & $3.5 \%$ & & 5 & $9 \%$ \\
\hline Disagree Total & & 4 & $7 \%$ & & 5 & $9 \%$ \\
\hline
\end{tabular}

Table 5b. Interrater Reliability: Code Comparison of Coder 2 to Coder 1

\begin{tabular}{|c|c|c|c|c|c|c|}
\hline \multirow[b]{2}{*}{ CODES } & \multicolumn{3}{|l|}{ IV\#1 } & \multicolumn{3}{|l|}{ IV\#2 } \\
\hline & Coder 1 & & oder 2 & Coder 1 & \multicolumn{2}{|c|}{ Coder 2} \\
\hline Raw Codes & 53 & & 65 & 52 & & 55 \\
\hline Invalid Codes & 0 & & 3 & 0 & & 2 \\
\hline Duplicate Codes & 0 & & 6 & 1 & & 6 \\
\hline Duplicate Related Codes & 0 & & 11 & 1 & & 5 \\
\hline Total Valid Codes & 53 & & 45 & 50 & & 42 \\
\hline \multicolumn{2}{|l|}{ CODER 2 to CODER 1} & \multicolumn{2}{|c|}{ Sum Percent } & \multicolumn{3}{|c|}{ Sum Percent } \\
\hline Match Exact & Code & 27 & $48 \%$ & Code & 26 & $46 \%$ \\
\hline Match Content & list $=$ & 9 & $16 \%$ & list $=$ & 6 & $11 \%$ \\
\hline Match Related & 56 items & 9 & $16 \%$ & 56 items & 13 & $23 \%$ \\
\hline Match Total & & 45 & $80 \%$ & & 45 & $80 \%$ \\
\hline Disagree Related & & 3 & $5.5 \%$ & & 5 & $9 \%$ \\
\hline Disagree Definite & & 8 & $14.5 \%$ & & 6 & $11 \%$ \\
\hline Disagree Total & & 11 & $20 \%$ & & 11 & $20 \%$ \\
\hline
\end{tabular}


Intensive analysis of the errors revealed in the reliability tests, along with the codes themselves and the code outline, produced several benefits.

1. The difficulty of reliably separating problems from solutions became apparent, and this aspect of the coding was abandoned.

2. A closer appreciation was developed for the relations of codes in categories, with general codes enclosing more specific codes below it. An index system was adopted for the code outline, using decimals to organize ranks (e.g., 1.1., 1.1.1).

3. Close scrutiny of the codes and related quotations produced stronger concepts for the codes, allowing a latitude, but clear distinction from other codes. This proved to be an ongoing process.

4. The paramount importance of the code outline became apparent as a guide not only for organizing and locating codes, but also as a map of relevant topics that helped identify relevant arguments in the transcripts that might otherwise have slipped from view.

This learning process through the reliability test resulted in a decision that all transcripts would need to be coded twice. This would allow all codes observed in the first round to be available for reference in coding every transcript in the second round. Also, the code outline would be more fully developed and clearly defined in the second round, which might reveal new arguments that were previously missed. In several instances, an explicit argument in one transcript, clearly coded, helped to recognize the same argument raised more subtly in a different transcript. Double entry is a traditional method for reducing errors while creating a numerical database. In this case, the double entry was also useful to check and assist the recognition of embedded ideas (Barbour, 2003). 


\section{Notes on the Presentation}

After the first round of coding the entire collection of transcripts, the code outline was revised to develop a sequential narrative, beginning with a central problem statement. Subsequent sections represent topical areas. An unanticipated section was added, related to practice management. This topic was then added to the literature review (see Chapter 4). The complete code outline is presented for reference at the beginning of the results presented in the next chapter.

The final code outline consisted of 376 individual codes. This original list was maintained to highlight key issues while drafting the narrative of results, but the course of the presentation and the final summary follows a collapsed list of 95 categorical topics to improve the clarity of the main themes. A few minor codes that fit no larger category and were represented by only one or two stakeholder views were included in the presentation of results, but were excluded from subsequent summary measures.

Two levels of attention are presented in the narrative. The first level relates to the views of individual stakeholders as representatives of particular groups. Mention of views directs attention to the source of an argument, and levels of agreement or disagreement among individuals within or between groups (subjective rationality). Thus, for example, physician views may be compared with other physician views, or to hospital views or insurer views. Individual stakeholders are identified by their associated groups, though every individual in the physician group, for example, is not actually a physician, and no individual in the hospital group is a hospital. The group category is the source of the argument. In a few instances, where response on a topic is low and group affiliation 
appears to be inconsequential, an individual may be identified generically as a stakeholder.

The second level of attention refers to arguments as objective content (objective rationality), unrelated to persons. Thus, an argument may affirm or contradict an idea according to its content, without reference to a person making the argument. Note that ideas, topics, or themes are the component parts of an argument. Naturally, both subject and object are inherently connected, and a combined form may occur that gives attention to both aspects of discourse at once. For example, a physician may argue.

In all, the information provided by individual stakeholders as persons is raised to a level of abstraction in the presented results, organized by categories and codes. Attention focuses on (a) views associated with stakeholder groups, and (b) ideas associated with arguments.

\section{Descriptive Statistics}

In presenting aggregated views related to a particular argument, the percentage of the sample included is reported to indicate a level of agreement, starting with six views or $16 \%$ of the total number of interviewees. This number of views seemed to be a minimum for distinguishing representation of an argument by different groups. The percentages are presented only to give a sense for the prevalence of certain arguments, and must not be interpreted as quantitative measures and distinctions. As this study is qualitative and not reliably generalizable, small numbers are not reported as percentages and are left 
intentionally inexact to avoid size distinctions. One view supporting an argument is called one; two is called two, and three to five is a few.

Numbers in any aspect of social science must always be understood through interpretation, and particularly so in a qualitative study such as this one. Without clearly structured interview questions (which would have limited the response), and a random sample to allow some assurance of generalizability, the percentages reported here are only applicable to the present sample. Nevertheless, the numbers do indicate prevalence and levels of agreement in line with Kingdon's (1995) policy study.

Additional summary statistics were applied to characterize the entire set of arguments and the individuals and groups that supported them. Three summary displays are presented. First, a Jaccard measure of similarity was applied to all prominent codes, represented by at least one-third of all stakeholders (divided at a natural break in code clusters at 32\%). Using a model of the Jaccard proximity measure applied to content analysis by another researcher (Oleinik, 2011), a graphic figure was constructed to display associations greater than .5 on a scale to 1 . This figure provides a summary view of commonly associated topics in the discourse of individuals.

Two other summary displays represent group representation for the topics in each section. All codes represented by three or more views are presented in a table showing the prevalence of attention from each group. The table (Table 6) provides basic detail for the narrative results. The second table of summary results (Table 7) shows the group with the highest and lowest percentages for each topical section, and also a proximity measure using a Pearson correlation to identify associations between different groups. 


\section{Chapter 7}

Results

The outline below organizes the coded arguments related to feasible models of universal health insurance in Oregon, drawn from stakeholder interviews. Each category contains additional specific codes. The narrative of results in this chapter follows the outline. Main arguments and finer distinctions in individual views are presented. The 38 interviewees in the study represent seven groups: experts $(n=6)$, hospitals $(n=5)$, insurers $(n=6)$, physicians $(n=5)$, public interest $(n=6)$, purchasers $(n=5)$, and state officials $(n=5)$. The hospital and physician groups are sometimes referred to together as providers.

\section{Code Outline}
A. Cost Imperative
$\underline{\text { B. Politics }}$
1. Cost Control
1. Social Contract
2. Overutilization
2. State Capacity
3. High-Cost Conditions
3. Federal Role
4. High-Cost Technology
4. Business Relations
5. Low Value
5. Leadership
6. Uninsured Costs
6. Public Dialogue
7. Profits
7. Reform Vision
8. Medical Errors and Liability
8. Equity
9. Public Health
10. Framing the Problem 
Chapter 7. Results. Code Outline 189

C. Model Systems

1. Universal System

2. Oregon Action Plan

3. Medicare and Medicaid

4. Employment-Based Insurance

5. Self-Insured Employers

6. Utility Model

7. Central Funds

D. Insurance

1. Insurance system

2. Insurance Competition

3. Insurance Management

4. Benefit plans

5. Personal Risk

6. Rate Regulation

7. Risk Adjustment

8. Health Insurance Exchange

E. Purchasing

1. Third-Party Purchasing

2. Physician Purchasing

3. Consumer Choice

4. Transparency

5. Payment Systems
F. Delivery System

1. Coordinated Care and Teamwork

2. Clinical Management

3. Workforce Development

4. Coordinated Social Services

5. Information Infrastructure

G. Practice Management

1. Evidence-Based Practice

2. Managing Care

3. Insurer Managed Care

4. Accountable Care Organizations

5. Provider Practice Management

6. Community Practice Management

7. State and System Management

8. Liability Reform

$\underline{\text { H. Finance }}$

1. General Finance

2. State Tax System

3. Specific Taxes

$\underline{\text { Summary Results }}$

- Diagram of Associated Arguments

- Table of Group Response by Topic

- Table of Group Correlations 


\section{A. Cost Imperative}

In the views of the 38 stakeholders interviewed in this study, cost control was the main motivating force behind healthcare reform and universal health insurance. Over half of the stakeholders $(61 \%)$ directly mentioned cost control as a primary goal, some in the moderate language of "bending the cost curve," and others more emphatically as an "essential" concern and an "enormous economic burden." Stronger views were most common for purchasers and state officials, who were also more likely to mention an expanding cost crisis.

Overall, the public interest group was the least likely to identify specific cost problems. Each of the seven stakeholder groups contained one person who gave only passing or no attention to cost control as a pressing imperative, though everyone argued in some way for improved quality, organization, or value.

The primary argument from the earlier period of universal healthcare reform in the early 1990s, pertaining to the high cost of the uninsured-due to delayed care and lack of a primary-care relationship, resulting in more serious and expensive conditions and overuse of the hospital emergency department—was not mentioned more than other specific cost issues (16\% of all stakeholders). The high cost of the uninsured was most commonly mentioned in provider views, and was absent in expert, insurer, and state views. 
Crisis

A large number of stakeholders mentioned the exceptionally high rate of inflation in healthcare costs (37\% of all stakeholders). Every group was represented. A few stakeholders mentioned the pressure on employment-based benefits, and a few pointed to the usurpation of culture and other essential public services as a growing proportion of the gross domestic product is dedicated to health care.

One insurer dramatically enunciated the problem, saying: "The private sector for health care is dying, and it's dying a slow, ugly, painful death." One hospital stakeholder agreed, with similar force, saying: "It's an impossible scenario." Others recognized the growing crisis or "impending disaster" for physicians, purchasers, and the state.

\section{Delivery System Reform}

General concern for the delivery system was evident for a large majority of stakeholders ( $82 \%$ of all), referring in general terms to delivery system reform $(26 \%)$, low-value care (34\%), signs of inefficiency compared to other countries (16\%), and the necessity to improve value to make increased access sustainable $(26 \%)$. One state official fixed the cost crisis directly on the delivery system: "I think another fallacy is the insurance industry really drives the cost of health care. It's not: it's the docs, it's the hospitals, the pharmacies, and those folks that really have the big impact."

Specific arguments related to high costs referred to provider supply-driven care, including topics of overtreatment or marginal care, treatment variation, and perverse financial incentives with fee-for-service payment (53\%). Other topics included the high 
cost for certain drugs, equipment, and procedures (24\%), for end-of-life care (16\%), and one argument for neonatal care. Only a few arguments directed attention to consumer overutilization, mostly related to overuse of hospital emergency departments.

The delivery-system cost burden was also associated with excess profits (16\% of all stakeholders), attributed in order to physicians, hospitals, insurers, and to the healthcare system generally. All groups were represented, except hospitals. None accused their own group of excess profits.

\section{Medical Errors and Liability}

Another critical cost issue was raised related to medical errors, though little attention was directed to this area. One expert, one physician, and one state view raised the issue of reducing errors and increasing safety. All three were emphatic about the "enormous" costs and the potential for "huge savings."

Additional arguments, though still few, and all from provider perspectives, urged liability reform (discussed in more detail in the section on practice management). One said, "To cut costs it's essential"; another, "You have to have liability reform"; another, "It's "critical." One physician clearly stated the cost issue from the patient's perspective: "I think you could design a medical liability system that will streamline and get more money to the injured patient, and compensate more patients; sixty percent of the premium dollar currently goes to lawyers and administration." It was also believed that liability reform could improve transparency, quality, and decisionmaking. 
Three stakeholders argued that extra costs occur due to defensive medicine, and the problem of tort issues generates expensive and very personal conflict between providers and patients, which may drive physicians from practice. Politically, however, these arguments were recognized to have little force. Along with the general neglect of the topic by other groups, one physician observed: "There is no plan to institute reform at the medical liability level." One state official remarked: "I am not arguing for malpractice reform, because I think that's the wrong place to go."

\section{Public Health}

Nearly half of the stakeholders made arguments for public health as a "key" element in the cost issue (47\% of all stakeholders). Attention to the topic spanned all groups; purchaser views were least common.

All arguments related to the sustainability of universal health insurance in an environment of overloaded demand. The most concise version of the problem came from a physician: "I think the overall health of our population is a big issue-that we are really older, sicker, and fatter." For many stakeholders, obesity was the primary issue, regarded as a problem of epidemic proportion. All together, arguments related to public health raised topics of the aging population, nutrition, lifestyle, and social factors (housing, poverty, education, and class).

A number of arguments, particularly from the hospital group, regarded lifestyle as the central issue in public health, and argued to somehow raise personal accountability for healthy behavior (24\% of all stakeholders). Several stakeholders focused on careless 
individual behavior and the expectation of "redemption" through the healthcare system (moral hazard). Others expanded the context of healthy behavior to include employee wellness programs and community structures to assist healthy choices. Mostly, ideas for solutions were rare (a few arguments on this topic are presented later in the section on coordinated social services for the delivery system).

Framing the Problem

In a few explicit instances, reforms were summarized in mission frameworks that expanded attention to other issues along with cost control. The most prevalent was the newly ascendant triple aim (Berwick, Nolan \& Whittington, 2008), including (a) cost management, (b) population health, and (c) patient experience. Overall, the concept of population health was obscure. Sometimes it was mentioned in the context of medical care as a health outcome (quality of care); other times it related to the larger issue of public health, spanning a spectrum of institutions. Patient experience was defined by one insurer: "People's experience of care should be reasonable; they should be able to get it in a timely manner, generally have good dialogue with their providers, feel like they were taken care of, and respected."

Two stakeholders presented the triple aim as defined above, but then added access and quality as critical issues, reflecting the familiar triangle from the earlier era of Oregon Health Plan reforms: access-cost-quality. As one insurer argued, regarding access: "If we passed universal coverage tomorrow, we'd wake up a day later and say: Oops, we don't 
have enough primary care." These additions to the triple aim indicate the new framework does not sufficiently convey the essential elements of reform.

A third framework, suggested by one insurer, was unique. It encompassed (a) funding, (b) delivery system reform, and (c) accountability for value. In this framework, funding relates to the collection, pooling, and direction of funds into the system. Interesting here is that cost control is not mentioned, but is embedded in the two areas of delivery system reform and accountability. These topics are addressed in sections below as critical aspects of cost control.

\section{B. Politics}

A number of stakeholders viewed the feasibility of universal health insurance in Oregon first as a matter of policy and politics. In this perspective, reform was dependent on the capacity to imagine and agree upon real solutions. For many, this was a principal concern.

\section{Social Contract}

A system of universal health insurance was frequently conceived by stakeholders as an obligatory system of social insurance to prevent bankruptcy and ruin, or as a social responsibility for all citizens to improve health and prosperity for everyone, or as a moral responsibility to establish a civic or human right (37\% of all stakeholders). All groups were represented, except purchasers. Several arguments equated health care with education and public safety as a basic public good. As one state view put it succinctly: 
"We should be certain people get fed and housed, and are cared for, and educated." All but one stakeholder in this category also emphasized public health.

\section{State Capacity}

Arguments for the state's capacity to implement universal health insurance exhibited contradictions, sometimes expressed by the same person. Hospital views were least common.

A small number of stakeholders were confident in the public's collective will. A larger number were encouraged by Oregon's active organizations and people involved in reform; the high level of population awareness on the issues; and Oregon's character as a progressive state (26\% of all stakeholders). Physician and state views were absent here.

More arguments highlighted the lack of political will (39\% of all stakeholders); most focused on the entrenched status quo of business interests with lobby influence. Hospital views were absent. Additional arguments in this category highlighted the problem of money in politics and the need for campaign finance reform. A few stakeholders mentioned an embedded attitude of "Calvinism," which restricted willingness to help only the "deserving poor." Notably, all of these arguments were projected as the views of others in the state, not the respondents themselves.

More direct opposition to state reforms appeared in arguments expressing a lack of confidence in the state's capacity to manage a system of universal health insurance (18\% of all stakeholders). Physician views were absent. One state official said: "The state has failed." One expert said: "In terms of core competency, expertise, and track record, 
the state of Oregon, state of Massachusetts, state of California, state of anyone, I don't think they ought to be the one in charge of it." In another expert view: "They're doing the incremental kinds of things that I think you have to do, but I think many, if not most, are federal. I really don't think it's going to happen at the state level.” A few stakeholders emphasized the state's lack of fiscal capacity. One feared Oregon's initiative/referendum process was a sure way to defeat ambitious reform, especially the accompanying tax reforms that would be necessary.

\section{Federal Role}

Nearly all of those who lacked confidence in the state role in health system reform advocated a national solution (16\% of all stakeholders), partly because the national government is the source of most of the funding for publicly sponsored health insurance; partly due to the organizational limits of what one state can accomplish with a mobile population, open state boundaries, and global corporations; and partly, as enunciated above, because of perceived state incompetence. Other arguments exhibited an equal lack of confidence in the prospect of a national solution (13\%), mostly due to an intransigent, deadlocked Congress. One expert summarized the situation following the national health reform mandate in 2010: "I don't think we are going to get a major change in how to finance health reform and how to regulate health insurance out of the federal government for another 10 or 20 years. We're done with that." Arguments approving the current federal reforms as an adequate foundation for further action (18\%) were split on the 
correct course: one-third argued for more work on a national solution; the remainder argued the state could proceed nicely under the existing framework.

A middle ground appeared in a different set of arguments, which advocated state action with flexible support from federal waivers, policies, and assistance (24\% of all stakeholders). One state official summarized the situation: "I'm not sure the state of Oregon by itself can implement a sustainable model to provide universal health care without significant assistance—-from a regulatory standpoint, a funding standpoint, a social policy standpoint—-from the feds." Another state official articulated an argument that the national government expected this kind of contract with individual states. One hospital stakeholder strengthened this position: "I would say maximizing the flexibility ... is going to be absolutely essential."

\section{Business Relations}

Only a few arguments concerned political relations with businesses. One purchaser argued that businesses want to help employees and the community with health care benefits, but the cost is becoming too burdensome-they might welcome the advantages offered by the new reforms. The same purchaser and a public interest stakeholder emphasized the different interests of big businesses versus small businesses, and argued that small businesses need to be engaged with the local agenda, separate from the agenda of national business lobbyists. The complexity of the current reforms may make this difficult. One expert mentioned signs of confusion: "I've been talking to a lot of employers, and they're all scratching their head trying to figure [it] out." 


\section{Leadership}

Several arguments supported the need for leadership (18\% of all stakeholders). Public interest views were most common. The leading argument involved engaging knowledge experts or charismatic leaders, like John Kitzhaber, or Bruce Goldberg as director of the Oregon Health Authority, or legislative leaders, to set bold new directions for some aspect of reform, such as how to implement the concept of medical homes. Nearly as common was an argument to use these leaders to activate and lead stakeholders and the community in discussions to reach consensus on issues. As one hospital stakeholder stated: "Good advice he [Kitzhaber] gave long ago is that before you get anywhere you really have to have everyone agree on a unified vision."

\section{Public Dialogue}

Several arguments referred to a need for social discussions of values (18\% of all stakeholders). Public interest views were most common.

A few of the arguments for public dialogue involved relatively simple issues of sharing information, such as transparency in commercial operations for public accountability; or encouraging civic engagement to assist in democratic "ownership" of reform proposals. Other arguments were more ambitious, expecting communities to be confronted with hard decisions they must participate in making in an environment of scarce resources. One aspect involved helping to set priorities for medical services to include in benefit plans, particularly in controversial areas such as end-of-life care. As one insurer stated: "Does the community want to invest in [everything] anybody wants 
once they get in the hospital?" One state official put it more forcefully: "Society needs to debate ... We are not going to be able to give everything to everybody, and people are going to die." One physician pointed out that these kinds of decisions should not be left to the individual physician, but must be guided by an external authority and endorsed by society. Other value decisions to set before the public involved tax reform to finance universal health insurance, and establishing acceptable limits on remuneration for noneconomic damages in tort cases for medical errors.

One public interest stakeholder criticized the kind of public dialogue practiced so far in Oregon, saying such dialogue draws stakeholders and activists—-the same, predictable crowd—but not the general public. Part of the problem is that the issues are "beyond people." In addition: "Most people believe that when they need health care it's going to be there for them. They don't want to get involved."

\section{Reform vision}

A number of arguments referred to the complexity of reform and the difficulty of grasping its critical elements in a comprehensive plan (29\% of all stakeholders). According to one physician: "There are a whole lot of parts to it, and they are all connected." One state official and one insurer corroborated the connectedness of the "moving parts." Both introduced the example of a recent small-group insurance market reform, making the point that even a small change in a single area can have percussive results. 
"I just don’t know how to get there," another state official concluded, "I am having a hard time putting my head around how this would actually work and how a state reform could help make it happen."

On the other hand, for two insurers, reform appeared straightforward—at least so far as agreement on what the system should look like in the end. Getting there is the problem. In one purchaser view, the ideal was less clear: "60-40" for the prospects of the state's proposed model of managed competition—barely better than chance.

A preponderance of other stakeholders argued that ideals are not necessarily shared. One physician summarized the situation: "We don't all agree, and even people who agree on the end result don't agree on tactics."

Accordingly, a number of arguments referred to the need for a good story or a well-articulated ideal (18\% of all stakeholders). For insurers here, the "story" is particularly important once the public is asked to pay for the reform. As one insurer stated: "I don't think you can pass a new source of funding without being able to tell an important story about what you are really trying to do." According to another insurer: "You have got to get to a point where those people who have some insurance are willing to pay more in order for the 16 or 17 percent of the people who don't have insurance to be able to get insurance." According to one physician, articulating the ideal is the most important step. A few public interest stakeholders argued that people must be assured they will be better off.

Another set of arguments criticized the patina on this kind of storymaking, saying reform discussions are often unrealistic (16\% of all stakeholders). As one insurer argued: 
“There's going to be some pain_for somebody." Speaking of earlier Oregon Health Plan reforms, one expert remarked: "We pretended." A public interest stakeholder said: "We need to look at some of the other more controversial issues that tend to always hide behind the surface." One state official put it more pungently: "Pretense and performance are two different things. Pretense is all the little words of today ... it's all wonderful ... go back 20 years ago, we had these same conversations." In these arguments, frustration was palpable.

Several arguments supported incremental innovation (18\% of all stakeholders). Even for those who opposed this path to reform, nothing else appeared possible. Nearly an equal number, however, flatly rejected the incremental approach. In a public interest view: "You can't do that [achieve population health] by only chomping off segments of the pie." In a hospital view: "It doesn't seem very realistic in terms of trying to evolve our way out of where we are." A purchaser provided a cogent summary:

Part of the problem in what we do is we are so incremental that people can't get excited about: Gee, my life is actually going to get better ... I do believe you can defeat yourself as easily by having too small a vision as by having too big a vision.

\section{Equity}

A few arguments touched on issues of equity as components of the reform vision. In all, the topics here appear equally relevant to specific issues introduced later, in relation to funds, payment reform, and finance. They fit here, because state governments are constitutionally bound to observe equity in matters of taxation and public 
expenditures (Hirsch \& Rufolo, 1990), and equity issues could gain force in the politics of healthcare reform.

The most important argument related to equity involved paying the true costs of medical care ( $41 \%$ of all stakeholders). This argument was presented primarily by purchaser, hospital, and physician groups — those most involved with the payment system.

For these stakeholders, many of the perverse incentives and inefficiencies in the healthcare system arise from cost shifts: (a) covering uncompensated care and low government reimbursement for Medicare and Medicaid, (b) underpaid but necessary units in hospitals leads to promotion of high-end services to compensate, and (c) undervalued physician reimbursement in primary care in comparison to technical specialties leads to physician shortages. One hospital stakeholder put this issue up front:

You have to adopt a payment mechanism where hospitals and other medical providers are paid their true costs - that you don't underpay and require that provider to then bill your underpayment into somebody else's bill, which is the way it works today. That's first.

Other dimensions of equity, mentioned by only a few stakeholders, involved:

(a) equitable treatment for service users in terms of price and quality, and (b) equitable finance, reflecting core principles of taxation, with arguments that everyone should contribute (horizontal equity), and that those with greater resources should pay more (vertical equity). In regard to equitable treatment, one public interest stakeholder argued to standardize the different prices charged at hospitals and eliminate favorable contract prices with certain insurers and groups. Other stakeholders argued to fairly distribute healthcare resources and avoid disparities due to personal characteristics such as age, ethnicity, or income. 
In addition, one public interest stakeholder argued to eliminate welfare stigma:

There is a fairly large segment of our society that, right or wrong, sees certain programs that are welfare based in a bad light, in terms of a stigma, that they are not willing to go to until the ultimate dire emergency.

Other stakeholders addressed the issue of welfare stigma with positive proposals to eliminate the stigma (presented in the next section on model systems).

\section{Model Systems}

This section collects arguments related to systems of health insurance and healthcare funds as they now exist, and as they could exist in a model of universal health insurance. General features are presented first.

\section{Universal system}

All stakeholders in the study approved the idea of a universal healthcare system. In response to the standard question: Do you believe universal health insurance is a desirable goal in Oregon?-nearly all answered in the affirmative (89\%). The remainder approved, but not at the state level, believing instead in a national solution. Two stakeholders who argued for a national solution (discussed earlier) did not oppose a state solution, but thought it would be a huge challenge. Affirmative responses fell into four categories, in the following order: (a) Absolutely; (b) Yes, a good goal; (c) Yes, but coverage, not necessarily insurance; (d) Yes, but only if it's sustainable, with adequate cost control. (The question about the role of insurance versus coverage is discussed in the next section on insurance; a further aspect of sustainability appears in terms of finance in 
the final section.) With these caveats, and some measure of disagreement about the role of the state, the idea of a publicly supported universal system of health care was supported by all stakeholders.

Certain aspects of a universal system were mentioned. Most prominent was the argument that a universal system requires a mandate, without specifying the kind of mandate that was preferred ( $21 \%$ of all stakeholders). Two stakeholders opposed a mandate, arguing that individuals should retain a choice to participate, and believing some kind of voluntary system may be possible.

A few stakeholders argued that including the whole population would improve value by eliminating uncompensated care. In one public interest view: "The fact is, I am paying for that person if they go to the emergency room." Alternately, one state official warned that access alone will not create value: "We are never going to get a hold of healthcare costs just by putting people in the system."

Only one public interest stakeholder made an effort to emphasize that "all" includes all legal residents of Oregon, including new immigrants, as stated in the state reform bill HB2009, passed by the Oregon Legislative Assembly in 2009. A few others waffled on the meaning of universal, saying it meant somewhere between $3 \%-5 \%$ uninsured - a number comparable to "countries that have nationalized systems." As one insurer said: "You can think of lots of reasons why you are not going to get literally 100 percent in any system that requires enrollment." According to this argument, whether due to enrollment or other factors, such as class, transience, or illegal status, a marginal 
segment of the population will need to rely on safety net clinics outside the insurance system.

\section{Oregon Action Plan}

All together, over half of the stakeholders (55\%) made arguments that explicitly fell in line with the Oregon Action Plan, supported by the federal reform plan. A number of stakeholders specifically mentioned the HB2009 legislation, calling it a "great framework" or "pretty good blueprint" or "way forward," and similar terms (26\% of all stakeholders). This category was represented by nearly all stakeholders in the insurer, purchaser, and state groups-those most affected by the legal requirements.

Many of the stakeholders were careful to avoid endorsing every aspect of the legislation (details of the plan appear in later sections). One set of stakeholders (39\% of all) referred to the necessity of a "comprehensive package" in the plan: (a) individual mandate, (b) guaranteed issue of coverage to all who apply, and (c) premium subsidies for those with low incomes.

A separate set of arguments criticized the plan, for a variety of reasons (32\% of all stakeholders). The principal objection focused on the premium subsidies required by the individual mandate, mostly due to the "absolutely huge" public funding required to accomplish it, with no adequate strategy to finance it. Moreover, there was no adequate strategy to soften the impact for individuals. "People can't afford the cash flow," one state official argued, criticizing the idea of a refundable tax credit to distribute the subsidy. 
Two public interest stakeholders objected to the complexity of administering the subsidy and applying a welfare stigma to two-thirds of the population (up to $400 \%$ FPL).

Other arguments objected to the state plan, because the design of the funding and payment systems remains unchanged, and merely expands existing institutions that already do not work well. In one hospital view, echoed by others: "It exacerbates the problems." More dire, one expert warned: "It's going to break the system."

Regarding the individual mandate to purchase health insurance, a few supporters of the current plan regarded enforcement as a key issue. Critics found the current penalty system unconvincing. One insurer summarized the problem:

If you are going to fine me $\$ 100$ if I don't buy a $\$ 3,000$ policy-you can call that a mandate if you want. Now, if you fine me $\$ 4,000$ for not buying a $\$ 3,000$ policy, that's a different ballgame. But if I don't have the $\$ 3,000$, I don't have the $\$ 4,000$ - so I am probably not going to be able to pay the fine or penalty anyway.

A purchaser posed a simple solution to the penalty issue:

A lot of people talk about an individual mandate as a, you know: By God, you go out and get insurance or we will penalize you-by not giving you a deduction on your taxes or a variety of kinds of penalties ... But it seems to me that you want some kind of an automatic-enrollment scheme, so ... if somebody does not choose something, you enroll them in a default plan.

One public interest stakeholder emphasized that Oregon needs to "push the envelope" and think outside the box of the mandated federal reform, which the Oregon Action Plan follows:

I think Oregon has to be able to go beyond what they currently have laws that allow them to do. You have to be willing to push that or I don't see a way to achieve this goal of universal health insurance. 
Chapter 7. Results. C. Model Systems 208

\section{Medicare and Medicaid}

A variety of arguments related to Medicare and Medicaid, the two federal programs that cover healthcare costs for about one-fourth of the population in Oregon and comprise about half of all spending (see Table 1). All groups were represented; physician views were most common.

Most arguments addressed problems. One prominent argument, represented across all groups, referred to low Medicare payment in Oregon compared to other states (16\% of all stakeholders), supporting the equity argument discussed earlier to pay true costs and fairly distribute resources. A larger number of arguments discussed low payments from both Medicare and Medicaid as a principal, though not the only source of imbalance that drives a cost shift to commercial insurers and profitable activities, or induces selection by providers to avoid those patients (more on this topic appears below under provider practice management).

One physician argued for a system to augment unit payments to encourage physician participation. A public interest stakeholder recognized that government benefits are purposely inadequate, implying the two programs will never be standardized to cover full costs. A hospital stakeholder judged both programs as "broken" and not worth fixing. A physician was more ambivalent, seeing "some good" and "a lot of bad."

According to one state view, Medicare drives a lot of positive changes, but is incapable of managing care: "Even though they use their DRGs (diagnosis-related groups), they are still paying unit cost"-which means the sophisticated bundling for prospective payment, used by Medicare to control costs, remains a fee-for-service 
payment with a characteristic tendency to increase utilization. Another physician argued that Medicare does not help to manage care, but only issues rules on how to behave. One expert described the lack of overall management between the two government funds for so-called dual-eligibles — those individuals enrolled in both Medicare and Medicaid; administrators may protect funds in their own silo and not worry about expenses incurred by the other program for the same patient.

Several physicians introduced a further point, related to the attitude of entitlement frequently observed among Medicare and Medicaid patients: "The attitude of Medicare [or Medicaid] patients when they walk in the door can be very disturbing, because they know that everything is covered." Only gradually, with some indignation and conflict, do they learn the limits. Regarding the likelihood of rationing resources in a universal system, one hospital stakeholder inserted a relevant argument here, saying the Medicare entitlement might need to be redefined into a system of needs-based rather than categorical coverage.

A different, though somewhat overlapping set of stakeholders plainly argued for an expansion of Medicaid (18\%). Several adopted the argument as a logical expansion of the existing system as found in the federal and state reform agendas. Others saw expansion as a "no-brainer" strategy to maximize available federal matching funds.

For Medicare, one insurer proposed expansion of Medicare managed care plans. One expert opposed the plans, pointing out that they only succeeded in recent years, because funding was raised to $110 \%-115 \%$ of the cost of original Medicare beneficiaries, and now that extra funding is being withdrawn. Efficiency of the plans and beneficiary 
satisfaction have shown mixed results. Also, as a federally funded system, the plans fall outside the purview of state insurance regulation. In this view: "I think insurance commissioners ought to have oversight, so that consumers have a place to go when they've got issues."

\section{Employment-Based Insurance}

The idea of an employer mandate to help reach universal health insurance, though discredited in Oregon by earlier experience with the Oregon Health Plan, was supported by a few, mostly state officials, looking favorably at models under review at national and state levels. One state official pointed to the example in Massachusetts, where a small penalty on employers and employees provided just enough impetus to prompt compliance to an employer mandate.

An equal number of other stakeholders opposed the mandate as a burden on already overburdened employers. Separately, a single hospital stakeholder mentioned development of voluntary multi-share insurance products, which provide a subsidy, typically from a community source, to encourage employers to provide health insurance with a nominal contribution from employees, possibly in combination with state Medicaid funds.

More stakeholders argued instead to eliminate employment-based insurance (18\% of all stakeholders). Purchaser views were most common; provider and state views were absent. 
One purchaser argued that employment-based insurance did not make sense with a mobile workforce, because it forces constant change and gaps in individual coverage, and encourages employers to use temporary workers to avoid providing benefits. Most of the stakeholders argued, in particular, to empower individual choice for insurance, making employers distributors rather than sponsors of health insurance. A few mentioned the Healthy Americans Act $^{17}$ advanced in Congress by Oregon Senator Ron Wyden as a model for this kind of system.

\section{Self-Insured Employers}

A number of stakeholders mentioned the category of large self-insured employers protected from state regulation by the national ERISA law (21\% of all stakeholders), which covers an estimated 7\% (and probably more) of Oregon's population. The state group was the most common. ERISA impedes the scope and options for the state reform agenda (see the discussion of ERISA in relation to the employer mandate in Chapter 3, and in relation to self-insured firms in Chapter 5).

Mostly, the ERISA barrier was mentioned as an insuperable fact, which the state could not, and possibly should not seek to overcome. Only one state official forcefully challenged this hands-off perspective:

The legal construct and the system constructs that we work in now have gotten us to a place where we don't have universal coverage; so we've got

\footnotetext{
${ }^{17}$ The Healthy Americans Act was based on an individual mandate and guaranteed issue to purchase health insurance in a competitive market. Premium subsidies would be provided to low-income individuals. The principal difference was the broad application to all persons, which would eliminate employment-based insurance. Employers would be required to raise wages to account for diminished obligations for employee benefit plans. Also, a provision was made for long-term care insurance.
} 
to change some of that. You can't create a common universal system and have different people playing by different rules.

Solutions to overcome the ERISA barrier were marked by confusion. One public interest stakeholder suggested requiring the self-insured employers to adopt certain standards [prohibited by ERISA]; one state official suggested seeking a federal waiver [already failed in Oregon in 1995, and never granted to any state—Hawaii did not get a waiver but preceded the federal law]. Two other state officials found a reasonable way forward: one pointed to the example of San Francisco, where a pay-or-play law was passed that managed to survive an arduous 4-year court battle. A second state official elaborated the only recognized way to bypass ERISA:

Those are sticky issues. There's still a lot of development as to how far states can go; but if you were to say that you are regulating the individual, you are not regulating the plan, and you are saying every individual has to have coverage and the coverage has to meet some basic requirements ... [That could work].

\section{Utility Model}

A large number of stakeholders argued for an overall public system for the organization and funding of health care (50\% of all stakeholders). All groups were represented. Expert views were most common; purchaser views were least common. A few stakeholders explicitly named this a utility model, and this label appears appropriate for all arguments in this category, including those (13\% of all stakeholder) that interpreted the system with single-payer features (see Chapter 3).

Some arguments for the utility model equated the system with public fire or police departments, or electricity or natural gas—all familiar, publicly provided goods or 
services. One state official argued: "We've got to put everybody in the same pot; there can't be Medicaid, can't be TANF, can't be pregnant women, FHIAP, high-risk pooleverybody's got to be together." Adding to the list, an expert said: "I don't know how you do it at the end of the day without bringing Medicare to the party, and self-insured employers." A hospital stakeholder concurred: "If I were king for a day? You get rid of Medicare, you get rid of Medicaid, and you come up with some kind of universal platform." A purchaser described the problems of administering a fragmented insurance market, and added: "I would ideally like to get rid of employer-based [insurance] and ... the various components of the market for the individual and the group, especially the small-group market with their different rating rules."

One public interest stakeholder related the unified perspective for the state population to a concept of social solidarity:

The unfortunate thing about these patchworks ... 'you' are on Medicaid and 'you' are on a private plan and 'you' get help and 'you' don' $t$ - there is this feeling that it is not 'our' system. It's not our system as Oregonians that all of us belong to ... it creates this resentment ... Its sustainability may be undermined by the patchwork nature of it.

An expert saw the same picture in terms of equity:

You can't have artificial barriers, or artificial differentials set up among people with similar incomes and so on, just because one of them happens to be 65 and one happens to be younger, or just because somebody doesn't have any children and is not pregnant and has an income greater than $133 \%$ of the poverty level.

A state official summarized the purpose of a unified system:

Some of the larger reforms we need to do ... the only way I believe we can in the long run do that, in any way that is effective, is to understand that we have a single statewide healthcare system ... The biggest reform we 
need is to understand we all use the same system. We need a common system of rules, regulations, payment - rather than the system we have now, where 300 different insurance companies have 300 different formularies to control the pharmaceutical costs; where a hospital or a doctor get paid 17 different ways for the same service.

This argument for streamlining administration and purchasing was the main point for those stakeholders who supported a single-payer system. The added factor there was that for-profit insurers in the system would be eliminated as a further efficiency measure. A different set of stakeholders emphasized a separate purpose in a unified system: the necessity to pool all funds to establish global budgets. In other versions, the model did not necessarily require the elimination of insurers as intermediaries, nor the pooling of all funds.

\section{Central Funds}

The utility model described above involves a "universal platform" for the provision of a public good. The model implies a system of organized monopsony, with set budgets to pay for identified services, but only about one-third of the stakeholders in this category specifically mentioned global budgets; one referred to the state, the remainder referred to regional systems. A number of stakeholders advocated mandatory accountable regions ( $21 \%$ of all stakeholders); some referred to examples in the United Kingdom or Sweden.

One hospital stakeholder gave a concise description of the regionalized utility model. This description exhibits the simplest format: 
You fund it at a broader tax base, and you fund it so it pays for the cost, recognize you have a limit, force the local areas to figure out how to work within that budget, and you might adjust that budget based on nuances that exist within any given population base.

Centralized funds were opposed by others. One-fourth of the proponents of an overall public system joined others in various criticisms. All groups were represented among the critics (34\% of all stakeholders). Purchaser and insurer views were most common.

Opposition fell into three overlapping categories: (a) combining existing funds would be too complicated (or impossible) and disruptive, (b) a monolithic authority would be mismanaged by the state, bureaucracy would increase, and providers and patients would be threatened by monopsony power and government rules, and (c) an overall public system by itself would not necessarily solve problems of low value.

On the first issue, a few stakeholders were doubtful about the state's ability to assert control over federal funds and over the population covered by ERISA-protected employment-based health plans. Further, they doubted that a single Oregon-based plan was appropriate for funds and firms that now operated across state borders. Others believed a centralized fund would be "very disruptive" for existing employer-based coverage and independent carriers.

Opposing the idea of a centralized fund, two insurers focused on problems related to state management capacity:

I suspect even when we pass some kind of public plan, it will be contracted out [to an insurer] ... We have pretty good infrastructure in place in the private sector, particularly in insurance companies, to manage what I call the utilization and population risk. The federal government or 
the state government does not have that capability. They've never had it, and to think they are going to put it in place in the very near term does not make any sense. The only thing that Medicare and Medicaid have ever been good at is cutting fees. They've always been good at cutting provider fees, and they've done a lot of that over the years ... but they have never been very good at managing utilization, and that's the key.

One physician also mentioned the problem of the government setting prices: "If you don't fix those reimbursement rates for this state, and a lot of other small states, you will destroy the healthcare system, or you will change it radically, and not for the better." One public interest stakeholder added the specter of a bureaucracy that would "not do any public good at all." An insurer highlighted the importance of a free market:

I am adamant having everybody covered in the private marketplace; I believe that is where innovation lies. I believe that is what makes the whole system percolate. I don't [like] a single source saying: We are the ones who decide when you go to the doctor, what drugs you take ... I want to have choices.

The third criticism was not necessarily opposed to a centralized system, but questioned the purpose. How would a consolidated system actually meet the goal of controlling costs? Administrative simplification, for example, would produce a one-time benefit, but would not address underlying system issues to control cost inflation.

\section{Insurance}

Insurance System

A number of stakeholders questioned the role of insurance in health care (18\% of all stakeholders). Expert views were the most common. others:

One public interest stakeholder elaborated an idea of coverage that was shared by 
I think there are some things right now that are inside a health insurance model that shouldn't be ... things like immunizations, some primary care, some chronic disease management. I think anything where we want people to use those services, they don't belong in an insurance model, which is about managing risk. So, if we want to impact chronic disease management, if we want to have every child immunized, why should you have to be insured in order to promote that and make that happen in your population?

Others mentioned safety net clinics as an example of coverage that is not really insurance. One expert raised a different argument, from a consumer's perspective:

I think insurance is the wrong goal. I don't care if I have insurance; I want to know that I have access and I'll never be forced to go into medical bankruptcy. That's where I think the public really wants to be.

Other single arguments concerning health insurance as a system raised additional points: (a) current underwriting is not really insurance, but rather a complicated mechanism of claims processing for specific groups; and (b) consider the proposal to remove state borders for insurance as proposed in federal discussions, so purchasers can obtain insurance anywhere.

\section{Insurance Competition}

A number of stakeholders from all groups discussed insurance competition as proposed for the Oregon reform agenda (34\% of all stakeholders). All stakeholders in this category understood the plan: (a) the state standardizes insurance plan features to simplify individual consumer choice, (b) the insurers compete on the quality of care available through their network of providers, and respond to enrollee needs, and (c) quality scores on a variety of performance indicators inform consumers where to obtain the best value. 
According to one public interest stakeholder, the purpose of competition is: "You are making insurance companies responsible for the governance of health care - to keep costs low, to monitor and help reduce costs ... It could be governance, but it's also just through contracting."

One expert emphasized price competition as a natural factor in this process: "Because it would keep them more responsible to the consumer, keep their prices more competitive, and their margins lower." Insurers did not appear to agree, or did so only with reservations. One insurer approved the idea of standardized pricing and competing only on quality: "I would love to do that, and I suspect some of my competitors would, too"- then described problems in a competitive insurance market when companies play for market share by underpricing (so-called predatory pricing). According to another insurer, the competition "has to be heavily regulated." Others expected increased regulation to drive away "fly-by-night" carriers and consolidate the market to favor those "committed to administering a health benefits plan."

Only one purchaser identified the state's planned insurance market as a system of "managed competition." This stakeholder was also the only one who demonstrated familiarity with the criticism that managed competition will not work in low-population areas (Kronick, Goodman, Wennberg \& Wagner, 1993). In this and other views (18\% of all stakeholders) a public plan would be helpful to improve competition in the insurance market and ensure coverage for rural populations. 


\section{Insurance Management}

A number of stakeholders focused on the state setting standards for marketed insurance plans (21\% of all stakeholders). Purchaser and state views were the most common; expert, insurer, and physician views were absent.

According to this argument, state management is necessary to help "reduce costs and improve quality and expand access"-all goals for the healthcare delivery system, consistent with the trickle-down strategy in managed competition. The idea appeared to combine regulation and persuasion. One state official suggested using a seal of approval as in Massachusetts to distinguish highly approved plans for consumers.

A separate set of arguments, from all groups, urged the regulation of risk selection (37\% of all stakeholders), including guaranteed issue as introduced earlier as part of the necessary "comprehensive package" for the individual mandate. Also, regulation was expected to eliminate underwriting and curb other mechanisms by which insurers might avoid high-risk individuals. As one expert stated: “We don’t want an insurance plan succeeding because: Hey, we were the best at figuring out who was sick and getting rid of them. We don't want that to be one of the variables. Right now it is."

One public interest stakeholder explained some of the more subtle techniques for risk selection, such as marketing by zip code, which makes it difficult to monitor and control:

You need it to be required to just be in that pool ... there needs to be a very strict regulation around the games the insurers play with their agents, which we've seen played out in the Family Health Insurance Assistance Program. 
A few stakeholders raised uncertain arguments about reducing, regulating, or eliminating insurance agents. One insurer supported agents, giving an example in the California individual insurance market where an option was available to self-enroll or use an agent: "A huge percentage of people paid the extra [5\%] ... Most people are used to having, want an agent."

In addition, a few stakeholders argued for limiting the loss ratio (administration and profit margin) for insurers. A somewhat larger number urged insurance system transparency (13\% of all stakeholders). Only stakeholders from the expert and public interest groups advanced this argument. Suggested information to make available included executive salaries and administrative details behind the loss ratio, enrollment practices (to control risk selection), and also, approval practices at the Insurance Division.

Only a few stakeholders argued for assuring portability (keeping an insurance policy through a change of status in job, age, or other factors). One hospital stakeholder argued that portability is critical. A public interest stakeholder argued that portability would improve efficiency, reducing job lock (when employees keep a job to avoid losing benefits), and also reduce churning (the costly process of disenrollment and new enrollment in insurance plans, which insurers tend to encourage to cycle out bad risks). According to this view: "The carriers here, when I talk with their CEOs, are privately telling me that anywhere from $20 \%-30 \%$ of the cost of insurance is because of enrollment costs: disenrollment, reenrollment." 


\section{Benefit plans}

A large set of arguments covered the idea of a standard benefit package, or a minimum or essential benefit plan—concepts which may not be equivalent (53\% of all stakeholders). All groups were represented. Purchaser views supported this argument unanimously; provider views were least common.

The basic idea of standardized plans is to assist consumer choice through “apples-to-apples comparisons." A few arguments, all from the public interest group, referred to the complexity of choosing health benefit plans. In one view: "It's like, close your eyes and pick ... I believe in choice, but I can't make a decision here, because my eyes are cross-eyed and blurred."

Nearly half of the stakeholders in this category considered the Oregon Health Plan priority list a good model for the standard benefit package (21\% of all stakeholders). Only one state official argued for the possibility of a "catastrophic coverage" plan for certain healthy individuals who might want to choose the barest minimum to meet the state mandate for coverage. Most others expected a "minimum benefit set that everybody's entitled to." One expert made an analogy to public education: "So you get 'this,' and after that you are on your own."

Two stakeholders objected to the standard benefit package, for different reasons. An insurer wondered why choice should be limited at all. An expert was concerned that a standard benefit plan maintained the system of complex billing and charges, which perplex the system today. 
A substantial set of arguments supported the concept of benefit plans with value-based tiers, aiming to encourage the use of essential services and discourage marginal care (24\% of all stakeholders). One expert provided a succinct description:

Basically what it does is it says: These are really valuable things-just like a drug formulary - these are really valuable services, we'll pay $100 \%$ for these; here's a whole bunch of other services, they're so-so, we'll pay $80 \%$ of these; and here's a number of services that we don't think are very valuable, and we'll only pay $50 \%$ of those. Ultimately, those kind of benefit designs are going to become more and more common.

Many stakeholders discussed current activities among Oregon insurers and purchasers to implement such plans.

A few arguments were skeptical of value-based benefit plans, for different reasons. One expert had unspecified reservations about the actual plans underway in Oregon. Another expert considered the idea simply the latest version of insurance companies shifting costs to consumers, increasing the likelihood of catastrophic consequences. One purchaser, otherwise in support of value-based benefit designs, claimed it was probably irrelevant to produce such fiscal incentives for an integrated system, such as Kaiser, because it had other ways to manage care.

Two arguments emerged related to benefit plans that proponents believed were critical. First, two purchasers argued to stop politically mandated benefit rules. One referred to someone standing "up there in the legislature" thinking it's a good idea; the other observed the same process when Congress dictates prices for Medicare. Separately, one purchaser and one expert argued to switch the burden of proof on coverage:

At present, especially a public insurer is continually placed in the position of having to prove that something the health industrial complex wants to 
sell them is not effective before they say no. I think that's the wrong standard. I think the correct standard is that the public insurer should demand proof that benefit exceeds risks or harms if applied across the population ... before public resources are used to purchase something like that. There are some really important elements around that burden-ofproof piece.

A subset of arguments related to standardized benefit plans focused on add-on coverage (16\% of all stakeholders). One physician suggested removing for-profit insurance entirely from the standard benefit package, and restrict the commercial market to add-on (or buy-up) options. Another segment of stakeholders argued that add-on coverage was, like standard insurance options presently, beset with obscurity and complexity, and recommended standardized options, referring to models from Medicare supplemental coverage (Medigap) and Australia.

\section{Personal Risk}

A small number of stakeholders, added to those who supported a value-based benefit design mentioned above, expressed support for patient copays (32\% of all stakeholders). All groups were represented.

One physician described the purpose of co-pays:

It's called having skin in the game; if you are not accountable for the cost of the system, there is no downside for using the system. From a financial basis, there is no reason why you would not want to use it [moral hazard].

One insurer put it more forcefully:

You have to acknowledge that we can't afford all things for all people, you just can't. There has to be limits. And you can use the sorts of limits that copays create-copays and coinsurance-where you are telling people that 
no matter how important or how useful a treatment might be, you [the insurer] are not going to pay for all of it.

One expert described a cut-off point for standard benefits:

You've got the minimum out there, and that to me defines the public commitment. You set the minimum and you say: Nobody in Oregon is going to go without that ... here's how we finance it, and so on. And then, everything above that, you are on your own ... it's not more out-of-pocket costs, it's absolute out-of-pocket costs once it exceeds that minimum.

On the other side of this argument, a number of stakeholders focused on personal risk related to serious gaps in coverage, or underinsurance (21\% of all stakeholders). Only expert and public interest views presented this argument.

In one expert view: "It's really wrong to have people go personally bankrupt, because they have cancer or some other condition." Another said: "I've seen awful things happen as a result of not having insurance_to people who didn't deserve it."

Others suggested that the ongoing trend of shifting the burden of premiums and copayments to individuals was reaching a breaking point, particularly for those with lower incomes, which would result in more bankruptcies and levels of uncompensated care. One expert concluded: "I don't think that's a terrifically viable alternative." Echoing the note of impracticality, one state official observed that for all the talk about copays and deductibles in benefit design, this was probably not where the system was going to achieve cost control. 


\section{Rate Regulation}

A number of issues emerged regarding rate regulation, in a scatter of arguments.

The most prominent argument involved community rating (13\% of all stakeholders). One public interest stakeholder stated the main issue: "You will charge them all the same, regardless of their health condition." For one purchaser this meant getting "insurers to agree to eliminate health underwriting." An insurer basically agreed:

Once everybody is in, there are no underwriting rules; you take all comers. Whether we get to a single community rate, or a couple of rates depending on age and sex, I think we can look at that. There's room there.

Another issue involved the divided commercial market under the new individual mandate, operating in a system defined by group coverage. According to one state view: "Potentially, the policy decision that has to be made, regardless of whether the employer's paying for it or not, is: Is it a group product or is it an individual product on a guaranteedissue basis?" A purchaser recognized the same problem:

The fact that the individual and small-group markets are so different means that that small employer is looking at that and making decisions, and they have different effects on their workers. So, to me, a fundamental reform is to ensure that the price in the individual and the small-group markets are the same.

Homogenizing group rates to "even the playing field" and remove distortions in behavior due to different rates will be tricky. According to an insurer: "The problem you get into, which is the hard choices, is you only do that by having somebody else's rates go up." A separate state view reiterated: "Any time you change your market regulation, you may end up with a system that's more fair, but there are going to be huge winners and 
losers." Both stakeholders suggested the risk would have to be spread as broadly as possible to lessen the impact.

A few other stakeholders mentioned regulating insurance premiums. One mentioned favorably the new affordability standard, giving the Insurance Division authority to approve plans based on rates and other standards it might want to apply. One hospital stakeholder, familiar with cost shifting, argued that regulating the commercial market could exacerbate problems for providers if the low rates for Medicare and Medicaid were not also factored in.

Two stakeholders mentioned applying risk divisions in premiums to influence personal lifestyle choices, charging for example, 5\% more for smoking or 5\% less for wellness programs: "And you periodically come in and have a blood test to make sure there's no nicotine in your bloodstream," one hospital stakeholder suggested. According to a state official, such financial incentives to motivate healthy behavior appear theoretically sound, and the state currently allows such risk divisions, but most insurers do not use them.

\section{Risk Adjustment}

In a system of guaranteed issue with community rating in a competitive insurance market, the problem arises that some insurers will attract higher risks without adequate premiums to cover the costs. A number of arguments concerned the need for some form of risk adjustment between carriers to account for adverse selection (29\% of all stakeholders). All groups were represented, except physicians. 
A large share of the stakeholders accepted risk adjustment as an "easy and straightforward" mechanism—pointing to the model used by Medicare, or a procedure in Washington state_-applying an adjustment to a base rate across a carrier's pool according to individual characteristics. Only one purchaser expanded on the complexity of risk adjustment, and argued for a central organization to obtain the (so far nonexistent) information to apply to every individual—if the procedure was not performed instead at the much easier population level. The same purchaser described reinsurance as an easier mechanism, but also argued that it was less favorable as it reduced the incentive for a carrier to help manage high-cost beneficiaries, because it could simply dispose of the obligation to the reinsurer. Only one other stakeholder suggested reinsurance as an alternative.

One insurer downplayed the necessity for risk adjustment in a guaranteed-issue community-rated universal system. One expert took an opposite view, saying it was "critically important." One state official referred to the excessive burden of "very highcost individuals" and argued that the cost must be spread across "as broad a base as possible."

\section{Health Insurance Exchange}

The health insurance exchange (or connector) as a central feature of the state reform agenda under the proposed individual mandate was addressed by a little over one-third (37\%) of the stakeholders (see discussion in Chapter 3). All groups were 
represented, with the highest proportion among purchasers. Nearly all stakeholders merely described the function of the exchange familiar from other official sources.

One hospital stakeholder and one purchaser expressed the conviction that the exchange would adequately pool funds and spread risk for high-cost individuals, and save money. One insurer disagreed, pointing out that pooling alone does not save money:

A lot of policymakers automatically assume that pooling drives costs down ... but if you are going to try to kid everybody and tell [them] they are going to come out with lower costs in the long run because you pool them, you are playing with math that doesn't work.

Some stakeholders anticipated that costs would rise inside the exchange, due to the inclusion of high-risk groups and individuals, which could ruin its attraction and sustainability.

Several other stakeholders complained of divisions made in the population, with only certain categorical groups allowed into the exchange (13\% of all stakeholders). In one purchaser view, the distinctions and voluntary nature of the exchange opened a "terrible potential adverse selection problem," and preferred the stronger Wyden model, which included everyone. One expert pointed out that the exchange would have no effect on inadequate coverage for Medicare or dual-eligible (Medicare/Medicaid) individuals. One public interest stakeholder concurred: "If they are really going to achieve what they said they were going to achieve, they would be willing to take on those controversial issues as well, and say: We really need to be talking about everybody."

Another public interest stakeholder was skeptical about the prospects for invigorated competition among insurers in the exchange, when single-company 
dominance is the norm in Oregon as well as other states. Among the critics, in the worst outcomes, the exchange would be redundant, irrelevant, and possibly disastrous.

\section{E. Purchasing}

The topics related to purchasing are numerous and interrelated. The following sections are ordered to address more general concepts first. Divisions in some sections highlight main arguments.

\section{Third-Party Purchasing}

The topic of third-party payment for healthcare services was addressed by a majority of the stakeholders (66\%), encompassing a variety of issues. All groups were represented in this broad category of arguments, including all stakeholders in the expert group.

Market failure. Several stakeholders recognized market failure in health care, mostly due to third-party payment (18\% of all stakeholders; see discussion of market failure in Chapter 3). Physician, purchaser, and state views were absent.

According to one public interest stakeholder: "Every economic study has demonstrated competition does not work in health care. The more you have, the more costs you have." One hospital stakeholder took the same line: "Health care does not function in a free-market world anyway — and I'm a free-market guy, by the way."

Two stakeholders argued for the necessity of third-party payment. One expert expressed a theme of social solidarity: 
The problem is that health care costs so much money, when you do get sick it lends itself to an insurance model. You can't really say: You are going to pay. Because then you are penalizing anyone who gets sick.

An insurer corroborated the point as a practical matter of cost sharing:

Even the most basic of healthcare costs, those basic services, are out of the reach of the average person anymore. If you look at a routine physical for $\$ 500-\$ 600 \ldots$ if you had to spend this kind of money for a physical, would you go take one? ... My friend [at an insurance company] is telling me about a drug that he is paying for right now ... it's $\$ 38,000$ a month.

Another factor in market failure is not due to third-party payment, but also to the

nature of health care as a valued service. One insurer explained with a story:

You are the head of a pharmaceutical company, and your scientists come to you and say: It's 10 percent better than what is on the market; the problem is it costs 10 times as much. That drug will not only get manufactured, but as soon as it's out on the market, it will become the new standard of care.

In contrast, the story went, a new car with that ratio would fail:

There is not anybody [who] says: Wait a minute, is the value equation right? Should we as a society be willing to pay 10 times, or 2 times, or 3 times, or 4 times as much for something that has only a relatively small marginal benefit?

The lesson here is that saying no is difficult, for all involved.

Fragmented payment. Another segment of arguments described the problems of fragmented payment, due to the multiplicity of insurance carriers (18\% of all stakeholders). Purchaser views were absent.

One expert described the problem:

The complexity comes from different coverage packages, different benefit packages for every different insurance company, even within an insurance company; if you have Medicaid you have 'this' package, if you have Medicare you have 'this' package, so it becomes this dizzying array. 
A hospital stakeholder described the same situation.

We spend in health care an inordinate amount of our time trying to figure out how we are going to get someone to pay for the services that people need, whether they are uninsured or underinsured. Everyone who comes in the door, we get paid differently for the same service. That's insane.

As one small solution, a few stakeholders suggested implementing a card-swipe system to immediately identify covered services and applicable prices.

A few stakeholders described a different, more insidious problem, related to different sources of payment inserting themselves into the administration of care, even within a single organization. As an example, one state official offered an example of different insurance carriers conducting their own disease management programs, uncoordinated with the provider: "So, if you are a diabetic [in a hospital], you could in fact be touched by four to five different case management systems." Others described the same issue, where investment from different sources in specific systems of care contribute to fragmentation in the delivery system. According to one physician: "When they [a capitated health system] have them as their patients, they tend to hang onto them as their patients, and jealously guard their care and don't share it."

Standardized rules. One formal initiative in Oregon reforms to overcome fragmentation—addressed by a number of stakeholders ( $21 \%$ of all)—involves persuading purchasers to "agree to the same rules." In relation to this argument, expert and physician views were absent.

One insurer described the initiative:

There is some dialogue going on ... The Oregon Health Leadership Council is a place where the insurance companies, the big providers- 
some even are trying to represent the not-so-big providers-but the industry is coming together and trying to talk across the table about things like this: Do we really need 17 different methodologies for prior approval programs? Or should we have one? The problem is, you have all these different insurance companies, all of whom are taking risks to manage populations ... Let's say you see this trend in cataract surgery; maybe that then motivates this one insurance company to say: We need to do a prior approval on cataract surgery ... Another carrier might not be having that same trend, or might see it and say there is nothing we can do about that. Or a third carrier might be seeing the same trend, and they pick criteria that are different. .. So you get all these scenarios.

This dialogue is different from the state setting standards (observed above in the section on insurance management). All of the arguments indicate a voluntary process. None referred to dialogue with provider systems where the policies are being enacted.

Administrative simplification. One extension of the standardization effort involves administrative simplification. This topic, which is included in both federal and state reform bills, was addressed by a segment of stakeholders (13\% of all).

Aspects mentioned here involved doing away with a lot of the "needless paperwork in the insurance and hospital systems," using standardized billing and claims forms, and more use of electronic communications. One expert expanded on the problem:

If you go around the world, there is no place I go that has taken billing to the extremes we have. There should be no reason why we spend over ... $20 \%$ of every U.S. healthcare dollar for administration ... [It's] amazing how much time and energy you have in the billing department, in any hospital, how much of nursing time, everyone's time. The reason we need so many staff is because of these damned bills.

In one physician view: "Expansion requires administrative simplification ... [but it's] hard to believe insurers will simplify without legislation." 
All-payer system. Another extension of the standardization effort referred to the concept of an all-payer system-addressed by a segment of stakeholders (13\% of all). Provider and purchaser views were absent.

One public interest stakeholder described the all-payer system as an "all-claims database." One state official expanded on this version of the idea:

The state has been trying to work on an all-payer all-claims database, without tremendous success yet ... I think it's a great idea ... if you want to measure the input components into what you call Oregon's healthcare system. Right now it's in 50,000 places, or maybe 50 places if you take the top 50 payers, the third-party administrators that are paying claims for selffunded employers, and Medicare and Medicaid. Put it all together, maybe that's it, but we don't have a product to help us understand that [healthcare claims]—which could really go to great lengths to help define ... global payments.

A public interest stakeholder took the all-payer concept further, describing it as a system "where reimbursement rates for every provider are the same, regardless of whether they are Medicaid or Medicare or [commercial payers]." This version of the concept describes a solution to the problem of different payments for the same services, which the hospital stakeholder above called "insane."

An insurer took the concept yet further: "There has to be a way that the purchasing power of the public is leveraged, so the public can buy a reliable product; some sort of way in which funds are amalgamated." The same state official as above concurred: "What would be most powerful is if you had an alignment of private payers ... and the state, aligning for a whole population, regardless of who you are enrolled by."

Purchaser power. Without necessarily relying on a unified all-payer system, of whatever description, a number of stakeholders addressed the concept of driving market 
change of the delivery system through purchaser power (26\% of all stakeholders). Physician and public interest views were absent.

According to this argument, group-based purchasers of health insurance would combine to agree upon expected standards, then make demands to insurers, who then pass on the demands to providers, who then pass on the demands to influence medical practice. Purchasing power here represents an effort to influence how insurance carriers purchase health care.

In one purchaser view: “The purchasers are saying: I can't afford this anymore”and are making demands for economy. One insurer summarized: "They have a lot of power to say: We don't want to pay for this, we do want to pay for that, and we want to have accountability."

A segment of these arguments focused on the state mega-purchaser, presently being formed to include public employee organizations and other state-managed funds. One state official described the strategy: "Right now the state buys coverage for about 800,000 lives. That's a lot of lives. So the state can use its purchasing power to push benefit design."

A segment of those describing the argument for purchaser power expressed skeptical views as well. One state official explained that treating the delivery system like a market is a mistake, because providers, and particularly hospitals, tend to have monopoly power:

This thing about one big purchaser of health care, I am not convinced is going to reduce costs, because in some ways it puts the seller in a better position, not the buyer, because this is not a service that's discretionary. 
One purchaser reflected other arguments that minimized the impact of purchaser power: "We can only reach a certain point at getting costs out of the system doing those things."

A few arguments from a separate set of stakeholders addressed conflict among providers due to insurer contracting activities. Examples included physicians and hospitals wrangling over limited funds in insurer purchasing contracts, which by one account, was purposely staged by the insurer as a market strategy to reduce costs. Another area of "dissonance" involved dentists; another, pediatricians; invested interests in mental versus physical health; and primary care physicians versus specialists. This line of arguments, related to contracting, raised a new source of skepticism over the effectiveness of purchaser power to improve the delivery system.

\section{Physician Purchasing}

Only a few arguments addressed the physician relationship with prices for services. The principal argument was that physicians are completely divorced from price, apart from some awareness of medication prices. One expert described the situation:

One of our fellows did a survey here of how aware physicians are of what things cost-everything from an IV to a CAT scan to an MRI to an angiogram to a surgery, an hour in the operating room. Nobody knew. Literally, we have zero awareness of it.

A purchaser continued the argument: "If you are going to ask a doctor, for example, to be cost sensitive about what they choose to provide, then you want them to actually tell what it costs." 
Price awareness is a standard indicator for market mechanisms, but possibly not the only tool to encourage efficient choices. One physician changed the language slightly to encourage "accountability," which might involve other options in some situations, with only a general notion of prices.

\section{Consumer Choice}

In a similar line, looking for market discipline in the clinical encounter, a few arguments addressed consumer choice. One stakeholder wanted to see a price tag on health services, like everything else in the marketplace. Two others wanted to encourage consumer independence, questioning physician choices and using the Internet to investigate options.

Another stakeholder countered the argument for consumer choice with the common observation that the physician acts as a trusted agent: "Basically, patients trust their physicians. You can't ask patients to argue with a physician who's had 4 years of medical education, post-graduate training, and years of experience. People are going to rely on their physician's opinions." Another stakeholder added elements of trust and choice:

The number one thing that people really want out of the healthcare system is the ability to have a relationship with a provider of their choosing that they trust, and that the relationship can continue ... The most important building block of good health is the relationship I have with a provider of my choice. 
Nevertheless, within the trusted agent relationship, price information at the point of service can help both parties reach a more efficient choice. One expert described how this could work:

One of the problems with health care is it's not like cars; you do not do your research ahead of time. Some health services are like that ... but a lot of services are not. You go in, you've got a headache, the doctor says you should get an MRI ... but maybe you should get a CAT scan instead of an MRI, and it would cost you a quarter of the price and give you maybe a tiny bit less information. How do you make that decision? If the support for that decision is not right at the point of care, is not at the fingertips of the person, what are you going to do? ... People need to know what is covered and what is not covered. They need to be able to sit down with their doctor right in the office, look at a computer screen and say: This is what the MRI is going to cost you, this is what the CAT scan is going to cost you, here is what I think the tradeoffs are going to be if you go with the MRI versus the CAT scan; and patients and doctors need to be able to make those decisions together.

\section{Transparency}

A number of arguments favored provider reporting to establish published quality indicators and prices (37\% of all stakeholders). All groups were represented.

Most arguments exhibited strong convictions. As one public interest stakeholder stated: "The whole issue of transparency needs to be quintessential." In nearly all instances, the purpose of the quality reporting was conceived as an information tool for consumer choice, some referring to Consumer Reports as a model. Another public interest stakeholder expanded on this notion: "We need state laws to require hospitals, and doctors, and insurance companies, and drug companies to open their databases in order for us and others to figure out what is really happening here, and to report it." One 
purchaser mentioned the need to obtain access to Medicare data to include in quality reporting.

Separately, one physician argued that reporting that involves financial,

professional, or legal consequences would make providers selective:

I am going to maybe not see or have that difficult patient, undereducated patient, high-risk patient ... One way to have better results is not operate on high-risk patients. That happens all the time. Hospitals and physicians, certainly surgery groups, don't have to take all comers ...They can say: I'm sorry, you are too high risk ... Doesn't mean there isn't somebody who will do it. Doesn't mean it shouldn't be done. It just means that physician says: You know, it's not worth it to me ... If you have a complication, you might sue me; I might get a bad outcome reported on my report card; I might get thrown off a panel. It's not worth it.

An insurer told how this very issue is one of the "raging debates" in the national health measurement community.

Even if such consequences can be muted, the validity of the indicators comes into question. According to one physician: "If you don't find a way to risk stratify the patients, and if you don't take in multiple factors on the report card, it's a silly proposition."

Others also mentioned this problem of "black box" methodology. One expert pointed out some exceptions, related to hospital safety reporting: "When it comes to infections [for example], patient mix is not an issue."

Finally, a few arguments questioned the effective use of quality indicators, mostly related to the proposed use as information to guide consumer choice. One insurer asked, as an open question, how we make transparency and accountability work together. Another insurer, fully supportive of transparency, pointed out: "So far, consumers of health care have not proven that we use that information to change our buying behavior." 
One public interest stakeholder expected a better working strategy for quality indicators in advance:

What is it going to really do? What kind of enforcement is it going to have? Are we just creating another bureaucracy out there to report things? ... It's not very understandable to the general public ... What does it do in the end? Does it provide anything? Does it allow somebody to get the health they need?

\section{Payment Systems}

A large majority of stakeholders mentioned applying payment reforms to reduce provider overtreatment and marginal care ( $76 \%$ of all stakeholders). Specific models varied. Many arguments raised the idea of payment reform and the need for experimentation with different models, without offering details (29\% of all stakeholders). Others carried the idea forward with something specific in mind.

Price setting. A few arguments addressed the general principles of price setting. One purchaser expanded an argument related to market failure:

The notion that seems to be a bit pervasive in the world is that somehow you can bargain, you can create structures where the right prices will be bargained. It can't happen in health care. The provider or the seller side of the negotiation is too powerful in too many places for that to be a reasonable way of setting prices.

Another purchaser joined by a physician protested price setting by government

fiat: first, because the price is imposed, and also probably too low to match costs; and second, because a set price can always be gamed by increasing volume and fails to provide an incentive to

improve the system, to be more efficient, to provide better care, or to go into the healthcare business, because you have [government regulation] that 
decides your rates and your reimbursements and sets your standards, and there's no competition, there's no effort to get better, no motivation to get better.

A price set by government through negotiation appeared more favorable. A purchaser joined by a hospital stakeholder directed attention to the model of hospital ratesetting in Maryland, where the state negotiates with hospital administrators to set standard prices for units of service for all payers.

Pay for quality. By far the most popular strategy for payment reform involved tagging at least a portion of payment to quality measures (53\% of all stakeholders). All groups were represented.

One insurer provided an example of contracted terms:

This is the [set of] outcomes we want. We are willing to invest in you as long as you deliver these outcomes. And we are going to hold you to that. We do not want, say $30 \%$ of elderly patients to be readmitted to the hospital within 30 days. That's unacceptable.

In another insurer view: "If they are hitting certain quality indicators, there is an additional bonus." A few stakeholders added the notion, derived from recent Medicare policy, to also stop paying for errors, and if possible, for marginal care.

One public interest stakeholder imagined a code for getting well: "I wait for the day when there is a code a physician can fill in that says: I actually cured this patient." Other stakeholders revealed the same intent, suggesting proxy measures through quality indicators.

One state official described how spending more on quality could save money: "If physician costs are $20 \%$ of the system, and their pen drives $80 \%$ of the system, what we 
need to do is pay them more to do the right thing, earlier." One purchaser pointed to an apparently successful model in a pilot program for chronic care management performed by Boeing, which paid a combination upfront payment, regular fee for service, and "an incentive plan, based on accomplishing key performance outcomes." The upfront money was dedicated to paying for a nurse manager and other case management support.

A few separate stakeholders criticized the pay-for-performance strategy. One physician and one purchaser pointed to the typical disjunction between price and true costs. According to the purchaser: "They still have costs, whether they perform well or not, and they are still going to shift those costs." The physician expanded the argument:

That means I am not going to be paid for the work that I do, which is unfortunate, because I perform work all the time. It means you are going to pay me based on how well you think I am doing my work; but we can argue that point all day long, because you have no real benchmarks for grading how I do my work. You are going to use a surrogate, because it's something you can pick off an electronic medical record, or worse yet, off a Medicare billing code; and that does not tell you anything about the patient.

Quality information was reported to be readily available for indicators, but a hospital stakeholder was the only one to claim access to "truckloads of metrics." Others referred to reviewing paper files, or most commonly, claims data, sometimes with laboratory data. "We would like to be getting electronic health records," said one expert, "We would like to be getting patient experience data."

A second criticism from a physician was more terse: "Delusional! Another way of gaming payment: Oh, we don't pay when you do this, this, and this. Who reads the fine 
print?" This appears to be another argument to simply pay true costs, and a similar swipe at the information demands of external bureaucrats.

Bundling payments. A number of stakeholders argued for bundling payments (29\% of all stakeholders). All groups were represented, except the state; hospital views were the most common.

A frequently mentioned model for bundled payments referred to diagnosis-related groups (DRGs), introduced by Medicare in the 1980s as a system of prospective payment for hospital services. In one hospital view: “They are far more effective on surgical-type procedures than they are on medical problems, because medical problems tend to be more complicated.” Nevertheless, an insurer and others expected bundling to reach more services: "Physicians should be paid based on bigger, broader units of care, and a continuum of care for a given patient. So, in the world of diabetes, it might be a year's worth of diabetes maintenance treatment for a diabetic patient." In a public interest view: "A typical example is childbirth, from the time a woman knows she is pregnant to when she actually has the baby and the follow-up."

Analogies abounded, illustrating the absurdity and expense of paying for a car or other valuable object piece by piece. Most understood the concept as paying for larger units of care, but others appeared to view the concept as an alternative to fee-for-service, something different, and more akin to capitation. Sometimes the two concepts were run together. One insurer provided a balanced summary:

There are a lot of people who think if you change payment, you bundle things or whatever, that somehow things are going to magically change ... In spite of the bumps we went through when we did that in the past, I do 
think that is going to be the shape of payment in the future. It won't solve everything, but it will at least begin to structure things in a way that supports doing things effectively and efficiently.

Capitation. A number of arguments addressed a variety of ideas around capitation - a global payment for a set population, constituted as an upfront per-person fee to cover the costs of defined medical services ( $32 \%$ of all stakeholders). All groups were represented, except public interest; physician views were most common.

Arguments in this category were diverse and generally more guarded. One insurer summarized the purpose:

The key is for the providers to know that the budget is fixed, and they are going to have get on a budget, too ... At some point the paradigm will shift from generating lots of services to make your margin, to accepting a flat amount of money and managing underneath that.

Who gets the payment was less clear. One purchaser stated:

There are a lot of different ways it could work. In some cases, the physician would take a global capitation ... or it could go to the hospital, and then the hospital makes payments to the physicians ... or it could go to the medical group as a whole.

No other arguments stated that providers would receive a capitated payment

directly. Rather, the amorphous entity called a health plan emerged—in all contexts either a regular insurance carrier, or something like an insurer, accepting risk in a capitated fund. From a health plan that receives a capitated payment for anticipated medical care, the payment is then distributed to a variety of service providers. One physician pointed to two essential difficulties for the capitated entity, whatever it is: one, the size of the covered population must be large enough to manage the risk; and two, specialists must be somehow integrated or taken into account. 
How the discipline of capitation trickles down to providers-if they do not accept the capitated risk directly—was unclear in most arguments. A few arguments approved the kind of capitation in Medicare managed care plans, which is typically accepted by a regular insurance carrier, not unlike a regular premium payment. The carrier would then "manage" the care to fit within the budget, apparently the same as it might do for any other population with a premium from other sources.

A few other arguments favored a system of shared risk with providers, or "withhold" as a specific instance of the model. One insurer described it well:

Let's say the payment per unit of service is $\$ 50$, and all services are valued at a different unit [a fraction or multiple of the basic unit payment]; they have a different relative value. What we do is we say: OK, there is a withhold taken from the $\$ 50$. Every time we pay you for a service, we pay $\$ 50$ minus a certain withhold, and that is the limit of your downside. Doctors can only lose as much as the withhold every year. You can't go down to zero payment ... and then, if the performance exceeds the budgeted target in these various areas, like primary care, specialty care, hospital cost charging, then that's when you start sharing the gains.

Supplier payments. Several arguments favored drug formularies. Only one argument, from a physician, raised the possibility of achieving savings with a coordinated purchasing group, possibly organized by the state, to negotiate with manufacturers. Also, only this physician and an expert argued to apply pressure to equipment suppliers:

We have to deal with private industry for durable medical equipment [DME]. The markups are enormous-1000\%. We preauthorize DME ... There are lots of private DME suppliers who are highly entrepreneurial and tend to encourage patients to request and expect DME services above and beyond their needs.

Fixed costs and pricing. Two arguments from hospital stakeholders regarded the relationship of cost and price. The first argument was straightforward: increased 
insurance coverage is beneficial, even at low government Medicaid prices. Facing the problem of uncompensated care, more low-pay coverage for hospitals is better than nothing. The second, related argument made an analogy between hospitals and airlines, both with high fixed costs and increased efficiency when operating at full capacity. One implication drawn from the argument was to "let a monopoly form, funnel all that business into one place ... so they are always running at a high capacity—most efficient."

\section{F. Delivery System}

A large majority of stakeholders addressed specific problems and solutions for the organization of the delivery system (89\% of all stakeholders). When combined with management of the delivery system (discussed separately in the next section) stakeholder attention to delivery-system issues was nearly unanimous (97\%).

\section{Coordinated Care and Teamwork}

A substantial number of arguments related to coordinated care and teamwork (61\% of all stakeholders). Both concepts appeared as primary objectives for the delivery system, usually together and difficult to separate, though each is distinct and involves different structural requirements. Over half of these arguments referred to the concept of a "medical home" as an organization to produce both coordinated care and teamwork (37\% of all stakeholders). All groups were represented in this category of combined arguments; provider views were the most common; expert views were the least common. 
Three basic problems for coordinated care were identified through the course of these arguments: (a) a service user could be "touched" by multiple providers from different organizations for the same condition or aspects of a condition, (b) the providers were not communicating with one another, or even if they were, tests could be repeated, treatments overlapped or contradicted, and patients confused; and (c) with multiple providers concerned with aspects of care, rather than the whole person, none was accountable for the outcome.

In one physician view: "A lot of times things get farmed out, even with someone designated as your primary care provider." A few stakeholders recommended a system where the primary care physician would act as care coordinator and source of specialist referrals- "the patient coming to their primary care home and getting consults when they are needed, but not seeing a specialist willy nilly at the patient's idea of what they need." According to terminology offered by the physician above, the primary care physician would employ a perspective as a "gate opener" rather than a "gate keeper." This was the only actual solution for coordinating care that appeared.

An overlapping category of arguments referred to teamwork in a single setting. Public interest stakeholders gave this topic special attention. The idea involved more usefully employing the services of nurses, nurse practitioners, physician assistants, and staff to allow all, and particularly the physician, to work at the "top of their license." Teamwork was mostly associated with more efficient medical practice, but also from a patient perspective as a way to allow more personalized care with adequate time to discuss issues. 
How to achieve teamwork was another matter. One purchaser emphasized communication:

You can't dictate that relationship and that negotiation at the policy level ... you need the frontline physicians and health plans in the same room, talking through all this stuff, and that can't happen at a policy level. You just can't have those conversations.

An insurer argued that payment reform would help the process:

The state could ... [say]: Instead of paying for just physician-level care, we are going to pay for team-based care ... When you come in, on any given day, you might see the doctor, you might not, but based on what you need, you are seeing somebody on the care team ... Fee schedules pay for things like nurse-practitioner-level care, they pay for physician-assistant-level care; what they don't tend to pay for is things like nurse-level care. A lot of times they don't pay for care geared toward education ... to make sure: $\mathrm{Oh}$, as long as you're in, let's make sure and have a whole conversation about your whole-person care, not just the thing that brought you in. What we don't do a good job of in the payment system is paying for that teambased approach to caregiving.

Many arguments expected the medical home to solve all of these issues, containing and coordinating care both within the clinical setting and among different providers. One physician suggested the medical home might be a medical group that accepted a capitated payment per patient, giving it an incentive to track and manage care. Other stakeholders placed a "health plan" in that position. Another physician argued that it would be too complicated to integrate specialists in this model, except on a disease-bydisease basis. Yet another physician argued to make sure mental health services were coordinated, with access to patient information, which is presently restricted in some areas of the state. A public interest stakeholder added to this point: "It's the political issue of who has the power and who has access to the dollars." 
Another physician agreed that a per-person-per month capitated payment of some kind could compensate for the time involved in managing and coordinating care, but also questioned the scope of the proposed reforms:

This is a brand new concept to a lot of people, but it's the kind of medicine that we have always practiced and the kind that we were trained to do ... We refer out to a specialist, the patient comes back to us with the recommendations, and we are responsible for implementing or at least making sure things are followed through. We keep track of everythingchanges of medication that are recommended, follow-up-so there is somebody steering the ship ... The thing is, they [state reformers] are trying to define it in terms of a big system.

In several arguments, the idea of a medical home went beyond the notion of coordinated care and teamwork, and even beyond the bounds of medical care. One insurer argument, reflected by other stakeholders, called for providers "to transform themselves from the kind of reactive, visit-based care, to a proactive population-based care." A common term used was "nurse triage," leading to issues of clinical management (discussed in the next section). The issue of population-based management is something different again, reserved for a following heading on the wider arena of social services.

\section{Clinical Management}

A substantial number of stakeholders proposed specific measures to improve the efficiency of health care through clinical management (55\% of all stakeholders). All groups were represented. All stakeholders in the physician group expressed arguments here; insurer views were the least common. The basic elements of clinical management 
that drew the most attention were assuring access to primary care, improving prevention, and active case and disease management.

Focusing on primary care (24\% of all stakeholders), a few stakeholders argued to improve continuous access on all days at all hours-so-called 24/7 access. Moving a step further, one hospital stakeholder argued to encourage storefront health clinics to help busy working families access primary care right away, without resorting to the hospital emergency department. Other arguments called for building the supply of primary care physicians and paying more for primary care. According to one physician: "Being in debt for $10-15$ years is not very attractive ... we ought to make it a little sweeter for people to do this." (Issues of workforce shortage are discussed separately in the next section.)

Arguments directed toward prevention often concerned specific conditions that could be controlled with timely attention, such as high blood pressure, asthma, diabetes and other chronic diseases, depression, and smoking cessation. A few stakeholders argued that preventive care should be free or very inexpensive. For one purchaser, the cost benefit would be dependent on patient behavior: "If you are compliant with your medical tests and your doctor visits and taking your medications, all your medications and supplies will be free; you'll have no deductible and no copay.” In this view, self-management would be tested and graded to apply a fiscal incentive.

An expert was skeptical of this approach, even with minimal payments:

There was a time I thought: Oh, let's institute a $\$ 5$ copayment, because we can reduce some of the inappropriate utilization; and what I have seen even from trying to get the economic incentive stuff right is that it's sufficiently complicated, such that for a middle-class population that makes sense, but if you do that ... for that segment of the population with 
families making less than $\$ 50,000$ a year, the last thing you want to do is put up barriers for things that are either good health promotion or prevention.

Further arguments for case management, and particularly chronic disease management, demanded positive attention from primary care providers. Arguments related to prevention incorporated this particular area of concern (combined, $42 \%$ of all stakeholders), which is central to the concept of the medical home. The design was clear: better supervision of a practice's panel of patients, followed by active outreach to provide timely treatment and engage individuals with chronic conditions in active self management.

The purpose was also clear. As one purchaser observed: "Chronically ill patients use the greatest number of resources within the healthcare system." One insurer amplified the point: "There is so much low-hanging fruit in avoiding unnecessary emergency visits or avoiding unnecessary hospitalizations, looking at the most cost-effective drug for your condition ... Just doing those kinds of things at a population level, there are costs to be gained by that kind of thinking."

For many stakeholders, the process of clinical management should be initiated by "nurse triage" to identify high-risk patients. Outreach and education followed. According to one purchaser: "Right now a lot of the health plans have disease management programs where the nurse will call you and say you better get in for you insulin shot." A public interest stakeholder also mentioned telephone contact as a way to reinforce selfmanagement: 
We really talk about how to manage your asthma, for example, and maybe follow up a week later over the phone; and if you do not renew that medication, you get a call as opposed to no one noticing that you didn't renew it.

One physician expanded the argument for education:

I think we are going to change the paradigm of care in health care. We are going to understand that the acute care model is not an effective way of treating chronic illness, and [yet] that is what physicians are practicing. If you have diabetes, they will treat you with insulin and medications. What you need to do is take those patients and give them an educational program that makes them realize that there are a large number of things in changing their own behavior that will make their disease much better and manageable.

Key factors in education mentioned by others included losing weight, getting exercise, better nutrition, counseling on drug use, tracking medications, and selfmonitoring one's condition. One physician noted that organized educational activities occur at various community locations.

Factors of teamwork and finding ways to pay the whole team are central to this endeavor. One public interest stakeholder pointed to a fundamental limit on the role of the nurse:

The nurse practitioner as the primary care provider is perfectly accepted in rural Oregon; it's when you get closer into the metropolitan areas where there's competition from the physicians that the role of these primary care providers other than physicians is challenged at every step, and ... the scope of practice. The state Board of Medical Examiners is very vigilant to make sure they are the only people that can control the scope of practice for people doing this work ...The barriers are the professional groups who are trying to protect their own financial turf.

Several arguments concentrated on providing payment for time and staff to perform clinical management. Two purchasers argued for an upfront payment to hire a 
case manager, using as a model a Boeing project that implemented chronic disease management for high-risk employees; they also mentioned fee schedules that have been adopted to pay for phone calls and data processing. Others mentioned a combination of fee-for-service and capitation in per-person-per-month payments.

A few other topics were addressed regarding clinical management. A few stakeholders addressed managing end-of-life care. One purchaser mentioned as a model the Physician Orders for Life-Sustaining Treatments form (POLST) instituted at Oregon Health \& Science University. In one hospital view: “We don't pay doctors to sit down and have that conversation. Not that they don't have the conversation, but now we are saying: This is another billable service that is totally reasonable, to sit down and have this conversation." One physician expanded the argument:

There is a lot of treatment that happens because there is a financial benefit to doing something versus nothing. And you have to have a patient and a family that are receptive to at least having the discussion. In the end, perhaps, you may have to have a system that says no. There are an awful lot of countries where you don't get dialysis after age X, at least not on the government system. If you have your own money for it, great ... Those are tough discussions. For us as a society, there is a part of us that says everybody deserves everything, or should have access to everything.

A few arguments addressed the necessity of hospital discharge planning, with one reference to an initiative by Medicare to reduce rehospitalization. Two other arguments addressed the development of "care coordination pathways." One argument favored the use of checklists to avoid medical errors. 


\section{Workforce Development}

Corresponding to the body of arguments to invigorate primary care in the delivery system, an overlapping number of arguments focused on the workforce shortage in medical practice (24\% of all stakeholders). Physician and public interest views were the most common; hospital and insurer views were absent.

One state official stated the problem forcefully: "When you start talking about universal access, you don't have a medical system that can support 600,000 more people going to primary care physicians. You don't have them, and they're not coming." One public interest stakeholder expressed a similar note of alarm: "You have these huge shortage areas ... in Portland, everywhere, I think it's nationwide. I think studies show that we are short physicians all over the place, and dentists and everything else." One physician addressed the problem with more assurance: "There is going to be a bigger demand than we have doctors for awhile; but I think that's addressable, and I think the reform legislation does address it. I just think they need more of that."

Barriers to supplying the needed workforce included the high cost of medical education; built-in financial incentives that favor specialist training; and a lack of facilities. A variety of solutions were suggested: make medical education free for those willing to practice 10 years in Oregon, or other types of loan forgiveness ("start hoarding the doctors"); activate the legislature to increase funding for medical education; open another medical school or two; develop educational programs to encourage students in primary care and other needed skills. One physician argued to expand the uniformed National Health Service and establish NHS clinics in underserved areas. 
Two other points arose related to workforce shortages: (a) an increase in available services and population needs, and (b) a decrease in individual commitment by physicians. One physician described the work-family balance in the physician workforce:

Most women physicians don't work 70-hour weeks. They work part time; a lot of them job share, so they can raise their families. The men are following them, in part because they know they are not necessarily going to make more money by working those hours, so they are balancing life.

According to another physician: "It's one of the 80-20 rules: $80 \%$ of the care is given by $20 \%$ of the providers; and there are providers who don't want to take Medicare patients, and there are providers who don't want to take Medicaid patients."

\section{Coordinated Social Services}

A number of arguments focused on the broader area of population-based health management (24\% of all stakeholders). All groups were represented, except insurers.

Largely, this line of argument involved an extension of clinical management objectives. In one state view: "My argument with disease management is that it ought to be done at a community level." The implication of this argument led to a further argument for a community perspective. In another state view: "Metrics need to be established around obesity. The things that lead to high-cost care are not diabetes and cancer: they are nutrition, exercise-it's those things you really need to get communities to focus on." Two stakeholders referred to Alcoholics Anonymous and Weight Watchers as existing models for community-based programs. From another angle, one physician 
argued that a plan for capitation to fund disease management would need to include the entire community in order to bear the risk and coordinate services for the "whole patient."

One hospital stakeholder wondered how healthcare providers could partner with the state around these larger goals:

We spend $99 \%$ of our time focusing on the medical delivery side, and that's where the financing is, that's where all the energy is; but if we were really focused on population health throughout the continuum, we have got to think about things completely differently. And when you start looking at what those other elements are ... it's more than just the medical community; it is [the state], county and city governments, schools, business. It's really everybody kind of getting on the same page.

Two other stakeholders—acknowledging Oregon's progressive alternatives for long-term care-argued for better medical oversight for the elderly at home, and service coordination to get individuals into assisted living facilities to avoid more expensive skilled nursing facilities or hospitalization. Partly, this goal involved coordinating providers that operate under separate Medicare and Medicaid funds.

\section{Information Infrastructure}

A substantial number of arguments focused on developing an electronic information infrastructure for the delivery system (50\% of all stakeholders). All groups were represented; provider views were the most common, state views the least common.

One hospital stakeholder stated the issue simply: "Long term, we are going to improve quality and reduce costs if we have a better health information technology infrastructure across the state.” Many stakeholders proceeded from this premise to provide examples related to avoiding test duplication, improved care coordination, and 
clinical management. Kaiser was often cited as a model for its effective use of its information infrastructure.

The core of the information infrastructure was electronic health records; a core feature was interoperability, conceived mostly as the ability of systems at different organizations to communicate with one another (see the discussion of information infrastructure in Chapter 4). One expert argued, in addition, for interoperable health records, so patients could own their own portable records, rather than an organization owning the patient through the record.

An additional use for information infrastructure involved evidence-based decisionmaking tools (16\% of all stakeholders). One expert illustrated how the tools work:

I can look with the click of a button to see, for example, urinary infection: what in our hospital the resistance patterns are, what the best antibiotics are, what the cost of the antibiotics is; I can look at all of that.

One purchaser related a similar story by a physician, and concluded: "To me, that is the value of these electronic health records: it's the decision-support tools that can be embedded into these systems." A hospital stakeholder concurred: "We also know that if we have a healthcare IT infrastructure, we are probably better able to inform and guide physicians and other care providers in adopting best practices, clinical practices that are evidence based."

The expert above also pointed out that a portion of these tools can be provided over the Internet and do not require a completely integrated system with the patient's private electronic health record. One physician explained how information was accessible 
from local hospital records and other independent sources, without real interoperability, which nevertheless helped in clinical management.

Ideas to broadly implement information infrastructure in Oregon varied. Taking advantage of federal funding was a natural step. A few arguments favored state action to either persuade, facilitate, or legislate adoption. In one hospital view: "The nature of it is, though, if you have a statewide system, you need the state to come in and help bring people together, create that infrastructure, and facilitate the creation of that interoperability."

A few stakeholders suggested small pilot projects and piece-by-piece development. Favorable single mentions were made of work done in Oregon by the Health Information Technology Oversight Council (HITOC), and the Oregon Community Health Information Network (OCHIN).

A few stakeholders raised problematic issues related to an expanded information infrastructure. First, the concern for privacy and security for electronic health records has not yet been completely resolved, and remains a potent obstacle to wider applications. Second, it appears the federal government will not choose a definite standard for an interoperable system, and the state may need to make that decision or examine ways to operate with independent systems. Third, "it's a very expensive proposition," as one insurer pointed out, especially if it demands some established systems to change to meet a required standard.

Separately, two physicians criticized the expectations attached to the information infrastructure. In one view, the expense is daunting for a small practice and the value for 
good primary care is not obligatory. Also, the additional investment of time was

perceived to be an obstacle:

Putting information into the system takes more time than we currently invest in producing a patient record. I think, if we're lucky, it's time neutral. I'm afraid the electronic health record really means we are going to be spending more time in documenting things. Although it would be better in some respects, it's going to be more work.

The second physician was more blunt: "Electronic medical records won't save the world ... The problem for electronic medical records currently is that there is a real disparity between what people think about them and reality." According to this view, the problems of privacy and interoperability will not be easily or soon resolved. Data quality was a further issue:

Electronic medical records are great for a chronic problem list, past history. They are not quite so good for acute care episodes, because so many times the data or the information or history of present illness is entered based on a template: you check some things, and you end up with very generic information ... When I look at a patient, there are nuances to the history, which are important for deciding what they might have or coming to a diagnosis ... Narrative is important ... Templating it and checkboxing it is useless ... I've looked at a lot of electronic medical records, I've looked at patient charts from around the state ... and you get this useless template, you have no idea why the patient was there. Their chief complaint could be wrong; it's just a mess.

Erratic coding could include checking nothing or checking everything, or upgrading coding for billing purposes or quality reports. "It might actually cost the system more."

\section{G. Practice Management}

Insurance carriers, purchasers, and the state all have natural financial interests in improving value in health care. Hospitals and physicians, as service providers, may 
operate with different incentives to improve value, involving both financial and professional interests. This section begins with a discussion of general tools and ideas to manage the delivery of health care, and then moves to different options for who should be doing the management. Arguments referred to active roles for insurers, accountable care organizations, hospitals and physicians, the community, and broader governance from state and system-level perspectives.

\section{Evidence-Based Practice}

A substantial number of arguments addressed evidence-based practice as a key feature for managing effectiveness and value in health care (55\% of all stakeholders). All groups were represented. The concept included variations, which may have been understood by individual stakeholders according to the following standard definitions.

1. Evidence-based practice (EBP) — production of a knowledge base for effective healthcare practice.

2. Evidence-based medicine (EBM) — often refers to a clinical information system, usually with electronic decisionmaking tools, to apply medical evidence in actual practice (Eddy, 2005); for others, the term is substituted for the more general idea of EBP in relation to medicine.

3. Clinical effectiveness-EBP related to a specific setting or application.

4. Comparative effectiveness - side-by-side comparison of treatments for a condition to compare effectiveness, variations in dose, use, outcomes, side effects, and so on.

5. Cost effectiveness - comparative effectiveness with price included.

Arguments for EBP often arose in connection to the value-based benefit design discussed above under benefit plans. In that context and other similar references, the goal 
was not merely to inform physicians, but also to inform service users about evidence for various types of medical care to direct and limit choices. One public interest stakeholder wanted "publicly available, publicly supported studies of the efficacies of treatment, and [to] start getting that information out there."

Others endorsed evidence-based practice as a broadly applied management tool, used for statewide standards, benefit designs, and treatment protocols. One insurer argued for an "evaluation system"; another insurer wanted to make sure providers were "really delivering the best care at the best time for the best cost." A state official wanted to be "more aggressive" in getting care that works. Another state official pursued this point for managerial control:

Could we come up with a set of evidence-based guidelines for diagnosis and treatment in particular areas, and then say that compliance with those guidelines constitutes the community standard of care for litigation purposes? Because what we want to do is have doctors follow those protocols - whether you use financial incentives or whether you use regulatory approaches, I don't know, but how do you in fact make sure that we are using [for example] checklists for surgery?

One purchaser addressed the same issue, turning guidelines into standards. Two hospital stakeholders referred to proactive steps to organize peer review of standards to get an "entire community to buy off on evidence-based criteria and adhere to that," leading to a collective contract negotiation with insurers. A purchaser also mentioned a local dimension, referring to a "peer review of standards," including a "process of appeal" if a physician disagrees with a standard.

Other stakeholders proposed less stringent arguments. In one hospital view, the idea was to "focus as much as possible on evidence-based medicine guidelines—not 
requirements, but information." One expert observed: "A lot of decisions have to be made on a physician's opinion. They can't be made entirely on evidence: the evidence base is not complete." In this view, an evidence "platform" is needed, using information, a set of electronic decisionmaking tools, and coverage standards.

Others referred to the limits of evidence. One physician remarked: "The majority of guidelines and best practices that are published and available currently are based upon local habit and have no science behind them, so they are not supported by double-blind randomized studies that show a benefit." One purchaser understood a similar limit: "There is about $20 \%$ of proven evidence-based guidelines that guide care, and the rest of it is kind of optional." One insurer concluded: "OK, let's use the ... percent we have." Establishing the evidence base was another issue. One purchaser revived a familiar argument to "borrow a lot from other places in the world that are doing that, so we don't have to do all the research and analysis ourselves." (Institutional support for evidence-based practice is discussed separately in a later section.)

One segment of arguments referred to cost effectiveness as a second, more difficult hurdle (16\% of all stakeholders). One insurer summarized the views of others, related to the challenge of applying cost-effectiveness research:

Also, there is the question: One thing may be better than another, but is it significantly better than the other in terms of cost and outcome? It may cost more, but ... how do you decide if the incremental cost is worth the improvement in outcome? ... It's very hard to answer. But those are the questions that somebody needs to be asking, right?

A physician addressed the same challenge: 
Comparative effectiveness is a tough one ... and that's going to offend some people. So, if treatment A is $5 \%$ more effective than treatment B, but 3 times as expensive, does that justify it? Or are you against it? ... You have to believe that the cost part of the discussion is valid ... but there are lots of folks who don't want to have the cost discussion as part of the whole marginal benefit, comparative-effectiveness discussion.

\section{Managing Care}

A number of arguments discussed the necessity and difficulties of managing care, and usually proposed or described effective mechanisms (45\% of all stakeholders). All groups were represented, except hospitals, which addressed the management issue in system-level terms (presented separately below). The role of insurance carriers in managed care is introduced separately in the next section. Here, the issue is about how care is managed, rather than who governs the process.

A segment of stakeholders in this category argued in different ways for the general principle of rationing or shared scarcity, with the plain statement: "We cannot afford to just give everything that's available to everyone. We know that." A few arguments related to a further point—-that saying "no" is difficult. An expert described how insurers, once they are "slammed" for denying coverage, find it easier to simply drop objections and raise rates: "There is very little political will to deny coverage." A few stakeholders mentioned a common, implicit form of rationing in waiting times, which avoids the uncomfortable confrontation of denying coverage. As one physician noted: “Oh, we don't want a system like the Canadian system of reform ... because there would be rationed care, there would be long waits. Well, there already is." 
Supervising the clinical encounter. In terms of active management, two sides

appeared in the discussion. A public interest stakeholder illustrated one side in the value for clinical autonomy:

Now, this is one where you don't really want to go: Doc, you must do this. Patient, you must do that. There are exceptions. You want doctors and patients to make those decisions together, looking at all the information they need-them being the exception, that patient's specific circumstance, but you want to make sure they have access to the best information.

An expert added a different perspective, related to prudent purchasing:

There is this sort of hue and cry from the public that doctors and patients should make the decisions, which is a little specious, right? - to say doctors and patients are the only ones making decisions, insurance companies should stay out of it. Well, insurance companies ... are paying the bill.

One physician described how clinical supervision may be approached by a medical director, employing standards of practice from a national EBP database and other sources to help match conditions and diagnoses with treatments:

Somebody wants to do something that is imaginative and not mainstream, then I'll say: That's not EBP, that's not what we do ... and I can look in there and see whether or not the provider has come close to a funded [service], and say: You've asked for this, but that doesn't pair with the condition the patient has, but these other treatments-CPT codes-do, so you might want to consider that instead.

Another physician remarked favorably on this framework of accountability, saying: "I have someone looking over my shoulder." If a disagreement arises, the first physician continued: "They can appeal directly ... to the plan, and then it goes to ... an independent review organization ... and we do that fairly frequently."

Supervision is important because physicians in the community "try to do things that are innovative very frequently," and often verge toward medications not approved for 
a condition or "often try to do experimental treatments [when] standard treatment may not be effective." The supervising authority has to remind them: "You are trying to give somebody a hat, and they need a pair of shoes."

"Deny payment for service" was the more blunt way one insurer described this kind of transaction. An intermediate position involves pre-authorization for commonly applied, and perhaps too often misapplied services, such as MRI-type imaging. One purchaser described a system of electronic pre-authorization applied through an independent vendor:

The fact the physicians have to go through this, they think twice about whether or not they really need to order. They've actually seen in some plans where they've been able to bring those double-digit annual increases down to flat.

Pre-authorization is also evident in drug formularies. According to a physician:

"Without any management, the overall cost of providing medication to health plan recipients would be enormous. So all health plans limit formulary choice."

Regarding the overall framework of accountability, one state official made an analogy to public school teachers, who must be certified, and within a context of professional autonomy must still meet standards and goals, and respond to supervision. Similarly, other stakeholders argued to "increase the consistency around known standards.”

The very presence of a third-party supervisor may improve decisionmaking capacity in cases when immediate participants may find it difficult to make rational (as in rationing) choices. A purchaser repeated an earlier physician argument: 
Those kinds of decisions to use cost-effective treatment modalities are not a kind of decision that can be made at the individual level. They really have to be made at the societal level; because when your mom goes into the hospital and you are making decisions for her, you are going to have them do everything that can be done. You just are. So am I ... You have to say yes. So we need to collectively say no.

Utilization review. Another segment of arguments referred to systems of utilization review ( $24 \%$ of all stakeholders). This procedure involves retroactive review of files and data to match codes and standards for appropriate care. Flagged cases are reviewed, and the parties involved may be contacted to supply details and rationale for the course taken. This process was usually described in general terms, sometimes as an internal process within a medical group, or through an external auditor or vendor. The nature of this form of management would vary according to the source of authority, purpose, and characters involved in the review.

Related to this common practice, a few stakeholders recommended a type of continuous learning model, with a separate authority providing training, information, and feedback to providers, and also learning in turn from them. One insurer gave a description and reference for this concept (Grumbach \& Mold, 2009), which crystallized vestiges of the argument elsewhere:

Some people are proposing that it look something like the agriculture extension services that were used in the 1930s to fundamentally change agriculture ... The proposal is that some sort of similar social agency needs to assist on a community basis, on a local level, to help change the delivery system. It would certainly make sense for primary care, and probably for specialty care ... if our ultimate goal is to create better health, then it is probably a continuous process. We are always going to be improving. You can't just say for the delivery system, we want you to go from point $\mathrm{A}$ to point $\mathrm{B}$, and you're done. 
Chapter 7. Results. G. Practice Management 266

\section{Insurer Managed Care}

A number of arguments favored an active role for the insurer in managing care (32\% of all stakeholders). Insurer views were the most common; hospital and state views were absent. An overlapping set of arguments was skeptical of insurers managing care (26\% of all arguments). The categories overlap, because those who favored an argument were often the first to raise objections to frame what was intended. Skeptical arguments were led by physicians, with nearly all included; expert views were absent.

A segment of favorable arguments here pointed out the important role of insurance carriers in the kind of care management described in the last section. Several stakeholders shaped this argument into a mission statement- to develop social value and support system quality. One insurer defined the insurer role:

What is our social value? Paying claims? That is not much social value... We have taken the tack that the social value of a health plan is increasingly about supporting delivery system change and increasing quality in the delivery system. That's our social value - that we are an agent of change.

Along this same line, one public interest stakeholder wanted to encourage a "forbenefit" business model, and offered a reference to Visa founder and president, Dee Hock's (1999), Birth of the Chaordic Age. Another public interest stakeholder expressed a similar mission: "They should be fertilizing, feeding; they should be using their wisdom and caseload experience to really help redefine how health care is delivered." One insurer described opportunities for an active role:

We are doing this slowly in community by community, reshaping our provider relationships ... we probably won't call it capitation, but it will have some aspects of meaningful risk sharing and getting all the incentives and risk aligned, and probably identifying some critical aspects of care, 
probably around chronic care and other high-cost care ... This is a longterm process that will be iterative in every way ... constantly going back and looking at systematic continuous improvement.

Another insurer was more specific and assertive:

The key in this business is to find the sickest $10 \%$ in your pool, because $10 \%$ of the pool every year eats $70 \%$ of the costs. Every year this happens. So you have to find them, and you have to make sure you are doing everything for them, so they do not use the emergency room or the hospital unnecessarily, because that's where the money is ... Somebody has to do that work. Somebody has to manage the population utilization, and I think integrated health plans that have strong roots in care delivery are best positioned to do it.

Reference to "integrated health plans" and "strong roots in care delivery" in this view raises the question: To what degree and by what means are commercial insurers as presently structured capable of integrating activities with patients, the delivery system, and whole communities they intend to manage? One expert argued that integration is a key issue:

If insurers have the incentive ... to drive evidence-based, cost-conscious decisionmaking, then they can develop those tools and make them available to doctors and patients. The VA [Veterans Affairs] does it, Kaiser does it, Group Health Cooperative does it, a lot of integrated systems do it. The issue is integrating systems that are owned by different people ... but I think that concept of integration [is essential], such that the information, the delivery, and the reimbursement are all aligned to promote health, evidence, efficiency.

One purchaser described the ambition to create integrated networks:

We are not going to contract with every hospital in the area; we are only going to contract with hospitals that deliver the best quality and lowest price. That works best in a market where there are multiple health systems ... so the insurers can make a choice of who is included in their panel ... A number of insurers have tried this with varying degrees of success. They say: To be part of our network, you need to meet these quality, affordability, and service standards. 
According to one physician, preferred provider organizations (PPOs), though not dominant in Oregon, are currently a typical agent for contracting with providers to form networks.

Critics of a new era of insurer-led managed care raised several points, first being the likelihood of pushback from the public, objecting to an insurance company denying care or giving providers incentives to deny care. A purchaser was uncomfortable with the potential conflict between the goals of an insurer's disease management program and the physician's assessment of the situation and management plans. In one public interest view: "I am actually not comfortable when people say we need to have health insurers doing more health promotion stuff ... I don't think they belong in insurance.” An insurer made a similar, though slightly different point: "In fact, I think that is probably not a very good place for ... insurers to be, is getting between physicians and patients."

A few other arguments focused on the incapacity of insurers to lead effective change in local settings. In one state view, distant fiscal incentives were not enough:

In terms of the reform of the industry itself ... carriers are really just claims payers. They are not managers of care. Managers of care are in the hospitals and in primary care physicians offices, and in specialists. Those are the guys that can really reduce the costs of health care.

A physician agreed, placing the locus of quality improvement in clinical management activities by physicians and hospitals among themselves.

In another hospital view, a local insurer did not quite have the "horsepower to do what we've been looking at." Describing the insurance industry, this argument continued: "They are risk averse. They are not in this to do anything innovative, for the most part. So 
when you talk about creating a new way of reimbursing, it really comes from the delivery side." Yet, again, integration of insurance and delivery incentives is essential, because delivery system quality improvements and cost control accrue to the benefit of the insurer: "We don't get paid for it, and we're not even getting rewarded for it."

\section{Accountable Care Organizations}

The concept of accountable care organizations (ACOs) represents a current effort to find a solution to the problem of integration in the finance and delivery of health care within a given community or population setting. A number of stakeholders addressed ACOs (32\% of all stakeholders). All groups were represented; physician views were the most common, followed by insurer and hospital views.

The basic concept of the ACO was clear in each argument-integration of finance and delivery under a global budget—but the arguments went in several different directions. One hospital stakeholder described the purpose of an ACO:

We can evolve as a community or even as a state to get to a place where we can ... be much more focused on community health, community-based population, and look at ... a different way of incentives, metrics, and governance.

In other views, the idea of community was less inclusive. In a second hospital view, the ACO was defined as "anything ... it could be a large medical system, or a medical group, or medical society—any group that comes together and says: We are going to take responsibility for this community." An insurer divided the community differently, defining a possible ACO as a population of beneficiaries matched to a local 
contracted network. One physician added the stipulation that the organization needed "a big enough group of physicians and a big enough patient base to statistically make a difference and manage that." A second physician added another organizational component: "Shared risk only works when integrated into a single legal entity."

Overall, there was a sense of critical importance surrounding the issue of ACOs, but also pervasive uncertainty. One insurer observed: "There is some frustration ... nobody is defining it for us." Another insurer imagined an ACO model that was not yet fully articulated:

It would be the purchasers as a collective dealing with the providers as a collective, overseen by some community agency that says this meets our values ... [embodying] a normative function, transparency function ... We don't quite know how this is going to work.

Suggested models for ACOs included examples in Central Oregon and Washington County, where voluntary hospital-anchored organizations of physicians and other providers have developed the capacity to contract directly with insurers. One insurer expanded on the uncertainty in the definition:

One of the things buried in the Oregon Health Authority plan is the notion of ACOs ... some understanding that there is a mechanism that needs to be created to create community-level accountability ... but it's going to be the hardest thing to get people moving on, because a lot of people just look at you funny when you talk about ACOs and getting the government involved ... to get their act together and get that under control; but I don't see another way. I think that's a critical component.

The collection of arguments here indicated what is needed from government is a clear definition, first to clarify requirements for contractual relationships and legal entities allowed to accept global budgets and risk, because the ACO creates a new kind of 
insurance carrier; and second, to decide whether voluntary associations really meet the criteria for a communitywide plan to improve population health, and if so, what will be done with providers and service users who are left out. In this context, the arguments reviewed earlier regarding mandatory accountable regions are relevant.

\section{Provider Practice Management}

A diverse array of arguments referred to practice management by physicians and hospitals. The following subsections proceed from general to specific arguments.

Provider culture. One large set of arguments in this category referred to a need to change provider culture ( $26 \%$ of all stakeholders). Expert and state views were the most common; hospital and purchaser views were absent.

One state official said physicians want to be recognized as "doing good." In this view, a change in culture involved better facilities: boosting payment for primary care, providing more support for rational decisions, and more rewards for quality care that produced healthy outcomes and reduced costs. A few other stakeholders added regulated standards to avoid medical errors and adverse events: "creating a culture among physicians that that's the way to practice."

Another line of arguments involved promoting health, not health care, and working more for prevention. In a few instances, this meant to "change the medical model," and to not "overmedicalize" conditions that could be better referred to social services. Usually, this argument was coupled with an allied argument to realign financial incentives to avoid the tendency to "do more." This argument is recognizable as a subtext 
in a number of other arguments elsewhere-expecting physicians or some element of the clinic or hospital to know how to provide something more than just medical care. Along another line, one expert argued that financial incentives are not the only determinant for behavior; the underlying "profit culture" also needs to change:

People who make their living from providing healthcare services have to view themselves less as business people and more as folks fulfilling a mission. I think one of the biggest difficulties that, for example, hospital administrators have, is that they are trained and society endorses them approaching hospital services as a business, even though they are nonprofit; and as a result of that, you get vast overutilization of things like high-tech imaging scans, and so forth, because these things are profit centers ... I think you can do a lot better job than we are doing now, but I don't think you will ultimately get to a real system that works [with the business mission].

One public interest stakeholder made much the same argument. One physician directed the argument toward medical education, saying that medical schools should do more to encourage students with "idealist tendencies" more suitable for primary care.

Patient selection. Arguments reviewed above (for payment systems) discuss financial incentives to encourage and reward quality care. Related arguments here cautioned that financial incentives can induce physicians to select patients as a way to manage the care they provide. The phenomenon, in one purchaser view, is "really good for those practices, but bad for society."

One insurer described an expanding problem in patient selection that was also recognized by others. With an aging population, providers become increasingly unable to shift the considerable costs for seniors, and those patients also demand much more time; so the likelihood increases that physicians will not only refuse new patients on Medicare, 
but also look carefully at the health status of new patients in their 50s and early 60s. According to this argument, as a physician: "You need to be sizing me up, looking at me, what my potential expenses are going to be in 2 years when my current plan turns into Medicare, because your risk factors change dramatically."

Group practice. Several arguments referred to aspects of physician group practice ( $29 \%$ of all stakeholders). Hospital views were the most common; purchaser and state views were absent. All hospital arguments related to an employment model of salaried physicians.

Almost exclusively, this collection of arguments favored group practice. One benefit was professional support. One expert observed: “No question that if you don't have any peers to learn from and we trained you 20 years ago, it's hard to keep up." In a hospital view, the group setting can "help physicians see themselves in a broader context ... how they do medicine in the context of how their peers do medicine for the same thing, and can learn from that."

Other stakeholders saw group practice as a survival choice. One physician described the motives for change:

The welfare of independent practices is being challenged by the shrinking margins that primary care and specialty practices-more primary care than specialty practices-have in trying to manage an ever-increasing administrative load, the complexity of revenue-cycle management, and overhead, which continues to go up at a time when reimbursement is shrinking, and at a time when a lot of independent PCPs have aging practices, so they are aging into Medicare and ... the payment for services shrinks. 
Another physician observed that small practices are incapable of securing and managing capitation contracts.

Nearly half of the arguments related to group practice focused on an employment model (13\% of all stakeholders), particularly in hospitals. As in the general arguments above on group practice, hospital employment became a financial necessity as independent contracting with physicians became unaffordable in some instances. One hospital stakeholder pointed out the benefit for the hospital:

A high percentage of primary care physicians are now employed by hospitals in the state ... There are reasons - it is very much in the interest of the hospital ... issues become much more solvable when there is an employer relationship.

Improved utilization management is one result:

As happens in some enlightened situations, the hospital, without having a tremendous number of employed physicians, can create an environment in which data is fed to a peer group of physicians, and they can normalize themselves ... or it may have a department of utilization review, or some data with management responsibility for increasing accountability ... I think both of those are viable models; they are not mutually exclusive ... You have to have the right kind of cooperative spirit, and you have to have the right kinds of relationships, trusts built up, in order to foster those kinds of things into happening.

A salary model of reimbursement also neatly solves the highly criticized incentive

for overtreatment in fee-for-service payment. One expert framed the salary system as a natural corollary to medicine conceived as a public good:

I'm here on a salary. I don't get more money to do more, I don't get more money to do less ... This comes down to the question of whether medical care delivery should be a retail business, or should it be a service. Is it a service like fire safety, police safety, the public library, public educationis it like that? Or is it like an industry, where people are just out to make money? Now, if it's an industry, physicians should get paid for each time 
they deliver something ... but I think no one really thinks health care should work that way.

Another hospital stakeholder expanded this argument, referring to several Oregon

hospitals with a large base of employed physicians:

The rationale behind that is you begin to deliver care in a more coordinated fashion, and fee-for-service is no longer important. You are getting compensated on a base salary, plus some kind of productivity targets, so you produce-because physicians are funny, they work like crazy in the current mode where they get paid fee-for-service; you put them on salary and their productivity literally tanks, because they say: What the heck, why do I need to work this hard, I'm still going to get paid the same amount. All kind of studies will support that; but there is a way to create an incentive-based system where they get productivity.

In spite of recognized advantages to employ hospital physicians, one physician

argued that small-group practice should not be abandoned:

The whole idea of hospitalists is really physician centered. That trend is because it's more convenient for physicians ... but it's not patient-centered, because I don't necessarily think it's better care for the patients. There is a lot of effort to prove it's not any worse at least, that it's just fine, and there are arguments that they get even better care this way ... I don't happen to really believe that. I think patients get better care if [their primary care physician] is trained to ... take care of them in the hospital. You still get a consultant if you need a consultant, but I'm arguing to keep the model of care the way we've been delivering it here all along.

Clinical autonomy. Several stakeholders addressed issues of clinical autonomy

(16\% of all stakeholders). One public interest stakeholder argued that physicians are now not only worrying about how they will get paid, but also how to respond as they lose power over their own professional judgment as insurers and quality auditors increasingly intrude on their practice. One expert argued for the necessity of clinical autonomy:

You can't really completely crush physician discretion, because we don't have the evidence in all cases; and frankly, even if we do have all the 
evidence, even if we had evidence for every service, there is no way to apply population-based evidence to every single patient. There has to be individualized decisionmaking.

Other stakeholders concurred, giving examples of managed systems "where a physician always has the ability to say: "In this instance, I think this is clearly the treatment that's called for and we are going to proceed with that."

One hospital stakeholder emphasized the importance of trust:

The problem I think today is, if you have a physician who is not employed - he is independent, he has privileges at your hospital—you are in a difficult position. No matter how convincing the data [are] to call that physician in and say: Look, there are problems here with how you are practicing medicine- the physician is going to look at me as a CEO and say: What the hell do you know?

A physician described the same situation with a more successful outcome in terms of a physician-to-physician collegial dialogue.

Peer review. Only a few arguments addressed issues of peer review, but all appeared critical in terms of the pervasive concerns noted elsewhere for managed care, quality improvement, and cost control.

Peer review provides a framework of accountability (introduced earlier under managing care). A supervising physician, or medical director, can help "remind" physicians of the definitions for medical necessity, standard practices for treatment, and what will get paid. According to one physician: "Frequently, providers believe that if somebody has health insurance, they have total medical indemnity, whereas, all insurance plans are delimited."

Another physician expanded on the supervisory relationship: 
Physicians need to be part of a system that they feel a part of, that they have ownership in, whether real or imagined. So doing the oversight from Seattle or Boise - and believe me, I've called those places before for medical review, or even Portland-is not the same as talking to the medical director who is three blocks down the road from me, who I am going to see later on that day at a meeting or walking around the hospital or whatever. It's a different interaction to know, ultimately, that that medical director is making decisions that will be for my patient's wellbeing, but also will ultimately benefit me.

Other arguments described a different system of peer review to manage practice, beyond the strictures of coverage and payment. One hospital stakeholder described a self-organized group of physicians getting together to say:

We are going to work toward agreeing on what we think is the standard of care, because we recognize that we have this outlier experience going on in our community ... Let's work together to review, so that before a back procedure is conducted [for example], there is a peer-review process to sign off on; that we in effect develop our own standard within our own practice arena in order to moderate the volume and drive it toward the mean, toward some sort of community standard of care.

In this view, local action is the most effective:

I don't think it is necessary for big brother to come in. I think, in my discussions around trying to normalize physician practice patterns, it is usually peer pressure that drives people away from the margins and into the mean.

One insurer expanded this argument with a description of current practice by an insurance carrier in relation to its physician network, contracted through an independent practice association (IPA). This argument for "panels of doctors" is worth quoting at length:

Even with a withhold ... in a way it is still like a fee schedule, and there are physicians who will overprescribe, overtreat, and some physicians will play by the rules, some will be maximizing their gain through the fees that they get ... This will sound maybe kind of Pollyannaish, but I believe it has an impact ... Let's say the IPA has 500 physicians; the IPA breaks itself up into PODs [panels of doctors] of smaller groups of doctors ... and what 
tends to happen is, when you share the data with the PODs on a regular basis on: How's performance going this year? What percentage of your withhold are you projected to get back? ... They start to police each other, they start to have the conversation among themselves to identify outliers, and say: Why are you ordering an MRI on every single patient that comes into your office with low back pain? That is not standard of care, you're hurting me ...

We work with the IPAs to define those PODS, and then the feedback is shared with those PODs, so you get the insurance company out of the way of saying: You're bad. They have the doctors saying: We have these kinds of motivations around right care, right time, right setting, and we probably want to identify the outliers in our midst - the positive outliers and the negative outliers - and try to have some conversation around that bell curve ... There tends to be a quality management department of the IPA, so we tend to interact with those folks, who then interact with their POD leaders ... [they organize] however they choose to. And what you begin to see is this pattern emerge where, year after year, some PODS perform better than others. Some IPAs perform better than others. They take on a subculture based on physician leadership, or business leadership or whatever ...

What I like about this model is it doesn't feel to me like it's solely economically driven ... They are not sitting around saying: How do we eke out more money? They say: How do we provide right care, right time, right setting that's going to avoid ... some of the unwarranted variation in care-defects in a fragmented care system? ... It requires really good data to be shared, actionable data ...Then the insurance company is not necessarily this entity that says: Wait, we are taking all the risk, we need to dictate what we are going to pay and not pay for. No, we will take the risk that kind of looks like this, but there is some risk for you, too. You guys make the medical decisions; we trust that with good data and good motivation you are going to make the right medical decisions most of the time.

\section{Community Practice Management}

A number of arguments referred to community participation in practice management (24\% of all stakeholders). All groups were represented, except purchasers.

All of these arguments favored community action as something different than stakeholders or consumers only, saying in sum: Whatever is decided in health policy at 
higher levels by the national or state governments, by insurers, health plans, or other businesses, and even by local stakeholders, the community itself as a body needs to participate in determining values, plans, and practices. No stakeholders declared or could decide the geographical size of these "communities," but nearly all expressed strong conviction that health system reforms must be local.

According to one insurer, arguing for a community-based authority as a neutral party in health system transactions: "You have to build stewardship." A few stakeholders referred to a system of "community-level management" analogous to local school boards. For a second insurer:

This problem is so critical that maybe there are some organizational structures we could think about that could help make that happen - which is kind of weird, because I worry a lot about building bureaucracies; but I think it's one we should think about.

Some stakeholders imagined stewardship by a delimited group, in two arguments as an organization of purchasers and providers. On the other side, one physician argued that the value decisions that need to be made about community standards of carelimiting access to certain kinds of marginal care, and standards for medical liabilityrequires discussion "across the board as a society." One expert wavered between these two positions, from minimum to maximum involvement from the community: "I think those are things that need to be explored ... community calculus becomes important."

The arguments here all focused on a specific administration of responsibility and accountability, involving community engagement in governance. In other arguments, not included here, the term community was intended in its common usage as a vague 
reference to anyone who might want to step forward, as in community involvement, or community participation in multi-share insurance plans.

One state official thought of the state as a "facilitator rather than a leader" in these local solutions: "In terms of taking responsibility for health care, it's got to come from the communities ... The state has failed; and it's not because we haven't had bright people, it's because, I think, the solutions reside in the communities."

\section{State and System Management}

The assembled arguments regarding systemwide issues comprise a variety of topics that could rely on the state, due to current practice or a need for authority, but in certain instances might be implemented by other organizations. The combined category of "state and system" is used to avoid any predisposition on the appropriate context.

Institute for evidence-based practice. One set of arguments stands out in this category, regarding the need for an organization to support evidence-based practice (26\% of all stakeholders). Expert views were the most common; physician and purchaser views were absent.

Arguments here typically favored existing models in Oregon, often the longstanding Health Services Commission (HSC), sometimes the Health Resources Commission (HRC), and once the Oregon Evidence-based Practice Center for drug evaluations; but these were typically viewed as a "glimmering" foundation, a beginning that required expansion to embrace a more ambitious agenda. More highly endorsed models, confirmed by two stakeholders each, were the Institute for Clinical Systems 
Improvement (ISCI) in Minnesota, and the National Institute for Health and Clinical Excellence (NICE) in the United Kingdom.

Several expectations were attached to this supportive organization: (a) act as a gatekeeper to evaluate new drugs and technologies, (b) assemble and disseminate evidence-based practice, (c) establish diagnosis-treatment pairs, (d) develop clinical guidelines, (e) develop quality standards as evaluation indicators, (f) manage provider quality reports, (g) help drive policy decisions on coverage, reimbursement, and cost sharing, (h) evaluate cost effectiveness, (i) help develop a quality improvement learning system.

Several of these functions are presently conducted by existing state commissions, including others than those mentioned, as well system stakeholder organizations, and private and nonprofit organizations. The Minnesota model collects a number of such organizations into a single body, which several stakeholders here endorsed. A few other stakeholders, however, argued that the support organization needed to be neutral and exclude stakeholders, viewing them as potential sources of conflict of interest as with pharmaceutical companies in drug evaluations.

Certificate of need. A smaller set of arguments referred to some kind of certificate-of-need (CON) authority to regulate health system development (13\% of all stakeholders). Expert, insurer, and physician views were absent.

Examples of hospital overdevelopment, with imaging centers, cancer wards, and the like, introduced the topic. One public interest stakeholder observed that Oregon had [or has] a certificate-of-need program, and questioned if it really did [or does] any good. 
In this and other views here, the emphasis was on specific high-cost treatments in terms of "where" they were occurring. One purchaser alone captured the complex issues in this argument:

Everybody has to take a deep breath, and we need to look at what are the facilities that we have: How do we eliminate redundancies? How do we make sure that we are using all these facilities well? ... We tend to have this debate around: Should we have a CON program?

In this view, a kind of "licensure system for various kinds of services" could be fused to a CON evaluation, so relicensure would have to meet certain community standards of value, or lapse: "Instead of being a CON that just deals with requests to do new things, you would actually look at the existing stuff and ask how might we rearrange this."

One hospital stakeholder observed that internal cost shifts required at hospitals to balance undercompensated care produced the problem of overdevelopment, and simply paying true costs would solve it. One state official observed that applying global budgets for localities was the simplest and most effective solution; let them decide themselves how to economize.

Statutory practice. A few stakeholders observed that one track for health system reform was to simply pass laws to define standards of practice: "Thou shalt practice medicine like this." Two stakeholders appeared to view this option skeptically, but as a possibility. Two others appeared to view it as a natural solution. One purchaser alone suggested a model like the Medicare Advisory Board as an independent authority to 
cushion coverage decisions from political pressures—but also viewed any option in this direction as a poor choice.

Health care venues. A few arguments stated that hospitals need to be the last resort. In one hospital view: "You want them to be at the end of a long line of increasingly more sophisticated treatment options for the patient, but not the point of entry." No argument developed a plan how to accomplish this. A few individual stakeholders argued for using more specialty medical centers for chronic disease management, centers of excellence for particular treatments, and retail clinics for accessible primary care (cf., Pollack, Gidengil \& Mehrotra, 2010).

The hospital view above raised the argument that investor-owned specialty centers offering high-end treatments extract money from the community to absentee shareholders, and cripple hospitals in their capacity to shift profits from high-end to low-end departments. In this view, the blow would be softened if critical reforms were installed to pay hospitals their true costs, and thus eliminate the need to cost shift.

On a separate issue, one public interest stakeholder addressed the problem of physician ownership influencing overtreatment, particularly in relation to medical imaging centers, and suggested a model instituted in California to regulate fees in these instances of potential conflict of interest. This same pubic interest stakeholder, joined by a physician, regarded direct-to-consumer drug advertising, and drug detailing and samples for physicians, as sources of substantial cost increases. These venues for drug marketing, it was argued, should be managed or eliminated. 


\section{Medical Liability Reforms}

The problem of medical errors and liability was introduced as a critical issue in cost control at the beginning of the results (see A. Cost Imperative). Solutions for medical liability are now addressed here as the last topic in system reform. The placement is partly due to the external character of the topic, largely divorced from the functions of the delivery system; and partly due to the small number of stakeholders who addressed it. This set of arguments was presented by one expert, one hospital stakeholder, and two physicians. As mentioned earlier, three of the stakeholders believed medical liability reform is a critical element in healthcare system reform to improve transparent safety information, decisionmaking, and quality.

Three of the stakeholders proposed a system of no-fault compensation, designed to compensate patients and families for medical errors, without requiring assignment of blame to a particular provider for the error, as is done in tort cases. All three cautioned that no-fault did not mean compensation for any bad outcome. For one physician:

We know that in any given situation there is a known rate of complication for bad outcomes ... that is unrelated to physician negligence (and yet doctors get sued every day because babies are born with cerebral palsy). Just because a patient has a complication or an unexpected outcome from a medical or a surgical intervention does not mean they should receive compensation for it. Not in the medical liability system.

A second physician, also fixing on the cerebral palsy example, suggested a system of social insurance to assist families with certain kinds of bad outcomes, for whatever reason. "But that," said the first, "is a whole other issue." The domain of medical error 
was defined by three criteria: (a) a doctor-patient relationship, (b) a deviation from the standard of care, and (c) an ill effect to the patient because of that deviation.

The first physician suggested a model like Workers' Compensation:

The majority of money in the system currently does not go to patients. That's wrong. You could have a system of medical courts, defined benefits, standards, and adjudication that would in some ways look like a Workmens' Compensation system in this state, but would compensate more patients in a more efficient fashion and take the profit motive out of the system ... You have courts in the system that are experienced at looking at medical malpractice, rather than having a system that goes to lawyers, judges, and juries that are inexperienced at adjudicating those issues ... Physicians would still have to pay liability insurance.

As in Workers' Compensation, the patient would still have the right to bypass the system and pursue a tort case.

The expert suggested a system of tracking and assigning errors to individual practitioners, teams, or organizations that was also similar to Workmens' Compensation—creating a form of supervision without necessarily assigning blame. Tracking incidents could lead to sanctions or education. Both physicians made similar arguments, and regarded the Oregon Board of Medical Examiners as the ultimate arbiter.

Two stakeholders also addressed the issue of acknowledging errors to patients. According to one physician: "A majority of patients actually just want an answer about their malpractice, they don't necessarily want a lot of money; and then, if there's compensation, they want reasonable compensation, they are not looking for a multimillion dollar judgment." According to the expert, evidence shows that acknowledging errors reduces lawsuits—but then, under the current liability system 
acknowledging errors is dangerous: "Most liability companies, and most hospitals, and most doctor groups advise doctors to not say a word."

In the physician view, acknowledging errors is not just a strategy to reduce potential conflict. Providers need to acknowledge errors to themselves, too. We would improve value for everyone and save money if we "truly took care of injured patients and encouraged open discussion of medical errors."

\section{H. Finance}

Arguments related to finance were largely disconnected from all the other issues discussed. Only one hospital stakeholder made a clear connection to a tax-based system of finance as the simplest way to establish mandatory accountable regions under global budgets. Others discussed a similar strategy to establish global budgets by first pooling all funds, possibly from independent insurers and other sources, but the connections between finance, pooling, and later distribution of funds were not specified. Most arguments simply assumed some variation on the current system of finance, in the background, and concentrated on employing various fiscal strategies to advance reform agendas. The category of finance is placed here at the end of the presentation of results to reflect its common position as an afterthought in the discussion of feasible models of universal health insurance by stakeholders, if it was mentioned at all. 


\section{General Finance}

Among the various arguments on general issues of finance, the most common was an explicit reference to sustainability (32\% of all stakeholders). All groups were represented, except purchasers. Expert, hospital, and state views were the most common.

Sustainability more often referred to cost control rather than finance. In regard to sustainability of the system of finance, several arguments involved only a perfunctory remark, as vivid as most of the longer arguments: "I'm skeptical about the funding." One hospital stakeholder reflected on the experience in Massachusetts, where state legislators ignored the whole cost side of the equation: Well, we're just going to deal with that, we'll let that blow up in our face later. It's like: How can you be going down this road, providing insurance without realizing you have a cost problem that you're going to have to deal with?

One state official concluded: “Every idea has its ups and downs, but I haven't seen one that's sustainable."

About half of the arguments in this set referred to the instability of Medicaid funding in Oregon as a stock example of unsustainable financing, directed through the General Fund in competition with other priorities. Other states exhibit the same problem. Two stakeholders argued that financing universal health insurance will be "extraordinarily difficult" without a revived economy.

Separately, only two stakeholders remarked on the "price tag" to cover the uninsured-with an exclamation point. One state official argued the cost would be even greater in the short term to "retool the system." A few stakeholders made the argument that there is enough money in the system now to cover everyone, "if we redivide it and 
spend it more wisely." In one state view, this is a "fallacy ... because we are seeing they die ... We don't have the funds to provide the cost for the system we have today."

A few other stakeholders mentioned that the state needs to maximize federal funds, not just through expanding Medicaid, but also through grants for information infrastructure, Medicare demonstration projects, and anything else available. One public interest stakeholder argued passionately to activate the charity commitments of hospitals and other nonprofit institutions.

\section{State Tax System}

A number of arguments addressed the state tax system (45\% of all stakeholders).

All groups were represented; physician views were the least common. The overall collection is a congeries of arguments, without substantial direction. A few small clusters and individual arguments provided positive ideas.

Regarding the necessity for tax-based financing to fund the proposed subsidies for low-income purchasers of health insurance (once the legislated individual mandate is activated), most arguments referred to a "variety of mechanisms" (18\% of all stakeholders). Sometimes this involved a personal list. All groups were represented, except providers. One insurer summarized the array of tax options:

There are lots of different taxes that you can use, but there are big political problems with all of them ... [it] could be a payroll tax, it could be a sales tax, it can be a this tax or a that tax ... but you have to acknowledge that it is going to require an increment of dollars, and it's a significant increment of dollars, in order to fund that subsidy program. 
A separate set of stakeholders required tax reform, rather than a few additions here and there. One hospital stakeholder was blunt: "I don't know if you'd agree or not, but Oregon's tax system is pretty screwed up." A few stakeholders argued, specifically, to reform the kicker law. A few other stakeholders, including two from the hospital group (possibly motivated by the recent tax on providers), argued for a broader tax base.

A few other stakeholders argued for an ambitious tax that would eliminate the patchwork of funding sources, pay true costs, and provide overall security. For one purchaser: "People vote down taxes all the time no matter how tiny they are, so why not, if you are going to have to tax people ... do something big that people can be excited about. I'm serous!" One expert, with a different but related argument, made the point that taxes and premiums are basically equivalent levies on a person's income, suggesting there should be no prejudice for one over the other; but decide, rather, which works more efficiently.

One state official suggested the tax should be a "line-of-sight" tax, like the Social Security or Medicare tax, or dedicated gas taxes, which people view more favorably, because they see a fund accruing to their benefit:

We know where it's going, and we know what it's dedicated to, and we know that, hopefully, someday we may be a beneficiary of that ... I think one of the frustrations that people have with government, regardless of federal or state, is ... it's very convoluted where it all goes. 


\section{Specific Taxes}

A number of arguments addressed specific taxes (37\% of all stakeholders). All groups were represented, except physicians. State views were the most common. Taxes included income, payroll, provider, and sales taxes.

Only one state official argued for an income tax, while including the possibility of a sales tax:

If you were to think about spreading the costs across the broadest population, then a very progressive income tax and/or a sales tax would be the best way to do it ... Oregon has rejected a sales tax thirty-some times over the last 40 years, so it's kind of the third rail in Oregon politics, nobody's going to touch that ... The income tax is probably-both corporate and individual - is the fairest way, because it reaches on a progressive basis more people and spreads that cost.

A few arguments objected to an income tax. Three stakeholders, including the state official above, argued that raising the income tax to fund subsidies through the General Fund was not politically feasible. In addition, one state official raised the problem of tax flight; the border between Oregon and Washington is already porous for those who wish to shelter income from Oregon taxes. One hospital stakeholder added an objection that the state already depended too heavily on the income tax, which is especially sensitive to swings in the economy. More diversity in tax strategy is preferable.

A few arguments favored a payroll tax, without much elaboration. The plan was connected to an employer pay-or-play scheme emerging from committee deliberations for the Oregon Action Plan. In one public interest view: "Everybody is contributing a little bit more than they are now, but employers that already provide it [health insurance], it's 
credited back to them." This credit would also be returned to ERISA-protected plans, though the state is prohibited from evaluating the standard of insurance provided. In other arguments related to employers, one purchaser raised a point from the Wyden reform plan, where employers are taxed if the state takes over existing insurance for employees - to discourage crowdout. A few stakeholders aimed at eliminating the tax exemption for employment-based health insurance, which creates a system that favors more insurance for those who are already well off. In one state view: “I don't pay hardly a nickel for healthcare costs. I should be taxed like [crazy] for that.” One purchaser observed the mood of the business community toward any plan to eliminate tax benefits:

It was going to be a tremendous financial burden on the part of businesses in an environment where they were already feeling squeezed ... So employers were looking at that and saying: Yikes! How do we go from 'this' to 'this' in one fell swoop?

A few stakeholders regarded a provider tax as a feasible option, related to the kind of tax recently enacted in Oregon to expand the federal match for Medicaid. One state official referred to a similar tax in Minnesota:

Minnesota has a health transaction tax that's levied on hospitals, doctors, pharmaceuticals, etcetera, and they use that to fund Minnesota Care, where they get the federal match. So in essence you are taxing those who have coverage, because it is ultimately passed on to the insurer and the self-insured purchasers.

About the same number of arguments from others opposed the provider tax. One expert called it "far from ideal." One hospital stakeholder equated it with money laundering. 
Two stakeholders favored some kind of sales tax. One expert argued enthusiastically that the state should have had a sales tax years ago. One public interest stakeholder argued more cautiously for dedicated commodity taxes to promote health:

It's sort of a perfect thing-you tax the thing that is causing the harm to help fund helping people [for example] give up smoking; and then the less people smoke, the funding source runs out, but you don't need it so much, because fewer smoke. It's a wonderful little closed loop.

The scope of this funding was limited. No other examples of perfect, closed-loop commodities readily came to mind.

\section{Summary Results}

Data displays are used here to summarize the coded arguments and the level of group response in the topical sections and each category of arguments. The summaries include (a) a diagram of commonly associated arguments in the discourse of individuals, (b) a table of all coded argument categories with group response rates, and (c) a further summary showing high and low response and group correlations in each section of topics.

The proximity diagram illustrates the clear focus of attention by a large number of stakeholders on delivery system reform. Insurance topics were more disconnected, but also showed a few common associations. The standard benefit package was strongly associated with an overall public system, but also, more distantly, with those who advocated a system of managed competition in the insurance market.

The summary of group responses and correlations in Table 7 relates to main topics with at least $32 \%$ support overall (12 stakeholders), and therefore differs from the 
summary results presented in Table 6 , which shows a more complete view, covering topics with at least $5 \%$ response overall (2 stakeholders). State officials had the most to say on the cost imperative and finance, purchasers the most on insurance issues, and physicians the most on the delivery system and practice management. The correlation between insurers and hospitals in several areas is notable. The topic of practice management exhibited the most correlations between groups, notably between physicians and hospitals.

The relations of particular groups of stakeholders to specific sets of ideas and to each other are difficult to establish from the open-ended results of this study, but a few correlations and distinctions appear strong enough to mention, and offer interesting insights with potential consequences.

- Cost imperative: Attention from all groups covered a number of different topics, except the public interest group, which focused the greatest attention on two points: low-value care and public health. All state officials mentioned the problem of low-value care. Purchasers mentioned public health the least.

- Politics: The public interest group clearly had more to say than other groups and covered a number of topics; the hospital group had the least to say and focused most on two points: pay true costs and favor a national solution.

- Model systems: The state group showed the broadest attention to a variety of topics. The physician and purchaser groups focused on different sets of issues: physicians gave much greater attention than any group to problems with Medicare and Medicaid, and favored an overall public system; purchasers focused on the elements of the HB2009/individual mandate plan.

- Insurance: All purchasers argued for a standard benefit package and had more to say than other groups on a variety of topics related to insurance. Physicians had the least to say. The insurer and hospital groups also had little to say on insurance topics, with a matching level of attention, mostly on two points: insurance competition and the need to manage risk selection. 
- Purchasing: Purchasers had the most to say on purchasing topics, but did not stand out from other groups, except on two points: purchasers completely ignored the problem of fragmented payment, while physicians mentioned the topic more often than any other group. The purchaser and hospital groups were the only ones to mention the idea of hospital rate regulation.

- Delivery system: All physicians argued for ideas related to primary care/prevention/clinical management, and had more to say overall than other groups. The expert group had the least to say. The hospital and physician groups both focused on the topical category of coordinated care/teamwork/medical home, and information infrastructure. The correlation between the hospital and insurer groups was notable only for the absence of any mention of the workforce shortage topic. Insurers also said nothing about population-based management.

- Practice management: Physicians had the most to say on a wide variety of topics, but other groups also covered a broad number topics, except purchasers who clustered on the topics of evidence-based practice, accountable care organizations, and insurer managed care.

- Finance: The state group had the most to say and covered all topics. Physicians had the least to say about finance. 
Chapter 7. Results. Summary Results 295

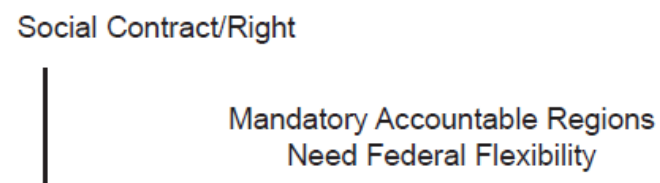

Evidence-Based Practice

\section{Standard Benefit}

Package

Individual Mandate Plan

Manage Risk Selection

Risk Adjustment

Insurance competition

Critics of Overall Public System

\section{Eliminate Emp-based Insurance}

Empower Individuals
Primary Care Prevention
Pay For Value
Clinical Management
Coordinated Care

- Teamwork -

Medical Home
Information
Technology

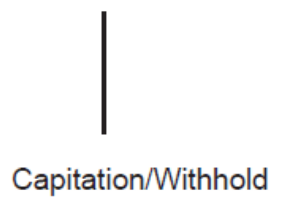

Figure 3. Proximity Diagram of Commonly Associated Arguments by Individuals

- Large font bold arguments are major arguments, with over $45 \%$ support and the most associations. These arguments are associated with all immediately surrounding arguments (using a Jaccard proximity measure).

- Smaller bold-faced arguments represent other major arguments (at least 32\% support). Associations for these and all other arguments are shown by connecting lines and in the combined lists, representing moderate to high associations.

- Arguments without connecting lines are placed in relative positions where they relate to other arguments more distantly. 
Chapter 7. Results. Summary Results 296

Table 6. Percentage Support for Coded Arguments by Group and Topic

\begin{tabular}{|c|c|c|c|c|c|c|c|c|}
\hline Sections-Codes & $\begin{array}{l}\frac{t}{d} \\
\stackrel{\alpha}{x} \\
\text { ' }\end{array}$ & 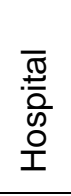 & 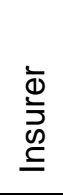 & $\begin{array}{l}\frac{\sqrt{0}}{0} \\
\frac{0}{N} \\
\frac{c}{a}\end{array}$ & 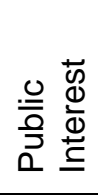 & 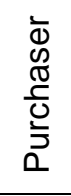 & $\frac{0}{\tilde{\omega}}$ & $\underset{b}{\stackrel{1}{E}}$ \\
\hline Overall Average & 25 & 22 & 24 & 24 & 27 & 26 & 26 & 25 \\
\hline A. COST IMPERATIVE & 28 & 28 & 28 & 34 & 28 & 24 & 40 & 30 \\
\hline Low-value care & 67 & 20 & 67 & 40 & 67 & 20 & 100 & 54 \\
\hline Overtreatment & 67 & 80 & 67 & 40 & 17 & 40 & 60 & 53 \\
\hline Public health & 33 & 60 & 50 & 40 & 67 & 20 & 60 & 47 \\
\hline Cost crisis & 33 & 20 & 17 & 40 & 17 & 60 & 80 & 38 \\
\hline High-cost drugs, treatments & 17 & 20 & 33 & 40 & 33 & 40 & 40 & 32 \\
\hline Profits & 17 & 0 & 17 & 20 & 17 & 20 & 20 & 16 \\
\hline Uninsured cost more & 0 & 33 & 0 & 33 & 17 & 17 & 0 & 14 \\
\hline Medical liability & 17 & 17 & 0 & 33 & 0 & 0 & 0 & 10 \\
\hline Consumer overutilization & 0 & 0 & 0 & 17 & 17 & 0 & 0 & 5 \\
\hline B. POLITICS & 25 & 13 & 25 & 20 & 34 & 23 & 19 & 23 \\
\hline Pay true costs & 17 & 60 & 17 & 60 & 17 & 80 & 40 & 41 \\
\hline Lack political will & 50 & 0 & 33 & 40 & 67 & 40 & 40 & 39 \\
\hline Social contract/right & 67 & 20 & 33 & 40 & 33 & 0 & 60 & 36 \\
\hline Entrenched status quo & 50 & 0 & 33 & 20 & 67 & 40 & 20 & 33 \\
\hline Reform complex, obscure & 0 & 0 & 67 & 40 & 33 & 40 & 20 & 29 \\
\hline Do have collective will & 17 & 20 & 50 & 0 & 50 & 60 & 0 & 28 \\
\hline Need federal flexibility & 33 & 20 & 17 & 40 & 17 & 0 & 40 & 24 \\
\hline Don't trust state & 33 & 20 & 17 & 0 & 17 & 20 & 20 & 18 \\
\hline Incremental innovation & 50 & 0 & 17 & 20 & 0 & 40 & 0 & 18 \\
\hline Need good story & 0 & 0 & 33 & 20 & 50 & 20 & 0 & 18 \\
\hline Leadership & 0 & 20 & 17 & 0 & 67 & 0 & 20 & 18 \\
\hline Public dialogue & 0 & 0 & 17 & 20 & 67 & 0 & 20 & 18 \\
\hline Cost/treatment equity & 17 & 0 & 17 & 17 & 50 & 17 & 0 & 17 \\
\hline Require national solution & 33 & 40 & 33 & 0 & 0 & 0 & 0 & 15 \\
\hline Reform discussions unrealistic & 33 & 0 & 17 & 20 & 17 & 0 & 20 & 15 \\
\hline Incremental reform - skeptical & 17 & 17 & 0 & 0 & 17 & 17 & 17 & 12 \\
\hline Business relations & 17 & 0 & 0 & 0 & 17 & 17 & 0 & 7 \\
\hline C. MODEL SYSTEMS & 20 & 21 & 24 & 18 & 21 & 28 & 33 & 24 \\
\hline Overall public system & 83 & 40 & 33 & 60 & 50 & 20 & 60 & 50 \\
\hline Individual mandate plan & 17 & 20 & 83 & 0 & 33 & 60 & 60 & 39 \\
\hline Critics of public system & 17 & 40 & 50 & 20 & 33 & 60 & 20 & 34 \\
\hline HB2009 - skeptical & 17 & 40 & 17 & 0 & 83 & 40 & 20 & 31 \\
\hline HB2009 Plan & 0 & 60 & 33 & 20 & 17 & 40 & 20 & 27 \\
\hline ERISA & 17 & 0 & 0 & 0 & 17 & 40 & 80 & 22 \\
\hline Mandatory accountable regions & 17 & 40 & 17 & 20 & 0 & 0 & 60 & 22 \\
\hline
\end{tabular}


Chapter 7. Results. Summary Results 297

\begin{tabular}{|c|c|c|c|c|c|c|c|c|}
\hline Sections-Codes & $\begin{array}{l}\frac{\pi}{\Phi} \\
\frac{0}{x} \\
\ddot{\Psi}\end{array}$ & 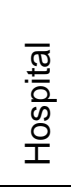 & 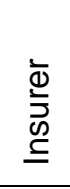 & 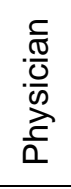 & 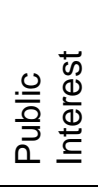 & 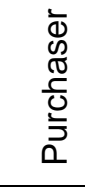 & $\frac{\Phi}{\omega}$ & $\frac{\stackrel{1}{\leftarrow}}{\stackrel{0}{6}}$ \\
\hline Mandate (general) & 17 & 20 & 33 & 40 & 0 & 0 & 40 & 21 \\
\hline Medicare/Medicaid problems & 17 & 20 & 17 & 60 & 17 & 0 & 20 & 21 \\
\hline Eliminate emp based insurance & 33 & 0 & 17 & 0 & 17 & 60 & 0 & 18 \\
\hline Expand Medicaid & 17 & 17 & 17 & 17 & 0 & 17 & 33 & 17 \\
\hline Empower individual choice & 17 & 0 & 17 & 0 & 17 & 60 & 0 & 16 \\
\hline Employer pay-or-play & 17 & 0 & 0 & 0 & 0 & 0 & 33 & 7 \\
\hline Employer mandate - skeptical & 0 & 0 & 0 & 17 & 17 & 0 & 17 & 7 \\
\hline D. INSURANCE & 29 & 18 & 19 & 10 & 31 & 35 & 24 & 24 \\
\hline Standard benefit package & 67 & 20 & 33 & 20 & 67 & 100 & 60 & 52 \\
\hline Health Insurance Exchange & 50 & 20 & 17 & 20 & 50 & 80 & 20 & 37 \\
\hline Manage risk selection & 50 & 40 & 33 & 20 & 33 & 40 & 40 & 37 \\
\hline Insurance competition & 17 & 40 & 50 & 20 & 50 & 40 & 20 & 34 \\
\hline Value-based copays & 50 & 20 & 33 & 20 & 17 & 60 & 20 & 31 \\
\hline Risk adjustment & 17 & 20 & 50 & 0 & 17 & 60 & 40 & 29 \\
\hline State catalyst setting standards & 0 & 20 & 0 & 0 & 17 & 60 & 60 & 22 \\
\hline Copays - skeptical & 50 & 0 & 0 & 0 & 67 & 0 & 20 & 20 \\
\hline Question role of insurance & 50 & 0 & 0 & 20 & 17 & 0 & 40 & 18 \\
\hline Add-on coverage & 33 & 20 & 17 & 20 & 17 & 0 & 0 & 15 \\
\hline Community rating & 0 & 17 & 17 & 0 & 33 & 17 & 0 & 12 \\
\hline Exchange - skeptical & 17 & 0 & 17 & 0 & 33 & 17 & 0 & 12 \\
\hline Rate regulation & 0 & 17 & 0 & 0 & 17 & 17 & 0 & 7 \\
\hline Apply risk divisions & 0 & 17 & 0 & 0 & 0 & 0 & 17 & 5 \\
\hline E. PURCHASING & 20 & 17 & 21 & 18 & 20 & 24 & 16 & 19 \\
\hline Pay for value & 67 & 60 & 50 & 40 & 50 & 40 & 60 & 52 \\
\hline Transparency & 33 & 40 & 50 & 20 & 50 & 40 & 20 & 36 \\
\hline Capitation/withhold & 17 & 20 & 33 & 80 & 0 & 60 & 20 & 33 \\
\hline Bundle payments & 17 & 60 & 50 & 20 & 17 & 40 & 0 & 29 \\
\hline Purchaser power & 33 & 20 & 17 & 0 & 0 & 60 & 60 & 27 \\
\hline Purchasers agree to same rules & 0 & 20 & 33 & 0 & 17 & 40 & 40 & 21 \\
\hline Fragmented payment & 17 & 20 & 17 & 40 & 17 & 0 & 20 & 19 \\
\hline Market failure & 33 & 20 & 33 & 0 & 33 & 0 & 0 & 17 \\
\hline Admin costs/simplification & 17 & 0 & 0 & 17 & 33 & 17 & 0 & 12 \\
\hline All-payer system & 0 & 0 & 33 & 0 & 33 & 0 & 17 & 12 \\
\hline Consumer choice & 33 & 0 & 0 & 17 & 17 & 17 & 0 & 12 \\
\hline Purchaser power - skeptical & 17 & 0 & 0 & 0 & 17 & 17 & 33 & 12 \\
\hline Hospital rate regulation & 0 & 33 & 0 & 0 & 0 & 33 & 0 & 10 \\
\hline Insurer contract conflict & 33 & 0 & 0 & 0 & 33 & 0 & 0 & 10 \\
\hline Pay for quality - skeptical & 0 & 0 & 0 & 33 & 0 & 33 & 0 & 10 \\
\hline Physician price awareness & 17 & 0 & 17 & 17 & 0 & 17 & 0 & 10 \\
\hline Report cards - problems, issues & 0 & 0 & 17 & 17 & 17 & 0 & 0 & 7 \\
\hline
\end{tabular}


Chapter 7. Results. Summary Results 298

\begin{tabular}{|c|c|c|c|c|c|c|c|c|}
\hline Sections-Codes & 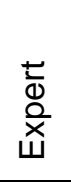 & 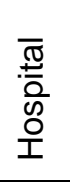 & 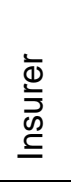 & 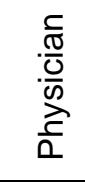 & 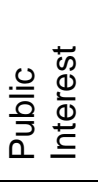 & $\begin{array}{l}\bar{D} \\
0 \\
0 \\
\overline{0} \\
0 \\
\bar{~} \\
0\end{array}$ & $\frac{\pi}{\omega}$ & 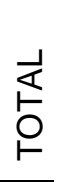 \\
\hline F. DELIVERY SYSTEM & 29 & 55 & 38 & 80 & 50 & 50 & 35 & 48 \\
\hline $\begin{array}{l}\text { Coordinated care/teamwork/ } \\
\text { medical home }\end{array}$ & 17 & 80 & 67 & 80 & 67 & 60 & 60 & 61 \\
\hline $\begin{array}{l}\text { Primary care/prevention/ } \\
\text { clinical management }\end{array}$ & 50 & 60 & 33 & 100 & 50 & 60 & 40 & 56 \\
\hline Information infrastructure & 33 & 80 & 50 & 80 & 33 & 60 & 20 & 51 \\
\hline Population-based management & 17 & 40 & 0 & 40 & 17 & 20 & 40 & 25 \\
\hline Workforce shortage & 17 & 0 & 0 & 60 & 50 & 20 & 20 & 24 \\
\hline G. PRACTICE MANAGEMENT & 24 & 24 & 25 & 36 & 21 & 17 & 22 & 24 \\
\hline Evidence-based practice (EBP) & 50 & 40 & 50 & 60 & 50 & 60 & 80 & 56 \\
\hline Managing care & 50 & 0 & 50 & 80 & 33 & 40 & 60 & 45 \\
\hline Accountable care organizations & 17 & 40 & 50 & 60 & 17 & 20 & 20 & 32 \\
\hline Insurer managed care & 33 & 0 & 67 & 20 & 50 & 40 & 0 & 30 \\
\hline Insurer managed care - skeptical & 0 & 20 & 17 & 80 & 17 & 40 & 20 & 28 \\
\hline Change provider culture & 50 & 0 & 17 & 20 & 33 & 0 & 60 & 26 \\
\hline EBP institutional support & 67 & 20 & 33 & 0 & 17 & 0 & 40 & 25 \\
\hline Community governance & 17 & 40 & 33 & 40 & 17 & 0 & 20 & 24 \\
\hline Group practice & 33 & 50 & 17 & 50 & 0 & 0 & 0 & 21 \\
\hline Venue management & 17 & 33 & 33 & 17 & 33 & 17 & 0 & 21 \\
\hline Clinical autonomy & 17 & 33 & 0 & 17 & 33 & 0 & 0 & 14 \\
\hline Certificate of need & 0 & 33 & 0 & 0 & 17 & 17 & 17 & 12 \\
\hline Liability solutions & 17 & 17 & 0 & 33 & 0 & 0 & 0 & 10 \\
\hline Peer review - panels of doctors & 0 & 17 & 17 & 33 & 0 & 0 & 0 & 10 \\
\hline Patient selection & 0 & 0 & 17 & 33 & 0 & 17 & 0 & 10 \\
\hline H. FINANCE & 38 & 34 & 21 & 10 & 25 & 29 & 63 & 31 \\
\hline State tax system - general & 67 & 40 & 33 & 20 & 50 & 40 & 60 & 44 \\
\hline Specific taxes & 33 & 20 & 33 & 0 & 33 & 60 & 80 & 37 \\
\hline Sustainability & 50 & 60 & 17 & 20 & 17 & 0 & 60 & 32 \\
\hline Income tax opposition & 0 & 17 & 0 & 0 & 0 & 17 & 50 & 12 \\
\hline
\end{tabular}


Chapter 7. Results. Summary Results 299

Table 7. Comparison of Stakeholder Groups: Prevalence of Attention and Proximity Correlation of Groups on Main Items Within Topical Sections

\begin{tabular}{|c|c|c|c|c|c|c|c|}
\hline & Expert & Hospital & Insurer & Physician & $\begin{array}{c}\text { Public } \\
\text { Interest }\end{array}$ & Purchaser & State \\
\hline $\begin{array}{c}\text { A. } \\
\text { Cost } \\
\text { Imperative }\end{array}$ & $\begin{array}{l}\text { Medium: } \\
\text { +Insurer } \\
\text { +State }\end{array}$ & & $\begin{array}{l}\text { Medium: } \\
\text { +Expert }\end{array}$ & & $\begin{array}{c}\text { Oppose: } \\
\text { Purch. }\end{array}$ & $\begin{array}{l}\text { Oppose: } \\
\text { Pub Int. }\end{array}$ & $\begin{array}{c}\text { Medium: } \\
\text { Expert } \\
\text { Most } \\
\text { common: } \\
\text { Avg 57\% }\end{array}$ \\
\hline $\begin{array}{c}\text { B. } \\
\text { Politics }\end{array}$ & & $\begin{array}{c}\text { Least } \\
\text { common } \\
\text { Avg } 14 \%\end{array}$ & & & $\begin{array}{c}\text { Most } \\
\text { Common } \\
\text { Avg 36\% }\end{array}$ & & \\
\hline $\begin{array}{c}\text { C. } \\
\text { Model } \\
\text { Systems }\end{array}$ & & & & $\begin{array}{l}\text { Oppose: } \\
\text { Purch. }\end{array}$ & & $\begin{array}{c}\text { Oppose: } \\
\text { Phys. } \\
\text { Most } \\
\text { Common: } \\
\text { Avg 35\% } \\
\end{array}$ & $\begin{array}{c}\text { Most } \\
\text { Common: } \\
\text { Avg 35\% }\end{array}$ \\
\hline $\begin{array}{c}\text { D. } \\
\text { Insurance }\end{array}$ & & $\begin{array}{l}\text { Medium: } \\
\text { +Insurer }\end{array}$ & $\begin{array}{l}\text { Medium: } \\
\text { +Hospital }\end{array}$ & $\begin{array}{c}\text { Least } \\
\text { common: } \\
\text { Avg } 14 \%\end{array}$ & & $\begin{array}{c}\text { Most } \\
\text { Common: } \\
\text { Avg 44\% }\end{array}$ & \\
\hline $\begin{array}{c}\text { E. } \\
\text { Purchasing }\end{array}$ & & $\begin{array}{l}\text { Medium: } \\
\text { +Insurer }\end{array}$ & $\begin{array}{c}\text { Medium: } \\
\text { +Hospital } \\
\text { Most } \\
\text { Common } \\
\text { Avg 35\% }\end{array}$ & & & $\begin{array}{c}\text { Most } \\
\text { Common: } \\
\text { Avg 35\% }\end{array}$ & \\
\hline $\begin{array}{c}\text { F. } \\
\text { Delivery } \\
\text { System }\end{array}$ & $\begin{array}{l}\text { Medium: } \\
\text { +Phys. } \\
\text { Least } \\
\text { common: } \\
\text { Avg 29\% }\end{array}$ & $\begin{array}{l}\text { High: } \\
\text { +Purch. } \\
\text { +Insurer }\end{array}$ & $\begin{array}{l}\text { High: } \\
\text { +Hospital } \\
\text { Medium: } \\
\text { +Purch. }\end{array}$ & $\begin{array}{c}\text { Medium: } \\
\text { +Expert } \\
\text { +Purch. } \\
\text { Most } \\
\text { Common: } \\
\text { Avg 80\% }\end{array}$ & $\begin{array}{l}\text { Medium: } \\
\text { +State }\end{array}$ & $\begin{array}{l}\text { High: } \\
\text { +Hospital } \\
\text { Medium: } \\
\text { +Insurer } \\
\text { +Phys. }\end{array}$ & $\begin{array}{l}\text { Medium: } \\
\text { +Pub Int. }\end{array}$ \\
\hline $\begin{array}{c}\text { G. } \\
\text { Practice } \\
\text { Mgmt }\end{array}$ & $\begin{array}{l}\text { High: } \\
\text { +State } \\
\\
\text { Medium: } \\
\text { +Pub Int. } \\
\text { +Insurer }\end{array}$ & $\begin{array}{l}\text { Medium: } \\
\text { +Phys. }\end{array}$ & $\begin{array}{l}\text { High: } \\
\text { +Purch. } \\
\text { Medium: } \\
\text { +Expert }\end{array}$ & $\begin{array}{c}\text { High: } \\
\text { +Purch. } \\
\text { Medium: } \\
\text { +Hospital } \\
\text { Most } \\
\text { Common: } \\
\text { Avg 46\% }\end{array}$ & $\begin{array}{l}\text { High: } \\
\text { +Purch. } \\
\text { Medium: } \\
\text { +Expert }\end{array}$ & $\begin{array}{l}\text { High: } \\
\text { +Pub Int. } \\
\text { +Phys. } \\
\text { +Insurer } \\
\text { Medium: } \\
\text { +State } \\
\text { Least } \\
\text { common: } \\
\text { Avg 22\% }\end{array}$ & $\begin{array}{l}\text { High: } \\
\text { +Expert } \\
\text { Medium: } \\
\text { +Purch. }\end{array}$ \\
\hline $\begin{array}{c}\mathrm{H} . \\
\text { Finance }\end{array}$ & & & & $\begin{array}{l}\text { Least } \\
\text { common: } \\
\text { Avg } 13 \%\end{array}$ & & & $\begin{array}{c}\text { Most } \\
\text { Common: } \\
\text { Avg } 67 \%\end{array}$ \\
\hline
\end{tabular}

Proximity measures with Pearson Correlation: Medium=.7-.899; High=.9-1.0; Oppose=-.6 to -1.0 


\section{Chapter 8}

\section{Discussion}

In the results presented in the previous chapter, the current discourse of Oregon health policy leaders in relation to universal health insurance appears quite different from the arguments heard in the reform efforts of the early 1990s. Two remarkable points are clear.

First, many issues in delivery system reform appear to have matured in health policy research and discussion, until they have reached general acceptance. Coordinated care and teamwork are notable examples. Achieving efficiency in the delivery system by these and other means was a principal concern for a large majority of the stakeholders.

Second, all stakeholders agreed that a system of universal health insurance-the main theme of this study—is a desirable goal. This basic level of agreement on the ideal changed the nature of the whole discourse to focus on "how," instead of "why." In the early 1990s, with the reform initiatives that generated the Oregon Health Plan, a great deal of effort was expended to justify universal health insurance and persuade the public and policymakers to accept it. Currently, in contrast, arguments differed only in regard to how such a universal healthcare system could or should work. The most common caveat related to universal health insurance involved doubts about the capacity of any state to achieve it. Objections to the state perspective referred to poor fiscal and management 
capacities. A few other stakeholders disputed the role of insurance, preferring the term coverage (discussed below).

The imperative to control costs was apparently strong enough to generate ready acceptance of universal health insurance as a possible solution- - just as the OHP Administrator had suggested was necessary in 1995 (see Chapter 1). A few stakeholders emphasized sustainability in finance and cost control. Although notions of public welfare were sometimes mentioned in general terms as a corollary to the ideal of a universal healthcare system, in the few instances the uninsured were mentioned, the problem was expressed as a cost issue, focusing on delayed treatment, lack of primary care, or a personal threat of bankruptcy. Moral arguments related to poverty and misfortune, children suffering and preventable death, appeared to be no longer as relevant in arguments for universal health insurance.

The discussion in this chapter focuses on the most prominent topics that emerged in the results from the stakeholder interviews. Multiple perspectives do not coalesce into a single vision of a feasible model of universal health insurance in Oregon, but do provide a broad perspective on critical topics and a variety of important issues.

\section{Prominent Results}

In terms of levels of agreement on prominent topics, several categories of arguments were supported by half or more of the stakeholders. These topics may be associated with a policy window for successful political action. The following list provides a summary of positive proposals for a feasible model of universal health 
insurance in Oregon, in direct response to the study's main research question. The items are ordered according to the level of agreement.

- Delivery system. Institute coordinated care, teamwork, and medical homes $(61 \%)$. No counterarguments were made, though the terms of the policy solutions were not generally well defined.

- Delivery system. Encourage primary care, prevention, and clinical management (56\%). No skeptical counterarguments were made.

- Practice management. Establish evidence-based practice (56\%). No counterarguments were made, but an evident division existed in proposed implementation strategies, related to management versus information functions.

- Insurance. Define a standard benefit package (52\%). Two stakeholders suggested alternatives might be possible to eliminate the need for a defined set of benefits.

- Purchasing. Pay for quality (52\%). This topic involved variations on a theme, sometimes referring to familiar pay-for-performance models, and other times referring to pay-for-value models that involved upfront payments to support case management. Skeptical arguments were made by a small number of stakeholders (10\%) in the physician and purchaser groups.

- Delivery system. Establish an information infrastructure for the delivery system $(51 \%)$. Skeptical arguments were delivered by a few physicians, who suggested that expectations for information technology might be overstated, or that alternative, less comprehensive systems might be possible with a combination of resources.

- Model systems. Implement an overall public system, or utility model (50\%). A number of stakeholders were skeptical (34\%).

In this collection of prominent topics, except for the last item, related to an overall public system, the emphasis is on the delivery system or elements to manage the delivery system. The six top items—coordinated care and medical homes, primary care and clinical management, evidence-based practice, a standard benefit package, pay for quality, and information infrastructure-all indicate an intent to rationalize the purchasing and 
delivery of health care. They are evidently expected to work, eventually, as mechanisms for efficiency. The seventh item—an overall public system—fits the same goal, in terms of its relation to global budgeting. Evidently, the top priorities for health policy leaders concerned rationing resources through rational means. Reforms to health insurance itself appear to have been a secondary concern.

The summary diagram of associated arguments by individuals (see Figure 3 at the end of the previous chapter) adds perspective to these prominent topics. The top six items in the list, as a set, were mostly presented by the same stakeholders. As a comprehensive model, the topics correspond to the model developed in the Oregon Action Plan, and in the Affordable Care Act at the national level. This indicates broad support for a definite strategy.

The model composed from these elements also corresponds to reforms related to clinical governance in the United Kingdom and the Netherlands. The connection between here and there can be recognized in the theory of new public management, which was applied in recent years in the UK's National Health Service, and is also evident in reforms in education in both the UK and the USA (Skelley, 2002). This perspective clarifies how this health system model came into existence as the result of a theoretical or ideological position applicable to governance in general. The specific mechanisms of transmission to Oregon remain unclear.

Clinical governance in the UK followed a model now called managerialism (see Chapter 4). The case offers a glimpse of what could occur if the same model is adopted in Oregon. The most serious negative result was disaffection by a large body of physicians 
once the system was implemented. Other results included paradoxes: a dominant rhetoric for markets and competition, alongside a prevailing growth of bureaucracy and authority; and an announced motive for cost control that failed to materialize or increased costs instead. Hopefully, the cautionary reports from overseas may help advise implementation strategies in Oregon for similar managerial reforms that appear in themselves worthwhile, if approached with care.

The imperative for cost control was a dominant reason for reform among stakeholders, and the cost paradox in the managerial model may be a point of concern worth reexamining. As illustrated in the review of practice management (see Chapter 4), systems of prospective care, such as the PACE program, disease management, or upfront payments to compensate for clinical management, are themselves expensive to operate and rarely manage to make a profit. The quality of care may be improved, indicating such plans can effectively address value, but they are less likely to directly, or quickly, address the problem of cost control. Instead, each item in the list of topics representing the managerial model involves substantial investments and a transfer of resources to administration. The challenges and costs of these initiatives appear to have been underestimated by stakeholders, or were simply not mentioned. Anticipation of this growth sector may partly explain the support given to these reform options by stakeholders who may expect to benefit from them. 


\section{Alternative Models}

Concerning the central question, related to feasible models of universal health insurance, two prominent sets of arguments stand out. One set supported the state-sponsored plan embodied in HB2009 and the Oregon Action Plan, partially represented in the list of prominent topics discussed above. This plan conforms to a model of managerialism and also to a model of managed competition (see Chapter 3). An overview of the plan includes the following principal components.

- Individual mandate (with guaranteed issue and premium subsidies)

- Managed competition (with the health insurance exchange)

- Clinical governance (with evidence-based practice, managed care)

- Purchaser power (with network contracting and value-based benefit plan)

- Medical homes (with coordinated care, etc.)

A separate set of stakeholder arguments supported the idea of an overall public system, or utility model. The main theme in this model involved a unified system that would eliminate the multiplicity of coverage rules and special rates, and incorporate all those presently covered by employment-based insurance and self-insured firms, plus Medicare, Medicaid, and other publicly funded programs. All Oregonians would be covered in a single system of community-rated coverage. This inclusive risk pool would not in itself control costs, but could be expected to more easily absorb the high costs of health care attributed to a small percentage of individuals in the population (see Figure 1 in Chapter 3). A few stakeholders, though not necessarily in support of an overall public system, mentioned the importance of spreading risk across the broadest population 
possible. Expanding coverage to the whole population is likely to raise premium costs or taxes for those who now possess favorable terms of coverage through an employer. Spreading the costs through a unified risk pool would reduce the shock.

Most supporters of the utility model argued for a central fund to establish global budgets in mandatory accountable regions. A few came at the model with regionalized community governance as the defining feature. A few stakeholders introduced this model with the idea of a broad-based tax that would focus attention on individual rather than group coverage, which appears to be the one way to elude ERISA restrictions on state authority over self-insured firms. In the variations of this model, the details and implications were not always clear. The following list outlines the distinguishing features of the proposed overall public system or utility model.

- Centralized fund

- Eliminate group coverage distinctions in the population

- Global budgets

- Regional governance

The measure of support for these two model systems must be interpreted cautiously, because they may only represent a surface of discourse and not necessarily a depth of related convictions. One point stands out, however, that supports the idea of two coherent alternatives. According to the percentages of stakeholders that favored different arguments (Table 5), the HB2009/individual mandate plan was most strongly supported by insurer and purchaser groups. The utility model was most strongly supported by expert 
and physician groups. The public interest, state, and hospital groups were divided between the two models. Support by different groups suggests a real distinction.

\section{Other Principal Arguments}

The following sections discuss a few principal arguments in each of the topical categories presented in the results. All of the arguments raised by stakeholders present interesting aspects that deserve attention, but including all of them would expand the discussion beyond the direct purposes of this study, which focuses specifically on prominent arguments and their objective possibilities as observed in the health policy literature. The chapter of results reveals a number of additional topics not covered here, advanced by the stakeholders themselves.

\section{A. Cost Imperative}

Stakeholders commonly mentioned low-value, inefficient care as a primary problem. The principal factor mentioned, with various examples, was overtreatment. Several stakeholders based this view on Dartmouth Atlas research, which has demonstrated unexplained treatment variations in Medicare (Iglehart, 2004). Also regularly mentioned was the popular article, "The cost conundrum," by Atul Gawande (2009), which illustrated supplier-induced demand by physicians and hospitals to maximize profits.

Another clear result related to costs was the strong recognition of public health as a critical issue by all stakeholder groups. Nearly half of the stakeholders argued for a 
mission to improve public health, indicating that universal health insurance may be unsustainable without reduction in the demand for health care. This idea relates to the axiom of insurable risk, stating that the insured must not be subject to "simultaneous destruction" (see Chapter 5). A recent national opinion survey showed strong public support for increased government spending on public health, with some areas more popular than others (Blendon, Benson, SteelFisher \& Connolly, 2010). A significant political divide was observed, with Republicans generally opposed to increased spending, except in relation to chronic illnesses, which appeared to be the main area of concern for stakeholders here as well.

Attention to public health among stakeholders may have emerged from the wide dissemination of the triple-aim framework into health policy discussions (Berwick, Nolan \& Whittington, 2008). Several stakeholders referred to "population health" (one of the three aims), but they appeared to attach different meanings to the term: one related to public health, the other to expanded medical management. Many stakeholders were well aware that population health involves an array of social determinants, far outside the bounds of medical care. Obesity was mentioned as a serious epidemic. A recent survey of healthcare expenditures showed obesity and overweight as the most costly behavioral factor (Darling, 2010). Several stakeholders appeared to understand the irony of supporting universal health insurance in a society where many people are homeless and unable to meet basic needs. The rate of severe poverty in the population, in the USA and Oregon, has increased sharply since 2000, and includes a disproportionate number of 
children (Oregon Housing and Community Services, 2008; Woolf, Johnson \& Geiger, 2006).

In terms of medical management, a segment of stakeholders appeared to believe the healthcare delivery system alone could solve many public health issues if it would expand its attention and become proactive. A model for this idea was implemented in the United Kingdom, involving new types of professional staff and funding (Ansari, Russell, Spence et al., 2003). A similar model is being developed in Oregon and other states through the federal Prevention and Public Health Fund established in the Affordable Care Act. Contrary to this initiative, David Lawrence (2010) recently argued that the optimistic view of combining population health into the model of the medical home does not represent a mere organizational expansion, but a "major departure" from the medical mission of primary care. He was skeptical it could occur or succeed, but believed innovation is possible through other business models and by empowering individuals through other venues as health consumers.

Acknowledging the distinct missions of medicine and public health is important: first, to ensure that distinct factors such as food, shelter, and exercise are not neglected in the pursuit of health outcomes, and also, to separate these factors from the purview of health insurance. This issue of separate but equally important domains for health was a central feature of the debates over the U.S. national health insurance proposal in the 1950s (Falk, 1952). Combining the two perspectives appears in the ongoing trend of medicalization, which is drawing social and behavioral health problems into the domain of medical care. Clinical management of obesity, children's moods, and drug abuse are 
partly responsible for escalating healthcare expenditures and veritable epidemics of new types of "illness" (Angell, 2011; Conrad, 2005). The trend may be fueled by profit motives for companies involved in pharmaceutical treatments and biotechnology.

Related to this issue of medicalization and profit motives, a few stakeholders mentioned the high costs of new treatments, but none connected this problem to the pace of innovation in health care. One stakeholder referred to a book on the topic by Richard Deyo and Donald Patrick (2005), Hope or hype, which discusses the "obsession with medical advances" and the marginal benefits, occasional harm, and high costs of a number of new health technologies. The proposed methods to cut the waste-by the authors and stakeholders here-were better use of evidence-based practice, regulation, and management.

Missing in this perspective is any mention of the heated environment of innovation itself, described by Daniel Callahan (2003) as a research imperative, supported by patent protection, massive government funding through the National Institutes of Health, commercial research and development, private endowments, and public campaigns to race for cures. This paradigm of progress in health care appears to be widely embraced by businesses, researchers, the state, and the public, however slight the benefits or great the cost. As David Cutler (2004) pointed out in Your money or your life, perhaps we are getting exactly the healthcare system we want. No stakeholder here offered an idea on how to slow this march for "progress." 


\section{B. Politics}

The most common argument in the domain of politics was to "pay true costs." This argument was firmly stated, and spanned nearly every other area of concern, related to issues of cost control, insurance, payment reform, and system management. Without equity in this one area, reform could fail to gain the support of a number of stakeholders. The main problem appeared to be associated with dictated prices by Medicare and fee cuts in the Medicaid program to balance state budgets.

It was not clear, however, how to actually determine the true costs of particular healthcare services. Earlier experience with cost-plus pricing according to local practice in the Medicare program resulted in unsustainable cost inflation (see Chapter 3. Monopsony Power). Through the 1970s, no market forces existed to hold prices level or determine relative prices for different services. Many stakeholders here agreed that market failure in health care required regulated prices, which is what Medicare gradually implemented across the spectrum of covered services. A few stakeholders supported the idea of hospital rate regulation. Even those who would be regulated indicated support for this argument, if rates were managed according to the Maryland model, with prices set through fairly negotiated contracts under government supervision.

Another issue relates to the fairness of a single "true" price. A few stakeholders argued for equitable prices, so everyone would be charged the same; yet, another stakeholder pointed out the different economies of a full versus an empty hospital, for example, which could make variable pricing an acceptable option for both payer and 
provider. Variable pricing could also be applied to physicians, dependent on the volume of services for the individual physician or group.

Discussing issues of efficient pricing before a U.S. Senate committee, Len Nichols (2009) warned of the complexities and illustrated problems, without arriving at a solution. The demand to "pay true costs" is clearly a major problem in health policy, for which no one, apparently, has a clear answer. Many stakeholders in this study, for example, suggested the need to experiment with different payment systems, yet were unable to articulate a definite plan. Problems are evident for both markets and regulation, and neither can be relied upon as a superior method by theory alone or in all cases, or even by itself in a specific area. Politically, the prominence of the cost/price dilemma as a topic among stakeholders here indicates a great deal of care needs to be taken to assess the available evidence for payment systems, and engage stakeholders to arrive at a fair plan or set of plans to apply to different areas of the healthcare system.

\section{Model Systems}

The principal arguments related to model systems involved the two alternatives introduced above — the HB2009/individual mandate plan and the utility model—followed immediately by criticism for each of the two alternatives. The division among stakeholders and the number of critics on each side indicates neither model, as presently articulated, provides a feasible political alternative for universal health insurance. Current plans may erode and different options emerge. 
The individual mandate plan, associated with the managerial model and managed competition, was criticized mostly for the unwieldy system of enrollment, premium subsidies, and enforcement. Other stakeholders referred to the lack of change from the status quo, which would exacerbate present problems once the system of funding and purchasing is expanded to cover the whole population. Critics of the utility model principally opposed state control and questioned state capacity. Insurers may have opposed an overall public system, because it calls into question the role of private insurance carriers, and the single-payer version of the plan proposes to eliminate them.

Accommodating the two models into a single plan may be possible. A few stakeholders supported elements of both. Possibly, a close analysis of the two models and associated arguments by proponents and critics could find a way to combine them and generate unified support.

\section{Insurance}

The principal topics raised by stakeholders related to insurance were reviewed earlier (see Chapter 3), covering issues of competition, regulation, adverse selection, risk selection, risk adjustment, personal risk, benefit standards, and the health insurance exchange. One notable result in relation to these topics was the confidence many stakeholders exhibited for the ability of a state system to manage competition, regulate risk selection, and calculate and apply risk adjustment. The literature review indicated many difficulties in these areas. 
Risk adjustment, in particular, is recognized worldwide to be a complex endeavor, requiring considerable data resources, analytic capacity, and constant monitoring and feedback from insurers and providers to evaluate the results (e.g., Lamers, 2001). Two stakeholders mentioned lack of data about the general population in Oregon, but did not mention that this would obstruct proposals for risk adjustment in the health insurance exchange. Only a few stakeholders argued for population-based budgets and risk adjustment, involving a procedure that would require far less effort and concern than risk adjustment fixed upon individuals.

A separate topic raised by several stakeholders, from different perspectives, related to the distinction between coverage and insurance, which did not emerge as an issue in the literature reviewed earlier. The main question posed to stakeholders in this study asked about state-level reforms they thought were necessary to implement a feasible model of universal health insurance (not health care or the healthcare system). The intent was to focus attention on funding and payment systems. As expected, all stakeholders discussed aspects of health care and the healthcare system anyway, as natural corollaries to health insurance. Attitudes toward insurance itself, and the need for insurance, appeared to vary. Some stakeholders questioned the need for insurance carriers. One stakeholder pointed out that the current practice of experience rating for group health insurance in the commercial market is not really insurance; other accounts support this view of experience rating as something more like a prepaid contract for services (Lakdawalla \& Sood, 2006; Wrightson, 2002). Some stakeholders disputed the label of insurance for unexplained reasons, but accepted it as a commonly applied term for any 
kind of coverage for health benefits. One stakeholder pointed out that from the perspective of the individual any coverage for health benefits is insurance, because it refers to a potential benefit in the future, not a definite product.

It was usually unclear how different stakeholders interpreted the distinction between insurance and coverage. One stakeholder referred to areas of coverage for public health issues, such as immunizations or access to primary care, as being possibly outside the insurance system, because everyone would need it. Coverage through the safety net for certain vulnerable populations was also posited as an example of coverage, rather than insurance. Some of these coverage applications might well be separated from the present medical insurance and delivery system, but they do not appear to obviate the need for insurance. The correlation of individual health to risk, and the use of insurance as a way to manage risk, appears to make a definite pact between health insurance and health care (cf., Liebman \& Zeckhauser, 2008).

Apparently, a number of stakeholders needed to be convinced of the value added to the healthcare system by insurance. Or, as stated by several stakeholders here, including insurers, the institution of insurance needs to be positioned in a way to demonstrate its value.

\section{E. Purchasing}

Many stakeholders appeared to comprehend the healthcare system according to familiar market rhetoric as it applies to other areas of the economy. Among the principal arguments related to healthcare purchasing—extra payment to support quality care, 
transparency, purchasing power, capitation, and bundled payments—-the most notable feature in stakeholder arguments was the confidence that these proposals could improve efficiency in the delivery system and reduce costs. The review of the literature indicated this is not necessarily true, though limited applications may be effective if narrowly directed to a definite purpose (see Chapter 4). In some cases, greater expense, harm, or disaster are possible results.

Some confusion was also evident in relation to bundled payments, which was favored by nearly one-third of the stakeholders. Convincing arguments were made to pay for "bigger, broader units of care," with analogies to building a house or a car as a unit rather than a collection of composite parts. Some stakeholders understood the difficulties of applying bundled payments to different types of healthcare services. One stakeholder understood the main benefit to be as a classification system to begin getting a grip on the relationship between costs and prices. The usefulness of Medicare's DRG system of bundled payments for patient classification helped it diffuse widely to other countries to understand hospital productivity (Kimberly, de Pouvourville \& D'Aunno, 2008). In the USA, however, Medicare has long called its DRG system a form of prospective payment, and consequently, several stakeholders here appeared to consider bundling as a kind of capitation that would replace fee-for-service payment. In fact, although DRGs are like a contracted price and do set limits, they remain an activity-based form of payment, the same as fee-for-service. Cost inflation in the use of DRGs is one reason many countries use them only as a management tool and not for payment. Bundling may be less useful as a payment model for cost control than many stakeholders believed. 
Arguments related to capitation, also mentioned by one-third of the stakeholders, were usually vague. In several instances, stakeholders appeared to support capitating smaller groups of providers, such as a hospital, medical home, or health plan, which could potentially lead to financial collapse over a broad span of the healthcare system (see discussion in Chapter 4. Capitation). Several other stakeholders were more mindful of the risk for smaller entities, and the need for the insurer to stay involved in bearing risk. This view led to descriptions of shared risk and withhold arrangements that appear to be working well in the current system.

One interesting argument that emerged from different perspectives was the fragmentation of the delivery system that occurs with capitation. Barriers to patient choice or physician referral may be erected through capitated contracts to health plans and their contracted networks of providers. The network effect-a form of monopoly observed in markets for information technology (Reback, 2009)—appears to be present as well in the healthcare system. Stakeholders mentioned barriers between primary care and specialists, and between mental and physical health.

Apart from the effects of capitation, fragmented payment was a key issue for several stakeholders. Different payers, different coverage and rules, and different prices make practice difficult. Many arguments focused on purchasers agreeing to the same rules, either through voluntary agreements or state standards. 


\section{F. Delivery System}

As a principal feature of delivery system reform, the overall vision of the medical home by stakeholders appeared to be a kind of catch-all organization, with all the right elements to provide ideal health care. The idea was diffuse, illustrated from disparate sources, theory, or a single model organization, similar to accounts of the medical home in the health policy literature (Fields, Leshen \& Patel, 2010). It was not clear how these desired attributes in delivery system reform would be institutionalized across the whole population. The only definite applications appeared in the context of contracted networks between insurers and providers, if any could be found, indicating a patchwork system with overlapping boundaries and inevitable gaps. Also, although a number of stakeholders mentioned population-based management in relation to the medical home, only a few addressed the array of community services that would be needed to achieve the goals of improved quality and cost control. Overall, the conception and implementation of the medical home poses major challenges that appear to be underestimated (Landon, Gill, Antonelli \& Rich, 2010).

In relation to the principal topic of installing a comprehensive information infrastructure, a few stakeholders provided interesting alternatives. One argument indicated that an expensive electronic system in every office is not strictly necessary to practice up to the standards of the medical home. A second argument offered an example of fairly easy access to alternate systems for management purposes without requiring direct interoperability. A third argument proposed the Internet as a supplement to private systems. These examples suggest that the ideal of coordinated care, so prominent in the 
arguments for delivery system reform, might be well served by attention to limited facilities with organizational interoperability, and not necessarily a completely tuned information infrastructure.

\section{G. Practice Management}

The general ideas of evidence-based practice and managing care were the most common topics in practice management, each represented in arguments by about half of the stakeholders. Many of the arguments for evidence-based practice contained a note of unrealistic expectation, as if science-based management would readily solve problems of efficiency and the "facts" were clear. In medicine, of course, probabilities rather than certainties predominate. The commonly contested distinction between rules and guidelines was ignored by many stakeholders. This is the same tone of managerial determinism that has caused so much ill will in the now dismantled experiment with clinical governance in the United Kingdom (see Chapter 4, Practice Management). The costs and friction involved in producing, disseminating, and using evidence-based practice appear to have been invisible to the proponents of the managerial model. Providers generally approached the topic with more reserve, and suggested ways evidence-based guidelines can be effectively used with clinical decisionmaking tools and medical management.

Many options were advanced for managing care, involving governance by insurers, hospitals, physicians, and communities. Several stakeholders expected an active role for insurers in promoting value in the delivery system. In a few arguments, this role 
sounded more like limiting losses in the traditional manner of insurance, but a number of specific ideas referred to constructive initiatives, mostly related to developing and disseminating decisionmaking tools and quality standards, applying incentives, and preferred network contracting.

Most intriguing was the argument by a few stakeholders for a continuous learning model, in one case based on the model of Oregon's agriculture extension services. Another stakeholder provided an example of supplying claims data in a format to share information to select physician groups (panels of doctors, or PODS), operating under shared-risk contracts. The targeted information and organization in PODS was apparently proving to be an effective mechanism for physician peer review and professional self-management.

In any governance option, one problem that must be overcome, mentioned by a few stakeholders, is the disincentive for providers to improve value when cost savings accrue to the insurer. Integration of finance and delivery presents a solution, which a few stakeholders mentioned, with Kaiser as a model. Some hospital systems and capitated health plans may be able to establish a similar kind of integration. The most common choice by stakeholders for an integrated system was in the idea of an accountable care organization. In most arguments, not much more than the name was mentioned. The federal definition of the accountable care organization allows for contract networks of various descriptions. Stakeholders mentioned nascent local examples in Central Oregon and Washington County. The argument for a utility model suggested mandatory accountable regions as way to integrate whole communities. Model healthcare networks 
with community governance include an example in Colorado (Thorson, Brock, Mitchell \& Lynn, 2010).

Also related to practice management, medical liability reform was mentioned by only a few stakeholders, but with strong conviction. Reform was viewed as a critical component of quality improvement, because the necessary information on quality and safety is unlikely to be truthfully reported without a change in liability laws. Arguments related to cost control referred to extra expense from defensive medicine and waste through excessive litigation. Moreover, according to these views, more patients should be helped and compensated as a matter of social justice. A type of no-fault system was supported, with a suggested model in Workers' Compensation.

\section{H. Finance}

Finance was the least developed of all the principal topics related to healthcare reform. This result is hardly surprising. The immense difficulty of raising the possibility of state-level taxation is commonly compounded by disagreement once the issue is raised. A recent Task Force on Comprehensive Revenue Restructuring (2009), appointed by the Oregon legislature, demonstrated this lack of unanimity in its tepid proposals, which were all that was able to emerge from a divided body.

In specific proposals by stakeholders here, supporters of an income tax were countered by critics of higher income taxes, considering the state already relies heavily on this single source of revenue. A sales tax as an alternative was mentioned only once. No one mentioned property tax as a potential source of revenue, except in relation to current 
exclusions, wondering if hospitals and other nonprofit healthcare organizations should really be exempt. Heavy reliance on federal funds was taken for granted, and some advocated a national solution to avoid typical problems for a state, such as tax flight and tax competition with other states (Gold, 1986). Uncertainty in finance strengthened the position of those stakeholders who lacked confidence in state capacity to fund or manage a system of universal health insurance.

\section{Group Affinities}

Among the seven groups of stakeholders, firm similarities and differences are difficult to establish. Physicians presented the clearest singularity, with a focus on issues related to their domain in the delivery system and practice management, and almost no mention of issues related to insurance and finance. Interestingly, insurers did not show the same level of attention to their own domain of insurance, and instead, talked more about purchasing and the delivery system. The two provider groups, hospitals and physicians, appeared to think similarly on issues of practice management; however, the hospital group was more frequently aligned with the insurer group, with similar interests on an array of topics related to insurance, purchasing, and the delivery system. Other groups overlapped in shifting patterns. The public interest group was clearly more interested in political issues than other groups, and state officials were clearly more interested in finance than other groups. The expert group ranged most widely over all topics.

Ideology may have affected many of the stakeholder views, in the original sense of economic and practical interests influencing support for certain ideas (Mannheim, 1954). 
Insurers and hospitals are clear beneficiaries of the individual mandate promoted in federal and state reform legislation. Premium subsidies paid by the federal government will greatly expand funding for both health insurance and health care. For insurers, the associated model of managed competition is likely to concentrate the commercial market among the most prominent firms. In addition, the managerial model centralizes control over cost exposure, already used by insurers through underwriting and benefit design. The interests of other stakeholder groups were less easy to place.

Individually, the mood of stakeholders toward universal health insurance reforms ranged from an easy confidence to utter skepticism, deflated by years of failed efforts. Addressing what was necessary was straightforward for some, complex for others. Those few with little to say on universal health insurance as a system, having given it little thought, instead discussed their own direct experiences. Many were clearly informed by the well-publicized reform activities at state and federal levels over the past few years, and through direct participation in various stakeholder committees and task forces. For others, information and arguments had apparently accumulated over time through experience, some exposure to health policy literature, and the nature of their leadership positions. Nearly all participants rose to the challenge of the main interview question with a broad range of arguments. 
Chapter 9. Conclusion 324

\section{Chapter 9}

\section{Conclusion}

In response to the question: What state-level reforms do you believe are necessary to implement a feasible model of universal health insurance in Oregon? — two distinct models appeared in stakeholder responses. One model, based on managed competition and a managerial regime, comprised the elements of reform familiar in national and state policy agendas. This model was supported by written documents developed into a plan in Oregon from 2006 through 2008, and established in state and federal laws in 2009 and 2010. The second model proposed an overall public system, based on a public utility model. This second model appeared to be different, in most cases, from the single-payer model that remains common in state reform efforts. Both models supported the idea of a standard benefit package, but other details differed. The managed competition model concentrated on market forces, managing a complex insurance market, purchasing power, and delivery system reform. The utility model concentrated on finance and governance. Insurers and purchasers distinctly favored the managerial model. Physicians and experts distinctly favored the utility model. Other stakeholders groups were divided.

Although a fairly equal number of stakeholders supported each of these two alternative models, political feasibility favors the managerial model, due to support from insurers and federal policy, plus the ability to proceed incrementally on the basis of existing institutions and practices. Moreover, finance through a broad and ambitious tax 
measure can be deferred as long as the federal government remains willing to fund the system. In contrast, the utility model would probably disrupt current institutions and practices in ways that are not entirely clear, and it requires a broad and ambitious tax measure up front in order to implement an overall public system.

In an objective sense, according to evidence of what is likely to work, both models appear to be important. Combining them could possibly strengthen both political and practical prospects for a universal system of health insurance and health care. The managerial model maintains an array of institutional partners to concentrate on mechanisms for cost control and quality improvement in health care; the utility model provides a framework that has a better likelihood to succeed in those goals, using regionalized global budgets and a unified perspective on population health (see Chapter 4). The topic of global budgets and how they might work remained undeveloped here, because only a few stakeholders mentioned the concept and details were scarce.

Another interesting division in stakeholder views appeared in relation to the implementation of evidence-based practice. A more thoughtful review by policymakers may be necessary on this topic. Some stakeholders appeared to favor rules and standards, while others favored guidelines and information resources. This distinction produces different types of management and expectations.

Regarding the extensive body of other points that stakeholders believed were necessary in a feasible model of universal health insurance, the most prominent were discussed in the previous chapter, and were covered as well in the introductory review chapters. Other valuable points, mentioned by only one or a few participants, may have 
been partially covered or may remain isolated in the results chapter. A close look at the results will find arguments related to issues such as add-on insurance coverage, price awareness by physicians, retail clinics, the employment model of group practice, costeffectiveness studies, the certificate-of-need program, and a hospital rate-setting regime. Also, a number of solitary criticisms were made, related to such issues as value purchasing, electronic health records, and other reforms that a larger number of other stakeholders took for granted as straightforward elements in a model plan.

One category of topics needed to be more definite, related to the organization of an integrated delivery system. Fragments of this large topic appeared in concepts of a medical home, accountable care organizations, community governance, and a utility model; and in certain payment models, peer review, and the problems of hospitals cooperating with physicians and physicians with nurses; and in comments on legal barriers and antitrust laws. A plan to resolve the complexities and obstacles into a "universal" health system was unavailable as a prominent, well-considered model argument. This topic of an integrated system was the principal omission in the model reform proposal presented to the legislature by the Oregon Health Fund Board (2008). Although delivery system reform was a central topic in that report and among stakeholders here, a model for an integrated, truly "universal" healthcare system—with both state and local governance, finance and delivery, and medical and social serviceswas absent. 


\section{Study Limitations}

The stakeholders in this study were chosen for their knowledge, authority, and participation in health policy in Oregon. Although instructive, the findings gathered here from their views cannot necessarily be generalized to represent the "average" views of health policy leaders in Oregon. A random sample was not possible, because a sampling frame could not be made to contain all the possible individuals who might qualify to be in it. Even physicians, who can be located through available licensing records, would require some further distinction to identify an individual as a health policy leader. This limitation is evident in similar studies, such as a recent opinion survey of health policy leaders conducted for The Commonwealth Fund (Stremikis, Davis \& Nuzum, 2010). There, the sample was drawn from a magazine mailing list, and used a snowball sample to select influential leaders as was done here. A more complete study of stakeholder views might be possible by targeting organizations in a stratified sample by region and industry sector.

The composition of the expert group in this study illustrates the variety of possible sources for eligible individuals (see Appendix $\mathrm{C}$ for the full list interviewees). This group, like others, comprised individuals known for previous as well as current associations. It included the director of the health division at Consumer Reports in New York; a director of research for evidence-based practice at OHSU; a director of a private nonprofit company that contracts with the state to gather and report information on quality indicators; a college professor; a public hospital physician; and the director of a state agency for long-term care facilities. 
The small sample in this study could hardly do justice to many areas of concern. A few underrepresented elements deserve mention. First, due to the attention the study participants gave to delivery system reform, it became apparent that the perspective of nurses should have been represented. The same was true for mental health, long-term care, home health care, and public health organizations. In regard to insurance, an agent was included here, but more attention could be directed to this interest group, and also to the extensive number of smaller insurers.

Related to purchasing, it appears a targeted effort is needed to engage self-insured firms in meaningful dialogue at the state level. The effort to engage representatives from such firms for this study failed, because state issues were not relevant to their broader perspectives. Perhaps the individuals contacted were merely uninvolved with the topic of this study, but a question arises to what degree self-insured firms, exempted from state laws by ERISA, are or could be stakeholders in Oregon health policy. These firms are among the largest organizations in the state.

Pharmaceutical and device suppliers make up another segment of private interests that were not included here. In this case, though, stakeholder participation might not be necessary, because these organizations could be susceptible to management through typical market forces, and may be understood in those terms.

Finally, although the public interest stakeholders were expected to represent the interests of the general population from a consumer or voter perspective, it remains unclear how well this was accomplished. Views from the general public could raise different and unexpected issues. 
Many of the stakeholders who did participate in this study represented a somewhat insulated group near the center of political action at the state level. This selection bias occurred purposely as a criterion for inclusion, but it should be recognized as a distinct orbit where views have developed and harmonized, so many stakeholders spoke of the same concepts and concerns. An effort was made to include various perspectives, but a more directed sample that aimed to include health policy leaders with more parochial policy interests might introduce different sets of arguments.

\section{Future Research}

Many directions for future study appeared among the topics raised here by stakeholders. The most prominent topics were identified and discussed briefly, and broader descriptions and critical issues related to them were reviewed in the opening chapters. In several cases, systematic reviews were available to help understand the objective possibilities of various arguments for reform. Often, however, significant topics could not be adequately addressed, because few stakeholders mentioned them, and the length of a single document could not contain detailed expositions on every point. The final discussion swept over a vast territory. The organized narrative of the healthcare system provided here may be considered a major accomplishment for its presentation of a universal view and identification of key topics, but full justice to the whole and to each part would require many more details. Such additions would transform the presentation into something much longer. With a systematic approach, a new synthesis might be possible to help understand how disparate models of finance, organization, management, 
and practice can fit together to form the most likely, feasible model of universal health insurance and health care for the state of Oregon.

Apart from the content presented in this study, the policy process also deserves closer attention. The presentation of legislative action here only observed expenditures of the top lobbyist organizations as a measure of influence. A few stakeholders emphasized the importance of general features of politics, politicians, and interests in health reform. More should be recorded on the ways insurer, hospital, and physician organizations, and other smaller interest groups and state bureaucrats actually compete and cooperate, and how they gain access and succeed in lobbying activities and cooperative enterprises.

The many "moving parts" of the healthcare system, as some stakeholders described it, make it clear why models are so important to translate knowledge into practice. Very often, stakeholders in this study clearly relied on written models, current discussions, and existing practices to shape their arguments. Models supply a depth of thought and evidence in a concise format that may be readily transmitted. The current reform model to establish a system of universal health insurance in Oregon, favored by a number of stakeholders in this study, represents only a partial step toward the stated goal—as many of its most enthusiastic supporters recognized. Sustainability remains a critical issue. Developing a system that is also safe, effective, patient-centered, timely, efficient, and equitable poses a further, perpetual challenge. 


\section{References}

Aaron, H.J. (1998). Less is more: After the Clinton plan, let's think small. In S.H. Altman, U.E. Reinhardt \& A.E. Shields (Ed.), The future U.S. healthcare system: Who will care for the poor and uninsured? Chicago: Health Administration Press.

Abney, G. (1988). Lobbying by the insiders: Parallels of state agencies and interest groups. Public Administration Review, 48; 911-917.

Abt Associates. (2000). Evaluation of the program of all-inclusive care for the elderly demonstration: Final report [Contract No. 500-01-0027]. Health Care Financing Administration.

Abt Associates. (1998). Evaluation of the program of all-inclusive care for the elderly (PACE) demonstration: Final [Contract No. 500-96-0003/TO4]. Health Care Financing Administration.

Achman, L. \& Chollet, D. (2001). Insuring the uninsurable: An overview of state highrisk health insurance pools. The Commonwealth Fund.

Achman, L. \& Gold, M. (2002). Medicare+Choice 1999-2001: An analysis of managed care plan withdrawals and trends in benefits and premiums. The Commonwealth Fund.

Acs, G., Long, S.H., Marquis, M.S. \& Short, F. (1996). Self-insured employer health plans: Prevalence, profile, provisions, and premiums. Health Affairs, 15(2), 266278.

Agency for Healthcare Research and Quality (2003). AHRQ's patient safety initiative: Building foundations, reducing risk [Interim report to the Senate Committee on Appropriations, Pub 04-RG005]. Available online (Apr 24, 2005): www.ahrq.gov/qual/pscongrpt/

Alakeson, V., Pande, N. \& Ludwig, M. (2010). A plan to reduce emergency room 'boarding' of psychiatric patients. Health Affairs, 29(9), 1637-1642.

Alexander, J.A., Waters, T.M., Boykin, S., Burns, L.R., Shortell, S.M., Gillies, R.H. et al. (2001). Risk assumption and physician alignment with health care organizations. Medical Care, 39(7), I-46 to I61. 
Alexander, J.A., Weiner, J. \& Bogue, R.J. (2001). Changes in the structure, composition, and activity of hospital governing boards, 1989-1997: Evidence from two national surveys. Milbank Quarterly, 79(2), 253-279.

Allen, F.L. (1935). The lords of creation. New York: Harper \& Brothers.

Allen, H., Balcker, K., Finkelstein, A., Taubman, S. \& Wright, B.J. (2010). What the Oregon Health Survey can tell us about expanding Medicaid. Health Affairs, 29(8), 1498-1506.

Allen, P. (2000). Accountability for clinical governance: Developing collective responsibility for quality in primary care. BMJ, 321; 608-611.

Amelung, V., Glied, S. \& Topan, A. (2003). Health care and the labor market: Learning from the German experience. Journal of Health Politics, Policy and Law, 28(4), 693-714.

American Association of Health Plans (AAHP). (2002). Medical necessity: Summary of enacted laws and selected state legislation. Available online (Sep 2002):

Members only. Organization now merged with HIAA, now at: www.ahip.org

Anders, G. A. (1996). Health against wealth: HMOs and the breakdown of medical trust. New York: Houghton Mifflin.

Anderson, G.F., Petrosyan, V. \& Hussey, P.S. (2002). Multinational comparisons of health systems data, 2002. The Commonwealth Fund.

Anderson, G.F., Reinhardt, U.E., Hussey, P.S. \& Petrosyan, V. (2003). It's the prices, stupid: Why the United States is so different from other countries. Health Affairs, 22(3), 89-105.

Anderson, G.F. \& Squires, D.A. (2010). Measuring the U.S. health care system: A cross-national comparison. The Commonwealth Fund.

Angell, M. (2011). The epidemic of mental illness: Why? The New York Review of Books, 58(11), 20-22.

Anonymous. (2000). Monitoring hospital-based infections to promote patient safetyUnited States, 1990-1999. Morbidity \& Mortality Weekly Report, 49(8), 149-153.

Ansari, W.E., Russell, J., Spence, W. Ryder, E. \& Chambers, C. (2003). New skills for a new age: Leading the introduction of public health concepts in healthcare curricula. Public Health, 117, 77-87. 
Appleby, J. (1998). Economic perspectives on markets and health care. In W. Ranade (Ed.), Markets and health care: A comparative analysis (p. 34-53). New York: Longman.

Arno, P.S., Levine, C. \& Memmott, M.M. (1999). The economic value of informal caregiving. Health Affairs, 18(2), 182-188.

Arrow, K.J. (1963). Uncertainty and the welfare economics of medical care. American Economic Review, 53(5), 941-973.

Asch, S.M., Sloss, E.M., Hogan, C., Brook, R.H. \& Kravitz, R.L. (2000). Measuring underuse of necessary care among elderly Medicare beneficiaries using inpatient and outpatient claims. Journal of the American Medical Association, 284(18), 2325-2333.

Ascuaga, C. (1992). Universal health care in Massachusetts: Lessons for the future. In H.M. Leichter (Ed.), Health policy reform in America: Innovations from the states (1st ed.), 173-190. Armonk NY: M.E. Sharpe.

Atherly, A. (2001). Supplemental insurance: Medicare's accidental stepchild. Medical Care Research and Review, 58(2), 131-161.

Atkins, D., Kupersmith, J. \& Eisen, S. (2010). The Veterans Affairs experience: Comparative effectiveness research in a large health system. Health Affairs, 29(10), 1906-1912.

Atkinson, G. (2009). State hospital rate-setting revisited (Issue Brief). The Commonwealth Fund.

Atkinson, G. \& Murray, R. (2008). The use of ambulatory patient groups for regulation of hospital ambulatory surgery revenue in Maryland. Journal of Ambulatory Care Management, 31(1), 17-23.

Austin, D.A. \& Gravelle, J.G. (2007). Does price transparency improve market efficiency? Implications of empirical evidence in other markets for the health sector. Congressional Research Service.

Atwood, K. (1985). An honorable history: 133 years of medical practice in Jackson County, Oregon. Medford: Jackson County Medical Society.

Avorn, J. \& Fischer, M. (2010). 'Bench to behavior': Translating comparative effectiveness research into improved clinical practice. Health Affairs, 29(10), 1891-1899. 
Ayres, S.M. (1996). Health care in the United States: The facts and the choices. Chicago: American Library Association.

Baker, L., Birnbaum, H., Geppert, J., Mishol, D. \& Moyneur, E. (2003). The relationship between technology availability and health care spending. Health Affairs Web Exclusives, (Nov 5), 537-551.

Banerjee, A., Iyer, L. \& Somanathan, R. (2007). Public action for public goods (Working Paper 12911). National Bureau of Economic Research.

Barbour, R.S. (2003). The newfound credibility of qualitative research? Tales of technical essentialism and co-option. Qualitative Health Research, 13(7), 1019-1027.

Barlett, D.L. \& Steele, J.B. (2004). Critical condition: How health care in America became big business - and bad medicine. New York: Doubleday.

Barlett, D.L. \& Steele, J.B. (1992). America: What went wrong? Kansas City: Andrews and McMeel.

van Barneveld, E.M., Lamers, L.M., van Vliet, R.C.J.A., van de Ven, W.P.M.M. (2001). Risk sharing as a supplement to imperfect capitation: A tradeoff between selection and efficiency. Journal of Health Economics, 20: 147-168.

Bärnighausen, T. \& Sauerborn, R. (2002). One hundred and eighteen years of the German health insurance system: Are there any lessons for middle- and low-income countries? Social Science \& Medicine, 54; 1559-1587.

Bates, F.G. (1914). State officers, boards and commissions created and abolished in 1913. American Political Science Review, 8(3), 431-436.

Bazzoli, G.J., Kang, R., Hasnain-Wynia, R. \& Lindrooth, R.C. (2005). An update on safety-net hospitals: coping with the late 1990s and early 2000s. Health Affairs, 2(4), 1047-1063.

Beck, C.M. \& Paul, R.I. (1998). Payment of emergency department bills by Medicaid patients [Abstract]. Academic Emergency Medicine, 5(4), 330-333.

Becker, D., Kessler, D., McClellan, M. (2004). Detecting Medicare abuse (Working Paper 10677). National Bureau of Economic Research.

Beckman, H.B., Mahoney, T. \& Greene, R.A. (2007). Current approaches to improving the value of care: A physician's perspective. The Commonwealth Fund. 
Bedregal, P. \& Ferlie, E. (2001). Evidence based primary care? A multi-tier, multiple stakeholder perspective from Chile [Abstract]. International Journal of Health Planning \& Management, 16(1), 47-60.

Behn, R.D. (2002). The psychological barriers to performance management: Or Why isn't everyone jumping on the performance-management bandwagon? Public Performance \& Management Review, 26(1), 5-25.

Beijer, H.J. \& de Blaey, C.J. (2002). Hospitalisations caused by adverse drug reactions (ADR): A meta-analysis of observational studies (abstract). Pharmacy World \& Science, 24(2), 46-54.

Beier, L.M. (2000). My twelve years in the U.K. health system. Health Affairs, 19(3), 185-190.

Bellows, N.M., Halpin, H.A. \& McMenamin, S.B. (2006). State-mandated benefit review laws. Health Services Research, 41(3, Part II), 1104-1123.

Berk, M.L. \& Monheit, A.C. (2001). The concentration of health care expenditures, revisited. Health Affairs, 20(2), 9-18.

Berry, J. \& White, R. (2000). An insurer's perspective on reform. Journal of Health Politics, Policy and Law, 25(1), 205-210.

Berta, W.B. \& Baker, R. (2004). Factors that impact the transfer and retention of best practices for reducing error in hospitals. Health Care Management Review, 29(2), 90-97.

Berwick, D.M., DeParle, N., Eddy, D.M., Ellwood, P.M., Enthoven, A.C. Halvorson, G.C. et al. (2003). Paying for performance: Medicare should lead. Health Affairs, 22(6), 8-10.

Berwick, D.M., James, B., \& Coye, M.J. (2003). Connections between quality measurement and improvement. Medical Care, 41(1 suppl), I30-I38.

Berwick, D.M., Nolan, T.W. \& Whittington, J. (2008). The triple aim: Care, Health, and Cost. Health Affairs, 27(3), 759-769.

Beveridge, W. (1943). Social security: Some trans-Atlantic comparisons. Journal of the Royal Statistical Society, 106(4), 305-332.

Biles, B., Dallek, G. \& Dennington, A. (2002). Medicare + Choice after five years: Lessons for Medicare's future. The Commonwealth Fund. 
Billington, M.L. \& Hardaway, R.D. (Ed.). (1998). African Americans on the western frontier. Niwot CO: University Press of Colorado.

Bindman, A.B., Weiner, J.P. \& Majeed, A. (2001). Primary care groups in the United Kingdom: Quality and accountability. Health Affairs, 20(1), 132-145.

Binney, C.C. (1894). Restrictions upon local and special legislation in state constitutions. Philadelphia: Kay \& Brother.

Blendon, R.J., Benson, J.M., SteelFisher, G.K. \& Connolly, J.M. (2010). Americans' conflicting views about the public health system, and how to shore up support. Health Affairs, 29(11), 2033-2039.

Blendon, R.J., Schoen, C., DesRoches, C., Osborn, R. \& Zapert, K. (2003). Common concerns amid diverse systems: Health care experiences in five countries. Health Affairs, 22(3), 106-121.

Blendon, R.J., Schoen, C., Donelan, K., Osborn, R., DesRoches, C.M., Scoles, K. et al. (2001). Physicians' views on quality of care: A five-country comparison. Health Affairs, 20(3), 233-243.

Blumenthal, D. (2006). Employer-sponsored health insurance in the United StatesOrigins and implications. New England Journal of Medicine, 355(1), 83-88.

Blumenthal, D. (1999). Health care reform at the close of the 20th century. New England Journal of Medicine, 340(24), 1916-1920.

Bodenheimer, T. (2005). Is evidence-based medicine evidence based? [Book review of J. Abramson, Overdosed America: The broken promise of American medicine]. Health Affairs, 24(2), 562-563.

Bodenheimer, T. (2000). Selective chaos: An internist's attempt to overcome the absurdity, for providers and patients, of managed care's selective-contracting system. Health Affairs, 19(4), 200-205.

Bodenheimer, T. (1999). Disease management—promises and pitfalls. New England Journal of Medicine, 340(15), 1202-1205.

Bodenheimer, T. (1997). The Oregon Health Plan -- lessons for the nation. New England Journal of Medicine, 337; 651-655 [Part 1]; 338, 720-723 [Part 2].

Bodenheimer, T. (1993). Single payer-Fifty players? Alternative payers for universal health insurance. Health/PAC Bulletin, (Fall), 24-28. 
Bohmer, R.M.J. (2010). Managing the new primary care: The new skills that will be needed. Health Affairs, 29(5), 1010-1014.

Bourke, P. \& DeBats, D. (1995). Washington County: Politics and community in antebellum America. Baltimore: Johns Hopkins University.

Bovbjerg, R., \& Holahan, J. (1982). Medicaid in the Reagan era: Federal policy and state choices. Washington DC: The Urban Institute.

Bovbjerg, R.R. \& Miller, R. H. (1999). Managed care and medical injury: Let's not throw out the baby with the backlash. Journal of Health Politics, Policy, and Law, 24(5), 1145-1157.

Bovbjerg, R.R. \& Raymond, B. (2003). Patient safety, just compensation, and liability reform. Oakland: Kaiser Permanente Institute for Health Policy.

Boyne, G.A. \& Walker, R.M. (2002). Total quality management and performance: An evaluation of the evidence and lessons for research on public organizations. Public Performance and Management Review, 26(2), 111-131.

Brach, C., Sanches, L., Young, D., Rodgers, J., Harvey, H., McLemore et al. (2000). Wrestling with typology: Penetrating the "black box" of managed care by focusing on health care system characteristics. Medical Care Research and Review, 57(Supp. 2), 93-115.

Brandes, S.D. (1976). American welfare capitalism, 1880-1940. Chicago: University of Chicago.

Brennan, T.A. \& Mello, M.M. (2003). Patient safety and medical malpractice: A case study. Annals of Internal Medicine, 139(4), 267-275.

Brody, H. (1997). Medical futility: A useful concept? In M.B. Zucker \& H.D. Zucker (Ed.), Medical futility and the evaluation of life-sustaining interventions (p. 1-14). New York: Cambridge University.

Brousseau, R.T., Langill, D. \& Pechura, C.M. (2003). Are foundations overlooking mental health? Health Affairs, 22(5), 222-229.

Brousselle, A. \& Lessard, C. (2011). Economic evaluation to inform health care decisionmaking: Promise, pitfalls and a proposal for an alternative path. Social Science \& Medicine 72, 832-839.

Brown, A.E. \& Stewart, Joseph, Jr. (1993). Competing advocacy coalitions, policy evolution, and airline deregulation. In P.A. Sabatier \& H.C. Jenkins-Smith (Ed.), Policy change and learning, p. 83-103. San Francisco: Westview. 
Brown, J. \& Finkelstein, A. (2011). Insuring long-term care in the U.S. (Working Paper 17451). National Bureau of Economic Research.

Brown, L.D. (1999). Management by objection? Public policies to protect choice in health plans. Medical Care Research and Review, 56(Supp. 1), 145-165.

Browne, W.P. (1990). Organized interests and their issue niches: a search for pluralism in a policy domain. Journal of Politics, 52(2), 477-509.

Bruen, B.K. \& Holahan, J. (2002). Acceleration of Medicaid spending reflects mounting pressures. KFF.

Buchmueller, T.C. (2009). Consumer-oriented health care reform strategies: A review of the evidence on managed competition and consumer-directed health insurance. The Milbank Quarterly, 87(4), 820-841.

Budetti, P.P., Shortell, S.M., Waters, T.M., Alexander, J.A., Burns, L.R., Gillies, R.R. et al. (2002). Physician and health system integration. Health Affairs, 21(1), 203210 .

Bunce, V.C. \& Wieske, J.P. (2010). Health insurance mandates in the states, 2010. Council for Affordable Health Insurance.

Buntin, M.B., Burke, M.F., Hoaglin, M.C. \& Blumenthal, D. (2011). The benefits of health information technology: A review of the recent literature shows predominantly positive results. Health Affairs, 30(3), 464-471.

Burns, N. (1994). The formation of American local governments: Private values in public institutions. New York: Oxford University.

Cabana, M.D., Rand, C.S., Powe, N.R., Wu. A.W., Wilson, M.H., Abboud, P.C. et al. (1999). Why don't physicians follow clinical practice guidelines? A framework for improvement. Journal of the American Medical Association, 282(15), 14581465.

Callahan, D. (2003). What price better health? Hazards of the research imperative. Berkeley: University of California.

Carey, K. \& Dor, A. (2004). Trends in contract management: The hidden evolution in hospital organization. Health Affairs, 23(6), 192-199.

Carey, K. \& Burgess, J.F. (1999). On measuring the hospital cost/quality trade-off. Health Economics, 8(6), 509-520. 
Carlson, M.J., Devoe, J. \& Wright, B.J. (2006). Short-term impacts of coverage loss in a Medicaid population: Early results from a prospective cohort study of the Oregon Health Plan. Annals of Family Medicine, 4(5), 391-398.

Carlson, M.J. \& Wright, B. (2005). The impact of program changes on enrollment, access, and utilization in the Oregon Health Plan Standard population. Oregon Health Policy and Research. Available online (Feb 6, 2006): www.oregon.gov/das/OHPPR/rsch/docs/OHREC.cohortflwup.03.05.rpt.pdf

Carrier, E.R., Reschovsky, J.D., Mello, M.M., Mayrell, R.C. \& Katz, D. (2010). Physicians' fears of malpractice lawsuits are not assuaged by tort reforms. Health Affairs, 29(9), 1585-1592.

Casalino, L. (2001). Canaries in a coal mine: California physician groups and competition. Health Affairs, 20(4), 97-108.

Cassel, C.K. (2005). Medicare Matters: What geriatric medicine can teach American health care. Berkeley: University of California.

Cassel, C.K., Johnston-Fleece, M. \& Reddy, S. (2010). Aging: Adding complexity, requiring skills. In W.B. Rouse \& D.A. Cortese, Studies in Health Technology and Informatics: Vol. 153. Engineering the System of Healthcare Delivery, p. 47-69. Washington DC: IOS Press.

Cassidy, R.B. (1956). Public utility regulation in California: Analysis. From West's annotated California codes. Available online (Jan 23, 2003): www.sandiego.edu/lrc/utilities.html

Cebul, R.D., Rebitzer, J.B., Taylor, L.J. \& Votruba, M.E. (2008). Organizational fragmentation and care quality in the U.S. health care system (Working Paper 14212). National Bureau of Economic Research.

Center for Public Integrity (1996). Well-healed: inside lobbying for health care reform, part III. International Journal of Health Services, 26; 19-46.

Center for Responsive Politics. (2010). Washington lobbying grew to $\$ 3.2$ billion last year, despite economy. Available online (Jun 19, 2011): www.projectcensored.org/top-stories/articles/6-lobbyists-buy-congress

Centers for Medicare \& Medicaid Services (CMS). (2010). Medicare Physician Group Practice Demonstration. Available online (May 12, 2011): www.cms.gov/DemoProjectsEvalRpts/downloads/PGP_Fact_Sheet.pdf 
Centers for Medicare \& Medicaid Services. (2009). National Health Expenditure tables. Available online (Jul 12, 2011): www.cms.hhs.gov/NationalHealthExpendData/25_NHE_Fact_Sheet.asp\#TopOfP age

Centers for Medicare \& Medicaid Services. (2003). Medicare managed care market penetration for all Medicare plan contractors - quarterly state/county data files. Available online (Feb 1, 2004): www.cms.hhs.gov/healthplans/statistics/mpsct

Centers for Medicare \& Medicaid Services. (2002). Medicaid in Oregon: Plan type breakout. Available online (Jan 28, 2003):

http://cms.gov/medicaid/managedcare/mmcss02.asp

Charlton, B.G. (2000). Infostat, cargo-cult science and the policy sausage-machine: NICE, CHI and the managerial takeover of clinical practice [Book chapter]. Available online (Apr 20, 2004): www.hedweb.com/bgcharlton/cargocult.html

Charlton, B.G. \& Miles, A. (1998). The rise and fall of EBM. Quarterly Journal of Medicine, 91; 371-374.

Cheit, R.E. (1993). State adoption of model insurance codes: An empirical analysis. Publius, 23(4), 49-70.

Chernew, M.E., Jacobson, P.D., Hofer, T.P., Aaronson, K.D. \& Fendrick, A.M. (2004). Barriers to constraining health care cost growth. Health Affairs, 23(6), 122-128.

Chirba-Martin, M.A., \& Brennan, T.A. (1994). The critical role of ERISA in state health reform. Health Affairs, 13(2), 142-155.

Chollet, D. (2002). Expanding individual health insurance coverage: Are high-risk pools the answer? Health Affairs Web Exclusives, 349-358.

Chollet, D.J. (2000). Consumers, insurers, and market behavior. Journal of Health Politics, Policy and Law, 25(1), 27-44.

Chollet, D. \& Achman, L. (2003). Approaching universal coverage: Minnesota's health insurance programs. The Commonwealth Fund.

Choudhry, N.K., Rosenthal, M.B. \& Milstein, A. (2010). Assessing the evidence for value-based insurance design. Health Affairs, 29(11), 1988-1994.

Christianson, J.B., Parente, S.T. \& Taylor, R. (2002). Defined-contribution health insurance products: Development and prospects. Health Affairs, 21(1), 49-64. 
Christianson, J.B., Wholey, D.R., Warrick, L. \& Henning, P. (2003). How are health plans supporting physician practice? The physician perspective. Health Affairs, 22(1), 181-189.

Christie, T. (2004). Insurer to the poor defends practices: LIPA tells state officials it hasn't mistreated Oregon Health Plan patients. The Register-Guard (Eugene OR, Sep 1), p. 1, 11.

Churchill, W. (1997). A little matter of genocide: Holocaust and denial in the Americas 1492 to the present. San Francisco: City Light Books.

City Club of Portland. (2002). Tax reform in Oregon.

Claremont Graduate University. (2000 Mar). Tort reform and patient safety discussion paper. Paper presented at roundtable conference, "Reporting as a Means to Improve Patient Safety," Claremont CA.

Claxton, G., DiJullio, B., Whitmore, H., Pickreign, J.D., McHugh, M., Osel-Anto, A. et al. (2010). Health benefits in 2010: Premiums rise modestly, workers pay more toward coverage. Health Affairs, 29(10), 1942-1950.

Clemmitt, M. (2000). HCFA coverage rule: Prudent purchasing or bureaucracy run amok? Medicine \& Health, 54(23 suppl), 1-4.

Coddington, D.C. \& Moore, K.D. (2002). Leading IDSs heed the call to invest in IT. Healthcare Financial Management (Feb), 36-40.

Coglianese, C. \& Lazer, D. (2003). Management-based regulation: Prescribing private management to achieve public goals. Law \& Society Review, 37(4), 691-730.

Cohen, A.W. (2004). The racketeer's progress: Chicago and the struggle for the modern American economy, 1900-1940. New York: Cambridge University.

Cole, C.R. Eastman, K.L., Maroney, P.F. \& McCullough, K.A. (2004). A review of the current and historical no-fault environment. Journal of Insurance Regulation, 23(1), 3-23.

Cole, C.R. \& McCullough, K.A. (2004). The debate over claims reporting databases in insurance issuance and pricing. Journal of Insurance Regulation, 23(2), 91-103.

Collins, S.R., Davis, K. \& Lambrew, J.M. (2003). Health care reform returns to the national agenda: The 2004 presidential candidates' proposals. The Commonwealth Fund. 
Colton, R., Frisof, K.B. \& King, E.R. (1997). Lessons for the health care industry from America's experience with public utilities. Journal of Public Health Policy, 18(4), 389-400.

Columbia Law Review. (1961). The Commerce Clause and state antitrust regulation. Columbia Law Review, 61(8), 1469-1496.

Conlan, T.J., Beam, D.R. \& Wrightson, M.T. (1995). Policy models and political change. In M. Landy \& M.A. Levin (Ed.), The new politics of public policy. Baltimore: Johns Hopkins University.

Conover, M. (1921). Pensions for public employees. American Political Science Review, 15(3), 350-365.

Conover, C.J. \& Sloan, F.A. (1998). Does removing certificate-of-need regulations lead to a surge in health care spending? Journal of Health Politics, Policy and Law, 23(3), 455-481.

Conrad, P. (2005). The shifting engines of medicalization. Journal of Health and Social Behavior, 46(1), 3-14.

Cooper, P.F., \& Schone, B.S. (1997). More offers, fewer takers for employment-based health insurance: 1987-1996. Health Affairs, 16(6), 142-149.

Cowper, P.A., Peterson, E.D., DeLong, E.R., Wightman, M.B., Wawrzynski, R.P., Muhlbaier, L.H. et al. (2001). The impact of statistical adjustment on economic profiles of interventional cardiologists. Journal of the American College of Cardiology, 38(5), 1416-1423.

Cozzens, P. (Ed.). (2002). Eyewitnesses to the Indian wars: 1865-1890. The wars of the Pacific Northwest. Mechanicsburg PA: Stackpole Books.

Crowley, J.C. \& Skocpol, T. (2001). The rush to organize: Explaining associational formation in the United States, 1860s-1920s. American Journal of Political Science, 45(4), 813-829.

Cukor, J., Fairbrother, G., Tassi, A., Butts, G.C. \& Friedman, S. (2002). Quality oversight for Medicaid managed care plans: Impact on providers. Journal of Public Health Management, 8(5), 1-10.

Cunningham, P.J. (2010). The growing financial burden of health care: National and state trends, 2001-2006. Health Affairs, 29(5), 1037-1044.

Cutler, D.M. (2004). Your money of your life: Strong medicine for America's health care system. New York: Oxford University. 
Cutler, D. (2002a). Moral treatment at the end of the Oregon Trail [Oregon Health \& Science University festchrift address]. Available online (Jan 18, 2007): www.ohsu.edu/psychiatry/grandrounds/moraltreatment.shtml

Cutler, D. (2002b). Health care and the public sector (Working Paper 8802). National Bureau of Economic Research.

Cutler, D. \& Reber, S.J. (1998). Paying for health insurance: The trade-off between competition and adverse selection. Quarterly Journal of Economics, 113(2), 433466.

Cutler, D.M. \& Zeckhauser, R.J. (1999). The anatomy of health insurance (Working Paper 7176). National Bureau of Economic Research.

Cutler, D.M. \& Zeckhauser, R.J. (1997). Adverse selection in health insurance (Working Paper 6107). National Bureau of Economic Research.

Dafny, L. (2008). Are health insurance markets competitive? (Working Paper 14572). National Bureau of Economic Research.

Dafny, L., Duggan, M., Ramanarayanan, S. (2010). Paying a premium on your premium? Consolidation in the U.S. health insurance industry. (Working Paper 15434). National Bureau of Economic Research.

Dahl, M. (1999). Commentary. Medical Care Research and Review, 56(Supp. 1), $166-171$

Darling, H. (2010). US health care costs: The crushing burden. In W.B. Rouse \& D.A. Cortese, Studies in Health Technology and Informatics: Vol. 153. Engineering the System of Healthcare Delivery, p. 87-104. Washington DC: IOS Press.

Davis, D.A. \& Taylor-Vaisey, A. (1997). Translating guidelines into practice. Canadian Medical Association Journal, 157(4), 408-416.

Delbecq, A.L., van de Ven, A.H. \& Gustafson, D.H. (1975). Group techniques for program planning: A guide to nominal group and delphi processes. Palo Alto CA: Scott Foresman.

Demel, B. \& Baker, J.R. (2000). Effects of the home care interim payment system on access to home health care for people on Medicare. Journal of Long Term Home Health Care, Case Management Journals, 2(2), 108-115.

Devers, K.J., Brewster, L.R. \& Casalino, L.P. (2003). Changes in hospital competitive strategy: A new medical arms race? Health Services Research 38(1, Part II), 447469. 
Devers, K.J., Casalino, L.P., Rudell, L.S., Stoddard, J.J., Brewster, L.R. \& Lake, T.K. (2003). Hospitals' negotiating leverage with health plans: How and why has it changed? Health Services Research 38(1, Part 2), 419-446.

DeVoe, J.E. Ray, M. \& Graham, A. (2011). Public health insurance in Oregon: underenrollment of eligible children and parental confusion about children's enrollment status. American Journal of Public Health, 101(5), 891-898.

Dewees, S. (1997). Healthcare organizations and 501(c)(3): Uncertainty in the post-Geisinger world. Health Matrix: Journal of Law Medicine, 7(2), 351-380.

Deyo, R.A. \& Patrick, D.L. (2005). Hope or hype: The obsession with medical advances and the high cost of false promises. New York: Amacom.

DiPrete, B. \& Coffman, D. (2007). A brief history of health services prioritization in Oregon. Oregon Health Policy and Research. Available online (May 23, 2011): www.oregon.gov/OHA/OHPR/HSC/docs/PrioritizationHistory.pdf?ga=t

Division of Medical Assistance Programs. (2010). 2009 Physician workforce survey. Oregon Department of Human Services.

Dix, D. (2006/1843). "I tell what I have seen" -The reports of asylum reformer Dorothea Dix. American Journal of Public Health, 96(4), 622-624.

Dlugacz, Y.D. (2010). Value based health care: Linking finance and quality. San Francisco: Jossey-Bass.

Dobbin, F.R. (1992). The origins of private social insurance: Public policy and fringe benefits in America, 1920-1950. American Journal of Sociology, 97(5), 1416-50.

Doonan, M.T. \& Tull, K.R. (2010). Health care reform in Massachusetts: Implementation of coverage expansions and a health insurance mandate. The Milbank Quarterly, 88(1), 54-80.

Doran, T. \& Roland, M. (2010). Lessons from major initiatives to improve primary care in the United Kingdom. Health Affairs, 29(5), 1023-1029.

Dorn, S. (2008). Comment [on Janet Holtzblatt, "The challenges of implementing health reform through the tax system"]. In H.J. Aaron and L.E. Burman (ed.), Using taxes to reform health insurance. Washington DC: Brookings Institution.

Dowbiggin, I.R. (1997). Keeping America sane: Psychiatry and eugenics in the United States and Canada, 1880-1940. Ithaca NY: Cornell University. 
Dranove, D., Kessler, D., McClellan, M. \& Satterthwaite, M. (2002). Is more information better? The effects of 'report cards' on health care providers (Working Paper 8697). National Bureau of Economic Research.

Draper, D., Gold, M. \& McCoy, J. (2002). The role of national firms in Medicare+Choice. Kaiser Family Foundation.

Duchon, L., Schoen, C., Doty, M.M., Davis, K., Strumpf, E. \& Bruegman, S. (2001). Security matters: How instability in health insurance puts U.S. workers at risk. The Commonwealth Fund.

Dumenil, L. (1990). "The insatiable maw of bureaucracy": Antistatism and education reform in the 1920s. Journal of American History, 77(2), 499-524.

Dykstra, C.A. (1913). Blue sky legislation. American Political Science Review, 7(2), 230234.

E.A.M., Jr. (1932). State regulation of businesses affected with public interest. Virginia Law Review, 18(7), 769-774.

Ebeler, J. (1999). Commentary. Medical Care Research and Review, 56(Supp. 1), 172-176.

Eddy, D.M. (2005). Evidence-based medicine: A unified approach. Health Affairs, 24(1), 9-17.

Elliot-Smith, A. (2009). A final g'day to English general practice. British Journal of General Practice, (August); 618-620

Ellwood, P.M. (2003, Feb. 18). Crossing the Health Policy Chasm: "Pathways to Healthy Outcomes.” Jackson Hole Group. Available online (Mar 31, 2003): www.facct.org

Elsler, D., Troutlein, D., Rydlewska, I., Frusteri, L., Krüger, H., Veerman, T. et al. (2010). A review of case studies evaluating economic incentives to promote occupational safety and health. Scandinavian Journal of Work, Environment \& Health, 36(4) 289-298.

Employee Benefit Research Institute. (2001). Individual Social Security Accounts: Administrative Issues (Issue Brief/Special Report).

Endsley, S., Kirkegaard, M., Baker, G. \& Murcko, A.C. (2004). Getting rewards for your results: Pay-for-performance programs. Family Practice Management (March), p. 45-50. 
Enthoven, A.C. (2000). In pursuit of an improving National Health Service. Health Affairs, 19(3), 102-119.

Enthoven, A.C. (1980). Health plan: The only practical solution to the soaring cost of medical care. Menlo Park CA: Addison-Wesley.

Epstein, A. (1936). Insecurity: A challenge to America (3rd ed., Revised). New York: Random House.

Ettelt, S., Nolte, E., Thomson, S. \& Mays, N. (2007). The systematic use of cost-effectiveness criteria to inform reviews of publicly funded benefits packages. London School of Hygiene \& Tropical Medicine. Available online (July 6, 2011): www.international-comparisons.org.uk/IHC\%20Report\%20CEA\%20of $\% 20$ existing\%20interventions\%202007.pdf

Evidence-Based Medicine Working Group. (1992). Evidence-based medicine: A new approach to teaching the practice of medicine. Journal of the American Medical Association, 268(17), 2420-2425.

Falk, I.S. (1952). The economic issues of compulsory health insurance: Comment. Quarterly Journal of Economics, 66(4), 572-586.

Families USA. (2009). Hidden health tax: Americans pay a premium.

Families USA. (2004). One in three: Nonelderly Americans without health insurance, 2002-2003 [Pub 04-104].

Farnham, W.D. (1956). The development of an Oregon county, 1852-1890: Mines, farms, and a railroad. Pacific Historical Review, 25(1), 29-45.

Federal Trade Commission \& U.S. Department of Justice. (2004). Improving health care: A dose of competition. Washington DC.

Feldman, R., Thorpe, K.E., Gray, B. (2002). The Federal Employees Health Benefits Plan. Journal of Economic Perspectives, 16(2), 207-217.

Felt-Lisk, S., Barrett, A. \& Nyman, R. (2007). Public reporting of quality information on Medicaid health plans. Health Care Financing Review, 28(3), 5-16.

Fendrick, A.M., Smith, D.G. \& Chernew, M.E. (2010). Applying value-based insurance design to low-value health services. Health Affairs, 29(11), 2017-2021.

Ferguson, D. \& Ferguson, N. (1983). Sacred cows at the public trough. Bend OR: Maverick. 
Ferlie, E.B. \& Shortell, S.M. (2001). Improving the quality of health care in the United Kingdom and the United States: A framework for change. The Milbank Quarterly, 79(2), 281-315.

Fields, D., Leshen, E. \& Patel, K. (2010). Driving quality gains and cost savings through adoption of medical homes. Health Affairs, 29(5), 819-826.

Fireman, B., Bartlett, J. \& Selby, J. (2004). Can disease management reduce health care costs by improving quality? Health Affairs, 23(6), 63-75.

Fitzpatrick, M. (2009). Diagnostic delusions. British Journal of General Practice, $59(568), 876$.

Flanagan, J. \& Smith, F. (2003). The universal approach: Affordability is basic in health-care reform. San Francisco Chronicle (Jan. 2). Available online (July 25, 2011): www.pnhp.org/news/2003/january/public-utility-model-of-health-carereform

Foerster, R.F. (1912), The British National Insurance Act. Quarterly Journal of Economics, 26(2), 275-312.

Foote, S.B. (2002). Why Medicare cannot promulgate a national coverage rule: A case of regula mortis. Journal of Health Politics, Policy and Law, 27(5), 707-730.

Forget, E.L., Deber, R. \& Roos, L.L. (2002). Medical savings accounts: Will they reduce costs? Canadian Medical Association Journal, 167(2), 143-147.

Fossett, J.W., Goggin, M., Hall, J.S., Johnston, J., Plein, L.C., Roper, R. et al. (2000). Managing Medicaid managed care: Are states becoming prudent purchasers? Health Affairs, 19(4), 36-49.

Foundation for Medical Excellence. (2003). Oregon Health Assessment Project. Available online (Apr 20, 2003): www.tfme.org/OHAP/TFME/default.htm

Fox, D.M. (1997). The competence of states and the public health. In H.M. Leichter (Ed.), Health Policy Reform in America (1st ed.), 237-254.

Fox, D.M. \& Schaffer, D.C. (1989). Health policy and ERISA: Interest groups and semipreemption. Health Politics, Policy and Law, 14(2), 239-260.

Frank, R.G. (2004). Behavioral economics and health economics (Working Paper 10881). National Bureau of Economic Research.

Frank, R.G., Sullivan, M.J. \& DeLeon, P.H. (1994). Health care reform in the states. American Psychologist, 49(10), 855-867. 
Freezor, A. (2002). CalPERS strategic plan. Available online (May 15, 2011): www.ehcca.com/presentations/healthpolicyaudio20020924/feezor2.doc

Fronstin, P. (2009). Addressing health care market reform through an insurance exchange: Essential policy components, the public plan option, and other issues to consider (Issue Brief No. 330). Employee Benefit Research Institute.

Fronstin, P. (2003). Tiered networks for hospital and physician health care services (Issue Brief). Employee Benefit Research Institute.

Frymark, T.B. \& Mullen, R.C. (2005). Influence of the prospective payment system on speech-language pathology services [Abstract]. American Journal of Physical Medicine \& Rehabilitation, 84(1), 12-21.

Fuchs, V.R. (2004). More variation in use of care, more flat-of-the-curve medicine. Health Affairs Web Exclusives, (Oct 7); VAR104-107.

Furrow, B.R., Greaney, T.L., Johnson, S.H., Jost, T.S. \& Schwartz, R.L. (2000). Health law (2nd ed.). St. Paul MN: West Group.

Gabel, J.R., Dhont, K. \& Pickreign. (2002), Are tax credits alone the solution to affordable health insurance? Comparing individual and group insurance costs in 17 U.S. markets. The Commonwealth Fund.

Gallay, A. (2002). The Indian slave trade: The rise of the English empire in the American South 1670-1717. New Haven: Yale University.

Galvin, R.S., Delblanco, S., Milstein, A. \& Belden, G. (2005). Has the Leapfrog Group had an impact on the health care market? Health Affairs, 24(1), 228-233.

Garland, M. (1992). Light on the black box of basic health care: Oregon's contribution to the national movement toward universal health insurance. Yale Law \& Policy Review, 10(2), 409-430.

Gawande, A. (2009). The cost conundrum. The New Yorker, (June 1), p. 36ff.

Gawande, A. (2004). The bell curve: What happens when patients find out how good their doctors really are? The New Yorker (Dec 6), p. 82ff.

Gaynor, M. \& Haas-Wilson, D. (1998). Vertical relations in health care markets. In M.A. Morrisey (Ed.), Managed Care and Changing Health Care Markets. Washington DC: American Enterprise Institute. 
Gaynor, M. \& Vogt, W.B. (2000). Antitrust and competition in health care markets. In A.J. Culyer and J.P. Newhouse (Ed.), Handbook of Health Economics (1B), p. 1405-1488. Amsterdam: Elsevier.

Gerber, A.S., Ptashnik, E.M., Doherty, D. \& Dowling, C. (2010). The public wants information, not board mandates, from comparative effectiveness research. Health Affairs, 29(10), 1872-1880.

Gilbart, E. (2003). Evidence-based guidelines, prioritised review criteria and feedback have no effect on adherence to care recommendations for angina and asthma [Comment]. Evidence-based Healthcare, 7; 157-158.

Gluck, M.E. \& Hanson, K.W. (2001). Medicare chart book (2nd ed.). Kaiser Family Foundation.

Goda, G.S. (2011). The impact of state tax subsidies for private long-term care insurance on coverage and Medicaid expenditures. Journal of Public Economics, 95, 744757.

Goddeeris, J.H. \& Weisbrod, B.A. (1998). Conversion from nonprofit to for-profit legal status: Why does it happen and should anyone care? In B.A. Weisbrod (ed.), To Profit or Not to Profit: The Commercial Transformation of the Nonprofit Sector. Cambridge: Cambridge University.

Gold, S.D. (Ed.). (1986). Reforming state tax systems. Washington DC: National Conference of State Legislators.

Gold, M. \& Achman, L. (2002). Average out-of-pocket health care costs for Medicare+Choice enrollees increase substantially in 2002 (Issue Brief). The Commonwealth Fund.

Gold, M.R., Hurley, R. \& Lake, T. (2001). Provider organizations at risk: a profile of major risk-bearing intermediaries, 1999. Health Affairs, 20(2), 175-185.

Goldman, W., McCulloch, J., Cuffel, B. \& Kozma, D. (1999). More evidence for the insurability of managed behavioral health care. Health Affairs, 18(5), 172-181.

Goldsmith, J. (2003). The road to meaningful reform: A conversation with Oregon's John Kitzhaber. Health Affairs, 22(1), 114-124.

Goldsmith, J., Blumenthal, D. \& Rishel, W. (2003). Federal health information policy: a case of arrested development. Health Affairs, 22(4), 44-55. 
Gollust, S.E., Dempsey, A.F., Lantz, P.M., Ubel, P.A. \& Fowler, E.F. (2010). Controversy undermines support for state mandates on the human papillomavirus vaccine. Health Affairs, 29(11), 2041-2046.

Gooden, S.T. \& Douglas, N.E. (2006). Ever present, sometimes acknowledged, but never addressed: Racial disparities in U.S. welfare policy. In K.M. Kilty \& E.A. Segal (Ed.), The promise of welfare reform, 207-222. New York: Haworth.

Goodrum, P. M. \& Gangwar, M. (2004). Examination of the effectiveness and long-term impact of safety incentive programs in construction [Session No. 645]. American Society of Safety Engineers: ASSE Professional Development Conference and Exposition, June 7 - 10, 2004, Las Vegas, Nevada

Goroll, A.H., Berenson, R.A., Schioenbaum, S.C. \& Gardner, L.B. (2007). Fundamental reform of payment for adult primary care: Comprehensive payment for comprehensive care. Journal of General Internal Medicine, 22; 410-415.

Gottlich, V. (2003). Medical necessity determinations in the Medicare program: Are the interests of beneficiaries with chronic conditions being met? Partnership for Solutions: Better Lives for People with Chronic Conditions. Johns Hopkins University \& Robert Wood Johnson Foundation.

Gottschalk, M. (1999). The elusive goal of universal healthcare in the U.S.: Organized labor and the institutional straightjacket of the private welfare state. Journal of Policy History, 11(4), 367-398.

Governor's Commission on Health Care. (1988). Report to Neil Goldschmidt on improving access to health care for all Oregonians. Salem: Office of Health Policy.

Gray, B.H., Gusmano, M.K. \& Collins, S.R. (2003). AHCPR and the changing politics of health services research. Health Affairs Web Exclusive (Jun 25).

Greaney, T. (2011). The Affordable Care Act and competition policy: Antidote or placebo? Oregon Law Review, 89, 811-845.

Greaney, T. (2007). Thirty years of solicitude: Antitrust law and physician cartels. Houston Journal of Health Law \& Policy, (6 Nov.), 189-226.

Greene, M.R. (1985). Insurance. In Encyclopaedia Britannica, 21; 678-691.

Greene, J. \& Peters, E. (2009). Medicaid consumers and informed decisionmaking. Health Care Financing Review, 30(3), 25-40. 
Greener, I. (2003). Performance in the National Health Service: The insistence of measurement and confusion of content. Public Performance \& Management Review, 26(3), 237-250.

Grimshaw, J.M., Shirran, L., Thomas, R., Mowatt, G., Fraser, C., Bero, L. et al. (2001). Changing provider behavior: An overview of systematic reviews of interventions. Medical Care, 39(8), II-2 to II-45.

Groopman, J. (2010). Health care: Who knows 'best'? New York Review of Books, 57(2), 13.

Groopman, J. (2000). Second opinions: Stories of intuition and choice in the changing world of medicine. New York: Viking.

Groopman, J. (1997). The measure of our days: New beginnings at life's end. New York: Viking.

Groopman, J. \& Hartzband, P. (2009, April 8). Why 'quality' care is dangerous. Wall Street Journal, A13.

Gross, R. (2003). Implementing health care reform in Israel: Organizational response to perceived incentives. Journal of Health Politics, Policy and Law, 28(4), 659-692.

Gross, R., Harrison, M. (2001). Implementing managed competition in Israel. Social Science \& Medicine, 52; 1219-1231.

Gruber, J. (2011a). The impacts of the Affordable Care Act: How reasonable are the projections? (Working Paper 17168). National Bureau of Economic Research.

Gruber, J. (2011b). Massachusetts points the way to successful health care reform. Journal of Policy Analysis and Management, 30(1), 184-192.

Gruber, J. (2008). Incremental universalism for the United States: The states move first? Journal of Economic Perspectives, 22(4), 51-68.

Gruber, J. (2004). Coverage and cost impacts of the president's health insurance tax credit and tax deduction proposals. Kaiser Family Foundation.

Gruber, J. \& Madrian, B.C. (2001, Jul). Health insurance, labor supply, and job mobility: A critical review of the literature. Prepared for "Research Agenda Setting Conference," University of Michigan. National Bureau of Economic Research.

Grumbach, K. \& Mold, J.W. (2009). A health care cooperative extension service: Transforming primary care and community health. Journal of the American Medical Association, 301(24), 2589-2591. 
Gunning, J.P. (2003). Rent Seeking [textbook chapter]. Available online (May 7, 2007): www.gunning.cafeprogressive.com/votehtm/vm-16.htm

Guyatt, G.H. (1991). Evidence-based medicine. ACP Journal Club, 114; A16.

Hackey, R.B. (1998). Rethinking health care policy: The new politics of state regulation. Washington, DC: Georgetown University.

Hadley, J. (2003). Sicker and poorer-the consequences of being uninsured: A review of the research on the relationship between health insurance, medical care use, health, work, and income. Medical Care Research and Review, 80(2 suppl), 3S$75 \mathrm{~S}$.

Hadley, J. \& Holahan, J. (2003). How much medical care do the uninsured use, and who pays for it? Health Affairs Web Exclusives (Feb 12), W3-66 to W3-81. Alternate version: Who pays and how much? The cost of caring for the uninsured. Kaiser Family Foundation.

Hadley, J. \& Reschovsky, J.D. (2002). Small firms' demand for health insurance: The decision to offer insurance. Inquiry, 39; 118-137.

Hadorn, D. (1996). The Oregon priority-setting exercise: Cost-effectiveness and the rule of rescue, revisited. Medical Decision Making, 16(2), 117-119.

Haines, V.Y., Merrheim, G. \& Roy, M. (2001). Understanding reactions to safety incentives. Journal of Safety Research, 32, 17-30.

Hall, M.A. (2002). Of magic wands and kaleidoscopes: Fixing problems in the individual market. Health Affairs Web Exclusives, 353-358.

Hall, M. (2000a). The structure and enforcement of health insurance rating reforms. Inquiry, 37(4), 376-388.

Hall, M. (2000b). The geography of health insurance regulation. Health Affairs, 19(2), 173-184.

Hall, M. (2000c). The role of independent agents in the success of health insurance market reforms. Milbank Quarterly, 78(1), 23-45.

Hall, M.A. (1992). The political economics of health insurance market reform. Health Affairs, 11(2), 108-124.

Hall, M.A., Wicks, E.K. \& Lawlor, J.S. (2001). HealthMarts, HIPCs, MEWAs, and AHPs: A guide for the perplexed. Health Affairs, 20(1), 142-153. 
Halvorson, G.C. \& Isham, G.J. (2003). Epidemic of care: A call for safer, better, and more accountable health care. San Francisco: Jossey-Bass.

Ham, C. (2004). Health policy in Britain (5th ed.). New York: Palgrave MacMillan.

Hamer, R. \& Anderson, D. (2000). PPO operations and markets. InterStudy Publications.

Hamerow, T.S. (1969). The social foundations of German unification, 1858-1871: Ideas and institutions. Princeton NJ: Princeton University.

Hamm K. (1986). The role of subgovernments in U.S. state policy making: An exploratory analysis. Legislative Studies Quarterly 11;321-351.

Hamm, K. (1983). Patterns of influence among committees, agencies, and interest groups. Legislative Studies Quarterly, 8(3), 379-426.

Hammond, T. (2004). Road to revolution: Kitzhaber stirs citizens to act. The Probe (Summer), 1. Oregon Public Health Association. Available online (July 18, 2005): www.oregonpublichealth.org

Hansen, J.J. (2003). Limits of competition: Accountability in government contracting. Yale Law Journal, 112(8), 2465-2507.

Hansen, Z. \& Law, M. (2006). The political economy of "truth-in-advertising” regulation during the Progressive Era (Working Paper 11927). National Bureau of Economic Research.

Hardy, B., Mur-Veemanu, I., Steenbergen, M. \& Wistow, G. (1999). Inter-agency services in England and the Netherlands: A comparative study of integrated care development and delivery. Health Policy, 48;87-105.

Harring, S.L. (1977). Class conflict and the suppression of tramps in Buffalo, 1892-1894. Law \& Society Review, 11(5), 873-911.

Harrington, S.E. (2000). Insurance rate regulation in the 20th century. Journal of Insurance Regulation, 19(2), 204-218.

Harvard Managed Care Industry Center Group. (2002). Managed care: An industry snapshot. Inquiry, 39; 207-220.

Hasenfeld, Y. (1985). The administration of human services. Annals of the American Academy of Political and Social Science, 479; 67-81. 
Hawryluk, M. (2010, June 10). Rationing health care: OHP's prioritized list of services helps control costs, but some question whether it's balanced. The Bend Bulletin. Available online (Jul 6, 2011): www.oregonrepublicanparty.org/node/452

Head, S. (2011). The grim threat to British universities. New York Review, 58(1),58-64.

Health Security Act. (1994). Available online (Jun 18, 2004): www.gettysburg.edu/ kmott/pol101/index4.html

Heaney, M.T. (2006). Brokering health policy: Coalitions, parties, and interest group influence. Journal of Health Politics, Policy and Law, 31(5), 887-929.

Heclo, H. (1978). Issue networks and the executive establishment. In A. King (Ed.), The new American political system. American Enterprise Institute.

Heffler, S., Smith, S., Keehan, S., Clemens, M.K., Won, G. \& Zezza, M. (2003). Health spending projections for 2002-2012. Health Affairs Web Exclusives (Feb 7), 5465.

Hegel, G.W.F. (1942/1821). Philosophy of right (Tr. T.M. Knox). New York: Oxford University.

Heget, J.R., Bagian, J.P., Lee, C.Z. \& Gosbee, J.W. (2002). System innovation: Veterans Health Administration National Center for Patient Safety. Joint Commission Journal on Quality Improvement, 28(12), 660-665.

Heider, D. \& Dietz, D. (1995). Legislative perspectives: A 150-year history of the Oregon legislatures from 1843 to 1993. Portland: Oregon Historical Society.

Helfand, M. (1992). Screening for thyroid dysfunction. In E.L. Mazzaferri (Ed.), Advances in Endocrinology and Metabolism (Vol. 3), (p. 271-308). St. Louis MO: Mosby Year Book.

Helms, W.D., Gauthier, A.K. \& Campion, D.M. (1992). Mending the flaws in the smallgroup market. Health Affairs, 11(2), 7-27.

Henderson, C.R. (1908). Social cost of accident, ignorance and exhaustion. Annals of the American Academy of Political and Social Science, 32(sup. 22), 11-18.

Henderson, C.R. (1907). Industrial insurance VI: Private insurance companies. American Journal of Sociology, 13(3), 349-379.

Hendricks, R. (1991). Medical practice embattled: Kaiser Permanente, the American Medical Association, and Henry J. Kaiser on the West Coast, 1945-1955. Pacific Historical Review, 60(4), 439-473. 
Hendriks, M., de Jong, J.D., van de Brink-Mulnen, A. \& Groenewegen, P.P. (2009). The intention to switch health insurer and actual switching behaviour: Are there differences between groups of people? Health Expectations, 13; 195-207.

Heslop, L., Elsom, S. \& Parker. (2000). Improving continuity of care across psychiatric and emergency services: Combining patient data within a participatory action research framework. Journal of Advanced Nursing, 31(1), 135-143.

Hess, C., Schwartz, S., Rosenthal, J., Snyder, A. \& Weil, A. (2008). States' roles in shaping high performance health systems (Pub. No. 1115). The Commonwealth Fund.

Hester, J.A. (2001). Individual-based risk adjustment by health insurers: Needs, options, and methods. Inquiry, 38(Fall), 310-314.

Hibbard, J.H. \& Peters, E. (2003). Supporting informed consumer health care decisions: Data presentation approaches that facilitate the use of information in choice. Annual Review of Public Health, 24; 413-33.

Hibbard, J.H., Stockard, J. \& Tusler, M. (2003). Does publicizing hospital performance stimulate quality improvement efforts? Health Affairs, 22(2), 84-94.

Hillman, B.J. \& Goldsmith, J. (2010). Imaging: The self-referral boom and the ongoing search for effective policies to contain it. Health Affairs, 29(12), 2231-2236.

Himmelstein, D.U., Warren, E., Thorne, D. \& Woolhandler, S. (2005). Illness And injury as contributors to bankruptcy. Health Affairs Web Exclusives (Feb 2), 63-73.

Hirsch, W.Z. \& Rufolo, A.M. (1990). Public finance and expenditure in a federal system. San Diego: Harcourt Brace Jovanovich.

Hock, D. (1999). Birth of the Chaordic Age. San Francisco: Berrett-Koehler.

Hodge, G.A. (1999). Competitive tendering and contracting out: Rhetoric or reality? Public Productivity \& Management Review, 22(4), 455-469.

Holahan, J. \& Blumberg, L. (2009). Massachusetts health reform: Solving the long-run cost problem. Robert Wood Johnson Foundation/Urban Institute.

Holahan, J. \& Cook, A. (2009). Changes in health insurance coverage, 2007-2008: Early impact of the recession [Issue brief]. Kaiser Family Foundation.

Holahan, J. \& Pohl, M.B. (2002). Changes in insurance coverage: 1994-2000 and beyond. Health Affairs Web Exclusives, 162-171. 
Holm, S. (1998). Goodbye to simple solutions: The second phase of priority setting in health care. British Medical Journal, 317; 1000-1007.

Holsinger, M.P. (1968). The Oregon School bill controversy, 1922-1925. Pacific Historical Review, 37(3), 327-341.

Holtz-Eakin, D. (2011). Does Massachusetts health care reform point to success with national reform? Journal of Policy Analysis and Management, 30(1), 178-184.

Homedes, N. \& Ugalde, A. (Ed.). (2006). Decentralizing health services in Mexico: A case study in state reform. La Jolla CA: University of California, San Diego, Center for U.S.-Mexican Studies.

Hornbrook, M.C. (2000). Commentary. Medical Care Research and Review, 57(2), 243251.

Horstman, K. (2001). Public bodies private lives: The historical construction of life insurance, health risks, and citizenship in the Netherlands, 1880-1920.

Rotterdam: Erasmus Publishing.

Hrebenar R.J. \& Thomas, C.S. (Ed.).(1987). Interest group politics in the American West. Salt Lake City: University of Utah.

Hudson, K. \& Coukos, A. (2005). The dark side of the Protestant ethic: A comparative analysis of welfare reform. Sociological Theory, 23(1), 1-24.

Hughes, R.A. \& Rissi, J.J. (2004). (2004). Arizona can! Coverage and access now. Arizona Health Futures. St. Luke's Health Initiatives.

Huntington, J., Gillam, S., Rosen, R. (2000). Organizational development for clinical governance. BMJ 321(16 Sep), 679-682.

Hurley, R., Grossman, J., Lake, T. \& Casalino, L. (2002). A longitudinal perspective on health plan-provider risk contracting. Health Affairs, 21(4), 144-153.

Hurley, R., Strunk, B.C. \& White, J.S. (2004). The puzzling popularity of the PPO. Health Affairs, 23(2), 56-68.

Huskamp, H.A., Epstein, A.M. \& Blumenthal, D. (2003). The impact of a national prescription drug formulary on prices, market share, and spending: Lessons from Medicare? Health Affairs, 22(3), 149-158.

Iatridis, D.S. (Ed.). (2000). Social justice and the welfare state in Central and Eastern Europe: The impact of privatization. Westport CT: Praeger. 
Iglehart, J.K. (Ed.). (2004). Variations revisited [Special issue]. Health Affairs Web Exclusives.

Iglehart, J.K. (1997). Interview: State regulation of managed care: NAIC President Josephine Musser. Health Affairs, 16(6), 36-43.

Iglehart, J.K. (1993). Managed competition. New England Journal of Medicine, 328(16), 1208-1212.

Ikenberry, G.J. \& Skocpol, T. (1987). Expanding social benefits: The role of Social Security. Political Science Quarterly, 102(3), 389-416.

Ingber, M.J. (2000). Implementation of risk adjustment for Medicare. Health Care Financing Review, 21(3), 119-126.

Institute of Medicine (IOM). (2004). Insuring America's health: Principles and recommendations. Washington DC: National Academies. Final volume of six, beginning in 2001. Other titles available online (Dec 3, 2003): www.iom.edu/report/asp?id=12313

Institute of Medicine. (2003a). Hidden Costs, Value Lost: Uninsurance in America. Washington DC: National Academies.

Institute of Medicine. (2003b). Priority areas for national action: Transforming health care quality. Washington DC: National Academies.

Institute of Medicine. (2002). Fostering Rapid Advances in Health Care. Washington DC: National Academies.

Institute of Medicine. (2001). Crossing the quality chasm. Washington DC: National Academies.

Institute of Medicine. (2000). To Err is human. Washington DC: National Academy.

Institute of Medicine. (1996). Primary care: America's health in a new era. Washington DC: National Academy.

Jacobs, L., Marmor, T. \& Oberlander, J. (1999). The Oregon Health Plan and the political paradox of rationing: What advocates and critics have claimed and what Oregon did. Journal of Health Politics, Policy and Law, 24(1), 161-180.

Jacobson, P.D. (2009). The Role of ERISA preemption in health reform: Opportunities and limits. Journal of Law, Medicine \& Ethics, (Fall) 88-100. 
Jacobson, P.D. (2001). Regulating health care: From self-regulation to self-regulation? Journal of Health Politics, Policy and Law, 26(5), 1165-1177.

Jennings, B. (1992). Democratic values and health policy reform. In H.M. Leichter (Ed.), Health policy reform in America: Innovations from the states (1st ed.), 191-205.

Jensen, G.A. (1995). The impact of ERISA (Issue Brief No. 167). National Center for Policy Analysis.

Jensen, G.A. \& Morrisey, M.A. (1999). Employer-sponsored health insurance and mandated benefit laws. Milbank Quarterly, 77(4), 425-459.

Jha, A.K., DesRoches, C.M., Kralovec, P.D. \& Joshi, M.S. (2010). A progress report on electronic health records in U.S. hospitals. Health Affairs, 29(10), 1951-1957.

Johnson, P. (2003). Medicaid: Access to health services. Year-end report-2002 [Issue brief]. Health Policy Tracking Service.

Johnson, H. \& Broder, D.S. (1996). The system: The American way of politics at the breaking point. Boston: Little Brown.

Johnston, M. (1982). Political corruption and public policy in America. Monterey CA: Brooks/Cole.

Johnston, R.D. (1998). The myth of the harmonious city: Will Daly, Lora Little, and the hidden face of Progressive-era Portland. Oregon Historical Quarterly, 99(3), 248297.

Johri, M., Beland, F. \& Bergman, H. (2003). International experiments in integrated care for the elderly: A synthesis of the evidence," International Journal of Geriatric Psychiatry, 18(3), 222-235.

Jones, K., Welch, E., Caiels, J., Windle, K., Forder, J., Davidson, J. et al. (2010). Experiences of implementing personal health budgets: 2nd interim report (PSSRU Discussion Paper 2747/2). London: Department of Health.

Josephy, A.M. (1965). The Nez Perce Indians and the opening of the Northwest. New Haven: Yale University.

Jost, T.S. (2009). Health insurance exchanges in health reform: Legal and policy issues. The Commonwealth Fund. 
Journal of the American Medical Association (JAMA). (2000). Unreliability of physician 'report cards' to assess cost and quality of care [Letters by E.D. Huff, L.G. Sandy, K.G. Shojania, J.E. Wennberg; reply by Hofer et al.; reply by Bindman, A.]. Journal of the American Medical Association, 283(1), 51-54.

Joyce, J.S., Cioffi, G.A., Petriwsky, J.G. \& Robinson, J.S. (2011). Legacy Health's 'Big Aims' initiative to improve patient safety reduced rates of infection and mortality among patients. Health Affairs, 30(4), 619-626.

Kaiser Family Foundation (KFF). (2011). Key questions about Medicaid and its role in state/federal budgets and health reform. KFF.

Kaiser Family Foundation \& eHealth Insurance. (2004). Update on individual health insurance. KFF.

Kaiser Family Foundation \& Harvard School of Public Health. (2002). Medical errors: Practicing physician and public views. KFF.

Kaiser Family Foundation \& Health Research and Educational Trust (KFF/HRET). (2010). Employer health benefits: Annual Survey. KFF.

Kaiser Family Foundation \& Health Research and Educational Trust. (2003). Employer health benefits: Annual Survey. KFF.

Kaiser Network (2006). Boston Globe examines influence of health care industry in brokering compromise on Massachusetts reform package (Mar 14). Daily Health Policy Report.

Kaiser Network. (2005). Washington Post examines lawsuits against hospitals for allegedly overcharging the uninsured (Jan 31). Also, Chicago Tribune examines charity care lawsuits against not-for-profit hospitals (Jan 26). Daily Health Policy Report.

Kaiser Network. (2004). Baltimore Sun examines hospitals' billing systems, effect of collection tactics (Sep 14). Also, Newspapers examine hospital billing and collections practices for the uninsured (Jun 24). Daily Health Policy Report.

Kaiser Permanente Institute for Health Policy. (2000 Mar). Roundtable discussion: Reporting as a means to improve patient safety. Available online (Apr 27, 2005): www.kpihp.org/publications/briefs/reporting_means.pdf:

Kaiser Permanente Northwest Division. (1999). The comprehensive computer-based patient record (CPR). The Permanente Journal, 3(2), 13-24. 
Kan, H. (2002). Does the Medicare Principal Inpatient Diagnostic Cost Group Model adequately adjust for selection bias? [Dissertation]. RAND Graduate School.

Kapowich, J.M. (2010). Oregon's test of value-based insurance design in coverage for state workers. Health Affairs, 29(11), 2028-2032.

Kapur, K., Gresenz, C.R. \& Studdert, D.M. (2003). Managing care: Utilization review in action at two capitated medical groups. Health Affairs Web Exclusives (Jun 18), 275-282.

Katz, M.B. (1995). Improving poor people: The welfare state, the "underclass," and urban schools as history. Princeton NJ: Princeton University.

Katz, M.B.(1989). The undeserving poor: From the war on poverty to the war on welfare. New York: Pantheon.

Keenan, P.S., Buntin, M.J.B., McGuire, T.G. \& Newhouse, J.P. (2001). The prevalence of formal risk adjustment in health plan purchasing. Inquiry 38, 245-259.

Keller, M. (1990). Regulating a new economy: Public policy and economic change in America, 1900-1933. Cambridge MA: Harvard University.

Keller, M. (1963). The life insurance enterprise, 1885-1910: A study in the limits of power. Belknap.

Kemper, P., Applebaum, R. \& Harrigan, M. (1987). Community care demonstrations: What have we learned? Health Care Financing Review, 8(4), 87-100).

Kenkel, P.J. (1991). Growth in self-insurance puts squeeze on Minnesota risk pool [Abstract]. Modern Healthcare, 21(34), 30.

Kessler, D. \& McClellan, M. (1996). Do doctors practice defensive medicine? Quarterly Journal of Economics, 111(2), 353-390.

Kimberly, J.R., de Pouvourville, G. \& D’Aunno, T. (Ed.). (2008). The globalization of managerial innovation in health care. New York: Cambridge University.

Kingdon, J.W. (1995). Agendas, alternatives, and public policies (2nd ed.). New York: Harper Collins.

Kitzhaber, J. (1989, May 11). Discussion paper, Senate Bill 27. Salem OR: Oregon State Senate.

Klarman, H.E. (1977). The financing of health care. Daedalus (Winter); 215-234. 
Klein, S. \& McCarthy, D. (2010). CareOregon: Transforming the role of a Medicaid health plan from payer to partner. The Commonwealth Fund.

Koen, V. (2000). Public expenditure reform: The health care sector in the United Kingdom (Economics Dept Working Paper No. 256). Organisation for Economic Cooperation and Development.

Kofman, M., Bangit, E. \& Lucia, K. (2004). MEWAs: The threat of plan insolvency and other challenges (Issue Brief). The Commonwealth Fund.

Kolstad, J. \& Chernew, M. (2009). Quality and consumer decision making in the market for health insurance and health care services. Medical Care Research and Review, $66(1), 28 \mathrm{~S}-52 \mathrm{~S}$.

Korn, L.M., Reichert, S., Simon, T. \& Halm, E.A. (2003). Improving physicians' knowledge of the costs of common medications and willingness to consider costs when prescribing," Journal of General Internal Medicine, 18(Jan.), 31-37.

Kornai, J. (1992). The socialist system: The political economy of Communism. Princeton NJ: Princeton University.

Kornai, J. \& Eggleston, K. (2001). Welfare, choice and solidarity in transition: Reforming the health sector in Eastern Europe. New York: Cambridge University.

Kornai, J., Haggard, S. \& Kaufman, R.R. (Ed.). (2001). Reforming the state. New York: Cambridge University.

Kornai, J. \& Rose-Ackerman, S. (Ed.). (2004). Building a trustworthy state in postsocialist transition. New York: Palgrave Macmillan.

Kotlikoff, L.J. \& Hagist, C. (2005). Who's going broke? Comparing healthcare costs in ten OECD countries (Working Paper 11833). National Bureau of Economic Research.

Kronick, R. (2001). Valuing charity. Journal of Health Politics, Policy and Law, 26(5), 993-1001.

Kronick, R. \& de Beyer, J. (Ed.). (1999). Medicare HMOs: Making them work for the chronically ill. Chicago: Health Administration Press.

Kronick, R., Goodman, D.C., Wennberg, J. \& Wagner,E. (1993). The marketplace in health care reform-The demographic limitations of managed competition. New England Journal of Medicine, 328(2), 148-152. 
Krueger, A.B. \& Reinhardt, U. (1994). The economics of employer- versus individual mandates. Health Affairs, 13(2), 34-53.

Kuhlmann, E. \& Burau, V. (2009). Managerial regimes meet the healthcare state: introduction and outlook. Journal of Health Organization and Management, 23(3), [guest editorial, no page number provided].

Kurtzman, E.T., O’Leary, D., Sheingold, B.H., Devers, K.J., Dawson, E.M. \& Johnson, J.E. (2011). Performance-based payment incentives increase burden and blame for hospital nurses. Health Affairs, 30(2), 211-218.

Kuttner, R. (1998). The risk-adjustment debate. The New England Journal of Medicine, 339(26), 1952-1956.

Lakdawalla, D. \& Sood, N. (2006). Health insurance as a two-part pricing contract (Working Paper 12681). National Bureau of Economic Research.

Lake, T., Devers, K., Brewster, L. \& Casalino, L. (2003). Something old, something new: Recent developments in hospital-physician relationships. Health Services Research 38(1, Part 2), 471-488.

Lamb, R.M., Studdert, D.M., Bohmer, R.M.J., Berwick, D.M. \& Brennan, T.A. (2003). Hospital disclosure practices: Results of a national survey. Health Affairs, 22(2), 73-83.

Lamers, L.M. (2001). Health-based risk adjustment: Is inpatient and outpatient diagnostic information sufficient? Inquiry, 38, 423-431.

Landon, B.E., Gill, J.M., Antonelli, R.C. \& Rich, E.C. (2010). Prospects for rebuilding primary care using the patient-centered medical home. Health Affairs, 29(5), 827834.

Larsell, O. (1945). History of the care of the insane in the State of Oregon. Oregon Historical Quarterly, 46(4), 295-326.

Larson, J.S. \& Larson, K.K. (2002). Evaluating end-of-life care from the perspective of the patients family. Evaluation \& the Health Professions, 25(2), 143-151.

Laschober, M.A., Kitchman, M., Neuman, P. \& Strabic, A.A. (2002). Trends in Medicare supplemental insurance and prescription drug coverage, 1996-1999. Health Affairs Web Exclusives (Feb 27), 127-138.

Lau, L. (2004). Oregon's first state-mandated uniform school readers. Oregon Historical Quarterly, 105(4), 20p. 
Laugesen M.J., Paul, R.R., Luft, H.S., Aubry, W. \& Ganiats, T.G. (2006). A comparative analysis of mandated benefit laws, 1949-2002. Health Services Research 41(3, Part II), 1081-1103.

Lawrence, D. (2010). How to forge a high-tech marriage between primary care and population health. Health Affairs, 29(5), 1004-1009.

Lawrence, D. (2002). From chaos to care: The promise of team-based medicine. Cambridge MA: Perseus.

Laws, K.E., Gabriel, R.M. \& McFarland, B.H. (2002). Integration and its discontents: Substance abuse treatment in the Oregon Health Plan. Health Affairs, 21(4), 284289.

Lazarou, J., Pomeranz, B.H. \& Corey, P.N. (1998). Incidence of adverse drug reactions in hospitalized patients. Journal of the American Medical Association, 279(15), 1200-1205.

Lecky, W.E.H. (1892/1969). A history of Ireland in the eighteenth century. New York: AMS.

Ledue, C. (2010, November 19). Doctors on coverage-Physicians' views on a new public insurance option and Medicare expansion. Healthcare Finance News. Available online (May 15, 2011): www.healthcarefinancenews.com/news/surveyphysicians-unh

Lee, A.F. (1987). Hawaii: Planters, public employees, and the public interest. In R.J. Hrebenar \& C.S. Thomas (Ed.), Interest group politics in the American West, 59-66. Salt Lake City: University of Utah.

Lee, S.D., Arozullah, A.M. \& Cho, Y.I. (2004). Health literacy, social support, and health: A research agenda. Social Science and Medicine, 58; 1309-1321.

Lee, J., Kim, H. \& Tanenbaum, S. (2006). Medicaid and family wealth transfer. The Gerontologist, 46(1), 6-13.

Legislative Revenue Office. (2004). Oregon public finance: Basic facts. Salem OR: Oregon Legislative Assembly.

Leichter, H.M. (2004). Obstacles to dependent health care access in Oregon: Health insurance or health care? Journal of Health Politics, Policy and Law, 29(2), 237268.

Leichter, H.M. (1999). Oregon's bold experiment: Whatever happened to rationing? Journal of Health Politics, Policy and Law, 24(1), 147-160. 
Leichter, H.M. (1997a). Health care reform in America: Back to the laboratories. In H.M. Leichter (Ed.), Health policy reform in America: Innovations from the states (2nd ed.), p. 3-28.

Leichter, H.M. (1997b). Rationing of health care in Oregon: Making the implicit explicit. In H.M. Leichter (Ed.), Health policy reform in America: Innovations from the states (2nd ed.), p. 138-162.

Leichter, H.M. (Ed.). (1997c). Health policy reform in America: Innovations from the states (2nd ed.). Armonk NY: M.E. Sharpe.

Lenert, L. (2010). Transforming healthcare through patient empowerment. In W.B. Rouse \& D.A. Cortese, Studies in Health Technology and Informatics: Vol. 153. Engineering the System of Healthcare Delivery, p. 159-175. Washington DC: IOS Press.

Levine, B. (1992). The migration of ideology and the contested meaning of freedom: German Americans in the mid-nineteenth century (Occasional Paper No. 7). Washington DC: German Historical Institute. Available online (Dec. 7, 2011): www.ghi-dc.org/publications/ghipubs/op/op07.pdf

Lewin, J.C., \& Sybinsky, P.A. (1993). Hawaii's employer mandate and its contribution to universal access. Journal of the American Medical Association, 269, 2538-2543.

Lewin Group. (1997). State regulatory experience with provider-sponsored organizations (Contract No. 100-93-0012). U.S. Department of Health and Human Services, Office of the Assistant Secretary for Planning and Evaluation. Available online (Jan 22, 2002): http://aspe.os.dhhs.gov/health/pso-6.htm

Liang, B.A. (2000). Creating problems as part of the "solution": The JCAHO Sentinel Event policy, legal issues, and patient safety. Journal of Health Law, 33(2), 263.

Liebman, C.B. \& Hyman, C.S. (2004). A mediation skills model to manage disclosure of errors and adverse events to patients. Health Affairs, 23(4), 22-32.

Liebman, J. \& Zeckhauser, R. (2008). Simple humans, complex insurance, subtle subsidies. In H.J. Aaron and L.E. Burman (ed.), Using taxes to reform health insurance: Pitfalls and promises. Washington D.C.: Brookings Institution.

Lieu, T.A., Solomon, J.L., Sabin, J.E., Kullgren, J.T., Hinrichsen, V.L. \& Galbraith, A.A. (2009). Consumer awareness and strategies among families with high-deductible health plans. Journal of General Internal Medicine, 25(3), 249-254.

Light, D.W. (1997). From managed competition to managed cooperation: Theory and lessons from the British experience. The Milbank Quarterly, 75(3), 297-341. 
Lipset, S.M. \& Marks, G. (2000). It didn't happen here: why socialism failed in the United States. New York: W.W. Norton.

Lischko, A.M., Bachman, S.S. \& Vangeli, A. (2009). The Massachusetts Commonwealth Health Insurance Connector: Structure and functions (Issue Brief). The Commonwealth Fund.

Liu, K., Doty, P. \& Manton, K. (1990). Medicaid spenddown in nursing homes. The Gerontologist, 30(1), 7-15.

Long, S.H. \& Marquis, M.S. (2002). Participation in a public insurance program: Subsidies, crowd-out, and adverse selection. Inquiry, 39(3), 243-257.

Long, S.H., \& Marquis, M.S. (1993). Gaps in employee coverage: Lack of supply or lack of demand? Health Affairs, 12(5), 282-292.

Lovern, E. (2001). Into the frying pan? Hospitals wary of plan to reform Medicare's contracting rules. Modern Healthcare, 31(33), p. 24, 4p.

Lowe, R.A., Fu, R. \& Gallia, C.A. (2010). Impact of policy changes on emergency department use by Medicaid enrollees in Oregon. Medical Care, 48(7), 619-627.

Lowe, R.A, McConnell, K.J., Fu, R., Weathers, C.C., Boyer-Quick, J., Adams, A.L. et al. (2006). Changes in access to primary care for Medicaid beneficiaries and the uninsured: The emergency department perspective. American Journal of Emergency Medicine 24, 33-37.

Lu, C.Y., Ross-Degnan, D., Soumerai, S.B. \& Pearson, S. (2008). Interventions designed to improve the quality and efficiency of medication use in managed care: A critical review of the literature. BMC Health Services Research, 8(1), 75-86.

Luft, H.S. (1999). Why are physicians so upset about managed care? Journal of Health Politics, Policy and Law, 24(5), 957-966.

Lupari M., Coates V., Adamson G., Crealey G.E. (2011). 'We're just not getting it right'-How should we provide care to the older person with multi-morbid chronic conditions? Journal of Clinical Nursing, 20(9-10), 1225-1235.

Lutz, S. \& Gee, E.P. (1995). The for-profit healthcare revolution: The growing impact of investor-owned health systems in America. Chicago: Healthcare 2000, Irwin.

Maarse, H. \& Paulus, A. (2003). Has solidarity survived? A comparative analysis of the effect of social health insurance reform in four European countries. Journal of Health Politics, Policy and Law, 28(4), 585-614. 
MacColl, E.K., with Stein, H. (1988). Merchants, money, and power: The Portland establishment, 1843-1913. Portland: Georgian.

MacColl, E.K. (1979). The Growth of a City: Power and politics in Portland, Oregon 1915-1950 Portland: Georgian.

Maciosek, M.V., Coffield, A.B., Flottemesch, T.J., Edwards, N.M. \& Solberg, L.I. (2010). Greater use of preventive services in U.S. health care could save lives at little or no cost. Health Affairs, 29(9), 1656-1660.

MacKinnon, N.J. \& Lipowski, E.E. (2000). Opinions on provider profiling: Telephone survey of views. American Journal of Health-System Pharmacy, 57(17), 1585-91.

Magasi, S., Durkin, E., Wolf, M.S. \& Deutsch, A. (2009). Rehabilitation consumers' use and understanding of quality information: A health literacy perspective. Archives of Physical Medicine and Rehabilitation, 90, 206-12.

Mahar, M. (1993, Mar 1). Memo to Hillary: How to cure what ails our health-care system. Barron's, $8 \mathrm{ff}$.

Maio, V., Goldfarb, N.I., Carter, C. \& Nash, D.B. (2003). Value-based purchasing: A review of the literature. The Commonwealth Fund.

Makover, M.E. (1998). Mismanaged care: How corporate medicine jeopardizes your health. Amherst NY: Prometheus Books.

Mann, C. \& Artiga, S. (2004, June). The impact of recent changes in health care coverage for low-income people: A first look at the research following changes in Oregon's Medicaid program (Issue Paper). Kaiser Family Foundation.

Mannheim, K. (1954/1929-31). Ideology and utopia: An Introduction to the sociology of knowledge. New York: Harcourt.

Mannion, R. \& Davies, H.T.O. (2002). Reporting health care performance: Learning from the past, prospects for the future. Journal of Evaluation in Clinical Practice, 8(2), 215-228.

Mapes, J. (1994). Oregon Health Plan faces trouble. The Oregonian (Nov 10), C1.

Marchev, M., Rosenthal, J. \& Booth, M. (2003). How states report medical errors to the public: Issues and barriers. National Academy for State Health Policy. Available online (Apr 30, 2005): www.nashp.org

Marmor, T. (2001). Fads and fashions in medical care policy and politics. The Nuffield Trust. 
Marmor, T.R., \& Goldberg, M. (1994). American health care reform: Separating sense from nonsense. In Understanding Health Care Reform, 1-18.

Marmor, T.R., \& Hamburger, T. (1994). The missing alternative: How Washington elites pushed single-payer reform plans off the agenda. In T.R. Marmor (Ed.), Understanding Health Care Reform, 159-169. New Haven: Yale University.

Marquis, M.S. \& Long, S.H. (1999). Trends In managed care and managed competition, 1993-1997. Health Affairs, 18(6), 75-88.

Mason, J., Khunti, K., Stone, M., Farooqi, A. \& Carr, S. (2008). Educational interventions in kidney disease care: A systematic review of randomized trials. American Journal of Kidney Diseases, 51(6), 933-951.

Massachusetts Taxpayers Foundation. (2009). Massachusetts health reform: The myth of uncontrolled costs. Boston MA.

Masson, V. (2010). Why I don't get mammograms. Health Affairs, 29(10), 1958-1960.

Mastrolanni, A.C., Mello, M.M., Sommer, S., Hardy, M. \& Gallagher, T.H. (2010). The flaws in state 'apology' and 'disclosure' laws dilute their intended impact on malpractice suits. Health Affairs, 29(9), 1611-1619.

Maxwell, S., Storeygard, M. \& Moon, M. (2002). Modernizing Medicare cost-sharing: Policy options and impacts on beneficiary and program expenditures. The Commonwealth Fund.

Mayer, A.J. (1981). The persistence of the old regime: Europe to the Great War. New York: Pantheon Books.

Mays, G.P., Claxton, G. \& White, J. (2004). Managed care rebound? Recent changes in health plans' cost containment strategies. Health Affairs Web Exclusives (Aug 11), 427-436.

McClellan, M. (2011). Reforming payments to healthcare providers: The key to slowing healthcare cost growth while improving quality? Journal of Economic Perspectives, 25(2), 69-92.

McClellan, M., McKethan, A.N., Lewis, J.L., Roski, J. \& Fisher, E.S. (2010). A national strategy to put accountable care into practice. Health Affairs, 29(5), 982-990.

McConnell, K.J., Wallace, N.T., Gallia, C.A. \& Smith, J.A. (2008). Effect of eliminating behavioral health: Benefits for selected Medicaid enrollees. Health Services Research 43(4), 1348-1365. 
McCormick, D., Himmelstein, D.U., Woolhandler, S., Wolfe, S.M. \& Bor, D.H. (2002). Relationship between low quality-of-care scores and HMOs' subsequent public disclosure of quality-of-care scores. Journal of the American Medical Association, 288(12), 1484-1490.

McDonough, J.E. (1997). Tracking the demise of state hospital rate setting. Health Affairs, 16(1), 142-149.

McGivern, G. \& Fischer, M. (2010). Medical regulation, spectacular transparency and the blame business. Journal of Health Organization and Management, 24(6), 597610.

McGlynn, E.A. (2003). Introduction and overview of the conceptual framework for a National Quality Measurement and Reporting System. Medical Care, 41(1 suppl), I1-7.

McLagan, E. (1980). A peculiar paradise: A history of blacks in Oregon, 1788-1940. Portland: Georgian.

McNeill, D. (2004). Do consumer-directed health benefits favor the young and healthy? Health Affairs, 23(1), 186-193.

Meador, M. (2011). Squeezing the middleman: Ending underhanded dealing in the pharmacy benefit management industry through regulation. Annals of Health Law, 20(1), 77-112.

Mechanic, D. (2003). Physician discontent: Challenges and opportunities. Journal of the American Medical Association, 290(7), 941-946.

Mechanic, D. \& McAlpine, D.D. (2010). Sociology of health care reform: Building on research and analysis to improve health care. Journal of Health and Social Behavior, 51(S), S147-S159.

Medicare Current Beneficiary Survey. (1999). Tables 3-1 and 3-2. Available online (Dec 3, 2003): http://cms.hhs.gov/MCBS

Medicare Payment Advisory Commission (MedPAC). (2010). Medicare payment policy. Washington DC.

Medicare Payment Advisory Commission (MedPAC). (2003). Medicare payment policy. Washington DC.

Medicare Payment Advisory Commission. (2002). Medicare beneficiaries' access to hospice. Washington DC. 
Mehrotra, A., Bodenheimer, T. \& Dudley, A. (2002). Employers' efforts to measure and improve hospital quality: Determinants of success. Health Affairs, 22(2), 60-71.

Mehta, R.H. \& Eagle, K.A. (1), and Holmboe, E. (2). (2003). Physician opinion leaders have limited influence on adherence to best-practice guidelines [Commentary]. Evidence-based Healthcare, 7; 154-156.

Meier, K.J. (1988). The political economy of regulation: The case of insurance. Albany: State University of New York.

Mello, M.M., Chandra, A., Gawande, A.A. \& Studdert, D.M. (2010). National costs of the medical liability system. Health Affairs, 29(9), 1569-1584.

Meltzer, D., Chung, J. \& Basu, A. (2002). Does competition under Medicare prospective payment selectively reduce expenditures on high-cost patients? RAND Journal of Economics, 33(3), 447-468.

Mercer Government Human Services Consulting. (2003). A study of alternative rate-setting approaches for Oregon Health Plan fully-capitated plans. Final report to the Office for Oregon Health Policy and Research. Available online (Apr 17, 2004): www.ohppr.state.or.us/

Merlis, M. (2002). Family out-of-pocket spending for health services: A continuing source of financial insecurity. Task Force on the Future of Health Insurance. The Commonwealth Fund.

Messing, J. (1966). Public Lands, politics, and progressives: The Oregon land fraud trials, 1903-1910. Pacific Historical Review, 35(1), 35-66.

Metzger, J., Welebob, E., Bates, D.W., Lipsitz, S. \& Classen, D.C. (2010). Mixed results in the safety performance of computerized physician order entry. Health Affairs, 29(4), 655-663.

Meyer, B.H. (1901). Fraternal beneficiary societies in the United States. American Journal of Sociology, 6(5), 646-661.

Meyerhoefer, C.D. \& Zuvekas, S.H. (2010). New estimates of the demand for physical and mental health treatment. Health Economics, 19, 297-315.

Milbank Memorial Fund. (2001). Value purchasers in health care: Seven case studies. New York.

Milbank Memorial Fund. (2000). Better information, better outcomes? The use of health technology assessment and clinical effectiveness data in health care purchasing decisions in the United Kingdom and the United States. New York. 
Miles, A., Bentley, P., Polychronis, A., Grey, J. \& Melchiorri, C. (2001). Recent developments in the evidence-based healthcare debate. Journal of Evaluation in Clinical Practice, 7(2), 85-89.

Miller, E.A. (2011). Flying beneath the radar of health reform: The Community Living Assistance Services and Supports (CLASS) Act. The Gerontologist, 51(2), 145155.

Miller, E.A., Mor, V. \& Clark, M. (2010). Reforming long-term care in the United States: Findings from a national survey of specialists. The Gerontologist, 50(2), 238-252.

Miller, E.G. (1958). Clatsop County, Oregon: A history. Portland: Binfords \& Mort.

Millis, H.A. (1908). Business and professional taxes as sources of local revenue. Journal of Political Economy, 16(2), 76-87.

Millis, H.A. (1898a). The law relating to the relief and care of dependents: I. American Journal of Sociology, 3(3), 378-391.

Millis, H.A. (1898b). The law relating to the relief and care of dependents: III. Immigrants and tramps. American Journal of Sociology, 3(5), 631-648.

Minnesota Department of Health. (1999). Uncompensated health care in Minnesota: An interim report to the legislature. Health Economics Program. Available online (Apr 30, 2005): www.health.state.mn.us/divs/hpsc/hep/reports/uncompcare99.pdf

Monheit, A.C., \& Short, P.F. (1989). Mandating health coverage for working Americans. Health Affairs, 8(4), 22-28.

Monheit, A.C. \& Vistnes, J.P. (2005). The demand for dependent health insurance: How important is the cost of family coverage? Journal of Health Economics 24(6), 1108-1131.

Moon, M. (1996). Medicare now and in the future (2nd ed.). Washington DC: The Urban Institute.

Moon, M., Nichols, L.M. \& Wall, S. (1996). Medical savings accounts: A policy analysis. The Urban Institute. Available online (Apr 30, 2005): www.urban.org/UploadedPDF/msa.pdf

Morone, J.A. (1995). Elusive community: Democracy, deliberation, and the reconstruction of health policy. In M.K. Landy \& M.A. Levin (Ed.), The new politics of public policy. Baltimore: John Hopkins University. 
Morone, J.A. (1992). The bias of American politics: Rationing health care in a weak state. University of Pennsylvania Law Review, 140(5), 1923-1938.

Mullen, K.J., Frank, R.G. \& Rosenthal, M.B. (2009). Can you get what you pay for? Payfor-performance and the quality of healthcare providers (Working Paper 14886). National Bureau of Economic Research.

Murray, R. (2009). Setting hospital rates to control costs and boost quality: The Maryland experience. Health Affairs, 28(5):1395-405.

Musgrave, R.A. (1997). Devolution, grants, and fiscal competition. Journal of Economic Perspectives, 11(4),65-72.

Myers, K.D. (1995). False security: Greed and deception in America's multibilliondollar insurance industry. Amherst NY: Prometheus Books.

Myles, J. (1989). Old age in the welfare state: The political economy of public pensions (Revised edition). University Press of Kansas.

Naderi, P.S.D. \& Meier, B.D. (2010). Privatization within the Dutch context: A comparison of the health insurance systems of the Netherlands and the United States. Health, 14(6), 603-618.

Narine, L., Senathirajah, M. \& Smith, T. (1999). Evaluating reference-based pricing: Initial findings and prospects. Canadian Medial Journal, 161(3), 286-288.

Nash, G.D. (1971). Bureaucracy and reform in the West: Notes on the influence of a neglected interest group. Western Historical Quarterly, 2(3), 295-305.

Nash, G.D. (1964). Government and business: A case study of state regulation of corporate securities, 1850-1933. Business History Review, 38(2), 144-162.

National Academy of Social Insurance (NASI). (2003). Medicare in the 21 st century: Building a better chronic care system.

National Academy of Social Insurance. (2002). Improving Medicare's governance and management.

National Association for Home Care. (2000). Crisis in home care: Dismantling of the Medicare home health benefit. Available online (Aug. 18, 2003): www.nahc.org/nahc/legreg/Crisis/crisishh.html

National Committee for Quality Assurance. (NCQA). (2003). The state of health care quality, 2003: Industry trends and analysis. Available online (Oct 20, 2003): www.ncqa.org 
National Conference of State Legislatures. (2011). Certificate of need: State health laws and programs. Available online (May 15, 2011):

www.ncsl.org/default.aspx ?tabid=14373

National Conference of State Legislatures. (2005). Universal health care: 2005 legislation. Available online (Feb 4, 2006): www.ncsl.org/programs/health/universalhealth.htm

Naylor, C.D. (1995). Grey zones of clinical practice: Some limits to evidence-based medicine. Lancet, 345(Apr 1), 840-842.

Nelson, H.D., Helfand, M., Woolf, S.H. \& Allan, J.D. (2002). Screening for postmenopausal osteoporosis: A review of the evidence for the U.S. Preventive Services Task Force. Annals of Internal Medicine, 137(6), 529-543.

NERA. (1995). The Oregon Health Plan economic impact analysis on the employer mandate. Los Angeles: National Economic Research Associates.

Neubauer, D. (1997). Hawaii: The health state revisited. In H.M. Leichter (Ed.), Health Policy Reform in America (2nd ed.), 163-188. Armonk NY: M.E. Sharpe.

Neuschler, E. (1990). Canadian health care: The implications of public health insurance. Health Insurance Association of America.

Newhouse, J.P. (2004). Consumer-directed health plans and the RAND Health Insurance Experiment. Health Affairs, 23(6), 107-113.

Newhouse, J.P. (1994). Patients at risk: Health reform and risk adjustment. Health Affairs, 13(1), 132-146.

Newhouse, J.P. \& the Insurance Experiment Group. (1993). Free for all? Lessons from the RAND Health Insurance Experiment. Cambridge MA: Harvard University.

Nichols, L (2009, July 16). Competition in the healthcare marketplace. Statement for the U.S. Senate Committee on Commerce, Science and Transportation. Washington DC.

Nichols, L. (2000). State regulation: What have we learned so far? Journal of Health Politics, Policy and Law, 25(1), 175-196.

Noble, C. (1997). Welfare as we knew it: A political history of the American welfare state. New York: Oxford University.

Nownes, A.J. \& Freeman, P. (1998). Interest group activity in the states. Journal of Politics, 60(1), 86-112. 
Nyman, J.A. (2004). Is 'moral hazard' inefficient? The policy implications of a new theory. Health Affairs, 23(5), 194-199.

Oberlander, J. (2006, December 19). Health reform interrupted: The unraveling of the Oregon Health Plan. Health Affairs Web Exclusives, w96-w105.

O'Brien, K.B. Jr. (1961). Education, Americanization and the Supreme Court: The 1920s. American Quarterly, 13(2-Part 1), 161-171.

O’Connell, J. (2007). Binding Early Offers versus Caps for Medical Malpractice Claims? Milbank Quarterly, 85(2), 287-296.

O’Connell, J. (1975). Ending insult to injury: No-fault insurance for products and services. Urbana: Illinois University.

Office of Inspector General. (2001). Medicare beneficiary access to skilled nursing facilities. U.S. Department of Health and Human Services.

Office of Medical Assistance Programs. (2006). Oregon Health Plan: An historical overview. Oregon Department of Human Services. Available online (July 6, 2011): www.oregon.gov/OHA/healthplan/data_pubs/ohpoverview0706.pdf?ga=t

Office of Technology Assessment. (1992). Evaluation of the Oregon Medicaid proposal [OTA-H-531]. U.S. Congress. Washington, DC: U.S. Government Printing Office.

Ofri, D. (2010). Ashamed to admit it: Owning up to medical error. Health Affairs, 29(8), 1549-1551.

Okma, K.G.H. (2008). Learning and mislearning across borders: What can we (not) learn from the 2006 health care reform in the Netherlands? Journal of Health Politics, Policy and Law, 33(6), 1057-1071.

Okma, K.G.H. (2001). Health care, health policies and health care reforms in the Netherlands. The Hague: Ministry of Health, Welfare and Sport-the Netherlands. Available online (June 12, 2004): www.healthlaw.nl/index2.html

Oleinik, A. (2011). Mixing quantitative and qualitative content analysis: Triangulation at work. Quality \& Quantity, 45(4), Pages 859-873.

Oliver, T.R. (2004) Policy entrepreneurship in the social transformation of American medicine: The rise of managed care and managed competition. Journal of Health Politics, Policy and Law, 29(4-5), 701-733. 
Oliver, T.R. (2000). Dynamics without change: The new generation. Journal of Health Politics, Policy and Law, 25(1), 225-232.

Oliver, T. (1999). The dilemmas of incrementalism: Logical and political constraints in the design of health insurance reforms. Journal of Policy Analysis and Management, 18; 652-683.

Oliver, T.R. \& Dowell, E.B. (1994). Interest groups and health reform: Lessons from California. Health Affairs, 13(2), 123-141.

Oliver, T.R. \& Fiedler, R.M. (1997). State government and health insurance market reform. In H.M. Leichter (Ed.), Health policy reform in America: Innovations from the states (2nd ed.). Armonk NY: M.E. Sharpe.

Oliver, T.R. \& Paul-Shaheen, P. (1997). Translating ideas into actions: Entrepreneurial leadership in state health care reforms. Journal of Health Politics, Policy and Law 22(3), 721-88.

Olsen, K.A., VanDerhei, J., Salisbury, D.L., Holmer, M.R. (1999). How do individual Social Security accounts stack up? An evaluation using the EBRI-SSASIM2 policy simulation model. In D.L. Salisbury (Ed.), Beyond ideology: Are individual social security accounts feasible? (p. 185-213). Washington DC: Employee Benefit Research Institute.

Opdycke, S. (1999). No one was turned away: The role of public hospitals in New York City since 1900. New York: Oxford University.

Oregon AFLCIO. (n.d.). A legislative proposal for a pay-or-play rule to make employment-based health insurance a reality for all workers. Available online (Apr 23, 2004): www.oraflcio.unions-america.com/healthcare/coverage.htm

Oregon Business Council Healthcare Task Force. (2004). A new vision for health care. Available online (Jan 27, 2012): www.orbusinesscouncil.org/docs/OBC\%20Health\%20Care\%20White\%20Paper\% 20(Draft\%2012.6.04).pdf

Oregon Coalition of Health Care Purchasers. (2009). Report from the Oregon Healthcare Payment Reform Summit. Available online (May 23, 2011): www.ochcp.org/default.asp?id=93

Oregon Department of Consumer \& Business Services. (n.d.) History of workers' compensation and safe employment laws in Oregon. Available online (May 23, 2011): www.cbs.state.or.us/wcd/administration/history.html 
Oregon Department of Human Services (DHS). (n.d.). OHP Managed Care Enrollment Reports. Available online (Feb 3, 2003):

www.dhs.state.or.us/healthplan/data_pubs/enrollment

Oregon Department of Human Services. (2003). Oregon Health Plan Fully Capitated Health Plan Contract. Available online (Apr 17, 2004): www. dhs.state.or.us/healthplan/data_pubs/contracts

Oregon Employment Department. (2009). Administrative overview. Available online (May 23, 2011): www.sos.state.or.us/archives/recmgmt/sched/special /state/overview/20080008employmentadov.pdf

Oregon Health Fund Board. (2008). Aim high: Building a healthy Oregon. Available online (Jan 27, 2012): www.oregon.gov/OHA/OHPR/HFB/docs/Final_Report_12_2008.pdf?ga=t

Oregon Health Leadership Council. (2010, October). Progress report. Available online (May 15, 2011): www.orhealthleadershipcouncil.org

Oregon Health Plan Administrator. (1995a). Alternatives for increased health coverage (Report to the Legislature). Salem OR: Office of Health Plan Administrator.

Oregon Health Plan Administrator. (1995b). Employer based insurance and the employer mandate (Report to the Legislature). Salem OR: Office of Health Plan Administrator.

Oregon Health Plan Administrator. (1994). Medical savings accounts. Oregon Health Plan Policy \& Research. Available online (Dec 17, 2003): www.ohppr.state.or.us/docs/pdf/medsavings.pdf

Oregon Health Policy and Research (OHPR). (2009). Oregon's acute care hospitals: Capacity, utilization and financial trends. Available online (May 15, 2011): www.oregon.gov/OHPR

Oregon Health Policy and Research. (2005a). Rising number of uninsured in Oregon. Available online (Feb 6, 2006): www.oregon.gov/DAS/OHPPR/RSCH/docs/OPShealthinsurance2004.pdf

Oregon Health Policy and Research. (2005b). Trends in Oregon's health care market and the Oregon Health Plan.

Oregon Health Policy and Research. (2004a). Oregon's acute care hospitals: Capacity, utilization and financial trends, 1995 to 2003. Available online (Feb 6, 2006): www.oregon.gov/DAS/OHPPR/RSCH/docs/hspuncompcare03.pdf 
Oregon Health Policy and Research. (2004b). Issue brief: 2004 Oregon policymaker and staff survey. Available online (Aug 1, 2011): www.oregon.gov/OHA/OHPR/RSCH/docs/LegsBrief11.16.04.pdf?ga=t

Oregon Health Policy and Research. (2003). Oregon Health Plan Medicaid Demonstration Project Quarterly Report [Jan-Mar]. Available online (Apr 23, 2006): www.oregon.gov/DHS/healthplan/data_pubs/quarterly/q2003/1q03.pdf

Oregon Health Policy and Research. (2001). Oregon HRSA state planning grant: Final report. Available online (Oct 20, 2003): www.ohppr.state.or.us

Oregon Health Policy and Research. (1999). Analysis of Oregon health care safety net services. Available online (Oct 20, 2003): "Documents" at www.ohppr.state.or.us

Oregon Health Policy Commission. (2007). Road map for health care reform. Available online (Jan 27, 2012): www.oregon.gov/OHA/OHPR/HPC/OHPCReformRoadMapFINAL.pdf?ga=t

Oregon Health Services Commission. (2011). Prioritization of health services. Available online (Jan 27, 2012): www.oregon.gov/OHA/OHPR/HSC/docs/R/2011BR.pdf?ga=t

Oregon Housing and Community Services. (2008). Report on poverty. Salem OR.

Oregon Insurance Division. (2011, 2010a). Health insurance in Oregon. Department of Consumer \& Business Services.

Oregon Insurance Division. (2010b). Report for Oregon insurance complaints. Department of Consumer \& Business Services.

Oregon Insurance Division. (2004a). Statement of need and justification ... In the matter of temporarily adopting Oregon Administrative Rule (OAR) 836-014-0400, relating to formation of a marketing assistance plan. Available online (Apr 20, 2005): www.cbs.state.or.us/external/ins/docs/rules/recent_adopt/id082004_need.pdf

Oregon Insurance Division. (2004b). Consumers: Beware of unlicensed health insurance plans. Available online (Jul 24, 2005): www.cbs.state.or.us/external/ins/docs/consumer/erisa_unlicensed.htm

Oregon Insurance Division. (2003). Geographic average premium rates. Oregon Department of Consumer \& Business Services. Available online (Dec 2, 2003): www.cbs.state.or.us/external/ins/docs/healthun/gars.htm

Oregon Medical Assistance Programs (1993). The Oregon Health Plan. Salem OR. 
Oregon Medical Insurance Pool (OMIP). (2011). Stat pack. Available online (Apr 28, 2011): www.oregon.gov/OHA/OPHP/OMIP/docs/omip_stat_pack.pdf

Oregon Office of Rural Health. (2006). Definitions of rural and assessing healthcare needs. Available online (Apr 23, 2006):

www.ohsu.edu/oregonruralhealth/what_is_rural.html\#assessneeds

Oregon Progress Board. (2005). 2004 Oregon Population Survey. Available online (Apr 21, 2005): http://egov.oregon.gov/DAS/OPB/popsurvey.shtml\#2004_Oregon_Population_Su rvey

Orloff, A.S. \& Skocpol, T. (1984). Why not equal protection? Explaining the politics of public social spending in Britain, 1900-1911, and the United States, 1880s-1920. American Sociological Review, 49(6), 726-750.

Osborne, D. \& Plastrik, P. (1997). Banishing bureaucracy: The five strategies for reinventing government. Menlo Park CA: Addison-Wesley.

Palmer, E.N. (1944). Negro secret societies. Social Forces, 23(2), 207-212.

Pande, A.H., Ross-Degnan, D., Zaslavsky, A.M. \& Salomon, J.A. (2011). Effects of healthcare reforms on coverage, access, and disparities: Quasi-experimental analysis of evidence from Massachusetts. American Journal of Preventive Medicine, 4l(1), 18.

Park, C.H. (2000). Prevalence of employer self-insured health benefits: National and state variation. Medical Care Research and Review, 57(3), 340-360.

Parliamentary Assembly, Council of Europe. (2003). The reform of health care systems in Europe: Reconciling equity, quality and efficiency (Recommendation 1626). Available online (Apr 26, 2004): http://assembly.coe.int/documents/adoptedtext/ta03/erec1626.htm

Parrington, V.L. (1930). The beginnings of critical realism in America, 1860-1920 [Main currents in American thought (Vol. 3)]. New York: Harcourt, Brace and Company.

Patient Protection and Affordable Care Act. (2010). U.S. Government Printing Office. Available online (Jun 24, 2011): www.gpo.gov/fdsys/pkg/PLAW111publ148/html/PLAW-111publ148.htm

Patterson, J.T. (1969). The New Deal in the West. Pacific Historical Review, 38(3), 317327. 
Pauly, M.V. (Ed.). (1980). National health insurance. Washington DC: American Enterprise Institute for Public Policy Research.

Pauly, M.V. \& Nichols, L.M. (2002). The nongroup health insurance market: short on facts, long on opinions and policy disputes. Health Affairs Web Exclusives (Oct 23), 325-344.

Pauly, M.V. \& Percy, A.M. (2000). Cost and performance: A comparison of the individual and group health insurance markets. Journal of Health Politics, Policy and Law, 25(1), 10-26.

Peele, P.B., Lave, J.R., Black, J.T. \& Evans, J.H. (2000). Employer-sponsored health insurance: Are employers good agents for their employees? The Milbank Quarterly, 78(1), 5-21.

Peikes, D., Chen, A., Schore, J. \& Brown, R. (2009). Effects of care coordination on hospitalization, quality of care, and health care expenditures among Medicare beneficiaries. Journal of the American Medical Association, 301(6), 603-618.

Penning, M.J. (2002). Hydra revisited: Substituting formal for self- and informal in-home care among older adults with disabilities. The Gerontologist, 42(1), 4-16.

Peterson, M.A. (2004). Insurance coverage and the states. Journal of Health Politics, Policy and Law, 29(2), 173-175.

Peterson, M.A. (Ed.). (2000). The individual health insurance market [Special issue]. Journal of Health Politics, Policy and Law, 25(1).

Pfaff, M. \& Wassener, D. (2000). Germany. Journal of Health Politics, Policy and Law, 25(5), 907-914.

Phelps, C.E. (1980). National health insurance by regulation. In M.V. Pauly (ed.), National Health Insurance, 52-73. Washington DC: American Enterprise Institute.

Phillips, D.P. \& Bredder, C.C. (2002). Morbidity and mortality from medical errors: An increasingly serious public health problem. Annual Review of Public Health, 23; 135-150.

Physicians' Working Group for Single-Payer National Health Insurance. (2003). Proposal. Journal of the American Medical Association, 290(6), 798-805.

Pinchot, G. (1932). Utility regulation: Federal and state. Annals of the American Academy of Political and Social Science, 159(Part 1), 69-75. 
Pirenne, H. (1915). Early democracies in the Low Countries [tr. J.V. Saunders 2004 as Belgian democracy: Its early history]. Batoche Books.

Pirenne, H. (1914). The stages in the social history of capitalism. American Historical Review, 19(3), 494-515.

Pitts, S.R., Carrier, E.R., Rich, E.C. \& Kellerman, A.L. (2010). Where Americans get acute care: Increasingly, it's not at their doctor's office. Health Affairs, 29(9), 1620-1628.

Pollack, C.E., Gidengil, C. \& Mehrotra, A. (2010). The growth of retail clinics and the medical home: Two trends in concert or conflict? Health Affairs, 29(5), 998-1003.

Pollitz, K., Sorian, R. \& Thomas, K. (2001). How accessible is individual health insurance for consumers in less-than-perfect health? Kaiser Family Foundation.

Pomeroy, E.R. \& Gates, C.O. (2000). State and federal regulation of the business of insurance. Journal of Insurance Regulation, 19(2), 179-188.

Powell, F.W. (1917). Hall Jackson Kelley_Prophet of Oregon (continued). Quarterly of the Oregon Historical Society, 18(3), 167-189, 191-201, 203-223.

Prescott, C.C. (2007). Gender and generation on the far western frontier. Tucson: University of Arizona.

Prince, D.W. (2000). Divided government and party responsiveness in the American states. Presentation for Southern Political Science Association, Nov 8-11, Atlanta GA. Available online (Feb 5, 1006):

http://home.insightbb.com/ davidprince/southern.pdf

Public Citizen. (2001). The other drug war: Big Pharma's 625 Washington lobbyists. Washington DC: Public Citizen's Congress Watch.

Quadagno, J.S. (2010). Institutions, interest groups, and ideology: An agenda for the sociology of health care. Journal of Health and Social Behavior, 51(2), 125-136.

Quadagno, J.S. (2005). One nation uninsured: Why the U.S. has no national health insurance. New York: Oxford University.

RAND (n.d.). Analysis of disease management. RAND Health Compare. Available online (July 16, 2011): www.randcompare.org

RAND (n.d.). Analysis of purchasing pools. RAND Health Compare. Available online (May 23, 2011): www.randcompare.org 
Reback, G.L. (2009). Free the market! Why only government can keep the marketplace competitive. London: Portfolio.

Reed, M., Benedetti, N., Brand, R., Newhouse, J.P. \& Hsu, J. (2009). Perspectives from deductible plan enrollees: Plan knowledge and anticipated care-seeking changes. BMC Health Services Research, 9, 244 (6 pages).

Reed, M.C., Cunningham, P.J. \& Stoddard, J.J. (2001). Physicians pulling back from charity care (Issue Brief). Center for Studying Health System Change. Available online (Apr 30, 2005): www.hschange.com/content/356/356.pdf

Reichert, S., Simon, T. \& Halm, E.A. (2000). Physicians' attitudes about prescribing and knowledge of the costs of common medications. Archives of Internal Medicine, $160 ; 2799-2803$.

Reinhardt, U.E. (2004). The Swiss health system: Regulated competition without managed care. Journal of the American Medical Association, 282(10), 1227-1231.

Reinhardt, U.E. (2003). The Medicare world from both sides: A conversation with Tom Scully. Health Affairs, 22(6), 167-174.

Reisman, A. (2010). End of a chapter. Health Affairs, 29(5), 1071-1073.

Rice, T. (2003). The economics of health reconsidered (2nd ed.). Chicago: Academy Health/Health Administration Press.

Richardson, J.G. (1980). Variation in date of enactment of compulsory school attendance laws: An empirical inquiry. Sociology of Education, 53(3), 153-163.

Riesenfeld, S.A. (1955). The formative era of American public assistance law. California Law Review, 43(2), 175-233.

Ringel, J.S., Hosek, S.D., Vollaard, B.A. \& Mahnovski, S. (2002). The elasticity of demand for health care: A review of the literature and its application to the military health system. Santa Monica CA: RAND.

Robbins, W.G. (2002). Oregon in depression and war, 1925-1945: Hard times. Oregon Historical Society. Available online (Nov. 7, 2007): www.ohs.org/ education/oregonhistory/narratives/subtopic.cfm?subtopic_ID=102

Robinson, J.C. (2001a). Theory and practice in the design of physician payment incentives. Milbank Quarterly, 79(2), 149-175.

Robinson, J.C. (2001b). Physician organization in California: Crisis and opportunity. Health Affairs, 20(4), 81-96. 
Robinson, J.C. (1999). The corporate practice of medicine: Competition and innovation in health care. Berkeley: University of California.

Robinson, J.C. \& Casalino, L.P. (2001). Reevaluation of capitation contracting in New York and California. Health Affairs Web Exclusives, 11-19.

Robinson, J.C. \& Dolan, E.L. (2010). Accountable care organizations in California: Lessons for the national debate on delivery system reform. Oakland: Integrated Healthcare Association.

Robinson, J.C. \& Yegian, J.M. (2004). Medical management after managed care. Health Affairs Web Exclusives (May 19), 269-280.

Rockefeller, J.D. IV. (1991). A call for action: the Pepper Commission blueprint for health care reform. Journal of the American Medical Association, 265, 2507-2510.

Rodriguez, H.P., von Glahn, T., Elliott, M.N., Rogers, W.H. \& Safran, D.G. (2009). The effect of performance-based financial incentives on improving patient care experiences: A statewide evaluation. Journal of General Internal Medicine, 24(12), 1281-1288.

Rodwin, M.A. (1993). Medicine money \& Morals: Physicians' conflicts of interest. New York: Oxford University.

Romano, P.S., Geppert, J.J., Davies, S., Miller, M.R., Elixhauser, A. \& McDonald, K.M. (2003). A national profile of patient safety in U.S. hospitals. Health Affairs, 22(2), 154-166.

Rose, P. \& Gidman, J. (2010). Evidence-based practice within values-based care. In J. McCarthy and P. Rose (Ed.), Values-based health and social care. Thousand Oaks CA: Sage Publications.

Rosen, B., Pawlson, L.G., Nissenholtz, R., Benbassat, J., Porath, A., Chassin, M.R. et al. (2011). What the United States could learn from Israel about improving the quality of health care. Health Affairs, 30(4), 764-771.

Rosenau, C.J. \& Lako, C.J. (2008). An experiment with regulated competition and individual mandates for universal health care: The new Dutch health insurance system. Journal of Health Politics, Policy and Law, 33(6), 1031-1055.

Rosenthal, A. (1993). The third house: Lobbying and lobbyists in the states. Washington DC: Congressional Quarterly. 
Rosenthal, J. \& Booth, M. (2003). Defining Reportable Adverse Events: A guide for states tracking medical errors. National Academy for State Health Policy. Available online (Apr 24, 2005): www.nashp.org/Files/GNL50.pdf

Rosenthal, M.B. (2004). Doughnut-hole economics. Health Affairs, 23(6), 129-135.

Ross, J.S. (2002). The Committee on the Costs of Medical Care and the history of health insurance in the United States. Einstein Quarterly Journal of Biology and Medicine, 19; 129-134.

Roth, E.J., Plastaras, C.T. Mullin, M.S., Fillmore, J. \& Moses, M.L. (2001). A simple institutional educational intervention to decrease use of selected expensive medications. Archives of Physical Medicine and Rehabilitation, 82(May), 633636.

Sage, W.M. (2003). Unfinished business: How litigation relates to health care regulation. Journal of Health Politics, Policy, and Law, 28(2-3), 387-419.

Sage, W.M. (2000). Accountability through information: What the health care industry can learn from securities regulation. Milbank Memorial Fund.

Sage, W.M., Hastings, K.E. \& Berenson, R.A. (1994). Enterprise liability for medical malpractice and health care quality improvement. American Journal of Law \& Medicine, 20(1-2), 1-28.

Salisbury, D.L. (Ed.). (1999). Beyond ideology: Are individual social security accounts feasible? Washington DC: Employee Benefit Research Institute.

Saltman, R.B., Bankauskaite, V., Vrangbaek, K. (Ed.). (2007). Decentralization in health care: Strategies and outcomes. European Observatory on Health Systems and Policies. Maidenhead, England: Open University.

Saltman, R.B. \& von Otter, C. (1995). Implementing planned markets in health care: Balancing social and economic responsibility. Philadelphia: Open University.

Samuel, S., Dirsmith, M.W. \& McElroy, B. (2005). Monetized medicine: From the physical to the fiscal. Accounting, Organizations and Society 30; 249-278.

Santiago, A. (2010). The Medicus Firm physician survey: Health reform may lead to significant reduction in physician workforce. Available online (May 15, 2011): www.themedicusfirm.com/pages/medicus-media-survey-reveals-impact-healthreform

Schaeffer, L.D. \& McMurtry, D.E. (2004). When excuses run dry: Transforming the U.S. health care system. Health Affairs Web Exclusives (Oct 7), 117-120. 
Schauffler, H.H., McMenamin, S., Cubanski, J. \& Hanley, H.S. (2001). Differences in the kinds of problems consumers report in staff/group health maintenance organizations, independent practice association/network health maintenance organizations, and preferred provider organizations in California. Medical Care, $39(1), 15-25$.

Schlesinger, A.M. (1959). The Age of Roosevelt: the Coming of the New Deal. Cambridge: Riverside.

Schlesinger, M. (2002a). A loss of faith: The sources of reduced political legitimacy for the American medical profession. Milbank Quarterly, 80(2), 185-235.

Schlesinger, M. (2002b). On values and democratic policy making: The deceptively fragile consensus around market-oriented medical care. Journal of Health Politics, Policy and Law, 27(6), 889-925.

Schmidt, E.P. (1931). The movement for public ownership of power in Oregon. Journal of Land \& Public Utility Economics, 7(1) 52-60.

Schoen, C., Osborn, R., Squires, D., Doty, M.M., Pierson, R. \& Applebaum, S. (2010). How health insurance design affects access to care and costs, by income, in eleven countries. Health Affairs, 29(12), 2323-2334.

Schoen, C., Doty, M.M., Collins, S.R. \& Holmgren, A.L. (2005). Insured but not protected: How many adults are underinsured? Health Affairs Web Exclusives (Jun 14), 289-302.

Schut, F.T., Gress, S. \& Wasem, J. (2003). Consumer price sensitivity and social health insurer choice in Germany and the Netherlands [Abstract]. International Journal of Health Care Finance \& Economics, 3(2), 117.

Schwantes, C.A. (1982). Protest in a promised land: Unemployment, disinheritance, and the origin of labor militancy in the Pacific Northwest, 1885-1886. Western Historical Quarterly, 13(4), 373-390.

Scully, T. (2002). The Changing World of Health Care. In R. Snyderman \& V.Y. Saito (Ed.), Enabling Prospective Health Care (p. 105-109). Duke University Medical Center \& Health System.

Seidman, I.E. (1991). Interviewing as qualitative research: A guide for researchers in education and the social sciences. New York: Teacher's College.

Seligman, E.R.A. (1890). The general property tax. Political Science Quarterly, 5(1), 2464. 
Senate Committee on Human Resources. (1993, Mar 26). Public hearing [Exhibits submitted for SB707]. Oregon Legislative Assembly. Salem: Oregon State Archives.

Senate Special Committee on the Oregon Health Plan. (1993, Jul 21). Informational meeting with invited testimony. Salem: Oregon State Archives. Summary of minutes available online: arcweb.sos.state.or.us/legminutesalias/ 1993\%20senate\%20oregon\%20health\%20plan/

Shern, D.L., Beronio, K.K., Minniear, C.I. \& Steverman, S.M. (2010). Comparative effectiveness research in mental health: An advocate's perspective. Health Affairs, 29(10), 1857-1861.

Short, P.F., Graefe, D.R. \& Schoen, C. (2003). Churn, churn, churn. How instability of health insurance shapes America's uninsured problem [Issue brief]. The Commonwealth Fund.

Shortell, S.M., Schmittdiel, J., Wang, M.C., Li, R., Gillies, R.R., Casalino, L.P. et al. (2005). An empirical assessment of high-performing medical groups: Results from a national study. Medical Care Research and Review, 62(4), 407-434.

Shortell, S.M., Zazzali, J.L., Burns, L.R., Alexander, J.A., Gillies, R.R., Budetti, P.P. et al. (2001). Implementing evidence-based medicine: The role of market pressures, compensation incentives, and culture in physician organizations. Medical Care, 39(7), I62-78.

Shrout, P.E. (1998). Measurement reliability and agreement in psychiatry. Statistical Methods in Medical Research, 7(3), 301-317.

Shulock, N. (1999). The paradox of policy analysis: If it is not used, why do we produce so much of it? Journal of Policy Analysis and Management, 18(2), 226-244.

Sigmond, R.M. (2004). Doing away with uncompensated care. Inquiry, 41(4), 365-375.

Simantov, E., Schoen, C. \& Bruegman, S. (2001). Market failure? Individual insurance markets for older Americans. Health Affairs, 20(4), 139-149.

Simmons, H.E. \& Goldberg, M.A. (2003). Charting the cost of inaction. National Coalition on Health Care. Available online (Dec 2, 2003): www.nchc.org

Skelley, D. (2002). The ambiguity of results: Assessments of the new public management. Public Administration \& Management, 7(2), 168-187.

Skocpol, T. (1996). Boomerang: Clinton's health security effort and the turn against government in U.S. politics. New York: W.W. Norton. 
Skocpol, T. (1993). America's first social security system: The expansion of benefits for Civil War veterans. Political Science Quarterly, 108(1), 85-116.

Sloan, F.A. (1990). Experience rating: Does it make sense for medical malpractice insurance? American Economic Review, 80(2), 128-133.

Sloan, L.E. (1998). Fraud, abuse, and Medicare billing: Should you be worried? AACAP News (Jul/Aug.). Available online (May 28, 2003): www.aacap.org/clinical/fraud.htm

Smith, P. (1984). The Rise of Industrial America: A People's History of the PostReconstruction Era, NY: McGraw-Hill Book Company.

Smith, P.C. (1999). Setting budgets for general practice in the new NHS. BMJ, 318(20 Mar), 776-783.

Smith, S.R. (1993). The new politics of contracting: Citizenship and the nonprofit role. In H. Ingram \& S.R. Smith (Ed.), Public policy for democracy (p. 198-221). Washington DC: The Brookings Institution.

Smith, V., Ramesh, R., Gifford, K. \& Ellis, E. (2003). States respond to fiscal pressure: State Medicaid spending growth and cost containment in fiscal years 2003 and 2004. Results from a 50-state survey. Kaiser Family Foundation.

Smoldt, R. (2010). Pay for value. In W.B. Rouse \& D.A. Cortese, Studies in Health Technology and Informatics: Vol. 153. Engineering the System of Healthcare Delivery, p. 195-206. Washington DC: IOS Press.

Snyder, R. (1999). After neoliberalism: The politics of reregulation in Mexico. World Politics, 51(2), 173-204.

Snyder, R. Rice, T. \& Kitchman, M. (2003). Paying for choice: The cost implications of health plan options for people on Medicare. Kaiser Family Foundation.

Somers, A. (1972). Regulation of hospitals. Annals of the American Academy of Political and Social Science, 400, 69-81.

Spitz, B. (2007). Medicaid agencies as managed care organizations: An "actuarially sound" solution? Journal of Health Politics, Policy and Law, 32(3), 379-413.

Starfield, B. \& Oliver, T. (1999). Primary care in the United States and its precarious future. Health and Social Care in the Community, 7(5), 315-323.

Starr, P. (1997). Smart technology, stunted policy: Developing health information networks. Health Affairs, 16(3), 91-105. 
Starr, P. (1982). The social transformation of American medicine: The rise of a sovereign profession and the making of a vast industry. New York: Basic Books.

Stearn, M. (1937), The history of Japanese people in Oregon (Thesis, reprinted 1974). San Francisco: R and E Research Associates.

Steffens, L. (1906). The struggle for self-government: Being an attempt to trace American political corruption to its sources in six states of the United States with a dedication to the czar. New York: McClure, Phillips.

Steffens, L. (1904). The shame of the cities. New York: Mclure, Phillips.

Stein, N. (1993). ERISA and the limits of equity. Law and Contemporary Problems, 56; 71-110.

Stein, R. (1998). The actuary as product manager in a dynamic product analysis environment. Casualty Actuarial Society. Available online (Jul 6, 2005): www.casact.org/pubs/dpp/dpp98/stein.pdf

Stern, A.L. (2003). Labor rekindles reform. American Journal of Public Health, 93(1), 95-98.

Stevens, R.A. (1996). Health care in the early 1960s. Health Care Financing Review, 18(2), 11-22.

Stoller, J.K. (2004). The effectiveness of respiratory care protocols. Respiratory Care, 49(7), 761-765.

Stone, D. (2004). Shopping for long-term care. Health Affairs, 23(4), 191-196.

Stone, D.A. (1980). The limits of professional power: National health care in the Federal Republic of Germany. Chicago: University of Chicago.

Stremikis, K., Davis, K. \& Nuzum, R. (2010). Health care opinion leaders' views on health reform, implementation, and post-reform priorities. The Commonwealth Fund.

Stroupe, K.T., Kinney, E.D. \& Kniesner, J.J. (2001). Chronic illness and health insurance-related job lock [Abstract]. Journal of Policy Analysis \& Management, 20(3), 525-544.

Studdert, D.M. \& Brennan, T.A. (2001). No-fault compensation for medical injuries: The prospect for error prevention. Journal of the American Medical Association, 286(2), 217-223. 
Sturm, R. (1997). How expensive is unlimited mental health care coverage under managed care? Journal of the American Medical Association, 278(18), 15331537.

Suchy, K. (2010). A lack of standardization: The basis for the ethical issues surrounding quality and performance reports. Journal of Healthcare Management, 55(4), 241251.

Task Force on Comprehensive Revenue Restructuring. (2009). Final report. Salem OR.

Tennyson, D.H. \& Fottler, M.D. (2000). Does system membership enhance financial performance in hospitals? Medical Care Research and Review, 57(1), 29-50.

Thomas, J.W., Grazier, K.L. \& Ward, K. (2004). Comparing accuracy of risk-adjustment methodologies used in economic profiling of physicians. Inquiry 41(2), 218-231.

Thomasson, M. A. (2002). Did Blue Cross and Blue Shield suffer from adverse selection? Evidence from the 1950s (Working paper 9167). National Bureau of Economic Research.

Thorne, J.I. (1997). The federal-state relationship in health care reform: a view from the trenches. In H.M. Leichter (ed.), Health Policy Reform in America: Innovations from the States (2nd ed.), 126-137. Armonk NY: M.E. Sharpe.

Thorpe, K.E. (2004). The medical malpractice 'crisis': Recent trends and the impact of state tort reforms. Health Affairs Web Exclusives (Jan 21), 20-30.

Thorson, M., Brock, J., Mitchell, J. \& Lynn, J. (2010). Grand Junction, Colorado: How a community drew on its values to shape a superior health system. Health Affairs, 29(9), 1678-1686.

Throckmorton, A.L. (1961). Oregon argonauts: Merchant adventurers on the western frontier. Portland: Oregon Historical Society.

Tillman, R. (1998). Broken promises: Fraud by small business health insurers. Boston: Northeastern University.

Timmermans, S. \& Mauck, A. (2005). The promises and pitfalls of evidence-based medicine. Health Affairs, 24(1), 18-28.

Timmins, N. (2010). Letter from Britain: Across the pond, giant new waves of health reform. Health Affairs, 29(12), 2138-2141. 
Todd, J.S., Seekins, S.V., Keichbaum, J. \& Harvey, L.K. (1991). Health Access America-strengthening the U.S. health care system. Journal of the American Medical Association, 265; 2503-2506.

Tompa, E., Dolinschi1, R., de Oliveira1, C. \& Irvin, E. (2007). A systematic review of OHS [occupational health and safety] interventions with economic evaluations. Toronto, ON Canada: Institute for Work \& Health.

Toy, E.V. (1986), The Ku Klux Klan in Oregon. In G.T. Edwards and C.A. Schwantes, Experiences in a Promised Land, 269-286. Seattle: University of Washington.

Trattner, W.L. (1999). From poor law to welfare state: A history of social welfare in America (6th ed.). New York: The Free Press.

Trisolini, M., Aggarwal, J., Leung, M., Pope, G. \& Kautter, J. (2008). The Medicare Physician Group Practice Demonstration: Lessons learned on improving quality and efficiency in health care. The Commonwealth Fund.

Trottier, L.H., Champagne, F., Contandriopoulos, A.P. \& Denis, J.L. (1999). Contrasting visions of decentralization. In D. Drache \& T. Sullivan (Ed.), Health reform: Public success, private failure. New York: Routledge.

Truffer, C.J., Keehan, S., Smith, S., Cylus, J., Sisko, A., Poisa, J.A. et al. (2010). Health spending projections through 2019: The recession's impact continues. Health Affairs, 29(3), 522-529.

Tuohy, C.H. (2003). Agency, contract, and governance: Shifting shapes of accountability in the health care arena. Journal of Health Politics, Policy and Law, 28(2-3), 195215.

Tuohy, C.H. (2002). The costs of constraint and prospects for health care reform in Canada. Health Affairs, 21(3), 32-46.

Tyack, D.B. (1968). The perils of pluralism: The background of the Pierce case. American Historical Review, 74(1), 74-98.

Tyack, D.B. (1967). Bureaucracy and the common school: The example of Portland, Oregon, 1851-1913). American Quarterly, 19(3), 475-198.

Tyack, D. \& James, T. (1986). State government and American public education: Exploring the "primeval forest." History of Education Quarterly, 26(1), 39-69.

Ullrich, C.G. (2002). Reciprocity, justice and statutory health insurance in Germany. Journal of European Social Policy, 12(2),123-136. 
University of California at San Francisco (UCSF) Evidence-based Practice Center. (2001). Making health care safer: A critical analysis of patient safety practices [Contract 290-97-0013]. Rockville MD: Agency for Healthcare Research and Quality.

Unruh, J.D. Jr. (1979). The plains across: The overland emigrants and the Trans-Mississippi West, 1840-60. Chicago: University of Illinois.

Urofsky, M.I. (1985). State courts and protective legislation during the Progressive Era: A reevaluation. Journal of American History, 72(1), 63-91.

U.S. General Accounting Office. (2009). Overview of approaches to control Prescription drug spending in federal programs [GAO-09-819T].

U.S. General Accounting Office. (2008). Medicare Advantage: Characteristics, financial risks, and disenrollment rates of beneficiaries in private fee-for-service plans [GAO-09-25].

U.S. General Accounting Office. (2004). Private health insurance: Unauthorized or bogus entities have exploited employers and individuals seeking affordable coverage [GAO-04-512T].

U.S. General Accounting Office. (2003). Information technology: Benefits realized for selected health care functions [GAO-04-224].

U.S. General Accounting Office. (2002). Medicare: Using education and claims scrutiny to minimize physician billing errors. Testimony of Leslie G. Aronovitz before the U.S. Senate Committee on Finance [GAO-02-778T].

U.S. General Accounting Office (2000). Medicare home health care: Prospective payment system could reverse recent declines in spending [GAO/HEHS-00-176].

U.S. General Accounting Office. (1987). Medicaid: Interstate variations in benefits and expenditures [HRD-87-67BR].

U.S. Preventive Services Task Force. (1996). Guide to clinical preventive services (2nd ed.). Philadelphia: Lippincott Williams \& Wilkins.

van de Ven, W.P.M.M., Beck, K., Buchner, F., Chernichovsky, D., Gardiol, L., Holly, A. et al. (2003). Risk adjustment and risk selection on the sickness fund insurance market in five European countries. Health Policy, 65(1), 75-98.

van de Ven, W.P.M.M., van Vliet, R.C.J.A., van Barneveld, E.M. \& Lamers, L.M. (1994). Risk-adjusted capitation: Recent experiences in the Netherlands. Health Affairs, 13(5), 120-136. 
Verdier, J.M., Byrd, V. \& Stone, C. (2009). Enhanced primary care case management programs in Medicaid: Issues and options for states. Center for Health Care Strategies and Oklahoma Health Care Authority. Mathematica Policy Research.

Victor, K. (1989, Oct 28). Crying wolf? National Journal, 21; 2630-33.

Villagra, V.G. \& Ahmed, T. (2004). Effectiveness of a disease management program for patients with diabetes. Health Affairs, 23(4), 255-266.

Vladeck, B.C. (2004). Ineffective approach [Letter]. Health Affairs, 23(2), 285-286.

Vogel, R.J. (1999). Medicare: Issues in political economy. Ann Arbor: University of Michigan.

van de Voorde, C., van Doorslaer, E. \& Schokkaert, E. (2001). Effects of cost sharing on physician utilization under favourable conditions for supplier-induced demand. Health Economics, 10; 457-471.

Wachter, R.M. (2004). The end of the beginning: Patient safety five years after 'To Err is Human.' Health Affairs Web Exclusives (Nov 30), 534-545.

Wagstaff, A., van Doorslaer, E., van der Burg, H., Calonge, S., Christiansen, T., Citoni, G. et al. (1999). Equity in the finance of health care: Some further international comparisons. Journal of Health Economics, 18; 263-290.

Walker, J., Pan, E., Johnston, D., Adler-Milstein, J., Bates, D.W. \& Middleton, B. (2005). The value of health care information exchange and interoperability. Health Affairs Web Exclusives (Jan 19), 10-25.

Wall, B.M. (2002). The pin-striped habit: Balancing charity and business in Catholic hospitals, 1865-1915. Nursing Research, 51(1), 50-58.

Wallace, N.T., McConnell, K.J., Gallia, C.A. \& Smith, J.A. (2008). How effective are copayments in reducing expenditures for low-income adult Medicaid beneficiaries? Experience from the Oregon Health Plan. Health Services Research, 43(2), 515-530.

Wallack, S.S., Weinberg, D.B. \& Thomas, C.P. (2004). Health plans' strategies to control prescription drug spending. Health Affairs, 23(6), 141-148

Waring, J., Dixon-Woods, M., Yeung, K. (2010). Modernising medical regulation: Where are we now? Journal of Health Organization and Management, 24(6), 540-555. 
Warren, E., Sullivan, T. \& Jacoby, M. (2000, May). Medical problems and bankruptcy filings. Norton's Bankruptcy Advise. Available online (Jun 9, 2003):

http://papers.ssrn.com/paper.taf?abstract_id=224581

Warshaw, G.A., Bragg, E.J. \& Shaull, R.W. (2002). Geriatric medicine training and practice in the United States at the beginning of the 21st century. New York: Association of Directors of Geriatric Academic Programs.

Waters, H.R., Anderson, G.F., Mays, J. (2004). Measuring financial protection in health in the United States. Health Policy, 69, 339-349

Weber, M. (1968/1920). The definition of sociology and of social action. In Economy and society: An outline of interpretive sociology (G. Roth \& C. Wittich, Tr., Ed.), Vol. 1, p. 4-24. Berkeley: University of California.

Weil, T.P. (2001). Health networks: Can they be the solution? Ann Arbor: University of Michigan.

Weiner, S.J. \& Andes, S. (2010). Predictors of payment behavior among the medically uninsured: A prospective cohort study of patients seeking ambulatory services. Journal of Health Care for the Poor and Underserved, 21(4), 1395-1407.

Weinstein, J. (1968). The Corporate ideal in the liberal state, 1900-1918. Boston: Beacon.

Weiss, C.H. (1977). Research for policy's sake: The enlightenment function of social research. Policy Analysis, 3(4), 531-545.

Weissman, J.S, Annas, C.L., Epstein, A.M., Schneider, E.C., Clarridge, B., Kirle, L. et al. (2005). Error reporting and disclosure systems: Views from hospital leaders. Journal of the American Medical Association, 293(11), 1359-1366

Weissman, J.S., Wachterman, M. \& Blumenthal, D. (2005). When methods meet politics: How risk adjustment became part of Medicare managed care. Journal of Health Politics, Policy and Law, 30(3), 475-504.

Welch, H.G., Miller, M.E. \& Welch, P. (1994). Physician profiling-an analysis of inpatient practice patterns in Florida and Oregon. New England Journal of Medicine, 330; 607-612.

Wennberg, J.E., Fisher, E.S., Stukel, T.A. \& Sharp, S.M. (2004). Use of Medicare claims data to monitor provider-specific performance among patients with severe chronic illness. Health Affairs Web Exclusives (Oct 7), VAR5-18. 
Werner, R.M. \& Asch, D.A. (2005) The unintended consequences of publicly reporting quality information. Journal of the American Medical Association, 293(10), 12391244.

Werner, R.M., Kolstad, J.T., Stuart, E.A. \& Polsky, D. (2011). The effect of pay-forperformance in hospitals: Lessons for quality improvement. Health Affairs, 30(4), 690-698.

Whaples, R. \& Buffum, D. (1991). Fraternalism, paternalism, the family, and the market: Insurance a century ago. Social Science History, 15(1), 97-122.

Whitman, D.B. (2006). The structure of Social Security individual account contributions and investments: Choices and implications (Report for Congress). Congressional Research Service, The Library of Congress.

Wicks, E.K. \& Hall, M.A. (2000). Purchasing cooperatives for small employers: Performance and prospects. The Milbank Quarterly, 78(4), 511-546.

Wiener, J.M., Illson, L.H. \& Hanley, R.J. (1994). Sharing the burden: Strategies for public and private long-term care insurance. Washington DC: The Brookings Institution.

Wigder, H.N., Cohan Ballis, S.F., Lazar, L., Urgo, R. \& Dunn, B.H. (1998). Successful implementation of a guideline by peer comparisons, education, and positive feedback. Journal of Emergency Medicine, 17(5), 807-810.

Wildavsky, A. (1977). Doing better and feeling worse: The political pathology of health policy. Daedalus, 106(1), 105-123.

Wilensky, H.L. (1997). Social science and the public agenda: Reflections on the relation of knowledge to policy in the United States and abroad. Journal of Health Politics, Policy and Law, 22(5),1241-1265.

Wilentz, S. (1990). Property and power: Suffrage reform in the United States, 1787-1860. In D.W. Rogers (Ed.), Voting and the spirit of American democracy. University of Hartford.

Williams, P, with Chamberlain, I.C. (1932). The purchase of medical care through fixed periodic payment. New York: National Bureau of Economic Research (No. 20).

Williamson, O.E. (1996). The mechanisms of governance. New York: Oxford University.

Winterbotham, J. (1994). Umpqua: The lost county of Oregon. Brownsville OR: Jerry Winterbotham. 
Wollner, C. \& Dodds, G.B. (2000). Third party in paradise: History of the Blue Cross and Blue Shield movement in Oregon. Portland OR: draft ms.

Woolf, S.H., Johnson, R.E. \& Geiger, H.J. (2006). The rising prevalence of severe poverty in America: A growing threat to public health. American Journal of Preventive Medicine, 31(4), 332-341.

Wright, B.J., Carlson, M.J., Allen, H., Holmgren, A.L. \& Rustvold, D.L. (2010). Raising premiums and other costs for Oregon Health Plan enrollees drove many to drop out. Health Affairs, 29(12), 2311-2316.

Wrightson, C.W. (2002). Financial strategy for managed care organizations. Chicago: Health Administration Press.

Wynia, M.K., Cummins, D.S., VanGeest, J.B. \& Wilson, I.B. (2000). Physician manipulation of reimbursement rules for patients: Between a rock and a hard place. Journal of the American Medical Association, 283(14):1858-1865.

Yale Law Journal. (1950). Use of vagrancy-type laws for arrest and detention of suspicious persons. Yale Law Journal, 59(7), 1351-1364.

Yegian, J.M. (2003). Tiered hospital networks. Health Affairs Web Exclusives (Mar 19), 147-153.

Yount, L. (2001). Patients' rights in the age of managed health care. New York: Facts on File.

van Zandt, T. (2004). Information overload in a network of targeted communication. RAND Journal of Economics, 35(3), 542-560.

Zedlewski, S.R., Acs, G.P. \& Winterbottom, C.W. (1992). Play-or-pay employer mandate: Potential effects. Health Affairs, 11(1), 62-83.

Zhou-Richter, T., Brown, M.J. \& Grundl, H. (2010). Don't they care? Or, are they just unaware? Risk perception and the demand for long-term care insurance. Journal of Risk and Insurance, 77(4), 715-747.

Zuvekas, S.H. \& Cohen, J.W. (2010). Paying physicians by capitation: Is the past now prologue? Health Affairs, 29(9), 1661-1666.

Zussman, R. (1992). Intensive care: Medical ethics and the medical profession. Chicago: University of Chicago. 
Initial Contact Letter to Interview Subjects

e-mail message

Subject: Interview request

Dear $[X]$,

I am contacting you to request a 1-hour interview for research I am conducting for my doctoral dissertation in health policy at Portland State University. I am collecting the views of health policy leaders in Oregon to understand the current political situation and feasible options for universal health insurance at the state level. Your participation will be a valuable addition to this study.

Results from this study will be published. Your connection with any specific ideas or information will be kept confidential.

I will call you in the next few days to determine your willingness to participate, and hopefully schedule a convenient time for an interview.

Thank you for your consideration of this request. I look forward to the opportunity to understand your perspective on health insurance reform in Oregon. Please feel free to contact me for more information.

Sincerely,

[contact phone and e-mail] 
Appendix B

\section{PORTLAND STATE UNIVERSTIY Informed Consent Form}

\section{Feasible Models of Universal Health Insurance in Oregon According to Stakeholder Views}

You are invited to participate in a study conducted by Terry Hammond for his doctoral dissertation in health policy through the department of Urban Studies and Planning at Portland State University. The results will be published and may be used subsequently in further publications. The research aims to characterize the prospects for state health insurance reform by examining the ideas of health policy leaders in Oregon, in order to identify the issues and interests involved, and levels of agreement.

You have been selected by the researcher or your name has been given to the researcher by a participant in the study, because you fit the criteria of the project as (a) a person knowledgeable on health insurance issues, and (b) holding a position of authority in an organization with influence in state policy decisions, which is also (c) a stakeholder with an intrinsic interest in the outcome of health insurance reform. You must also be aged 21 or over.

If you agree to participate, the researcher will interview you in a session that will last approximately 1 hour. The interview will be conducted at a location and time convenient to you. Please feel free to inform the researcher if you feel uncomfortable with the content of the questions or the manner in which they are asked. You may refrain from sharing anything that makes you uncomfortable.

Specific ideas and information obtained in connection with this study that can be linked to you or identify you or your organization will be kept confidential. All notes and tapes related to you will be identified by a label with a separate key, and will be stored in a secure location where only the researcher has access. Original information from your interview will not be referenced to you or your organization. The study text will identify you only in an institutional category as a state official, insurer, purchaser, hospital, physician, public interest group, or "detached expert." If you agree, your name, title, and affiliation, or just your title and affiliation, will be appended to the study in a general list of participants and information sources.

Your participation is voluntary. If you decline to participate, your relationship with the researcher or Portland State University will not be affected in any way. If you agree to participate, please understand that you may withdraw from the study at any later time without question or penalty, and your information will be removed from the study results.

If you have concerns or problems about your participation in this study or your rights as a research subject, please contact the Human Subjects Research Review Committee, Office of Research and Sponsored Projects (600 Unitus Bldg, Portland State University, 503-7254288 or 1-877-480-4400.). If you have questions about the study itself, please contact Terry Hammond (503-282-1242), or dissertation committee chair Dr. Tony Rufolo (503-725-4049) at the department of Urban Studies at Portland State University.

The researcher intends to fully protect your privacy and assures confidentiality for you and your organization if you desire. In the three sets of choices below, please indicate your specific preferences in matters of confidentiality. 
Appendix B 396

MAY THE RESEARCHER USE YOUR NAME, TITLE, AND AFFILIATION IN A LIST OF INFORMATION SOURCES FOR THE STUDY? (Please check one box only.)

[ ] The researcher may include my name, title, and affiliation in an appended list of information sources.

[ ] The researcher may include my title and affiliation, but not my name, in an appended list of information sources.

[ ] Do not include my name, title, or affiliation anywhere in the published study.

(Name as it should appear)

(Title as it should appear)

[Or attach business card]

(Affiliation as it should appear)

PERMISSION TO RECORD THE INTERVIEW (Please check one box only.)

An audiotape recording will help ensure accuracy in representing your views. If you choose not to be recorded during our interview, I will rely on handwritten notes.

[ ] I give permission to record the interview on an audio tape for later transcription.

[ ] I prefer that no audio recording be made during the interview.

\section{FURTHER CONTACT}

The researcher may want to contact you in the future for possible clarification or follow-up questions. Please check the box below if you prefer not to be contacted by the researcher after the initial interview.

[ ] I prefer not to be contacted for clarification or follow-up questions following the initial interview.

Signature

Date

Your signature indicates that you have read and understand the above information, and agree to take part in this study. By signing this consent form, you are not waiving any legal claims, rights, or remedies. The researcher should provide you with a copy of this form for your own records.

[ ] Please send me a copy of the study when completed.

RESEARCHER CONTACT

INFORMATION

Terry Hammond

5734 NE $27^{\text {th }}$ Ave \#3

Portland OR 97211 


\section{Health Policy Leader Interviews - June 2008 to June 2010}

\section{Hospitals}

Kevin Earls

Vice President Policy and Advocacy

Oregon Association of Hospitals and Health

Systems (Lake Oswego)

Dan Field JD

Director External Affairs

Kaiser Permanente (Portland)

Dick Stenson FACHE FACMPE

President \& CEO

Tuality Healthcare (Hillsboro)

Norman F. Gruber

President \& CEO

Salem Hospital (Salem)

Mike Bonetto

Vice President Business \& Community

Development

St. Charles Medical Center (Bend)

\section{Physicians}

Peter Bernardo MD

President

Oregon Medical Association (Tigard)

Chuck Hofmann MD

General Internal Medicine/

Oregon Health Policy Board (Baker City)

Robert Law MD

Dunes Family Health Care (Reedsport)

Phil W. Armstrong MBA MPH

Administrator

The Oregon Clinic (Portland)

David M. Balmer MD MPH FACPM

Associate Medical Director

Mid-Valley Independent Physicians

Association

(Salem)

\section{Insurers}

Kerry E. Barnett

Executive Vice President Corporate

Services

The Regence Group (Portland)

David Labby MD PhD

Medical Director

CareOregon (Portland)

Jack Friedman

Chief Executive Officer

Providence Health Plans (Beaverton)

Ken Provencher

President \& CEO

PacificSource Health Plans (Springfield)

Dan Stevens

Regional Director

Providence Health Plans (Portland)

Rick Rebel

Employer Benefits Consultant

Western States Benefit Planning (Albany)

\section{Purchasers}

Lynn-Marie Crider

Public Policy Specialist

SEIU Local 49 (Portland)

Denise Honzel

Health Policy Consultant

Oregon Business Council (Portland)

Barbara Prowe

Executive Director

Oregon Coalition of Health Care Purchasers

(Portland)

Bill Kramer

Health Care Consultant

Oregon Health Leadership Council

(Portland)

Betsy Earls

Vice President \& Counsel

Associated Oregon Industries (Salem) 
Appendix C 398

\section{State Officials}

Barney Speight

Executive Director

Oregon Health Fund Board (Portland)

Rocky King

Administrator

Oregon Medical Insurance Pool (Salem)

Corey Streisinger

Director

Oregon Dept of Consumer \& Business

Services

(Salem)

Tim Nesbitt

Deputy Chief of Staff

Governor's Office (Salem)

Bruce Goldberg MD

Director

Oregon Dept of Human Services/

Oregon Health Authority (Portland)

\section{Public Interest}

Ellen Pinney

Health Policy Advocate

Oregon Health Action Campaign (Salem)

Thomas Aschenbrener

President

Northwest Health Foundation (Portland)

Liz Baxter

Executive Director

The Archimedes Movement (Portland)

Laura Etherton

Advocate

OSPIRG (Portland)

Jerry Cohen JD MPA

State Director

AARP Oregon (Clackamas)

Diane Lund-Muzikant

Editor-in-Chief

The Lund Report (Portland)

\section{Experts}

\author{
John Santa MD MPH \\ Director \\ Consumer Reports Health Rating Center \\ (Yorkers NY)
}

Mark Gibson

Director

Center for Evidence-based Policy

Oregon Health \& Science University

(Portland)

Nancy Clarke

Executive Director

Oregon Health Care Quality Corporation

(Portland)

Michael Leahy

Visiting Associate Professor Health

Sciences

Linfield College (Portland)

Somnath Saha MD MPH

Chair

Oregon Health Services Commission

(Portland)

Jim Carlson

President \& CEO

Oregon Health Care Association (Portland) 